\title{
Expressionsanalyse des humanen Histonsubtyps H1x
}

\author{
Dissertation \\ zur Erlangung des Doktorgrades \\ der Mathematisch-Naturwissenschaftlichen Fakultäten \\ der Georg-August-Universität \\ zu Göttingen
}

vorgelegt von

Julia Warneboldt

aus Münster

Göttingen 2007 
D 7

Referent:

Korreferent:

eingereicht am:

Tag der mündlichen Prüfung:
Prof. Dr. D. Doenecke

Prof. Dr. R. Hardeland

30.05.2007

05.07.2007 
Teilergebnisse aus dieser Arbeit wurden mit Genehmigung der Mathematisch-Naturwissenschaftlichen Fakultät, vertreten durch den Betreuer der Arbeit, in folgenden Beiträgen vorab veröffentlicht:

\section{Tagungsbeiträge:}

J. Warneboldt, D. Doenecke, N. Happel: “Expression of the human H1x gene” (Poster), EMBO Conference: Chromatin and Epigenetics, Heidelberg, Deutschland (19. 22.05.2005)

J. Warneboldt, F. Haller, L. Füzesi, D. Doenecke, N. Happel: “Analysis of the human H1x expression in neuroendocrine tumours” (Poster), 3rd International PhD Symposium Horizons in Molecular Biology, Göttingen, Deutschland (14. - 16.09.2006)

J. Warneboldt, F. Haller, L. Füzesi, D. Doenecke, N. Happel: "Expression of human H1x in neuroendocrine tumours" (Poster), 8th Young Scientist Meeting of the DGZ „Cell Biology of Cancer”, Heidelberg, Deutschland (21. - 23.09.2006)

J. Warneboldt, F. Haller, L. Füzesi, D. Doenecke, N. Happel: „Human H1x is upregulated in neuroendocrine tumours "(Poster), EMBO Conference: Chromatin and Epigenetics, Heidelberg, Deutschland (03. - 06.05.2007) 

Die vorliegende Arbeit wurde von Januar 2004 bis Mai 2007 am Institut für Biochemie und Molekulare Zellbiologie der Georg-August Universität Göttingen unter der Leitung von Prof. Dr. Detlef Doenecke angefertigt.

Ganz besonders bedanken möchte ich mich an dieser Stelle bei Herrn Prof. Dr. D. Doenecke für die Bereitstellung des interessanten und vielseitigen Themas, die ausgezeichnete wissenschaftliche Betreuung und für die anregenden Diskussionen.

Herrn Prof. Dr. R. Hardeland danke ich für die bereitwillige Übernahme des Korreferats.

Frau Dr. Nicole Happel gilt mein außerordentlicher Dank für die fabelhafte Betreuung, die ständige Hilfsbereitschaft während der Durchführung und Erstellung meiner Arbeit und die wertvollen Ratschläge und Denkanstöße.

Allen weiteren Mitarbeitern der Abteilung Molekularbiologie, insbesondere Christa Bode und Kristina Hänecke, danke ich sehr herzlich für die ausgezeichnete Zusammenarbeit und die hilfreiche Unterstützung im Labor, sowie für viele gute Hinweise zu den verschiedenen Arbeitstechniken.

Herrn Prof. Dr. L. Füzesi danke ich für die gute Zusammenarbeit und besonders für die finanzielle Unterstützung in der Endphase dieser Arbeit. Vielen Dank für die vielen interessanten Gespräche, die große Hilfsbereitschaft und für die zur Verfügung gestellten Gewebeproben.

Bei Herrn Dr. Florian Haller möchte ich mich ganz herzlich für die hervorragende Betreuung und Einführung am iCycler und die vielen intensiven Diskussionen bedanken, nicht zuletzt auch für die großartige Hilfe bei der Zusammenstellung des Kollektivs und der Auswertung der Daten.

Stefanie Schwager und allen anderen Mitarbeitern der Abteilung Gastroenteropathologie danke ich für ihre freundliche, stets hilfsbereite Art und ihre Geduld und für die exzellente Zusammenarbeit.

Herrn Dr. Fabio Quondamatteo ein besonderes Dankeschön für die netten Diskussionen und für wertvolle Tips am Mikroskop.

Allen Mitarbeitern der Abteilung Histologie gilt mein spezieller Dank für ihre Hilfsbereitschaft und Unterstützung bei histologischen Fragestellungen, sowie für die angenehme Atmosphäre und dafür, daß ich mich immer willkommen gefühlt habe.

Des weiteren bedanke ich mich bei Herrn Andreas Nolte für die Durchführung der Sequenzierungen und bei den Mitarbeiten des Hauses und der Werkstatt für ihre freundliche Unterstützung.

Bei meinen Freunden bedanke ich mich ganz herzlich fürs Zuhören, für gute Ratschläge, Anregungen und Kritik zur Arbeit.

Ganz speziell möchte ich mich bei Wolfgang, der mir außerhalb des Labors immer zur Seite gestanden und mich hervorragend unterstützt hat, bedanken.

Abschließend möchte ich meinen Eltern ganz herzlich für ihre umfassende Unterstützung und ihr stetiges Interesse danken! 

Inhaltsverzeichnis

Seite

$1 \quad$ Einleitung 13

$\begin{array}{lll}1.1 & \text { Chromatin } & 13\end{array}$

$\begin{array}{lll}\text { 1.1.1 Histone } & 15\end{array}$

$\begin{array}{ll}\text { 1.1.2 H1-Histonsubtypen } & 16\end{array}$

$\begin{array}{llr}1.2 & \text { Der H1-Subtyp H1x } & 18\end{array}$

$\begin{array}{lll}1.3 & \text { H1-Histone und maligne Transformation }\end{array}$

$1.4 \quad$ Neuroendokrine Tumore 22

1.5 Zielsetzung der Arbeit 23

$2 \quad$ Material 25

$\begin{array}{lll}2.1 & \text { Geräte } & 25\end{array}$

$\begin{array}{lll}2.2 & \text { Verbrauchsmaterial } & 27\end{array}$

$\begin{array}{lll}2.3 & \text { Software } & 28\end{array}$

$\begin{array}{llr}2.4 & \text { Chemikalien } & 29\end{array}$

$\begin{array}{lll}2.5 & \text { Reagenziensätze } & 30\end{array}$

$\begin{array}{lll}2.6 & \text { Enzyme } & 31\end{array}$

$\begin{array}{lll}2.7 & \text { Vektoren und Plasmide } & 31\end{array}$

$\begin{array}{lll}2.8 & \text { Oligonukleotide } & 32\end{array}$

$\begin{array}{lll}2.9 & \text { Antibiotika }\end{array}$

2.10 Bakterien, Zellen und Gewebe 32 
$2.11 \quad$ Antikörper 33

2.11.1 Primärantikörper 33

2.11.2 Sekundärantikörper 34

$\begin{array}{lll}2.12 & \text { Farbstoffe } & 34\end{array}$

$2.13 \quad$ Größenstandards 35

$2.14 \quad$ Kulturmedien 35

2.14.1 Zellkulturmedien 35

2.14.2 Bakterienmedien und Nährböden 35

$\begin{array}{lll}2.15 & \text { Lösungen und Puffer } & 36\end{array}$

$3 \quad$ Methoden 41

3.1 Molekularbiologische Methoden 41

3.1.1 Arbeit mit Bakterien 41

3.1.1.1 Kultivierung von E. coli zu Expressionszwecken (Übernachtkulturen) 41

3.1.1.2 Glycerol-Dauerkulturen 42

3.1.1.3 Herstellung chemisch kompetenter E. coli nach der $\mathrm{CaCl}_{2}$-Methode 42

3.1.2 DNA-Aufreinigung 43

3.1.2.1 DNA-Fällung mit Ethanol 43

3.1.2.2 Präparation von Plasmid-DNA mittels Mini-Plasmid-Kit 43

3.1.2.3 Präparation von Plasmid-DNA mittels Pure Yield ${ }^{\text {TM }}$ Plasmid Midiprep System 44

3.1.2.4 Bestimmung der DNA-Konzentration 44

3.1.3 Klonierung 45

3.1.3.1 Schneiden von DNA mittels Restriktionsendonukleasen 45

3.1.3.2 Dephosphorylierung eines linearisierten Vektors 45

3.1.3.3 Ligation 46

3.1.3.4 Hitzeschock-Transformation in E. coli 47

3.1.3.5 Agarose-Gelelektrophorese 47

3.1.3.6 Isolierung von DNA-Fragmenten aus Agarose-Gelen (Gelextraktion) 48 
3.1.3.7 Polymerase-Kettenreaktion (PCR) 48

3.1.3.8 DNA-Sequenzierung 51

3.1.3.9 Sequenzvergleich 52

3.1.3.10 Erstellung von GFP-Konstrukten für die Expression in HeLa-Zellen 53

3.1.3.11 Konstrukte für siRNA-Versuche ${ }^{1}$

3.1.3.12 Annealing der DNA-Oligonukleotide für siRNA-Versuche ${ }^{1}$

3.1.3.13 5'-Phosphorylierung der DNA-Oligonukleotide 55

\subsubsection{Promotoranalyse 56}

3.1.4.1 Erstellung von Promotorkonstrukten 56

3.1.4.2 Reportergenassays 58

3.1.5 In situ Hybridisierung $\quad 59$

3.1.5.1 Einbetten der Gewebe und Schneiden der Paraffinblöcke 59

3.1.5.2 Entwurf und Vorbereitung von Sonden für die in situ Hybridisierung 59

3.1.5.3 Nicht-radioaktive Markierung von RNA durch in vitro Transkription 60

3.1.5.4 Bestimmung der Markierungseffizienz von nicht-radioaktiv markierten RNA-Sonden 62

3.1.5.5 In situ Hybridisierung 64

3.1.6 Quantitative real-time RT-PCR $\quad 67$

3.1.6.1 Gewebeproben $\quad 67$

$\begin{array}{lll}\text { 3.1.6.2 RNA-Isolierung } & 67\end{array}$

3.1.6.3 Konzentrationsbestimmung der RNA 68

$\begin{array}{lll}\text { 3.1.6.4 Reverse Transkription } & 70\end{array}$

3.1.6.5 Primerdesign für die quantitative RT-PCR 72

3.1.6.6 Durchführung der quantitativen real-time RT-PCR 73

3.1.6.7 Schmelzkurvenanalyse 75

3.1.6.8 Bestimmung der Effizienz der PCR mittels Standardkurve 75

3.1.6.9 Berechnung nach $2^{-\Delta \Delta C_{T}}$-Methode 75

$\begin{array}{lll}3.2 & \text { Proteinbiochemische Methoden } & 77\end{array}$

$\begin{array}{lll}\text { 3.2.1 Antikörperaffinitätsreinigung } & 77\end{array}$

$\begin{array}{lll}\text { 3.2.1.1 Dot-Blot } & 78\end{array}$

3.2.1.2 Proteinbestimmung nach Bradford 79

$\begin{array}{ll}\text { 3.2.2 Immunhistochemie } & \mathbf{8 0}\end{array}$ 
3.2.2.1 Silanisierte Objektträger 80

3.2.2.2 Immunhistochemie mit der LSAB-Methode 80

3.2.2.3 Färbung mit Anilinblau 82

3.2.2.4 Färbung mit Hämalaun 83

3.2.2.5 Immunhistochemie Doppelfärbung 83

3.2.2.6 Tissue Microarray (TMA) 84

$\begin{array}{ll}\text { 3.2.3 Proteinextraktion aus Gewebe } & 85\end{array}$

3.2.3.1 Gesamtzelllysat aus Gewebe oder Zellen 85

3.2.3.2 Histonpräparation aus Gewebe oder Zellen mit Schwefelsäure $\left(\mathrm{H}_{2} \mathrm{SO}_{4}\right) 86$

\section{$\begin{array}{lll}\text { 3.2.4 SDS-Polyacrylamidgelelektrophorese } & 87\end{array}$}

3.2.4.1 Aufbau des SDS-Gels 88

3.2.4.2 Proteinauftrennung mit SDS-PAGE 89

3.2.4.3 Coomassie-Färbung 90

$\begin{array}{lll}3.2 .5 & \text { Western-Blot } & 91\end{array}$

3.2.5.1 Proteinnachweis mit Ponceau-S 92

3.2.5.2 Proteinnachweis durch Immunfärbung 92

3.2.5.3 Nachweis mittels Chemolumineszenz 93

3.2.5.4 Wiederverwendung einer Blotmembran nach Immunfärbung $\begin{array}{ll}\text { („Strippen“) } & 94\end{array}$

$\begin{array}{lll}3.3 & \text { Zellbiologische Methoden } & 94\end{array}$

3.3.1 Kultivierung von humanen Tumorzellinien $\quad 94$

3.3.1.1 Kultivierung und Passagieren von Suspensionszellen (Raji) 95

3.3.1.2 Kultivierung und Passagieren von adhärenten Zellen (HeLa und 293) 95

$\begin{array}{lll}\text { 3.3.1.3 Zellzählung } & 97\end{array}$

3.3.1.4 Ernte von Zellen 97

3.3.1.5 Präparation der Zellen für die Fluoreszenzmikroskopie 97

3.3.1.6 Langzeitlagerung von Zellen 98

3.3.1.7 Auftauen von Zellen 98

3.3.1.8 Synchronisation von HeLa-Zellen und Zellzyklusarrest 98

$\begin{array}{lll}\text { 3.3.2 Transiente Transfektion } & 99\end{array}$

3.3.2.1 Transiente Transfektion von Suspensionszellen 99

3.3.2.2 Transiente Transfektion von Adhäsionszellen 100 
3.3.2.3 Transiente Transfektion von HeLa-Zellen mit siRNA-Konstrukten ${ }^{1} \quad 100$

3.3.2.4 RNA-/ Proteinextraktion aus transfizierten HeLa-Zellen ${ }^{1} 101$

3.3.3 Stabile Transfektion von HeLa-Zellen mit siRNA ${ }^{1} \quad 101$

3.3.4 Fluoreszenzmikroskopische Analyse von Zellen 102

3.3.4.1 Fluoreszenzmikroskopische Analyse von Zellen mit GFP-Konstrukten 102

3.3.4.2 Dokumentation am Fluoreszenzmikroskop 103

$4 \quad$ Ergebnisse

105

4.1 Promotoranalyse von $H 1 x$

106

4.1.1 In silico Vergleich des H1x-Promotors mit Promotoren anderer H1-Gene 106

$\begin{array}{lll}\text { 4.1.2 Luciferase-Assay } & 109\end{array}$

4.1.3 Funktionalität des H1x-Promotors: Erstellung und Expression von H1x-GFP-Konstrukten

4.2 Vergleichende Expressionsanalyse von H1-Subtypen im Verlauf des Zellzyklus mittels quantitativer real-time RT-PCR

4.3 Differentielle Expression von H1x in Tumoren

4.3.1 Nachweis von H1x-mRNA in neuroendokrinen Tumoren durch in situ Hybridisierung

4.3.2 Nachweis von H1x-mRNA in neuroendokrinen Tumoren durch RT-PCR

4.3.3 Proteinanalyse mittels Western-Blot bestätigt Ergebnisse aus RT-PCR: H1x ist auch auf Proteinebene in neuroendokrinen Tumoren vermehrt nachzuweisen

4.3.4 Immunhistochemischer Nachweis von H1x in neuroendokrinen Tumorzellen

4.3.5 Chromogranin A-positive Zellen enthalten H1x 
5.1 Promotoranalyse von $\mathrm{H1x}$

5.2 Vergleichende Expressionsanalyse von H1-Subtypen im Verlauf des Zellzyklus mittels quantitativer real-time RT-PCR 159

5.3 Differentielle Expression von H1x in Tumoren 163

5.4 H1-mRNA Expression in Abhängigkeit des Entwicklungsstadiums 166

5.5 Ausblick 168

$6 \quad$ Zusammenfassung

7.1 Abkürzungsverzeichnis

7.2 Anhang

7.2.1 Primer

7.2.2 Primerspezifität für H1-Subtypen

7.2.3 Originaldaten aus RT-PCR fötal / adult

7.2.4 Originaldaten RT-PCR für Tumorkollektiv

7.2.5 Originaldaten RT-PCR für Zellzyklus

7.2.6 ISH-Sequenzen

7.2.7 GFP-Konstrukte Sequenzen

7.2.8 SiRNA $X 2$ und $T 1$ in pSilencer

7.2.9 Multiples Sequenzalignment der H1-Subtyp-mRNA-Sequenzen 


\section{Einleitung}

„Imagine trying to stuff about 10000 miles of spaghetti inside a basketball. Then, if that was not difficult enough, attempt to find a unique one inch segment of pasta from the middle of this mess, or try to duplicate, untangle and separate individual strings to opposite sites.“ Mit dieser Analogie beschreiben Peterson und Laniel (2004) die an ein Wunder grenzende Leistung der Natur, die DNA eukaryotischer Zellen so zu verpacken, daß sie bei jeder Transkription, Reparatur und Replikation korrekt abgelesen werden kann. Diese anschauliche Darstellung der Anforderungen im Zellkern zeigt, wie wichtig es ist, die DNA in einer Art und Weise zu komprimieren, die nicht nur das Platzproblem im Zellkern löst, sondern auch sicherstellt, daß die Nukleinsäure jederzeit korrekt gelockert werden kann und für Polymerasen, Endonukleasen und Ligasen zugänglich ist. Um diese Prozesse durchführen zu können, ist eine besondere Organisation der DNA im Kern der eukaryotischen Zelle nötig.

\subsection{Chromatin}

Die Organisation der DNA im Zellkern wird durch Nukleoproteinkomplexe ermöglicht. Deren Gesamtheit wird als Chromatin bezeichnet. Dieses besteht aus DNA und chromosomalen Proteinen, zu denen insbesondere die Histone gehören (Doenecke et al., 1997). DNA und Histone liegen zu etwa gleichen Anteilen vor, damit stellen Histone einen wesentlichen Bestandteil der Proteine des Chromatins in eukaryotischen Zellen dar. Es handelt sich bei ihnen um evolutionär stark konservierte basische Proteine, die direkt mit der DNA assoziiert sind und sich in fünf Proteinklassen einteilen lassen. Diese werden H1, H2A, H2B, H3 und H4 genannt.

Die Basiseinheit des Chromatins sind sogenannte Nukleosomen-Core-Partikel, die sich aus 146 Basenpaaren DNA und einem Oktamer aus den Core-Histonen H2A, H2B, H3 und H4 zusammensetzen (Carter, 1978; Simpson, 1978; Harp et al., 2000; Davey et al., 2002) (s. Abbildung 1). Das Oktamer besteht aus einem zentralen Heterotetramer aus je 
zwei H3- und H4-Histonen, dem zwei Heterodimere aus H2A und H2B anliegen (Eickbusch \& Moudrianakis, 1978, Arents et al, 1991; Arents und Moudrianakis 1995; Luger et al. 1997; Davey et al. 2002).

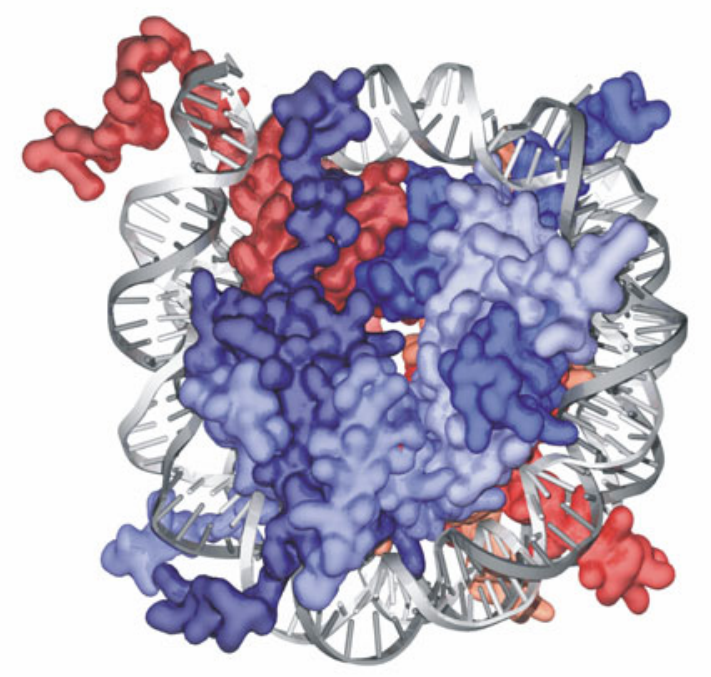

\section{Abbildung 1: Röntgenstruktur des Nukleosomen-Core-Partikels ${ }^{1}$}

Die Basiseinheit des Chromatins sind sogenannte Nukleosomen-Core-Partikel, die sich aus 146 Basenpaaren DNA und einem Oktamer aus den Core-Histonen H2A, H2B, H3 und H4 (hier in blau und rot dargestellt) zusammensetzen.

Die basischen chromosomalen Proteine der fünften Klasse, die H1-Histone, werden Linker-Histone genannt, da sie mit der Linker-DNA an ihrer Ein- und Austrittsstelle am nukleosomalen Core-Partikel interagieren (Thoma et al., 1979; Allan et al., 1986). Die Nukleosomen-Core-Partikel bilden zusammen mit je einem H1-Linker-Histon und der Linker-DNA die Nukleosomen (Kornberg \& Lorch, 1999).

Die aus dieser periodischen Anordnung von Histonen und DNA resultierende Nukleosomenkette bildet höher geordnete Strukturen (Thoma et al., 1979; Schalch et al., 2005; Robinson et al., 2006). Die Komprimierung der Chromatinfasern zu einer spiralförmig gewundenen $30 \mathrm{~nm}$ dicken Faser ist abhängig von der Anwesenheit der

\footnotetext{
${ }^{1}$ Mit den Programmen WebLab® Viewer (Accelrys ${ }^{\circledR}$ Software Inc.) und POV-Ray@ (www.povray.org) gerenderte Version der Struktur 1EQZ aus PDB (Protein Data Bank, www.pdb.org) (Harp et al., 2000)
} 
H1-Histone. Diese haben damit nicht nur eine Funktion auf nukleosomaler sondern auch auf supranukleosomaler Ebene (Thoma et al., 1979; Alan et al., 1986; Pruss et al., 1996, Thomas, 1999; Ausio, 2006).

\subsubsection{Histone}

Histone sind kleine basische Proteine, die direkt mit der DNA assoziiert sind (Allan et al., 1986). Die starke Basizität, die durch den hohen Anteil an Arginin und Lysin hervorgerufen wird (Stellwagen \& Cole, 1969), ermöglicht es, die DNA trotz ihres negativ geladenen Phosphatrückgrats so stark zu komprimieren, daß die zuvor beschriebenen Strukturen entstehen können (Arents et al., 1991).

Die Core-Histone bestehen aus einer globulären und zwei flexiblen terminalen Domänen (C-terminaler und N-terminaler Abschnitt) (Ausio et al., 2001; Ausio et al., 2006). Die globuläre Domäne ist aus miteinander verbundenen $\alpha$-Helices aufgebaut. Eine zentral gelegene $\alpha$-Helix und zwei kürzere flankierende $\alpha$-Helices bilden eine charakteristische Histondomäne, die sogenannte histone fold domain (Arents et al., 1991, 1995). Die amino- und carboxyterminalen Bereiche sind dagegen weniger strukturiert (Ausio et al., 2001; Ausio et al., 2006).

Auch die H1-Histone weisen eine dreigeteilte Struktur aus globulärer, N- und Cterminaler Domäne auf (Allan et al., 1986). Das Motiv der globulären Domäne von H1Histonen besteht aus drei $\alpha$-Helices (Cerf et al., 1994), die mit der DNA an der Symmetrieachse des Nukleosoms interagieren (Zhou et al., 1998; Brown et al., 2006). Ihre Struktur ist dem „winged Helix“-Motiv ähnlich, das für Transkriptionsfaktoren der forkhead-Familie charakteristisch ist (Clark et al., 1993).

Bemerkenswert ist der hohe Grad der Konservierung der Aminosäuresequenz der Histone im Laufe der Evolution. Die Core-Histone gehören zu den am stärksten evolutionär konservierten Proteinen (Isenberg, 1979) und sind in allen kernhaltigen Zellen vertreten. Im Gegensatz zu den hochkonservierten Core-Histonen sind die H1Histone durch eine hohe Variabilität in den $\mathrm{N}$ - und C-terminalen Abschnitten gekennzeichnet (Isenberg, 1979; Cole, 1984; Kasinsky et al., 2001; Ponte et al., 2003). Trotz der gemeinsamen Benennung „Histon“ sind Core- und Linker-Histone evolutionär 
nicht miteinander verwandt (Kasinsky et al., 2001). Sie haben sich unabhängig voneinander in Archaebakterien (als spätere Core-Histone) und allem Anschein nach in Eubakterien (als spätere Linker-Histone) entwickelt (Kasinsky et al., 2001).

\subsubsection{H1-Histonsubtypen}

Im Jahr 1966 beschrieben Kinkade \& Cole (1966) zum ersten Mal die Existenz von H1Subtypen. Bis heute sind elf verschiedene H1-Histonsubtypen in Säugern bekannt, für die verschiedene Nomenklaturen existieren (Parseghian et al., 1994). In der vorliegenden Arbeit wird die numerische Nomenklatur verwendet (Albig et al., 1991, 1993; Drabent et al., 1995).

Es wird vermutet, daß die einzelnen H1-Subtypen unterschiedliche Funktionen in der Zelle haben. Diese Vermutung beruht einerseits darauf, daß eine im Vergleich zu CoreHistonen große Zahl an H1-Subtypen existiert (Isenberg, 1979; Cole, 1984; Kasinsky et al., 2001) und andererseits darauf, daß die zelltypspezifische H1-Histonzusammensetzung des Chromatins variiert (Parseghian \& Hamkalo, 2001; Khochbin, 2001; Alami et al., 2003; Ausio, 2006). Über diese möglichen Funktionen ist bisher noch wenig bekannt. Gabrilovich und Mitarbeiter (2002) konnten zeigen, daß $\mathrm{H} 1^{\circ}$-defiziente Mäuse eine verringerte Produktion dendritischer Zellen aufweisen, der Subtyp H1.2 wurde als Transmitter apoptotischer Signale mit dem programmierten Zelltod in Verbindung gebracht (Konishi et al., 2003) und H1.5 wurde als genspezifischer Regulator der Muskeldifferenzierung identifiziert (Lee et al., 2004).

Die H1-Histone werden eingeteilt in ubiquitär und gewebespezifisch exprimierte Subtypen. Zu letzteren werden die testisspezifischen Subtypen H1t (Seyedin et al., 1981; Doenecke et al., 1997) und H1T2 (Martianov et al., 2005), das oozyten- und zygotenspezifische H1Foo (Tanaka et al., 2001, 2005) sowie das spermatidenspezifische H1-ähnliche HILS1 (Yan et al., 2003) gezählt. Sie werden nur in bestimmten Geweben oder während bestimmter Entwicklungsstadien exprimiert und werden deshalb als entwicklungs- und gewebespezifische H1-Histone bezeichnet.

Die ubiquitär exprimierten H1-Histonsubtypen lassen sich wiederum in zwei Gruppen einteilen: die replikationsabhängigen und die replikationsunabhängigen H1-Histone (s. 
Abbildung 2). $\mathrm{Zu}$ den replikationsunabhängigen wird bisher nur der Subtyp $\mathrm{H} 1^{\circ}$ gezählt, der - im Gegensatz zu H1.1, H1.2, H1.3, H1.4 und H1.5 - vermehrt in Zellen, die in der G1-Phase des Zellzyklus arretiert sind, und in terminal differenzierten Zellen exprimiert wird (Zlatanova, 1980; Khochbin \& Wolffe, 1994; Zlatanova \& Doenecke, 1994; Doenecke et al., 1994). Die replikationsabhängigen, sogenannten Hauptklassesubtypen H1.1, H1.2, H1.3, H1.4 und H1.5 (Doenecke et al., 1994; Khochbin 2001; Parseghian \& Hamkalo, 2001) werden verstärkt während der S-Phase exprimiert, wenn Histone für die Verpackung neu replizierter DNA benötigt werden (Heintz et al., 1983; Plumb et al., 1983; Osley 1991). Während das Vorkommen der Subtypen H1.2-H1.5 in allen somatischen Zellen dokumentiert wurde, konnte H1.1 lange Zeit nur in Thymus, Testis, und Milz und zu einem geringeren Teil auch in neuronalen Zellen und Lymphozyten nachgewiesen werden (Lennox \& Cohen, 1983, Pina et al., 1987; Rasheed et al., 1989; Franke et al., 1998). Inzwischen wurde die Aussage, das Vorkommen von H1.1 sei auf wenige Organe beschränkt, durch Wisniewski und Mitarbeiter (2007) revidiert. Diese konnten durch massenspektroskopische Analysen zeigen, daß H1.1 in allen von ihnen untersuchten Geweben der Maus vorkommt.

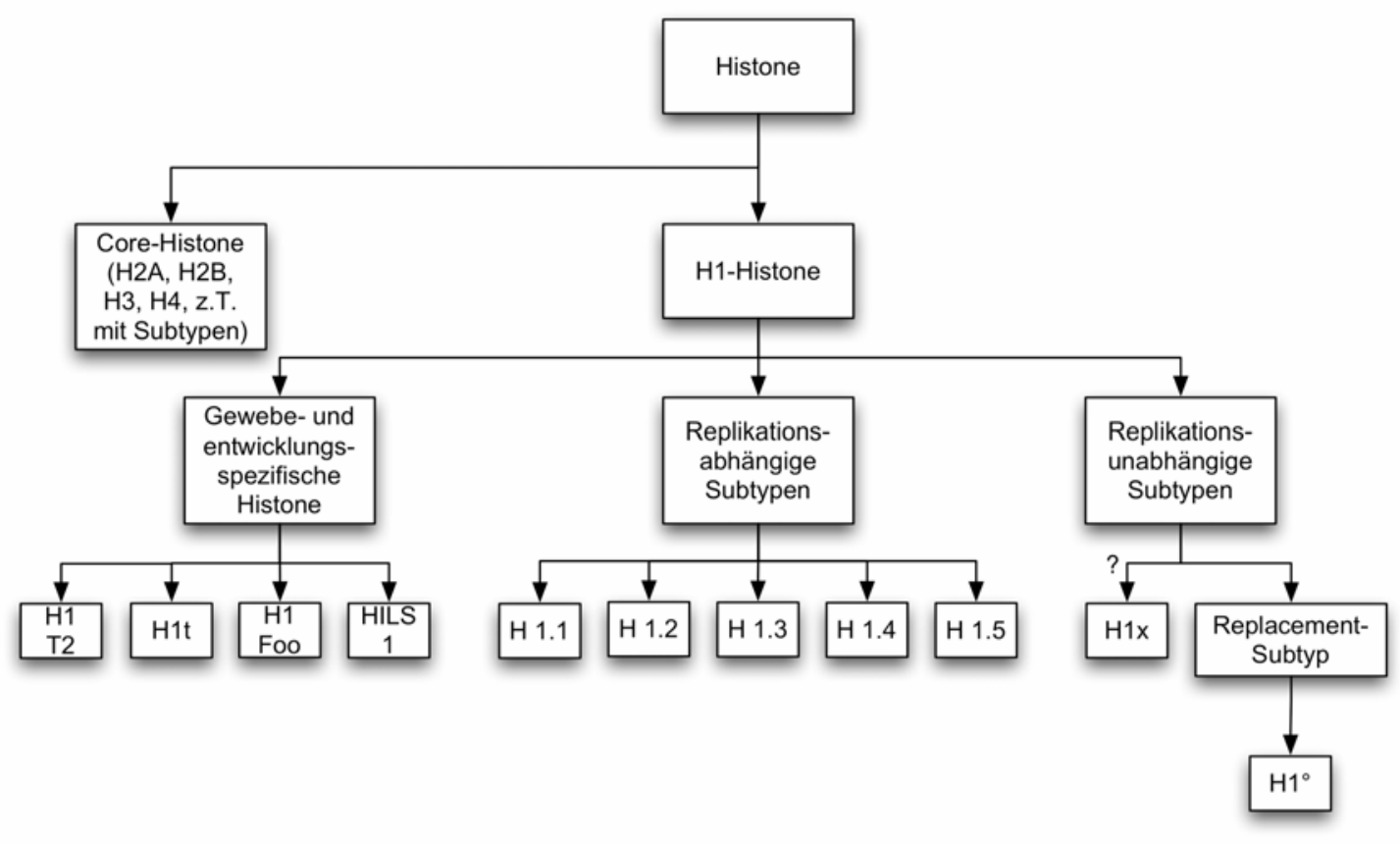

\section{Abbildung 2: Übersicht über die verschiedenen H1-Subtypen}

Einteilung der verschiedenen H1-Histonsubtypen in gewebespezifische, replikationsabhängige und replikationsunabhängige H1-Histone. Bei dieser Abbildung ist zu beachten, daß keine 
verwandtschaftlichen Beziehungen dargestellt sind, sondern nur eine Einordnung der Histone auf der Grundlage ihrer Expression.

\subsection{Der H1-Subtyp H1x}

Über den in der vorliegenden Arbeit genauer untersuchten Subtyp H1x ist bisher sehr wenig bekannt. Nachdem Yamamoto und Horikoshi (1996) bei einem two-hybrid screen eine cDNA-Sequenz in humanem Gewebe entdeckt hatten, die sie H1x nannten, beschäftigte sich erst im Jahr 2005 eine weitere Publikation mit diesem H1-Subtyp (Happel et al., 2005).

Yamamoto und Horikoshi (1996) untersuchten mittels Northern-Blot-Analyse die Verteilung von H1x in Gewebe und stellten das Vorkommen der H1x-mRNA in allen von ihnen untersuchten Geweben fest. Die H1x-cDNA kodiert ein 213 Aminosäuren langes, basisches Protein mit einem Molekulargewicht von 22487 Dalton und einem vorausgesagten isoelektrischen Punkt von 11,2 (Yamamoto \& Horikoshi, 1996). Aufgrund seines sehr basischen Charakters ist die elektrophoretische Mobilität des H1xProteins - ebenso wie die Mobilität der übrigen H1-Histone - in der SDSElektrophorese atypisch und entspricht einem apparenten Molekulargewicht von ca. 30 kDa (Happel et al., 2005).

Yamamoto und Horikoshi (1996) leiten in ihrer Arbeit aus der cDNA-Sequenz von H1x den für H1-Histone charakteristischen strukturellen Aufbau aus einer zentralen globulären Domäne und zwei terminalen Domänen ab. Ein Sequenzvergleich der globulären Domäne von H1x mit den globulären Domänen der bis dahin bekannten H1Histonproteine zeigte, daß $\mathrm{H} 1 \mathrm{x}$ die geringste Ähnlichkeit im Vergleich der verschiedenen H1-Histonsubtypen aufweist. Bei dem Vergleich der gesamten Aminosäuresequenzen bestätigte sich die geringe Übereinstimmung von H1x mit den anderen Subtypen, die 20-30 \% beträgt. Die Subtypen $\mathrm{H}^{\circ}{ }^{\circ}$ und $\mathrm{H} 1.1$ zeigen mit 28,4 \% bzw. 28,5 \% die größte Ähnlichkeit zu H1x (Happel et al., 2005).

Eine von Happel et al. (2005) durchgeführte Gendatenbankanalyse zeigt, daß orthologe H1x-Gene in weiteren Säugern, Vögeln, Amphibien und Fischen existieren. Der Vergleich dieser Orthologen in Bezug auf ihre Aminosäuresequenz ergab eine hohe Übereinstimmung der globulären Domänen, insbesondere im Vergleich von humanem 
H1x mit H1x des Huhns (Gallus gallus, 96 \% Identität der globulären Domäne), der Maus (Mus musculus, $90 \%$ Identität der globulären Domäne) und des Frosches (Xenopus laevis, 90 \% Identität der globulären Domäne). Die C- und N-terminalen Domänen eingeschlossen, zeigte das Protein der Maus mit 71 \% die größte Ähnlichkeit zu humanem H1x (Happel et al., 2005).

Das $H 1 x$-Gen des Menschen wurde im Rahmen des humanen Genomprojekts auf Chromosom 3 im Bereich 3q13.1-q13.2 kartiert (Sulimova et al., 2002). Diese solitäre Lokalisation läßt vermuten, daß das $H 1 x$-Gen, ebenso wie das Replacement-Histon $H 1^{\circ}$-Gen, nicht im Zusammenhang mit dem Histon-Cluster auf Chromosom 6, das die somatischen H1-Histonsubtypen H1.1-H1.5 und das testisspezifische $H 1 t$ enthält, exprimiert wird. Abgesehen von der solitären chromosomalen Lokalisation teilt H1x ein weiteres Merkmal mit $H 1^{\circ}$ : im Gegensatz zu den S-Phase-abhängigen Histongenen weist $H 1 x$ eine polyadenylierte mRNA auf (Kress et al., 1986 für $H 1^{\circ}$; Yamamoto \& Horikoshi, 1996 für H1x). Aus diesem Grund untersuchten Happel et al. (2005), ob die Expression von H1x ähnlich reguliert wird wie die des Replacement-Histons H1․ Die Proteinsynthese von $\mathrm{H} 1 \mathrm{x}$ konnte im Gegensatz $\mathrm{zu}$ der Synthese von $\mathrm{H}^{\circ}{ }^{\circ}$ durch Zellzyklusarrest oder Differenzierung der Zellen nicht angeregt werden. Daraus wurde geschlossen, daß die Expression von H1x einem anderen Regulationsmechanismus unterliegt als die Expression von $\mathrm{H} 1^{\circ}$. Zusätzlich konnten Happel und Mitarbeiter (2005) zeigen, daß das H1x-Protein nicht in allen untersuchten Tumorzellinien gleich stark synthetisiert wird.

\subsection{H1-Histone und maligne Transformation}

Im Jahr 2000 waren maligne Tumorerkrankungen für 12,6 \% aller Todesfälle weltweit verantwortlich. 5,2 Mio. Männer und 4,7 Mio. Frauen erkrankten im Jahr 2000 neu an Krebs und 6,2 Mio. Menschen starben daran (WHO, 2003). In den Prognosen der WHO wird davon ausgegangen, daß eine Zunahme der Neuerkrankungen um etwa $50 \%$ bis zum Jahr 2020 zu verzeichnen sein wird. Grund für diesen Anstieg ist zum einen die zunehmende Zahl alter Menschen, zum anderen die zunehmend ungesunden Lebensumstände vieler Menschen (WHO, 2003). 
Für die Entstehung von Tumoren sind einige Faktoren und Mechanismen bekannt. Tumore entstehen, wenn sich bestimmte Abschnitte der Erbsubstanz verändern und diese Veränderungen nicht mehr repariert werden können. Die Ursache für die Entstehung einer malignen Transformation sind zumeist fehlerhaft regulierte Onkogene oder Tumorsuppressorgene, die ihre Funktionalität verloren haben (Bailleul et al., 1989; Egan et al., 1991; Koeffler, 1991; Lehman et al., 1991; Hanahan \& Weinberg, 2000). Solche Mutationen in den Genen können durch UV-Strahlern, Zigarettenrauch, Chemikalien, Virusinfektionen, falsche Ernährung oder aufgrund einer erblichen Veranlagung ausgelöst werden. Damit ist Krebs zu einem großen Teil auf eine defekte Fehlerkorrektur der Erbsubstanz zurückzuführen.

Für einige Tumorarten existieren Markerproteine, mit deren Hilfe eine frühzeitige Diagnose der Krankheit möglich ist (Lindblom \& Liljegren, 2000). Tumormarker sind Proteine, die vermehrt in den Tumorzellen gebildet oder von ihnen in anderen Zellen induziert werden. Allzuhäufig wird entartetes Gewebe jedoch erst entdeckt, wenn das Wachstum der Tumorzellen nicht mehr zu stoppen ist.

Zwar haben sich die Behandlungsmöglichkeiten von Tumoren innerhalb der letzten 20 Jahre deutlich verbessert, doch ist auf zellulärer Ebene noch mehr über die molekularen Schlüsselmoleküle, die an der Tumorentstehung beteiligt sind oder dazu beitragen, entartete Zellen frühzeitig zu erkennen, zu lernen. Neue Behandlungsansätze, die auf Erkenntnissen der Molekularbiologie basieren, könnten entwickelt werden (Wiedenmann \& Pape, 2004). Auch ist es wichtig, Tumore so genau wie möglich zu charakterisieren, um eine gezielte Behandlung, die auf die speziellen Eigenschaften des Tumors abgestimmt ist, möglich zu machen. Ein Beispiel dafür, wie wichtig diese Charakterisierung sein kann, ist das Tumorsuppressorgen p53, das 1979 unabhängig voneinander von David Lane und Arnold Levine entdeckt wurde (Lane \& Crawford, 1979; Linzer \& Levine, 1979). Bei vielen Krebserkrankungen ist das p53-Gen durch Mutation ausgeschaltet. Defekte p53-Gene sind bei etwa der Hälfte aller Tumore nachweisbar. Bei der anderen Hälfte vermehren sich die Tumorzellen trotz funktionell aktivem p53. Die Tumorzellen, die p53 exprimieren, können sogar eine Chemotherapie, deren Wirkung darauf beruht, DNA der Krebszellen zu schädigen, überstehen. Diese Resistenz gegenüber der Chemotherapie beruht vermutlich darauf, daß das durch p53 
aktivierte DNA-Reparatursystem bzw. der p53-vermittelte Zellzyklusarrest als Barriere für die chemotherapeutische Behandlung wirkt. p53 kann also entgegen seiner eigentlichen Funktion, das Tumorwachstum zu hemmen, sogar das Krebswachstum fördern (Moreno et al., 2007).

Die Regulierung der Genexpression durch H1-Histone könnte eine ähnlich bedeutsame Rolle spielen. Die Beteiligung der Linker-Histone bei der Kondensierung der DNA und ihre strukturelle Ähnlichkeit mit Transkriptionsfaktoren lassen vermuten, daß H1Histone an der Regulierung der Genaktivität beteiligt sind. Man konnte zeigen, daß sie die Transkription aktivieren oder unterdrücken können (Brown, 2003; Harvey \& Downs, 2004). Außerdem wurden die H1-Histone in Verbindung gebracht mit Zellproliferation und Differenzierung (Kundahl et al., 1981; Okabe-Kado et al., 1981; Henriquez et al.,2002), sowie mit Zytotoxizität (Class et al., 1996; Pohlmeyer et al., 2000), Apoptose (Konishi et al., 2003), Zellalterung (Barra et al., 2000; Funayama et al., 2006) und DNA-Reparatur (Downs et al., 2003). Diese Prozesse sind auch bei der Entstehung maligner Transformation von Bedeutung.

In einigen Publikationen wurde eine Änderung des H1-Subtypverhältnisses während maligner Transformation beschrieben (s. beispielsweise Tan et al., 1982; Goodlad \& Clark, 1995; Kostova et al., 2005). Tan und Mitarbeiter (1982) verglichen die H1Subtypverteilung in normalen und neoplastischen kultivierten humanen Zellen. Dabei konnten sie feststellen, daß ein Zusammenhang besteht zwischen der Subtypzusammensetzung und der Fähigkeit der Zellen, Tumore in Mäusen hervorzurufen. In der Arbeit von Goodlad und Clark (1995) wurde bei Ratten mit Walker 256 Karzinom ein Anstieg der H1.2-Proteinmenge festgestellt. In Experimenten, in denen der replikationsunabhängig exprimierte Subtyp $\mathrm{H} 1^{\circ}$ untersucht wurde, konnte in einigen Tumoren eine Zunahme der $\mathrm{H}^{\circ}{ }^{\circ}$-Menge gezeigt werden (Ballal \& Busch, 1973; Mannironi et al., 1988), in anderen Tumoren dagegen eine Abnahme im Vergleich zu der Menge in ihren Herkunftsgeweben (Davie et al., 1987; Giancotti et al., 1993; Kostova et al., 2005).

Der Histonsubtyp H1x teilt, wie schon zuvor erwähnt, einige gemeinsame Eigenschaften mit dem replikationsunabhängigen $\mathrm{H}^{\circ}$. Für eine genaue Analyse der $H 1 x$-Expression und H1x-Funktion war es zunächst erforderlich, eine Übersicht über bisher erhobene Expressionsdaten zu erhalten. BLAST Datenbankrecherchen, die vor 
Beginn der vorliegenden Arbeit durchgeführt wurden, ergaben eine erhöhte Trefferrate für H1x-ESTs (expressed sequence tags) in Tumordatenbanken neuroendokriner Tumore.

\subsection{Neuroendokrine Tumore}

Neuroendokrine Tumore stellen eine heterogene Gruppe seltener Neoplasien dar, die sich an vielen Stellen innerhalb aber auch außerhalb des Gastrointestinaltraktes aus neuroendokrinen Zellen entwickeln (Touroutoglou et al., 1995). Als "neuroendokrin" werden Zellen neuronalen (nervenartigen) Ursprungs bezeichnet, die Hormone produzieren und so endokrin aktiv sein können. Diese neuroendokrinen Zellen sind im gastrointestinalen System und diffus im ganzen Körper verteilt. Sie bilden entweder kleine Organe, distinkte Zellcluster oder ein Netzwerk von über Lunge und Darm verstreuten Zellen (Klöppel \& Heitz, 1994).

Zunächst wurde vermutet, daß alle neuroendokrinen Zellen von der Neuralleiste abstammen und sich dann im gesamten Körper ausbreiten. Jedoch konnten ausführliche embryologische Untersuchungen zeigen, daß nicht alle neuroendokrinen Zellen auf das neurale Ektoderm zurückzuführen sind. Die Suche nach einem gemeinsamen embryonalen Ursprung hat angesichts der immunhistochemischen Möglichkeiten zur phänotypischen Charakterisierung der neuroendokrinen Zellen an Bedeutung verloren. Unabhängig von ihrer Herkunft haben sie ein gemeinsames genetisches Programm zur Expression biochemischer Marker mit neuroendokrinen Funktionen. Dementsprechend wird der Terminus „neuroendokrin“ verwendet, um deutlich zu machen, daß die Zellen durch ihre Sekretionsprodukte und zytoplasmatischen Proteine definiert werden und nicht durch ihre Herkunft oder embryonale Abstammung (Touroutoglou et al., 1995).

Fortschritte auf den Gebieten der Histochemie, der Elektronenmikroskopie und der Immunhistochemie haben dazu beigetragen, daß neuroendokrine Zellen besser erkannt und charakterisiert werden können. Einige Proteine, die spezifisch von neuroendokrinen Tumorzellen sezerniert werden, wurden identifiziert und können als Tumormarker eingesetzt werden. Diese zytoplasmatischen Proteine liegen in kleinen sekretorischen Vesikeln oder sekretorischen Granula in den Zellen vor (Bajetta et al., 1999; Lindblom \& Liljegren, 2000; Lamberts et al., 2001). Das basische Chromogranin A wurde als gut 
geeigneter Marker für neuroendokrine Gewebe und Tumore entdeckt. Es handelt sich dabei um ein lösliches Protein, das in den sekretorischen Granula lokalisiert ist. Zu den meistverwendeten Antikörpern zur Typisierung neuroendokriner Zellen und Tumore gehört daher der Chromogranin A-Antikörper (Lamberts et al., 2001).

Verschiedene Typen neuroendokriner Zellen teilen zwar viele Eigenschaften, doch handelt es sich bei der Gruppe neuroendokriner Tumore um eine sehr heterogene Gruppe mit verschiedenen biologischen und klinischen Eigenschaften. Aus diesem Grund ist es besonders wichtig, diese Tumore genauer zu charakterisieren und ihre Regulationsmechanismen zu untersuchen. Detaillierteres Wissen um genetische Kontrollprozesse in neuroendokrinen Tumoren könnte sich als wichtige Grundlage für neue Wege der Diagnose und Therapie erweisen.

\subsection{Zielsetzung der Arbeit}

Die Diversität der H1-Histone ist seit mehr als 40 Jahren bekannt, doch ist noch nicht geklärt, wie ihre Expression und die Verteilung der einzelnen Subtypen in unterschiedlichen Geweben reguliert werden. Am Beispiel des bisher wenig untersuchten Histonsubtyps $\mathrm{H} 1 \mathrm{x}$ sollte in der vorliegenden Arbeit ein Beitrag zur Aufklärung der Expression von H1-Histongenen und der Verteilung von einzelnen H1Histonsubtypen geleistet werden. Abgesehen von den durchgeführten Sequenzanalysen (Yamamoto \& Horikoshi, 1996; Happel et al., 2005), der Untersuchung des humanen H1x-Proteins in kultivierten Zellen (Garcia et al., 2004; Happel et al., 2005) und einer ersten Untersuchung mittels Northern-Blot-Analyse zur Verteilung von H1x in Gewebe (Yamamoto \& Horikoshi, 1996) existierten zu Beginn der vorliegenden Arbeit keine Daten zu dem H1-Histonsubtyp H1x.

Eine genauere Charakterisierung des Subtyps H1x in Bezug auf die Regulierung seiner Expression durch den $H 1 x$-Promotor, seine Expression im Verlauf des Zellzyklus, in Tumoren und in unterschiedlichen Entwicklungsstadien humanen Gewebes sollte vorgenommen werden. Das Ziel der Promotoranalyse und der Untersuchung der Expression des $H 1 x$-Gens im Verlauf des Zellzyklus war, herauszufinden, ob es sich bei 
dem $H 1 x$-Gen um ein replikationsabhängig oder um ein replikationsunabhängig exprimiertes Histongen handelt.

Ausgehend von den Ergebnissen einer bereits durchgeführten BLAST Datenbankrecherche sollte geklärt werden, ob $H 1 x$ in neuroendokrinen Tumoren vermehrt exprimiert wird und ob die Transkription des Gens mit der Synthese des H1x-Proteins korreliert. 


\section{Material}

\subsection{Geräte}

Agilent 2100 Bioanalyzer

Automat zur Silanisierung von

Objektträgern

Biofuge pico

Biofuge Stratos

Biofuge-13

Brutschrank

Brutschrank Cytoperm 2

Brutschrank Modell CO 24

Brutschrank Typ B5050

Coveraid

Dampfgarer MultiGourmet

Digitale Kamera C5050

Duomax 1030 Schüttler

Elektronisches Zellzählgerät CASY 1TT

FACSCalibur
Agilent Technologies (Palo Alto, CA, USA)

Vogel (Gießen)

Heraeus (Hanau)

Heraeus (Hanau)

Heraeus (Hanau)

Memmert (Schwabach)

Heraeus (Hanau)

New Brunswick Scientific Co. Inc. (New Jersey, USA)

Heraeus (Hanau)

Sakura Finetechnical Co. Ltd. (Nagano, Japan)

Braun (Deutschland)

Olympus (Japan)

Heidolph Instruments (Schwabach)

Schärfe System (Reutlingen)

Becton Dickinson (Heidelberg) 
Fluoreszenzmikroskop Axioskop

Fluoroskan Ascent FL Fluoro-

Luminometer

GeneAmp PCR system 2400

Hera Safe Sterilbank

iCycler

Inkubator Shaker, Model G 25

Intas Gel Jet Imager

Kamera Axio Cam MRm

Kühlplatte MediTe Tissue Cool Plate

COP20

Manual Tissue Arrayer

Megafuge 1,0, Model G25

Mikrodismembrator Ultra Turrax T25

Mikroskop BX40

Mikroskop CK40SLP

MTA-Booster ${ }^{\circledR}$ Version 1.01

Optical Module for iCycler
Zeiss (Göttingen)

Labsystems (Quickborn)

Perkin Elmer Applied Biosystems

(Weiterstadt)

Heraeus (Hanau)

Bio-Rad (München)

New Brunswick Scientific Co. Inc.

(New Jersey, USA)

Intas Science Imaging Instruments

GmbH (Göttingen)

Zeiss (Göttingen)

Medizin Technik (Burgdorf)

Beecher Instruments (Sun Prairie, WI, USA)

Heraeus (Hanau)

IKA-Werke GmbH (Staufen)

Olympus (Japan)

Olympus (Japan)

Aphelys (Plaisir, Frankreich).

Bio-Rad (München) 
Peristaltic pump P-1

pH-Meter CG 820

Power supply Power Pack 1000

Sequenziergerät ABI PRISM Model 3100

Sorvall RC 5B Plus

Speed Vac SC 100

Sterilbank Clean Air Typ: DLF BSS4

Sterilbank HERAsafe Typ 18/2

Tischzentrifuge 5415

UV-Schirm Transilluminator Model TM40

UV-Spektrophotometer Ultrospec 3000

UV-Stratalinker® 2400

Varifuge 3.0R

Vortex Genie $2^{\mathrm{TM}}$

\subsection{Verbrauchsmaterial}

Entwicklerlösung LX24

Filterpapier

Fixierer

High-Performance-ChemolumineszenzFilm
Pharmacia Fine Chemicals (Uppsala,

Schweden)

Schott Geräte (Hofheim)

BioRad (München)

Applied Biosystems (Darmstadt)

Kendro (Hanau)

Savant (Holbrook, NY, USA)

Kendro (Langenselbold)

Heraeus (Hanau)

Eppendorf (Hamburg)

UVP (San Gabriel, Kalifornien, USA)

Pharmacia Biotech (Freiburg)

Stratagene (La Jolla, CA, USA)

Heraeus (Hanau)

Bender \& Hobein (Zürich, Schweiz)
Kodak (Paris, Frankreich)

Schleicher \& Schüll (Dassel)

Kodak (Paris, Frankreich)

GE Healthcare (Buckinghamshire, England) 
Nitrozellulosemembran

Nylonmembran

Objektträger
Schleicher \& Schüll (Dassel)

Schleicher \& Schüll (Dassel)

Knittel Glasbearbeitungs-GmbH

(Braunschweig)

Einwegartikel wurden von folgenden Firmen bezogen: Eppendorf (Hamburg), Falcon

(Heidelberg), Greiner (Frickenhausen), Heinemann (Duderstadt), Qiagen (Hilden), Sarstedt (Langenhagen) und Schütt (Göttingen).

\subsection{Software}

AxioVision Rel.4.5

BLAST

Editseq

iCycler Software

MapDraw

MegAlign

Multalin Version 5.4.1

Primer3 Software

Target Finder

Tissue arrays design

software TMA-Designer ${ }^{\circledR}$

Version 1.1
Zeiss (Göttingen)

http://www.ncbi.nlm.nih.gov/BLAST/

DNASTAR (Madison, WI, USA)

Bio-Rad (München)

DNASTAR (Madison, WI, USA)

DNASTAR (Madison, WI, USA)

(Corpet, 1988)

http://frodo.wi.mit.edu/cgi-bin/primer3/primer3_www.cgi

Ambion, Applied Biosystems, Foster City, CA, USA

Aphelys, Plaisir, Frankreich 


\subsection{Chemikalien}

Aphidicolin

dNTPs

DTT

Natriumbutyrat

peq Gold Agarose

random-Hexamer-Primer

TEMED

TRIzol Reagenz

Vectashield ${ }^{\circledR}$ Mounting Medium mit

Diamino-2-phenylindol (DAPI)
Alexis Biochemicals (San Diego, USA)

PeqLab (Erlangen)

Invitrogen Life Technologies (Karlsruhe)

Sigma (München)

PeqLab (Erlangen)

Invitrogen Life Technologies (Karlsruhe)

Serva (Heidelberg)

Invitrogen Life Technologies (Karlsruhe)

Vector Laboratories (Burlingame, CA, USA)

Die übrigen Chemikalien wurden von den Firmen Applichem, Biochrom, Merck, Roth, Serva und Sigma bezogen.

Applichem GmbH (Darmstadt): Agar, Bacto-Trypton, Magermilchpulver, TCA (Trichloressigsäure)

Biochrom (Berlin): FCS, RPMI 1640, n-Acetyl-L-Alanyl-LGlutamin, MEM T437-10

Merck (Darmstadt): Magnesiumchlorid, Ammonium Peroxodisulfat (APS), $\mathrm{H}_{2} \mathrm{O}$ (HPLC gereinigt), Natronlauge

Roth (Karlsruhe): Aceton, Acrylamid-30 \% (w/v)-Bisacrylamid-0,8 \% (w/v)-Stammlösung, Ethanol, Glycerin, Glycin, Hepes, Isopropanol, Magnesiumchlorid, Methanol, Natriumchlorid, Natriumhydrogencarbonat, Salzsäure, Schwefelsäure, SDS, Tris, Tween-20

Serva (Heidelberg): EDTA, $\beta$-Mercaptoethanol, Saccharose, TEMED 
Sigma (München): BSA, Dimethylsulfoxid (DMSO), Ethidiumbromid, D-Glucose, LBBroth (Luria-Bertani-Medium), Triton X-100, Tween-20

\subsection{Reagenziensätze}

Cytomation ChemMate Detection Kit

Dako (Glostrup, Dänemark)

Alkaline Phosphatase/Red Rabbit/Mouse

Dual-Luciferase ${ }^{\mathrm{TM}}$ Reporter Assay System

Promega (Madison, USA)

ECL Plus Western Blotting Detction

GE Healthcare (Buckinghamshire,

Reagent Kit

England)

Effectene $^{\mathrm{TM}}$ Transfection Kit

Qiagen (Hilden)

Eurogentec qPCR Core Kit für SYBR

Eurogentec (Seraing, Belgium)

Green I ${ }^{\mathrm{TM}}$ No ROX

EZNA ${ }^{\circledR}$ Cycle Pure Purification-Ki

PeqLab (Erlangen)

GC-rich PCR System

Roche (Mannheim)

MinElute ${ }^{\circledR}$ Gel Extraction Kit

Qiagen (Hilden)

NucleoSpin RNAII Kit

Macherey-Nagel (Düren)

Nucleospin ${ }^{\circledR}$ RNA/Protein-Kit

Macherey-Nagel (Düren)

NucleoSpin, Plasmid-Kit

Macherey-Nagel (Düren)

Phusion PCR System

Finnzymes (Espoo, Finnland)

Polyfect

Qiagen (Hilden)

Pure Yield ${ }^{\mathrm{TM}}$ Plasmid Midiprep System

Promega (Madison, USA)

RNA 6000 Nano LabChip ${ }^{\circledR}$ Kit

Agilent Technologies (Palo Alto, CA, USA) 


\subsection{Enzyme}

Alkalische Phosphatase

Complete EDTA-frei (Proteaseinhibitor)

Lysozym

Pepstatin A

Proteinase K

$\operatorname{RedTaq}^{\mathrm{TM}}$

RNAase A

$\operatorname{RNasIn}^{\mathrm{TM}}$

Superscript ${ }^{T M}$ II RNase H- Reverse

Transcriptase

T4 DNA-Ligase

T4 Polynukleotidkinase

Trypsin
Roche (Mannheim)

Roche (Mannheim)

Sigma (München)

Roche (Mannheim)

Roche (Mannheim)

Sigma (München)

Roche (Mannheim)

Promega (Mannheim)

Invitrogen Life Technologies (Karlsruhe)

Fermentas (Vilnius, Litauen)

New England Biolabs (Ipswich, MA, USA)

Biochrom AG (Berlin)

Die verwendeten Restriktionsenzyme wurden von den Firmen New England Biolabs (Ipswich, MA, USA) oder Fermentas (Vilnius, Litauen) bezogen.

\subsection{Vektoren und Plasmide}

IM28 (H1x cDNA im Vektor pOTB7)

(Happel et al., 2005)

pBluescript II KS+

Stratagene (Amsterdam, Niederlande)

pEGFP-1

Biosciences Clontech (Mountain View, 
CA, USA)

pEGFP-N1

Biosciences Clontech (Mountain View, CA, USA)

pGEM $^{\circledR}$-T-Easy

Promega (Madison, USA)

pGL3-basic

Promega (Madison, USA)

pRL-CMV

Promega (Madison, USA)

pSilencer $^{\mathrm{TM}}$ 1.0-U6

Ambion Applied Biosystems (Foster

City, CA, USA)

pWA 311 (kodierenden Bereich von H1.2

(Albig et al., 1998)

in dem Hefeexpressionsvektor YEp51)

\subsection{Oligonukleotide}

Die verwendeten Oligonukleotide wurden bei MWG-Biotech (Ebersberg) oder Operon Biotechnologies (Köln) gefertigt. Die Sequenzen und Schmelztemperaturen der Oligonukleotide sind im Methodenteil angegeben.

\subsection{Antibiotika}

Ampicillin

Ratiopharm (Ulm)

G418

Sigma (München)

Gentamycin

Ratiopharm (Ulm)

Kanamycin

Invitrogen (Karlsruhe)

\subsection{Bakterien, Zellen und Gewebe}

Escherichia coli DH5 $\alpha$

Clontech (Palo Alto, USA) 
HEK-293

DSMZ (Braunschweig)

HeLa

DSMZ (Braunschweig)

HL60

CLS (Heidelberg)

Raji-Zellen

DSMZ (Braunschweig)

Archivierte Gewebeproben aus neuroendokrinen Tumoren und dem umgebenden gesunden Gewebe wurden von der Abteilung Gastroenteropathologie des Klinikums Göttingen (Abteilungsleiter Prof. Dr. Füzesi) bezogen. Die durchgeführten Versuche waren von der Ethikkommission bewilligt.

Humane Gesamt-RNA aus fötaler Lunge, adulter Lunge, fötalem Kolon und adultem Kolon wurde von der Firma Stratagene (Amsterdam, Niederlande) bezogen.

\subsection{Antikörper}

\subsubsection{Primärantikörper}

Kaninchen-anti H1x (Bezeichnung „305“, (Happel et al., 2005)

3. Blutung bzw. affinitätsgereinigt,

Fraktion 9-12)

Maus-anti $\mathrm{H} 1^{\circ}$

Prof. Dr. Zentgraf, DKFZ (Heidelberg)

Maus-anti-CEA, Klon Col-1

Zymed Laboratories, Invitrogen immunodetection (San Francisco, CA, USA)

Maus-anti-Chromogranin, Klon DAK-A3 Zymed Laboratories, Invitrogen immunodetection (San Francisco, CA, USA)

Maus-anti-H1, Klon AE-4 Upstate (Lake Placid, NY, USA) 
Maus-anti-H1 MAB, Klon 1415-1

Maus-anti-Vimentin, Klon Vim 3B4

Schaf-anti-Dig

Kaninchen-anti-H1.2

Maus-anti-CD45, Klon 2B11 und Klon PD7/26

\subsubsection{Sekundärantikörper}

Alexa-Fluor 488’ anti- Kaninchen

Alexa-Fluor 555’anti- Maus

Ziege-anti-Kaninchen IgG +HRP

Ziege-anti-Maus IgG + HRP

\subsection{Farbstoffe}

Anilin

BCIP

Bromophenol blue

Coomassie brilliant blue G250

Coomassie brilliant blue R250

Ethidium bromide

Hämatoxilin Certistain ${ }^{\circledR}$
Lab Vision (Fremont, CA, USA)

Dako (Glostrup, Dänemark)

Roche (Penzberg)

Abcam (Cambridge, England)

Zymed Laboratories, Invitrogen

immunodetection (San Francisco, CA, USA)

Molecular Probes Invitrogen (Karlsruhe)

Molecular Probes Invitrogen (Karlsruhe)

Sigma (Taufkirchen)

Sigma (Taufkirchen)

Schmidt GmbH (Köngen)

BioMol (Hamburg)

Merck (Darmstadt)

Serva (Heidelberg)

Fluka (Taufkirchen)

Sigma (Steinheim)

Merck (Darmstadt) 
Kernechtrot Certistain ${ }^{\circledR}$

NBT

Ponceau S concentrate

\subsection{Größenstandards}

$\lambda$-DNA/EcoRI+HindIII Marker 3

PageRuler ${ }^{\mathrm{TM}}$ Prestained Protein Ladder

RNA 6000 Ladder

\subsection{Kulturmedien}

\subsubsection{Zellkulturmedien}

\section{DMEM-Medium:}

67,7 g Biochrom T 043-05 (DMEM mit 4,5g D-Glucose, mit L-Glutamin, ohne $\mathrm{NaHCO}_{3}$ ), 19 gNaHCO$_{3}$ mit zweifach destilliertem $\mathrm{H}_{2} \mathrm{O}$ auf $5 \mathrm{~L}$.

\section{MEM-Medium:}

48,8 g Biochrom T437-05 (MEM Eagle mit L-Glutamin, ohne $\mathrm{NaHCO}_{3}$ ), 11,25 g $\mathrm{NaHCO}_{3}, 11,9$ g Hepes, mit zweifach destilliertem $\mathrm{H}_{2} \mathrm{O}$ auf $5 \mathrm{~L}$.

\section{RPMI-Medium:}

52,05 g Biochrom T 121-05 (RPMI 1640 mit L-Glutamin, ohne $\mathrm{NaHCO}_{3}$ ), 10,0 g $\mathrm{NaHCO}_{3}, 17,88$ g Hepes, mit zweifach destilliertem $\mathrm{H}_{2} \mathrm{O}$ auf $5 \mathrm{~L}$.

\subsubsection{Bakterienmedien und Nährböden}

\section{LB-Medium (Luria-Bertani-Medium) (pH 7,0):}

10 g Trypton, 5 g Hefe-Extrakt, 10 g NaCl, 2 g Maltose, pH 7,0, mit einfach destilliertem $\mathrm{H}_{2} \mathrm{O}$ auf $1 \mathrm{~L}$. 


\section{LB-Platten:}

10 g Trypton, 5 g Hefe-Extrakt, 10 g NaCl, 2 g Maltose, pH 7,0, mit einfach destilliertem $\mathrm{H}_{2} \mathrm{O}$ auf 1 L. Nach Einstellung des $\mathrm{pH}$-Wertes wurden $15 \mathrm{~g}$ Agar zugegeben.

\subsection{Lösungen und Puffer}

Alkalische Phosphatase Puffer:

100 mM Tris/HCl, pH 9,5, $100 \mathrm{mM} \mathrm{NaCl,} 50$ mM MgCl 2

Ammoniumpersulfat-Stammlösung (10 \%):

$10 \mathrm{~g}$ in100 mL zweifach destilliertem $\mathrm{H}_{2} \mathrm{O}$

\section{Anilinblau-Färbelösung:}

$1 \mathrm{~g} / \mathrm{L}$ Anilin in 1 \% Essigsäure

\section{Blottransferpuffer:}

38,4 mM Tris, 31,2 mM Glycin, 0,03 \% (v/v) SDS, $20 \%$ (v/v) MeOH

\section{Bradford-Lösung:}

70 mg Coomassie Brilliant Blue G250 in50 mL EtOH, 500 mL $\mathrm{H}_{2} \mathrm{O}, 100 \mathrm{~mL} 85$ \% ortho $\mathrm{H}_{3} \mathrm{PO}_{4}, 50$ mL Coomassie-EtOH-Lösung, 350 mL H $\mathrm{H}_{2} \mathrm{O}$

10 mM Citratpuffer (pH 6,0):

10 mM Citronensäuremonohydrat, pH 6,0 mit 2 N NaOH einstellen

\section{Complete-Stammlösung:}

1 Tablette Complete in $1 \mathrm{~mL} \mathrm{H}_{2} \mathrm{O}$ dd

\section{Coomassie-Färbelösung:}

0,2 \% (w/v) Coomassie Brilliant Blue R250, 0,05 \% (w/v) Coomassie Brilliant Blue G250, 42,5 \% (v/v) EtOH p.a., 5 \% (v/v) MeOH, 10 \% Essigsäure

100x Denhardts (Denhardt, 1966):

$2 \%$ PVP (w/v), 2 \% BSA Fraktion V (w/v), 2 \% Ficoll (w/v) 


\section{DEPC- $\mathrm{H}_{2} \mathrm{O}$ :}

$1 \mathrm{~mL}$ DEPC (v/v) in $100 \mathrm{~mL} 50$ \% EtOH lösen und mit $900 \mathrm{~mL}$ zweifach destilliertem $\mathrm{H}_{2} \mathrm{O}$ auffüllen, 30 min bei RT inkubieren, dann autoklavieren

\section{Starker Entfärber:}

$50 \%$ (v/v) MeOH, $10 \%$ (v/v) Essigsäure

\section{Schwacher Entfärber:}

$10 \%$ (v/v) MeOH, 5 \% (v/v) Essigsäure

\section{Färbelösung (in situ Hybridisierung):}

22,5 $\mu \mathrm{L} \mathrm{NBT} \mathrm{(50} \mathrm{mg/mL} \mathrm{in} 70$ \% DMF), 17,5 $\mu \mathrm{L}$ BCIP (50 mg/mL in DMF) in $10 \mathrm{~mL}$ Puffer III

\section{Hämalaun nach Meyer:}

$3 \mathrm{~g}$ Haematoxilin, 0,2 g Natriumiodat $\left(\mathrm{NaIO}_{3}\right), 50 \mathrm{~g}$ Kaliumaluminiumsulfat, $50 \mathrm{~g}$ Chloralhydrat, 1 g Zitronensäure in $1 \mathrm{~L}$ dd $\mathrm{H}_{2} \mathrm{O}$ lösen (über Nacht rühren, filtrieren)

\section{Hybridisierungslösung:}

50 \% deionisiertes Formamid (v/v), 10 \% Dextransulfat (v/v), 1x Denhardts, 0,5 mg/mL E. coli DNA, 0,5 mg/mL Hefe rRNA, 0,25 mg/mL Hefe tRNA, 4x SSC

\section{Kernechtrot Lösung:}

0,2 g Kernechtrot Certistain @ in $200 \mathrm{~mL}$ kochende fünfprozentige, wäßrige Aluminiumsulfat Lösung einrühren und für 5-10 min kochen lassen. Die Lösung wird nach dem Erkalten filtriert.

\section{5x Laemmli-Auftragspuffer:}

500 mM Tris/HCl (pH 6,7), $38 \%$ (v/v) Glycerol, $15 \%$ (w/v) SDS, 0,013\% (w/v) Bromphenolblau, 5 \% (v/v) ß-Mecaptoethanol

\section{5x Laemmli-Laufpuffer:}

0,25 M Tris/HCl (pH 8,7), 10 mM EDTA, 1,9 M Glycin, 0,5 \% (w/v) SDS 


\section{Magermilchpulver $5 \%$ in TBS-T:}

50 g Magermilchpulver, 1 LTBS-T

\section{M Natriumphosphatpuffer pH 7,5:}

$1 \mathrm{M} \mathrm{Na}_{2} \mathrm{HPO}_{4}, 1 \mathrm{M} \mathrm{NaH} \mathrm{PO}_{4} ; \mathrm{Na}_{2} \mathrm{HPO}_{4}$ vorlegen und mit $\mathrm{NaH}_{2} \mathrm{PO}_{4}$ einstellen

\section{NBT-Stammlösung:}

$75 \mathrm{mg} / \mathrm{mL}$ in $70 \%$ (v/v) Dimethylformamid

Pepstatin-Stammlösung:

7 mg Pepstatin A in10 mL 100 \% EtOH

PBS mit Protease-Inhibitoren:

Complete-Stammlösung 1:100, Pepstatin-Stammlösung 1:1000 in PBS

Phosphate buffered saline (1x PBS):

$137 \mathrm{mM} \mathrm{NaCl}, 2,7 \mathrm{mM} \mathrm{Kcl,} 9 \mathrm{mM} \mathrm{Na} 2 \mathrm{HPO}_{4}, 1,5 \mathrm{mM} \mathrm{KH}_{2} \mathrm{PO}_{4}, \mathrm{pH}$ 7,0

PMSF-Stammlösung (Phenylmethylsulfonylfluorid):

0,1 M PMSF gelöst in Isopropanol oder in $100 \% \mathrm{EtOH}$

Probenauftragspuffer für Agarosegelelektrophorese, 5x konzentriert:

$40 \%$ (w/v) Saccharose, 0,01 \% (w/v) Bromphenolblau, 0,1 \% EDTA (pH 7,5)

Probenauftragspuffer für SDS-PAGE, 2x konzentriert:

0,2 M Tris pH 6,7, 6 \% (w/v) SDS, $15 \%$ (w/v) Glycin, 0,05 \% (w/v) Bromphenolblau, $10 \%$ (v/v) $\beta$-Mercaptoethanol

\section{Proteinase K-Lösung:}

$10 \mu \mathrm{g} / \mathrm{mL}$ Proteinase K, 0,1 M Tris/HCl (pH 8,0)

\section{Puffer I:}

$100 \mathrm{mM}$ Tris/HCl (pH 7,5), $150 \mathrm{mM} \mathrm{NaCl}$

\section{Puffer II:}

$5 \%$ Magermilchpulver (w/v) in Puffer I 


\section{Puffer III:}

100 mM Tris/HCl (pH 9,5), 100 mM NaCl, 50 mM MgCl 2

Puffer A (Trenngelpuffer):

1,5 M Tris/HCl (pH 8,9)

Puffer B (Sammelgelpuffer):

0,5 M Tris/HCl (pH 6,8)

RNAase A-Lösung:

$20 \mu \mathrm{g} / \mathrm{mL}$ RNAase A, 10 mM Tris/HCl (pH 8,0), 1 mM EDTA, 0,5 M NaCl

Stoplösung:

10 mM Tris/HCl (pH 8,0), 1 mM EDTA

\section{Strippuffer:}

62,5 mM Tris/HCl (pH 6,7), 100 mM $\beta$-Mercaptoethanol, 2 \% (w/v) SDS

10x SSC:

1,5 M NaCl, 0,15 M Trinatriumcitrat

TBE 10x-Stammlösung:

0,9 M Tris pH 8,3, 0,89 M Borsäure, 25 mM EDTA

TBS 1x:

20 mM Tris pH 7,6 (eingestellt mit $\mathrm{HCl}$ ), $137 \mathrm{mM} \mathrm{NaCl}$

TBS/BSA/NaN -Puffer: $^{-}$

$5 \%$ BSA Fraktion V, 0,02 \% $\mathrm{NaN}_{3}$ in TBS

TBS-T 1x:

100 mL 10x TBS, 500 Tween-20 (0,05 \% (v/v)) mit zweifach destilliertem $\mathrm{H}_{2} \mathrm{O}$ auf $1 \mathrm{~L}$

TE-Puffer 1x:

10 mM Tris/HCl, pH 7-8, 1 mM EDTA 
Transferpuffer 10x-Stammlösung für semi-dry Western-Blotting:

39 mM Glycin, 48 mM Tris, 0,037 \% (w/v) SDS

\section{0x Transkriptionspuffer:}

400 mM Tris/HCl (pH 8,0), 60 mM MgCl , 100 mM DTE, 20 mM Spermidin, 100 mM

NaCl, $1 \mathrm{U} / \mu \mathrm{L}$ RNAase Inhibitor aus humaner Plazenta (Stammlösung: 4,8 U/ $\mu \mathrm{L}$ )

\section{Trap:}

0,25 \% Essigsäureanhydrid (v/v), 0,1 M Triethanolamin (pH 8,0)

\section{Trypsin-Lösung:}

0,05\% Trypsin (w/v), 0,02 \% EDTA (w/v) 


\section{Methoden}

\subsection{Molekularbiologische Methoden}

\subsubsection{Arbeit mit Bakterien}

3.1.1.1 Kultivierung von E. coli zu Expressionszwecken (Übernachtkulturen)

\section{Luria Bertani (LB)-Medium (pH 7,0):}

- $1 \%(w / v)$ Bacto-Trypton (AppliChem, Darmstadt, Deutschland)

- $\quad$ 0,5 \% (w/v) Bacto-Hefeextrakt (AppliChem, Darmstadt, Deutschland)

- $1 \%(w / v) ~ N a C l$ (Roth, Karlsruhe, Deutschland)

- 2 \% D-Maltose (Serva, Heidelberg, Deutschland)

Bei $121{ }^{\circ} \mathrm{C} 20$ min autoklaviert.

\section{LB $_{\text {Antibiotikum-Platten: }}$}

- LB-Medium (siehe oben)

- 15 \% BactoAgar (AppliChem, Darmstadt, Deutschland)

Bei $121{ }^{\circ} \mathrm{C} 20$ min autoklaviert.

Bei Zusatz eines Antibiotikums bis auf $50^{\circ} \mathrm{C}$ abkühlen lassen, dann Antibiotikumstammlösung in1:1000 Verdünnung hinzuzufügen.

\section{Tabelle 1: Antibiotikaverdünnungen}

\begin{tabular}{|l|l|}
\hline Antibiotikum & Endkonzentration \\
\hline Ampicillin & $100 \mu \mathrm{g} / \mathrm{mL}$ \\
\hline Kanamycin & $50 \mu \mathrm{g} / \mathrm{mL}$ \\
\hline
\end{tabular}


Tabelle 2: Antibiotikastammlösungen

\begin{tabular}{|l|l|l|}
\hline Antibiotikum & Konzentration & Hersteller \\
\hline Ampicillin & $100 \mathrm{mg} / \mathrm{mL} \mathrm{H}_{2} \mathrm{O}$ dd, steril & Ratiopharm, Ulm, Deutschland \\
\hline Kanamycin & $50 \mathrm{mg} / \mathrm{mL} \mathrm{H}_{2} \mathrm{O}$ dd, steril & Invitrogen, Karlsruhe, Deutschland \\
\hline
\end{tabular}

Escherichia coli DH5 $\alpha$ wurden entweder in $4 \mathrm{~mL}$ oder in $100 \mathrm{~mL}$ LB-Medium herangezogen. Je nach Resistenz der in DH5 $\alpha$ enthaltenen Plasmide wurde das Medium mit dem entsprechenden, sterilfiltrierten Antibiotikum $(100 \mu \mathrm{g} / \mathrm{mL}$ Ampicillin oder $50 \mu \mathrm{g} / \mathrm{mL}$ Kanamycin in der Endkonzentration) versetzt. Die Kultivierung erfolgte über Nacht bei $37^{\circ} \mathrm{C}$ im Schüttler bei $250 \mathrm{rpm}$.

\subsubsection{Glycerol-Dauerkulturen}

Für die Langzeitlagerung von Bakterien wurden 0,5 mL einer Übernachtkultur mit 0,5 mL sterilem Glycerol (98\%) gemischt und bei $-80^{\circ} \mathrm{C}$ gelagert. Bei genetisch veränderten Organismen wurden die Kulturen gemäß Vorschrift in einem GVOVerzeichnis protokolliert.

\subsubsection{Herstellung chemisch kompetenter E. coli nach der $\mathrm{CaCl}_{2}$-Methode}

Um die Bakterienwände für Plasmid-DNA durchlässig zu machen, wurden E. coli DH5 $\alpha$ in $100 \mathrm{~mL}$ LB-Medium bis zu einer optischen Dichte bei $600 \mathrm{~nm}$ von 0,6 bis maximal 0,9 über Nacht kultiviert und mit $50 \mathrm{mM}$ sterilfiltrierter $\mathrm{CaCl}_{2}$-Lösung behandelt. Die Bakterienkultur wurde 30 min auf Eis gekühlt und anschließend für $10 \mathrm{~min}$ bei $4{ }^{\circ} \mathrm{C}$ bei $3800 \mathrm{~g}$ (entspricht ca. $4000 \mathrm{rpm}$, „Varifuge 3.0“, Heraeus, Hanau, Deutschland) zentrifugiert. Das Bakteriensediment wurde in $10 \mathrm{~mL}$ eiskalter $50 \mathrm{mM}$ $\mathrm{CaCl}_{2}$-Lösung resuspendiert und weitere $30 \mathrm{~min}$ auf Eis gelagert. Es folgte eine Zentrifugation bei $3800 \mathrm{~g}$ und $4{ }^{\circ} \mathrm{C}$ für $10 \mathrm{~min}$. Das Sediment wurde in 4,5 mL eiskalter $\mathrm{CaCl}_{2}$-Lösung resuspendiert und mit $1 \mathrm{~mL}$ sterilem, eiskaltem Glycerin (98\%) durch Invertieren gemischt. Zur Lagerung wurde die Suspension à $120 \mu \mathrm{L}$ aliquotiert, in $\mathrm{N}_{2}$ schockgefroren und bei $-80^{\circ} \mathrm{C}$ aufbewahrt. 
Um die Kompetenz der Bakterien zu überprüfen, wurde ein Aliquot mit einem Testplasmid transformiert (s. Kapitel 3.1.3.4). Als Negativkontrolle wurde ein untransformiertes Aliquot auf einer $\mathrm{LB}_{\mathrm{Amp}}$-Platte ausgestrichen.

\subsubsection{DNA-Aufreinigung}

\subsubsection{DNA-Fällung mit Ethanol}

Die Alkohol-Fällung wurde zur Präparation von DNA aus der Sequenzierung (s. Kapitel 3.1.3.8) verwendet.

DNA in wäßriger Lösung kann in Gegenwart von Natriumacetat durch Zugabe von Ethanol gefällt werden. Die Endkonzentration des Alkohols muß mindestens 70 \% (v/v) betragen, d.h., daß zu der zu fällenden DNA-Lösung das 2,5-fache Volumen reinen Ethanols zugesetzt werden muß. Die wäßrige DNA-Lösung wurde vor Zugabe von EtOH mit 1/10 Volumen $3 \mathrm{M}$ Natriumacetat $(\mathrm{pH} 4,8)$ und 1/10 Volumen $125 \mathrm{mM}$ EDTA versetzt. Nach einer Inkubationszeit von 5 min wurde die DNA 15 min bei $18000 \mathrm{~g}$ in einer Tischzentrifuge sedimentiert. Das Sediment wurde mit 70 \% EtOH gewaschen, um die DNA von Salz- und Alkoholresten zu reinigen. Nach einer weiteren Zentrifugation für 5 min bei $18000 \mathrm{~g}$ wurde der Überstand vollständig entfernt und das Sediment in einer Speedvac SC 100 (Savant, Holbrook, NY, USA) 2 min getrocknet. Die DNA wurde in $\mathrm{H}_{2} \mathrm{O}$ dd gelöst und entweder bei $-20{ }^{\circ} \mathrm{C}$ gelagert oder direkt sequenziert.

\subsubsection{Präparation von Plasmid-DNA mittels Mini-Plasmid-Kit}

Transformierte E. coli DH5 $\alpha$ aus einer Dauerkultur oder von einer Kulturplatte wurden in $5 \mathrm{~mL}$ LB-Medium mit Antibiotikum über Nacht kultiviert. Die Aufreinigung der doppelsträngigen Plasmid-DNA aus den Bakterien erfolgte mittels NucleoSpin, Plasmid-Kit der Firma Macherey-Nagel (Düren, Deutschland) oder mittels EZNA $尺$ Cycle Pure Purification-Kit (PeqLab, Erlangen, Deutschland) den Herstellerangaben entsprechend. Das Prinzip dieser Kits beruht auf alkalischer Lyse der Bakterien (Birnboim, 1979) und anschließender Bindung der DNA an eine Silicamembran. Die 
Elution der Nukleinsäuren erfolgt schließlich in $\mathrm{H}_{2} \mathrm{O}$ dd. Die DNA-Konzentration der gereinigten DNA wurde photometrisch bestimmt (s. Kapitel 3.1.2.4).

\subsubsection{Präparation von Plasmid-DNA mittels Pure Yield ${ }^{\text {TM }}$ Plasmid Midiprep System}

Zur besonders reinen Präparation von DNA zu Transfektionszwecken wurden E. coliKulturen, die das gewünschte Plasmid enthielten, nach Angaben des Herstellers des Pure Yield ${ }^{\text {TM }}$ Plasmid Midiprep Systems (Promega, Madison, USA) verarbeitet. Wie die Mini-Plasmid-Kits (s. Kapitel 3.1.2.2) basiert auch dieses System auf alkalischer Lyse und der Bindung von Nukleinsäuren an eine Silicamembran. Zusätzlich wird bei der endotoxinfreien Präparation eine Lösung zur Entfernung der Endotoxine (Endotoxin Removal Wash) verwendet. Die gewonnene DNA wurde in endotoxinfreiem Wasser aufgenommen und ihre Konzentration photometrisch bestimmt (s. Kapitel 3.1.2.4). Die Lagerung der DNA bis zur Transfektion erfolgte bei $-20^{\circ} \mathrm{C}$.

\subsubsection{Bestimmung der DNA-Konzentration}

Die Konzentration von Plasmid-DNA wurde durch Messung der Absorption der verdünnten DNA bei einer Wellenlänge von $260 \mathrm{~nm}$ in einem UV-Spektralphotometer („Ultrospec 3000“, Pharmacia Biotech, Freiburg, Deutschland) bestimmt. Eine Absorption von 1,0 entspricht einer DNA-Konzentration von $50 \mu \mathrm{g} / \mathrm{mL}$. Die Nukleinsäurekonzentration wird nach Gleichung 1 berechnet. Der Reinheitsgrad der Probe wurde durch eine weitere Messung bei $280 \mathrm{~nm}$ ermittelt. Bei dieser Wellenlänge führen Proteinreste, genauer die Aminosäuren Tryptophan und Tyrosin, zur Absorption. Eine reine DNA-Probe hat einen Quotienten von $\mathrm{A}_{260} / \mathrm{A}_{280}=2,0$ (Handbuch des $E Z N A \otimes$ Cycle Pure Purification-Kit (PeqLab, Erlangen, Deutschland)).

\section{Gleichung 1: Berechnung der DNA-Konzentration}

Konzentration $(\mu \mathrm{g} / \mathrm{mL})=$ Abs $(260 \mathrm{~nm}) \cdot 50 \cdot$ Verdünnungsfaktor 


\subsubsection{Klonierung}

\subsubsection{Schneiden von DNA mittels Restriktionsendonukleasen}

DNA kann mit Hilfe von Restriktionsendonukleasen an definierten Sequenzabschnitten geschnitten werden. Diese bakteriellen Endonukleasen bauen doppelsträngige DNA durch hydrolytische Spaltung von Phosphorsäurediesterbindungen an Stellen mit spezifischen Erkennungssequenzen ab. Die Erkennungsmerkmale sind meist 4-8 bp lange, palindromisch aufgebaute Folgen von Nukleotiden. Abhängig vom jeweiligen Restriktionsenzym entstehen glatte Enden, sogenannte blunt ends, oder überstehende Enden (sticky ends).

Schnittstellen, die für die Klonierung von DNA-Stücken in Vektoren genutzt wurden, waren entweder in den entsprechenden Sequenzen vorhanden oder wurden durch speziell entworfene Primer mittels PCR (s. Kapitel 3.1.3.7) generiert (Scharf et al., 1986).

Die Reaktionen wurden nach Herstellerangaben durchgeführt, in den meisten Fällen bei $37^{\circ} \mathrm{C}$, da viele Enzyme bei dieser Temperatur optimal arbeiten. Pro $\mu$ g DNA wurden 0,2 U Enzym eingesetzt. Die geschnittenen DNA-Fragmente wurden über Agarosegelelektrophorese aufgetrennt (s. Kapitel 3.1.3.5) und anschließend aus dem Gel aufgereinigt.

\subsubsection{Dephosphorylierung eines linearisierten Vektors}

Nach der Linearisierung einer Plasmid-DNA durch Restriktionsenzyme bleiben an den 5'-Enden Phosphatreste zurück. Diese Phosphatreste werden zur Ligation benötigt. Werden sie mit einer Phosphatase entfernt, kann keine Verbindung der beiden Vektorenden erfolgen. Da das DNA-Fragment, das in den Vektor eingefügt werden soll, die benötigten Phosphatreste aufweist, kann die Ligation nur zwischen dem Insert und dem Vektor erfolgen. Damit diese anschließende Ligation ablaufen kann, muß die alkalische Phosphatase nach der Dephosphorylierung des Vektors entfernt oder inaktiviert werden. 
Für die Dephosphorylierung wurden 0,5 U alkalische Phosphatase (Roche, Mannheim, Deutschland) pro $\mu \mathrm{g}$ linearisierter DNA in 1x Phosphatasepuffer (vom Hersteller mitgeliefert) eingesetzt. Der Ansatz wurde für 30 min bei $37^{\circ} \mathrm{C}$ inkubiert. Anschließend wurde die alkalische Phosphatase bei $85{ }^{\circ} \mathrm{C}$ für 15 min inaktiviert. Um auch letzte Reste der alkalischen Phosphatase zu entfernen, wurde der Ansatz mit dem EZNA $®$ Cycle Pure Purification-Kit (PeqLab, Erlangen, Deutschland) nach Angaben des Herstellers aufgereinigt.

\subsubsection{Ligation}

DNA Fragmente können durch das Enzym T4-Ligase (Fermentas, Vilnius, Litauen) mit einem Vektor verknüpft werden. Die T4-Ligase katalysiert die Bildung von Phosphorsäurediesterbindungen zwischen dem 3'-Ende des einen DNA-Stranges und dem 5'-Ende des anderen DNA-Stranges.

Für die Klonierung eines DNA-Fragments in einen Vektor wurden das Insert, d.h., die einzusetzende DNA, und der Vektor jeweils mit den gleichen Enzymkombinationen geschnitten, um sie anschließend durch Ligation zusammenfügen zu können.

Eine Ausnahme bildet der Vektor pGEM-T Easy (Promega, Madison, USA), der bereits in linearisierter Form vorliegt und an beiden 3'-OH-Enden Thymidinüberhänge aufweist. Durch diese Thymidinüberhänge ist es möglich, ein PCR-Produkt direkt mit dem Vektor durch Ligation zu verbinden. Die einzige Voraussetzung dafür ist die Durchführung der PCR mit einer Polymerase, die Adenosinüberhänge an das Produkt anfügt (zum Beispiel die häufig verwendete Taq-Polymerase).

Die Ligation erfolgte für $3 \mathrm{~h}$ bei RT. Das Verhältnis von Insert zu Vektor wurde nach der im Protokoll des Herstellers angegebenen Formel (Gleichung 2) berechnet.

\section{Gleichung 2: Berechnung der Insertmenge}

$\frac{\text { ng Vektor } \cdot \text { Insertgröße in } \mathrm{kb}}{\text { Vektorgröße in } \mathrm{kb}} \cdot \frac{\text { Insert in } \mathrm{molL}^{-1}}{\text { Vektor in } \mathrm{molL}^{-1}}=$ Insert in ng

Das molare Verhältnis von Insert zu Vektor wurde 3/1 oder 5/1 gesetzt. 
Als Kontrolle diente ein Ligationsansatz, der statt Insert-DNA Wasser enthielt. Anhand dieser Negativkontrolle konnte abgeschätzt werden, zu wieviel Prozent der Vektor mit sich selber ligiert worden war. Nach der Ligation wurde der komplette Ansatz in kompetente Bakterien transformiert (s. Kapitel 3.1.3.4).

\subsubsection{Hitzeschock-Transformation in E. coli}

$100 \mu \mathrm{L} \mathrm{Ca}{ }^{2+}$-kompetente Bakterien wurden mit $100 \mathrm{ng}$ eines Vektors oder $10 \mu \mathrm{L}$ Ligationsansatz gemischt und $30 \mathrm{~min}$ auf Eis inkubiert. Anschließend erfolgte ein Hitzeschock für $90 \mathrm{~s}$ bei $42{ }^{\circ} \mathrm{C}$. Der Transformationsansatz wurde $5 \mathrm{~min}$ auf Eis gelagert und danach mit $1 \mathrm{~mL}$ LB-Medium versetzt. Die Bakterien wurden 20 min bei $37^{\circ} \mathrm{C}$ und $250 \mathrm{rpm}$ im Inkubator geschüttelt. Bei der Transformation mit Vektor-DNA wurden $50 \mu \mathrm{L}$ der Bakteriensuspension auf LB-Platten mit dem benötigten Selektionsantibiotikum ausgestrichen und über Nacht bei $37^{\circ} \mathrm{C}$ inkubiert. Bei Verwendung eines Ligationsansatzes zur Transformation wurde die Bakteriensuspension für $30 \mathrm{~s}$ bei $18000 \mathrm{~g}$ in einer Tischzentrifuge abzentrifugiert und das Sediment in etwa $50 \mu \mathrm{L}$ LBMedium resuspendiert. Diese aufkonzentrierte Bakteriensuspension wurde auf LBPlatten mit Antibiotikum ausgestrichen und ebenfalls bei $37^{\circ} \mathrm{C}$ über Nacht inkubiert.

\subsubsection{Agarose-Gelelektrophorese}

DNA-Fragmente können ihrer Größe nach in einem Agarosegel durch Elektrophorese aufgetrennt werden. Aufgrund des negativ geladenen Phosphatrückgrats der DNA wandert diese in einem elektrischen Feld in Richtung der Anode. Da die Siebstruktur des Gels kleineren Fragmenten weniger Widerstand bietet als großen DNA-Fragmenten, bewegen sie sich schneller in Richtung des Pluspols als große DNA-Stücke. Je kleiner die zu analysierenden DNA-Fragmente waren, desto konzentrierter wurde die Agarose angesetzt, maximal 2,5 \% (w/v). Die Laufstrecke der DNA ist umgekehrt proportional zum Logarithmus ihrer Länge.

1-2 \% (w/v) Agarose wurden durch Aufkochen in TBE-Puffer vollständig gelöst und vor dem Ausgießen in eine horizontale Gelkammer mit Geltaschenformer auf etwa $60{ }^{\circ} \mathrm{C}$ abgekühlt. Das Agarosegel erstarrt bei Raumtemperatur und wurde in der Gelkammer mit TBE-Puffer geflutet. Mit Auftragspuffer versetzte DNA-Proben wurden 
in die Taschen des Gels pipettiert und bei konstanter Spannung (100 V) aufgetrennt. Die Elektrophorese wurde beendet, nachdem der im Auftragspuffer enthaltene Farbstoff Bromphenolblau etwa 2/3 der Gesamtlänge des Gels zurückgelegt hatte. Nach 15 minütiger Färbung mit Ethidiumbromid $(2 \mu \mathrm{g} / \mathrm{mL})$ in einem Wasserbad wurden die DNA-Banden unter UV-Licht analysiert und zur Dokumentation fotografiert. Ethidiumbromid ist ein Farbstoff, der in doppelsträngige DNA interkaliert und bei UV-Anregung fluoresziert. Die Größenbestimmung der Fragmente erfolgte durch Vergleich mit einem Längenstandard. Als Standard diente eine mit den Restriktionsenzymen Eco RI und Hind III geschnittene $\lambda$-DNA (Fermentas, Vilnius, Litauen).

\subsubsection{Isolierung von DNA-Fragmenten aus Agarose-Gelen (Gelextraktion)}

DNA-Fragmente wurden aus Agarosegelen mittels MinElute ${ }^{\circledR}$ Gel Extraction Kit (Qiagen, Hilden, Deutschland) gemäß den Herstellerangaben extrahiert. Dazu wurde ein DNA-Fragment aus dem Agarosegel ausgeschnitten, das Gel in Puffer „QG“ (im Kit enthalten) bei $50^{\circ} \mathrm{C}$ für 10 min gelöst und die DNA schließlich nach Zugabe von Isopropanol an eine Säule gebunden. Die Elution der DNA erfolgte nach 2 Waschschritten mit Puffer „QG“ und Puffer „PE“ (im Kit enthalten) in $\mathrm{H}_{2} \mathrm{O}$ dd.

\subsubsection{Polymerase-Kettenreaktion (PCR)}

Teilsequenzen einer DNA-Vorlage können mittels PCR (Saiki et al., 1985) aus einer DNA-Vorlage (template) hergestellt werden. Für die PCR werden zusätzlich Oligodesoxynukleotide, sogenannte Primer, Desoxynukleosidtriphosphate (dNTPs) und eine thermostabile DNA-Polymerase benötigt.

Die PCR besteht aus drei aufeinanderfolgenden Schritten:

- Denaturierung der DNA-Vorlage

- Anlagerung (annealing) der Primer

- Elongation der gebundenen Primer 
Diese Abfolge wird bis zu 30-mal wiederholt, um das gewünschte DNA-Fragment exponentiell zu amplifizieren. Die PCR wurde in einem Thermocycler (Perkin Elmer, Applied Biosystems, Weiterstadt, Deutschland) durchgeführt.

Je nach Bedarf wurde das GC-rich PCR System von Roche (Mannheim, Deutschland) nach Herstellerangaben eingesetzt oder bei der Amplifikation besonders langer guanidin- und cytosinreicher DNA-Sequenzen das Phusion PCR System der Firma Finnzymes (Espoo, Finnland) nach Anleitung.

Tabelle 3: Zusammensetzung der PCR-Ansätze mit GC-rich System

\begin{tabular}{|l|l|l|}
\hline Komponente & Volumen/50 $\mathbf{H L - R e a k t i o n ~}$ & Endkonzentration \\
\hline $\mathrm{H}_{2} \mathrm{O}$ & Auf $50 \mu \mathrm{L}$ auffüllen & \\
\hline $\begin{array}{l}5 \mathrm{x} \text { GC-rich PCR-Reaktions- } \\
\text { puffer }\end{array}$ & $10 \mu \mathrm{L}$ & $1 \mathrm{x}$ \\
\hline 5 M GC-rich Lösung & $10 \mu \mathrm{L}$ & $1 \mathrm{M}$ \\
\hline 10 mM dNTP-Mix & $1 \mu \mathrm{L}$ & $200 \mu \mathrm{M}$ je dNTP \\
\hline $10 \mu \mathrm{M}$ downstream Primer & $1 \mu \mathrm{L}$ & $0,2 \mu \mathrm{M}$ \\
\hline $10 \mu \mathrm{M}$ upstream Primer & $1 \mu \mathrm{L}$ & $0,2 \mu \mathrm{M}$ \\
\hline $\begin{array}{l}\text { (enthält Taq- und Tgo- } \\
\text { DNA-Polymerase) }\end{array}$ & $1 \mu \mathrm{L}$ & $\begin{array}{l}\text { DNA bzw. 15 ng } \\
\text { Plasmid-DNA }\end{array}$ \\
\hline $\begin{array}{l}\text { DNA-Vorlage } \\
\text { DC-rich Enzym-Mix }\end{array}$ & $\mathrm{x} \mu \mathrm{L}$ & $0,04 \mathrm{U} / \mu \mathrm{L}$ \\
\hline
\end{tabular}


Tabelle 4: Zusammensetzung der PCR-Ansätze mit Phusion-Polymerase

\begin{tabular}{|l|l|l|}
\hline Komponente & Volumen/50 $\mathbf{\mu L - R e a k t i o n}$ & Endkonzentration \\
\hline $\mathrm{H}_{2} \mathrm{O}$ & Auf $50 \mu \mathrm{L}$ auffüllen & \\
\hline $5 \mathrm{x}$ Phusion GC-Puffer & $10 \mu \mathrm{L}$ & $1 \mathrm{x}$ \\
\hline $10 \mathrm{mM}$ dNTPs & $1 \mu \mathrm{L}$ & $200 \mu \mathrm{M}$ je dNTP \\
\hline $10 \mu \mathrm{M}$ downstream Primer & $2,5 \mu \mathrm{L}$ & $0,5 \mu \mathrm{M}$ \\
\hline $10 \mu \mathrm{M}$ upstream Primer & $2,5 \mu \mathrm{L}$ & $0,5 \mu \mathrm{M}$ \\
\hline DNA-Vorlage & $\mathrm{x} \mu \mathrm{L}$ & $\begin{array}{l}400 \mathrm{ng} \text { genomische DNA } \\
\text { bzw. } 15 \text { ng Plasmid-DNA }\end{array}$ \\
\hline DMSO & $1,5 \mu \mathrm{L}$ & $3 \%$ \\
\hline Phusion DNA Polymerase & $0,5 \mu \mathrm{L}$ & $0,02 \mathrm{U} / \mu \mathrm{L}$ \\
\hline
\end{tabular}

Tabelle 5: PCR-Bedingungen für GC-rich System

\begin{tabular}{|l|l|l|l|}
\hline & Temperatur & Zeit & Zyklen \\
\hline \begin{tabular}{l|l|l|} 
Initiale \\
Denaturierung
\end{tabular} & $95^{\circ} \mathrm{C}$ & $3 \mathrm{~min}$ & \\
\cline { 1 - 2 } Denaturierung & $95^{\circ} \mathrm{C}$ & $1 \mathrm{~min}$ & \multirow{2}{*}{30} \\
\cline { 1 - 2 } Anlagerung & $60-65^{\circ} \mathrm{C}$ & $30 \mathrm{~s}$ & \\
\hline Elongation & $72^{\circ} \mathrm{C}$ & $2 \mathrm{~min}$ & \\
\hline Finale Elongation & $72^{\circ} \mathrm{C}$ & $10 \mathrm{~min}$ & \\
\hline
\end{tabular}


Tabelle 6: PCR-Bedingungen für Phusion-Polymerase

\begin{tabular}{|l|l|l|l|}
\hline & Temperatur & Zeit & Zyklen \\
\hline $\begin{array}{l}\text { Initiale } \\
\text { Denaturierung }\end{array}$ & $98^{\circ} \mathrm{C}$ & $1 \mathrm{~min}$ & \\
\hline Denaturierung & $98^{\circ} \mathrm{C}$ & $10 \mathrm{~s}$ & \\
\cline { 1 - 2 } Anlagerung & $72^{\circ} \mathrm{C}$ & $30 \mathrm{~s}$ & \multirow{2}{*}{30} \\
\hline Elongation & $72^{\circ} \mathrm{C}$ & $30 \mathrm{~s}$ & \\
\hline Finale Elongation & $72^{\circ} \mathrm{C}$ & $10 \mathrm{~min}$ & \\
\hline
\end{tabular}

Anschließend wurden die Proben auf $4{ }^{\circ} \mathrm{C}$ abgekühlt und mittels Agarosegelelektrophorese analysiert.

\subsubsection{DNA-Sequenzierung}

Zur Überprüfung von DNA-Sequenzen wurde die zu untersuchende DNA mittels PCR als Einzelstrang amplifiziert und nach Ethanolfällung (s. Kapitel 3.1.2.1) sequenziert. Das Sequenzierungsverfahren erfolgte als Kettenabbruchreaktion nach Sanger (Sanger et al., 1977) in einem automatischen Sequenziergerät (ABI-Prism, Modell 3100)².

Tabelle 7: Zusammensetzung der Sequenzierungsansätze

\begin{tabular}{|l|l|l|}
\hline Komponente & Volumen/50 $\boldsymbol{\mu L}$-Reaktion & Endkonzentration \\
\hline $\mathrm{H}_{2} \mathrm{O}$ & Auf $10 \mu \mathrm{L}$ auffüllen & \\
\hline $10 \mathrm{x}$ Sequenzierungspuffer & $1 \mu \mathrm{L}$ & $1 \mathrm{x}$ \\
\hline
\end{tabular}

\footnotetext{
${ }^{2}$ Die Sequenz wurde freundlicherweise von Herrn A. Nolte ermittelt.
} 


\begin{tabular}{|l|l|l|}
\hline Komponente & Volumen/50 $\mathbf{\mu L - R e a k t i o n ~}$ & Endkonzentration \\
\hline $10 \mathrm{x}$ Sequenzierungsmix & $1 \mu \mathrm{L}$ & $1 \mathrm{x}$ \\
\hline $10 \mu \mathrm{M}$ Primer & $0,8 \mu \mathrm{L}$ & $0,8 \mu \mathrm{M}$ \\
\hline DNA-Vorlage & $\mathrm{x} \mu \mathrm{L}$ & $400 \mathrm{ng}$ \\
\hline
\end{tabular}

Tabelle 8: PCR-Bedingungen für die Sequenzierung

\begin{tabular}{|l|l|l|l|}
\hline & Temperatur & Zeit & Zyklen \\
\hline \begin{tabular}{l|l|l|} 
Initiale \\
Denaturierung
\end{tabular} & $96{ }^{\circ} \mathrm{C}$ & $1 \mathrm{~min}$ & \\
\cline { 1 - 2 } Denaturierung & $96{ }^{\circ} \mathrm{C}$ & $10 \mathrm{~s}$ & \multirow{2}{*}{25} \\
\cline { 1 - 2 } Anlagerung & $50^{\circ} \mathrm{C}$ & $5 \mathrm{~s}$ & \\
\hline Elongation & $60^{\circ} \mathrm{C}$ & $4 \mathrm{~min}$ & \\
\hline Finale Elongation & $60^{\circ} \mathrm{C}$ & $7 \mathrm{~min}$ & \\
\hline
\end{tabular}

\subsubsection{Sequenzvergleich}

Für jedes Konstrukt wurden die Sequenzen für Insert und Vektor (jeweils aus der Gendatenbank entnommen) an ihren Restriktionsschnittstellen in einem Textverarbeitungsprogramm (Microsoft Word) zusammengefügt, so daß eine Vergleichssequenz für die Sequenzierung vorlag.

Die durch Sequenzierung ermittelten DNA-Sequenzen wurden mit der Software MegAlign von DNA-Star analysiert, d.h., sie wurden mit den Originalsequenzen aus der Genbank oder den zusammengesetzten Sequenzen (s.o.) verglichen. 


\subsubsection{Erstellung von GFP-Konstrukten für die Expression in HeLa-Zellen}

Die H1x-GFP-Fusionskonstrukte wurden erstellt, um die Funktion und den Einfluß des H1x-Promotors in Zellen mittels Fluoreszenzmikroskopie zu überprüfen.

Zur Fertigung des Plasmids pJW 34, das aus dem H1x-Promotor 55, der kodierenden Sequenz von H1x und dem Vektor pEGFP-1 besteht, wurde der Vektor pEGFP-1 mit Bgl II und Bam HI linearisiert und mit alkalischer Phosphatase behandelt. Der linearisierte, dephoshorylierte Vektor wurde durch Agarosegelelektrophorese aufgetrennt und mittels MinElute $®$ Gel Extraction Kit (Qiagen, Hilden, Deutschland) gemäß den Herstellerangaben extrahiert (s. Kapitel 3.1.3.6). Der H1x-Promotor wurde aus dem Promotorkonstrukt 55 durch die Restriktionsendonukleasen Bgl II und Nco I herausgeschnitten und ebenfalls durch Gelextraktion gewonnen. Um die H1x-Sequenz mit den Schnittstellen Nco I und Bam HI zu versehen, wurde eine PCR mit den Primern oJW25 und oJW26 (Tabelle 9) und dem Plasmid oJW 9 als Vorlage mit dem GC-rich PCR System von Roche (Mannheim, Deutschland) durchgeführt (s. Kapitel 3.1.3.7) Das PCR-Produkt wurde in den Vektor pGEM-T Easy mittels T4-Ligase eingefügt (s. Kapitel 3.1.3.3), in E. coli vermehrt und aufgereinigt. Die H1x-Sequenz wurde aus pGEM-T Easy mit Nco I und Bam HI herausgeschnitten und durch Gelextraktion aufgereinigt. Das aufgereinigte H1x-Fragment (0,65 kb), der geschnittene Vektor pEGFP-1 (4,2 kb) und der H1x-Promotor (1,5 kb) wurden in einem Ligationsansatz miteinander verbunden. Das molare Verhältnis von Vektor : Insert : Insert wurde 1:5:5 gesetzt. Es wurden 53 ng Vektor, 88 ng „Promotor“ und 40 ng H1x eingesetzt. Der Ansatz wurde zunächst für $2 \mathrm{~h}$ bei RT und anschließend über Nacht bei $4{ }^{\circ} \mathrm{C}$ inkubiert. Nach Transformation in E. coli und Mini-Plasmidpräparation (s. Kapitel 3.1.2.2) wurden die Klone zur Kontrolle, ob die Inserts im Vektor enthalten sind, mit dem Restriktionsenzym Eco47 III geschnitten. 
Tabelle 9: Primer für pJW 34

\begin{tabular}{|l|l|l|l|l|}
\hline Name & Sequenz & $\begin{array}{l}\text { \#GC/ Gesamt- } \\
\text { länge }\end{array}$ & $\begin{array}{l}\mathbf{T}_{\mathbf{m}} \\
\text { in }\end{array}$ & Schnittstelle \\
\hline oJW25 & 5' ctaccatgggctctaccatgtccgtggagc 3’ & $18 / 30$ & 72,2 & Nco I \\
\hline oJW26 & 5' gcggatccttgcggcccttgggc 3, & $17 / 23$ & 71,3 & Bam HI \\
\hline
\end{tabular}

\subsubsection{Konstrukte für siRNA-Versuche $e^{i}$}

siRNA-Konstrukte wurden erstellt, um die Funktion von H1x in der Zelle genauer zu untersuchen. Zunächst wurden Sequenzabschnitte der mRNA von H1x (EMBL acc. no. D64142) mit dem Target Finder der Firma Ambion (Ambion, Applied Biosystems, Foster City, CA, USA) herausgesucht, die sich als siRNA-Inserts eigneten. Die Wahl fiel auf eine Zielsequenz, die im folgenden als T1 bezeichnet wird. Eine weitere Sequenz, X2, die von Dr. Nicole Happel gewählt worden war, wurde ebenfalls verwendet. Den Nukleotidsequenzen entsprechend wurden Oligonukleotide bei der Firma Operon (Operon Biotechnologies, Köln, Deutschland) synthetisiert (Tabelle 10). Diese einzelsträngig synthetisierten DNA-Oligonukleotide für die siRNA-Inserts wurden zu doppelsträngigen Oligonukleotiden hybridisiert (s. Kapitel 3.1.3.12) und danach an ihrem 5'-Ende phosphoryliert (s. Kapitel 3.1.3.13). Anschließend wurden die doppelsträngigen phosphorylierten DNA-Oligonukleotide durch Ligation mit dem mit Apa I und Eco RI linearisierten, dephosphorylierten Vektor pSilencer ${ }^{\mathrm{TM}}$ 1.0-U6 (Ambion, Applied Biosystems, Foster City, CA, USA) verbunden.

Tabelle 10: Oligonukleotide für siRNA-Versuche

\begin{tabular}{|l|l|}
\hline Bezeichnung & Sequenz \\
\hline oJWsiX2a3'->5' & 5'aattaaaaaagatctacaccgaggccaatctcttgaattggcctcggtgtagatctggcc3' \\
\hline oJWsiX2b5'->3' & 5'agatctacaccgaggccaattcaagagattggcctcggtgtagatcttttt3' \\
\hline
\end{tabular}




\begin{tabular}{|l|l|}
\hline Bezeichnung & Sequenz \\
\hline oJWsiT1a3'->5' & \begin{tabular}{l} 
5'aattaaaaaaatcctcttgctaccatgtcctctcttgaaaaggacatggtagcaagaggaggcc3 \\
\hline oJWsiT1b5'->3',
\end{tabular} 5'tcctcttgctaccatgtccttttcaagagaggacatggtagcaagaggatttttt3' \\
\hline
\end{tabular}

\subsubsection{Annealing der DNA-Oligonukleotide für siRNA-Versuche ${ }^{i}$}

Um doppelsträngige DNA-Oligonukleotide zu erhalten, wurden je $2 \mu \mathrm{g}$ der bestellten Oligonukleotide miteinander gemischt (T1a mit T1b und X2a mit X2b), mit siSuspensionspuffer der Firma Qiagen (Hilden, Deutschland) auf $50 \mu \mathrm{L}$ aufgefüllt und für $3 \mathrm{~min}$ auf $90^{\circ} \mathrm{C}$ erhitzt, um Sekundärstrukturen $\mathrm{zu}$ entfernen. Die Doppelstrangbildung erfolgte bei $37^{\circ} \mathrm{C}$ für $1 \mathrm{~h}$.

\subsubsection{5'-Phosphorylierung der DNA-Oligonukleotide ${ }^{i}$}

Da die synthetisierten Oligonukleotide keine 5'-Phosphatgruppen enthalten, die für die Ligation mit einem dephosphorylierten Vektor notwendig sind, wurde eine Kinasereaktion durchgeführt:

- $5 \mu \mathrm{L}$ doppelsträngiges Oligonukleotid (entspricht 20 pmol)

- $\quad$ 2,5 $\mu \mathrm{L}$ 10x Kinasepuffer (New England Biolabs, Ipswich, MA, USA)

- $1 \mu \mathrm{L}$ T4 Polynukleotidkinase (10 U/ $\mu \mathrm{L})$ (New England Biolabs, Ipswich, MA, USA)

- $\quad 2,5 \mu \mathrm{L} 10 \mathrm{mM}$ ATP

- mit $\mathrm{H}_{2} \mathrm{O}$ auf $25 \mu \mathrm{L}$ auffüllen

- 45 min bei $37^{\circ} \mathrm{C}$ phosphorylieren

- $\quad 10$ min bei $70^{\circ} \mathrm{C}$ die Kinase inaktivieren 


\subsubsection{Promotoranalyse}

\subsubsection{Erstellung von Promotorkonstrukten}

Für H1x wurden Promotorelemente durch Vergleich der H1x-Sequenz mit den Sequenzen bekannter Promotorelemente aus anderen H1-Subtypen (Bouterfa et al., 1993; Doenecke et al., 1994; Meergans et al., 1998) vorausgesagt. Anhand der Verteilung dieser Elemente wurden Konstrukte verschiedener Länge entworfen und in den Expressionsvektor pGL3-basic der Firma Promega (Madison, USA) eingefügt. Der pGL3-basic Vektor enthält das $l u c^{+}{ }^{+}$-Gen, das für die Firefly-Luciferase kodiert.

Die Konstrukte wurden aus genomischer DNA aus HL60-Zellen mittels PCR erstellt und mit Schnittstellen für Bgl II und Nco I versehen. Dazu wurden folgende Primer verwendet (Tabelle 11):

Tabelle 11: Primer für Promotorkonstrukte

\begin{tabular}{|c|c|c|c|c|}
\hline Name & Sequenz & $\begin{array}{l}\text { \#GC / } \\
\text { Gesamtlänge }\end{array}$ & $\begin{array}{l}\mathbf{T}_{\mathbf{m}} \\
\text { in }{ }^{\circ} \mathbf{C}\end{array}$ & $\begin{array}{l}\text { Schnitt- } \\
\text { stelle }\end{array}$ \\
\hline oNH55 & 5' cagatctcaagtggaggctgcaacggc 3' & $16 / 27$ & 69,5 & Bgl II \\
\hline $\begin{array}{l}\text { oNH56 } \\
\text { rev }\end{array}$ & 5' tccacggccatggtagcaagaggattg 3' & $15 / 27$ & 68,0 & Nco I \\
\hline oJW6 & 5' agcagatctgtcctagcgcagttcacgttgc 3' & $17 / 31$ & 70,8 & Bgl II \\
\hline oJW7 & 5 ' atcagatctgcgttctctgggttgccgg 3' & $16 / 28$ & 69,5 & Bgl II \\
\hline oJW8 & 5' agcagatctggagaggcgcggtccgaga 3' & $17 / 28$ & 72,4 & Bgl II \\
\hline oJW10 & 5' agcgagtctccggaccaggctgttgttg 3' & $16 / 28$ & 69,5 & Bgl II \\
\hline oJW18 & 5' atgccatggcgcctctggaactcg 3' & $15 / 22$ & 67,7 & Nco I \\
\hline oJW19 & 5' atcagatctggggcccgcgctattg 3' & $15 / 25$ & 67,9 & Bgl II \\
\hline
\end{tabular}




\begin{tabular}{|l|l|l|l|l|}
\hline Name & Sequenz & $\begin{array}{l}\text { \#GC / } \\
\text { Gesamtlänge }\end{array}$ & $\begin{array}{l}\mathbf{T}_{\mathbf{m}} \\
\text { in }{ }^{\circ} \mathbf{C}\end{array}$ & $\begin{array}{l}\text { Schnitt- } \\
\text { stelle }\end{array}$ \\
\hline oJW20 & 5' atcagatctcgcgctcccgcagc 3' & $15 / 23$ & 67,8 & Bgl II \\
\hline oJW21 & 5' agcagatcttccaggacgcaagtcgc 3' & $15 / 26$ & 68,0 & Bgl II \\
\hline oJW22 & 5' atcagatctgcgccgggagctcag 3' & $15 / 24$ & 67,8 & Bgl II \\
\hline oJW23 & 5' atcagatctgaagctataaaaagccgagagaagcg3' & $15 / 35$ & 68,3 & Bgl II \\
\hline
\end{tabular}

Die daraus resultierenden Konstrukte wurden wie in Tabelle 12 angegeben benannt.

Tabelle 12: Promotorkonstrukte für Reportergenassays

\begin{tabular}{|c|c|}
\hline Konstruktbezeichnung & Länge in bp \\
\hline 55 (Primer 55-56) & 1455 \\
\hline 6 (Primer 6-56) & 903 \\
\hline 7 (Primer 7-56) & 772 \\
\hline 8 (Primer 8-56) & 547 \\
\hline 10 (Primer 10-56) & 479 \\
\hline 18 (Primer 55-18) & 1082 \\
\hline 19(Primer 19-56) & 723 \\
\hline 20 (Primer 20-56) & 678 \\
\hline 21 (Primer 21-56) & 627 \\
\hline 22 (Primer 22-56) & 601 \\
\hline 23 (Primer 23-56) & 440 \\
\hline
\end{tabular}


Der Vektor pGL3-basic (4818bp) wurde mit den Restriktionsendonukleasen Bgl II und Nco I linearisiert und mit alkalischer Phosphatase (Roche, Mannheim, Deutschland) dephosphoryliert (s. Kapitel 3.1.3.2). Die ebenfalls mit Bgl II und Nco I geschnittenen PCR-Produkte wurden mit T4-Ligase in den linearisierten Vektor eingefügt, so daß insgesamt elf verschiedene Plasmide für die Transfektion in 293-Zellen (s. Kapitel 3.3.2.2) und die anschließenden Reportergenmessungen zur Verfügung standen.

\subsubsection{Reportergenassays}

Reportergenassays wurden mit dem Dual-Luciferase ${ }^{T M}$ Reporter Assay System (Promega, Madison, USA) durchgeführt. Als Maß für die Aktivität der in den Vektor pGL3-basic eingefügten Promotorfragmente diente die Lumineszenz der FireflyLuciferase. Als interner Standard wurde das Plasmid pRL-CMV (Promega, Madison, USA) kotransfiziert. Es enthält das Gen für die Renilla-Luciferase unter Kontrolle des CMV-Promotors.

Die Reportergenkonstrukte wurden mittels Pure Yield ${ }^{T M}$ Midiprep System der Firma Promega endotoxinfrei präpariert. Die Konzentration der Plasmid-DNA wurde spektrometrisch bestimmt. Humane 293-Zellen (s. Kapitel 3.3.1.2) wurden in 6-wellPlatten ausgesät und bis zu einer Konfluenz von 40-80\% herangezogen. Die anschließende Kotransfektion (s. auch Kapitel 3.3.3) von 400 ng eines Reportergenkonstrukts zusammen mit 10 ng des pRL-CMV Vektors wurde mit dem Effectene ${ }^{T M}$ Transfection Kit (Qiagen, Hilden, Deutschland) nach Herstellerangaben durchgeführt. Die Zellen wurden $20 \mathrm{~h}$ inkubiert und anschließend nach Vorschrift des DualLuciferase ${ }^{T M}$ Reporter Assay Systems (Promega, Madison, USA) gewaschen und lysiert. Das Lysat wurde nach Anleitung zentrifugiert und bis zur Dreifachbestimmung der Firefly- und Renilla-Luciferaseaktivitäten auf Eis gekühlt. Die Messungen wurden in einem Fluoroskan Ascent FL Fluoro-Luminometer der Firma Labsystems (Quickborn, Deutschland) durchgeführt.

Das Dual-Luciferase ${ }^{T M}$ Reporter Assay System ermöglicht eine direkt aufeinanderfolgende Messung von Firefly-Luciferaseaktivität und Renilla-Luciferaseaktivität: Beetle-Luciferin wird durch die Firefly-Luciferase in Oxoluciferin + "Licht" 
umgewandelt, anschließend wird eine Stop and Glow-Lösung dazugegeben, die Coelenterazin enthält. Die Firefly-Luciferase wird inaktiviert, die Renilla-Luciferase setzt das Coelenterazin zu Coelenteramid +“Licht“ um.

Das Verhältnis Firefly-Luciferase-Aktivität zu Renilla-Luciferase-Aktivität wurde als dimensionsloses Maß für die Aktivität eines Reportergenkonstrukts verwendet. Die Aktivität jedes Reportergenkonstrukts wurde aus mindestens drei voneinander unabhängigen Transfektionen und nachfolgenden Luciferaseaktivitätsbestimmungen ermittelt.

\subsubsection{In situ Hybridisierung}

Mit der in situ Hybridisierung ist es möglich, die mRNA eines bestimmten Gens in der Zelle (in situ) nachzuweisen. Ziel der Methode ist es, die gewebe- oder zelltypische Expression des untersuchten Gens sichtbar zu machen. Die hier beschriebene in situ Hybridisierung wurde an Gewebedünnschnitten durchgeführt. Als Sonde wurden in vitro synthetisierte, nicht-radioaktiv markierte RNA-Fragmente verwendet.

\subsubsection{Einbetten der Gewebe und Schneiden der Paraffinblöcke}

Das für die in situ Hybridisierung benötigte Gewebe wurde in der Pathologie nach Standardprotokoll in 4 \% Formaldehyd fixiert, in Paraffin eingebettet und trocken und dunkel gelagert.

Die Paraffinschnitte wurden routinemäßig in der Pathologie (Gastroenteropathologie, Abteilung Prof. Füzesi, Klinikum Göttingen) angefertigt.

\subsubsection{Entwurf und Vorbereitung von Sonden für die in situ Hybridisierung}

Die H1x-spezifische Sonde S2 wurde aus dem Konstrukt IM28 in pOTB7 (Happel et al., 2005) (H1x cDNA im Vektor pOTB7) Restriktionsverdauung hergestellt.

Die $H 1 x$-Teilsequenz für Sonde 2 wurde mit dem Restriktionsenzym Not I aus dem Konstrukt IM28 herausgeschnitten und über Gelelektrophorese aufgereinigt (s. Kapitel 3.1.3.5.). 
Die H1.2 spezifische Sonde S3 wurde durch Amplifikation einer Teilsequenz des kodierenden Bereichs des H1 Histon Subtyps H1.2 aus dem Konstrukt pWA 311 (Albig et al., 1998) gewonnen. Das Konstrukt pWA 311 besteht aus dem kodierenden Bereich von H1.2 in dem Hefeexpressionsvektor YEp51.

Durch die Wahl der Primer oNH51 und oNH52 wurden die Schnittstellen Xho I und Eco RI an die gewählte Sequenz aus H1.2 angefügt.

Tabelle 13: Primer für Sonde S3

\begin{tabular}{|l|l|l|l|l|}
\hline Name & Sequenz & $\begin{array}{l}\text { \#GC/Gesamt- } \\
\text { länge }\end{array}$ & $\begin{array}{l}\text { Tm } \\
\text { in }{ }^{\circ} \mathbf{C}\end{array}$ & Schnittstellen \\
\hline oNH51 & 5' cctcgagactgtaaccaagaaagtggc 3, & $14 / 27$ & 66,5 & Xho I \\
\hline $\begin{array}{l}\text { oNH52 } \\
\text { rev }\end{array}$ & 5' ggaattctggtggctctgaaaagagcc 3' & $14 / 27$ & 66,5 & Eco RI \\
\hline
\end{tabular}

Die geschnittenen H1-Teilsequenzen, die als Vorlage für die in vitro Transkription dienen sollten, wurden mittels Ligation (s. Kapitel 3.1.3.3) in den Vektor pBluescript II KS+ eingefügt und in E. coli DH5 $\alpha$ transformiert. Vor der in vitro Transkription wurden die Konstrukte durch Sequenzierung (s. Kapitel 3.1.3.8) auf ihre Korrektheit überprüft.

\subsubsection{Nicht-radioaktive Markierung von RNA durch in vitro Transkription}

Die RNA-Markierung durch in vitro Transkription ermöglicht die Herstellung strangspezifischer Sonden mit hoher spezifischer Aktivität (Cox et al., 1984; Krieg \& Melton, 1987). Dafür wird ein Vektor benötigt, der außerhalb der multiplen Klonierungsstelle (multiple cloning site, MCS) Promotoren für RNA-Polymerasen aufweist. Der in dieser Arbeit verwendete Vektor pBluescript II KS+ besitzt sowohl einen Promotor für die RNA-Polymerase aus dem Bakteriophagen T7 als auch für die RNAPolymerase aus dem Bakteriophagen T3. Da sich diese Promotoren jeweils auf den gegenüberliegenden Seiten der MCS befinden, kann von einem in die MCS klonierten DNA-Fragment ein für beide Stränge spezifisches in vitro Transkript hergestellt 
werden. Bei der Transkription werden durch Restriktionsendonukleasen linearisierte Vektoren als Vorlage eingesetzt, um Sonden definierter Länge zu erhalten (Tabelle 14). Die RNA-Polymerasen können durch die Linearisierung nur bis zur Schnittstelle transkribieren.

Tabelle 14: Restriktionsenzyme zur Linearisierung vor der Markierung der Sonden

\begin{tabular}{|l|l|l|}
\hline Enzym & Bezeichnung & Sonde für: \\
\hline Sac I & S2T3 & H1x, sense \\
\hline Eco RI & S2T7 & H1x, anti-sense \\
\hline Eco RI & S3T3 & H1.2, sense \\
\hline Xho I & S3T7 & H1.2, anti-sense \\
\hline
\end{tabular}

Die anti-sense-Sonden binden die RNA im Gewebe und führen zum Signal, die senseSonden werden als Negativkontrollen verwendet.

Zur Markierung der Sonden diente Digoxygenin markiertes UTP (DIG-UTP), das bei der in vitro Transkription eingebaut wurde. Digoxygenin kann durch eine Farbreaktion mit BCIP und NBT nachgewiesen werden.

\section{DEPC- $\mathrm{H}_{2} \mathrm{O}$ :}

- $1 \mathrm{~mL}$ DEPC (v/v) in $100 \mathrm{~mL} 50$ \% EtOH lösen

- mit 900 mL $\mathrm{H}_{2} \mathrm{O}$ dd auffüllen

- 30 min bei RT inkubieren, dann autoklavieren

\section{NTP-Markierungsgemisch:}

- 10 mM ATP

- 10 mM CTP

- 10 mM GTP

- $\quad 6,5$ mM UTP

- 3,5 mM Dig-UTP (pH 7,5) 


\section{0x Transkriptionspuffer:}

- $400 \mathrm{mM}$ Tris/HCl (pH 8,0)

- $60 \mathrm{mM} \mathrm{MgCl}_{2}$

- 100 mM DTE

- 20 mM Spermidin

- $100 \mathrm{mM} \mathrm{NaCl}$

- $1 \mathrm{U} / \mu \mathrm{L}$ RNAase Inhibitor aus humaner Plazenta (Stammlösung: 4,8 U/ $\mu \mathrm{L}$ )

$1 \mu \mathrm{g}$ linearisierte und mit EZNA ${ }^{\circledR}$ Cycle Pure Purification-Kit (PeqLab, Erlangen, Deutschland) gereinigte DNA wurde mit $2 \mu \mathrm{L}$ 10x Transkriptionspuffer, $2 \mu \mathrm{L}$ NTPMarkierungsgemisch und $1 \mu \mathrm{L}$ RNAase-Inhibitor gemischt und das Volumen auf $18 \mu \mathrm{L}$ mit DEPC- $\mathrm{H}_{2} \mathrm{O}$ eingestellt. Die Transkription wurde durch Zugabe von $2 \mu \mathrm{L}$ der entsprechenden RNA-Polymerase (T3- oder T7-Polymerase, $20 \mathrm{U} / \mu \mathrm{L}$ ) gestartet. Die Reaktion wurde nach $2 \mathrm{~h}$ bei $37^{\circ} \mathrm{C}$ durch Zugabe von $2 \mu \mathrm{L} 200 \mathrm{mM}$ EDTA-Lösung ( $\mathrm{pH} 7,5$ ) gestoppt. Die markierte RNA wurde nach Zugabe von 2,5 $\mu \mathrm{L} 4 \mathrm{M} \mathrm{LiCl}$ und $75 \mu \mathrm{L}$ eiskaltem $100 \%$ EtOH für 30 min bei $-70{ }^{\circ} \mathrm{C}$ präzipitiert. Die RNA wurde durch Zentrifugation für $30 \mathrm{~min}$ bei $18000 \mathrm{~g}$ in einer Tischzentrifuge sedimentiert und mit eiskaltem EtOH (70 \%) gewaschen. Nach erneutem Zentrifugieren und Trocknen in einer Speed Vac SC 100 der Firma Savant (Holbrook, NY, USA) wurde die RNA in $50 \mu \mathrm{L}$ DEPC- $\mathrm{H}_{2} \mathrm{O}$ für 20 min bei $37^{\circ} \mathrm{C}$ gelöst.

\subsubsection{Bestimmung der Markierungseffizienz von nicht-radioaktiv markierten RNA- Sonden}

Die Markierungseffizienz wurde überprüft, um definierte Mengen der Sonden einsetzen zu können.

\section{Puffer I:}

- $100 \mathrm{mM}$ Tris/HCl (pH 7,5)

- $150 \mathrm{mM} \mathrm{NaCl}$

\section{Puffer II:}

- 5 \% Magermilchpulver (w/v) in Puffer I 


\section{Puffer III:}

- $100 \mathrm{mM}$ Tris/HCl (pH 9,5)

- $100 \mathrm{mM} \mathrm{NaCl}$

- $50 \mathrm{mM} \mathrm{MgCl}$

\section{Färbelösung:}

- $22,5 \mu \mathrm{L}$ NBT (50 mg/mL in $70 \% \mathrm{DMF}$ )

- $17,5 \mu \mathrm{L}$ BCIP (50 mg/mL in DMF)

- $\quad$ in $10 \mathrm{~mL}$ Puffer III

\section{Stoplösung:}

- 10 mM Tris/HCl (pH 8,0)

- 1 mM EDTA

Die markierte RNA wurde in unterschiedlichen Verdünnungen (1:5, 1:20, 1:100 in DEPC- $\mathrm{H}_{2} \mathrm{O}$ ) à $1 \mu \mathrm{L}$ auf eine Nylonmembran („Qiabrane Nylon“, Qiagen, Hilden, Deutschland) aufgetropft. Um die Konzentration der Sonden bestimmen zu können, wurde Dig-markierte RNA bekannter Konzentration in den Verdünnungen 1:10, 1:100, 1:1000 1:10000 aufgetragen. Die RNA wurde in einem UV-Stratalinker ${ }^{\circledR} 2400$ (Stratagene, La Jolla, CA, USA) für 2 min mit UV-Licht in der Einstellung „autocrosslink“ auf der Membran fixiert. Die Membran wurde anschließend in Puffer I für 15 min gewaschen. Gegen unspezifische Bindung der Antikörper an die Membran schützte eine Inkubation für 30 min in Puffer II. Danach wurde die Membran 30 min bei RT mit anti-Dig-Antikörper (anti-Dig + alkalische Phosphatase, 1:5000 in Puffer II) inkubiert. Nach 2 Waschschritten in Puffer I für jeweils 15 min, wurde die Membran 5 min in Puffer III equilibriert und so lange mit Färbelösung behandelt, bis eine Farbreaktion erkennbar war. Die Farbreaktion wurde mit $\mathrm{H}_{2} \mathrm{O}$ gestoppt und die Konzentration der Sonden-RNA durch Vergleich mit der Standardreihe bestimmt. 


\subsubsection{In situ Hybridisierung}

100x Denhardts (Denhardt, 1966):

- $2 \%$ PVP (w/v)

- $2 \%$ BSA Fraktion V (w/v)

- $2 \%$ Ficoll (w/v)

\section{Trap:}

- $\quad$ 0,25 \% Essigsäureanhydrid (v/v)

- $\quad$ 0,1 M Triethanolamin (pH 8,0)

\section{Hybridisierungslösung:}

- 50 \% deionisiertes Formamid (v/v)

- $10 \%$ Dextransulfat (v/v)

- 1x Denhardts

- $\quad 0,5 \mathrm{mg} / \mathrm{mL}$ E. coli DNA

- $\quad 0,5 \mathrm{mg} / \mathrm{mL}$ Hefe rRNA

- $\quad 0,25 \mathrm{mg} / \mathrm{mL}$ Hefe tRNA

- 4x SSC

\section{RNAase A-Lösung:}

- $20 \mu \mathrm{g} / \mathrm{mL}$ RNAase A

- 10 mM Tris/HCl (pH 8,0)

- 1 mM EDTA

- $0,5 \mathrm{M} \mathrm{NaCl}$

\section{Puffer I:}

- 100 mM Tris/HCl (pH 7,5)

- $150 \mathrm{mM} \mathrm{NaCl}$

\section{Puffer II:}

- $5 \%$ Magermilchpulver (w/v)

- in Puffer I 


\section{Puffer III:}

- $100 \mathrm{mM}$ Tris/HCl (pH 9,5)

- $100 \mathrm{mM} \mathrm{NaCl}$

- $50 \mathrm{mM} \mathrm{MgCl}$

\section{Färbelösung:}

- $4,5 \mu \mathrm{L}$ NBT (50 mg/mL in $70 \% \mathrm{DMF}$ )

- $3,5 \mu \mathrm{L}$ BCIP (50 mg/mL in DMF)

- $240 \mu \mathrm{g}$ Levamisole in $1 \mathrm{~mL}$ Puffer III

\section{Stoplösung:}

- 10 mM Tris/HCl (pH 8,0)

- 1 mM EDTA

\section{Proteinase K-Lösung:}

- $10 \mu \mathrm{g} / \mathrm{mL}$ Proteinase K

- $\quad$ 0,1 M Tris/HCl (pH 8,0)

- $\quad 0,05$ M EDTA

Die Schnitte wurden zweimal für 15 min in Xylol entparaffiniert, in einer absteigenden Alkoholreihe (95\%, $80 \%$, $70 \%$, dann DEPC-Wasser, jeweils 2 min) rehydriert und anschließend mit dem ImmunoPen ${ }^{\mathrm{TM}}$ (Calbiochem, Merck, Darmstadt, Deutschland) umrandet. Diese Umrandung verhindert ein Wegfließen der Flüssigkeiten vom Objektträger. Die Objektträger wurden dreimal für 5 min in PBS getaucht und danach für 5 min in 0,1 M Glycin in PBS inkubiert, um Proteasen zu inhibieren. Eine Permeabilisierung des Gewebes erfolgte in 0,3\% Triton X-100 (v/v) in PBS für 15 min. Nach dreimaligem Waschen für jeweils 5 min in PBS wurde das Gewebe 20 min bei $37^{\circ} \mathrm{C}$ in $10 \mu \mathrm{g} / \mathrm{mL}$ Proteinase K behandelt, um es für die RNA-Sonden zugänglich zu machen. Die Proteinasebehandlung wurde durch eine dreiminütige Inkubation in $4 \%$ Paraformaldehyd in PBS abgestoppt, um die Gewebemorphologie zu erhalten. Um Hintergrundreaktionen zu reduzieren, wurden die Schnitte für 10 min in Trap-Puffer mit 0,25 \% Essigsäureanhydrid gestellt und danach einer einstündigen Prähybidisierung bei 
$37^{\circ} \mathrm{C}$ in Hybridisierungslösung unterzogen, die unspezifische Bindungen der RNASonde verhinderte.

Die Hybridisierung erfolgte in einer feuchten Kammer über Nacht bei $42{ }^{\circ} \mathrm{C}$ mit $80 \mathrm{ng}$ Sonden-RNA in Hybridisierungslösung. Die RNA-Sonden wurden vorher für 3 min bei $65{ }^{\circ} \mathrm{C}$ denaturiert, um Fehlpaarungen innerhalb der Sonde zu verhindern. Pro Schnitt wurden $100 \mu \mathrm{L}$ der Hybridisierungslösung mit Sonde direkt auf das Gewebe getropft. Nach der Hybridisierung wurden die Schnitte dreimal in 4x SSC für jeweils 10 min bei $42{ }^{\circ} \mathrm{C}$ gewaschen. Um überschüssige und unspezifisch gebundene RNA zu entfernen, wurden die Objektträger 10 min mit RNAase-Lösung bei RT behandelt. Der RNAAbbau durch RNAase wurde durch drei Waschschritte für je $10 \mathrm{~min}$ bei $42{ }^{\circ} \mathrm{C}$ in SSC (zweimal 2x SSC, einmal 0,5x SSC) unterbrochen.

Vor der Immunreaktion mit einem an alkalische Phosphatase gekoppelten Antikörper gegen Digoxygenin (Dako, Glostrup, Dänemark) wurden die Schnitte für $5 \mathrm{~min}$ in Puffer I umgepuffert. Um unspezifische Bindungen der Antikörper an das Gewebe zu verhindern, wurden die Schnitte für 30 min bei RT mit Puffer II bedeckt. Das Gewebe wurde mit 1:500 in Puffer II verdünntem Antikörper aus Kaninchen gegen Digoxygenin 90 min bei RT inkubiert. Nach drei Waschschritten in Puffer I für jeweils 10 min wurde die Membran 5 min in Puffer III equilibriert und für $18 \mathrm{~h}$ bei RT abgedunkelt mit Färbelösung behandelt. Die Farbreaktion wurde mit $\mathrm{H}_{2} \mathrm{O}$ gestoppt.

Das Gewebe wurde mit 0,1 \% Kernechtrot 30 s bei RT gegengefärbt.

Um die Schnitte haltbar zu machen, wurden sie in einer aufsteigenden Alkoholreihe dehydriert, 2x 10 min mit Xylol behandelt und mit DePeX eingedeckt.

\section{Kernechtrot Lösung:}

0,2 g Kernechtrot Certistain ${ }^{\circledR}$ (Merck, Darmstadt, Deutschland) werden in $200 \mathrm{~mL}$ kochende fünfprozentige, wäßrige Aluminiumsulfat Lösung $\left(\mathrm{Al}_{2}\left(\mathrm{SO}_{4}\right)_{3} \times 18 \mathrm{H}_{2} \mathrm{O}\right)$ eingerührt und für 5-10 min kochen gelassen. Die Lösung wird nach dem Erkalten filtriert.

Die Kernechtrotfärbung ist eine Kernfärbung, die vor allem als kontrastreiche Gegenfärbung gebraucht wird. Die eigentliche Kernfärbung wird durch den Aluminiumlack 
des Kernechtrots (Kernechtrotaluminiumsulfat) hervorgerufen. Hintergrund- und Zytoplasmafärbung sind auf restlichen freien Farbstoff in der Lösung zurückzuführen, der keine Aluminiumsulfatverbindung gebildet hat.

\subsubsection{Quantitative real-time $R T-P C R$}

\subsubsection{Gewebeproben}

Zwölf Proben von neuroendokrinen Tumoren und acht Proben gesunden Gewebes wurden im Zeitraum von 1997 bis 2006 in der Abteilung Gastroenteropathologie des Klinikums Göttingen (Abteilungsleiter Prof. Dr. Füzesi) gesammelt und dort beurteilt (s. Tabelle 22). Die Proben waren in 100-200 mg Stücken sofort nach der Operation in flüssigen Stickstoff überführt und bei $-80^{\circ} \mathrm{C}$ gelagert worden. Zusätzlich waren Gewebestücke dieser Proben in 4 \% Formalin fixiert und in Paraffin eingebettet worden (s. Kapitel 3.1.5.1).

Für die RT-PCR wurde außerdem kommerziell erhältliche humane Gesamt-RNA (Stratagene, Amsterdam, Niederlande) aus fötaler Lunge, adulter Lunge, fötalem Kolon und adultem Kolon verwendet sowie RNA aus je $5 \cdot 10^{6}$ HeLa-Zellen in unterschiedlichen Zellzyklusphasen (s. Kapitel 3.3.1.8).

\subsubsection{RNA-Isolierung}

Die Isolierung von Gesamt-RNA aus gefrorenem Gewebe erfolgte durch eine modifizierte Guanidinisothiocyanat-Phenol-Chloroform-Extraktion (Chomczynski \& Sacchi, 1987). Zunächst wurden 150-200 mg des Gewebes in TRIzol Reagenz (Invitrogen Life Technologies, Mannheim, Deutschland) mit einem Mikrodismembrator (Ultra Turrax T25, IKA-Werke GmbH, Staufen, Deutschland) bei $2400 \mathrm{rpm}$ für $30 \mathrm{~s}$ homogenisiert und anschließend $5 \mathrm{~min}$ bei RT inkubiert. Pro $50 \mathrm{mg}$ Gewebe wurde $1 \mathrm{~mL}$ TRIzol eingesetzt.

Das Homogenisat wurde mit 0,2 mL Chloroform pro mL TRIzol versetzt und $15 \mathrm{~s}$ geschüttelt. Nach fünfminütiger Inkubation bei RT wurden die Proben für 15 min bei $4^{\circ} \mathrm{C}$ und $3800 \mathrm{~g}$ in einem Festwinkelrotor (Festwinkelrotor 3046, „Biofuge Stratos“, 
Heraeus, Hanau, Deutschland) zentrifugiert. Die Fällung der RNA erfolgte durch Mischen des wässerigen Überstands mit 0,2 mL Isopropanol pro mL TRIzol. Danach wurden die Proben für $10 \mathrm{~min}$ bei RT inkubiert und für $30 \mathrm{~min}$ bei $4{ }^{\circ} \mathrm{C}$ mit $3800 \mathrm{~g}$ zentrifugiert. Das Sediment wurde in $1 \mathrm{~mL} 75$ \% Etanol pro mL TRIzol gewaschen und erneut für 5 min bei $4{ }^{\circ} \mathrm{C}$ mit $3800 \mathrm{~g}$ zentrifugiert. Bei der Wiederholung dieses Schritts erfolgte die Suspension des Sediments in 2 mL 75 \% EtOH. Nach der Zentrifugation wurde das Sediment für 10 min bei RT getrocknet und anschließend in $50 \mu \mathrm{L}$ DEPC$\mathrm{H}_{2} \mathrm{O}$ durch zehnminütige Inkubation bei $60{ }^{\circ} \mathrm{C}$ gelöst. Die Proben wurden bei $-80{ }^{\circ} \mathrm{C}$ gelagert.

Die Isolierung von RNA aus HeLa-Zellen in unterschiedlichen Zellzyklusphasen erfolgte aus $5 \cdot 10^{6}$ Zellen je Probe mittels NucleoSpin RNAII Kit (Macherey \& Nagel, Düren, Deutschland) nach Angaben des Herstellers.

\subsubsection{Konzentrationsbestimmung der RNA}

Für die Qualitätskontrolle und Quantifizierung der RNA wurden Nano-Chips aus dem RNA 6000 Nano LabChip ${ }^{\circledR}$ Kit der Firma Agilent eingesetzt und im Gerät Agilent 2100 Bioanalyzer (Agilent Technologies, Palo Alto, CA, USA) gemessen. Bei dieser Methode handelt es sich um eine elektrophoretische Auftrennung und Fluoreszenzbestimmung der Proben, deren Wanderungsgeschwindigkeit größenabhängig ist.

Die Detektion der RNA erfolgt mittels eines Fluoreszenzfarbstoffes, der an einzelsträngige Nukleinsäuren bindet und nur in gebundenem Zustand zur Fluoreszenz angeregt werden kann. Zur Beurteilung der RNA wird die gemessene Fluoreszenzintensität gegen die Zeit, die die einzelsträngigen Ribonukleinsäuren für die Strecke in der Kapillare bis zum Detektor benötigen, aufgetragen.

In einer intakten Gesamt-RNA-Lösung sind große Mengen an 18S- und 28S-rRNA enthalten, so daß sich bei der Messung unter den gegebenen Bedingungen nach 42 Sekunden und 48 Sekunden charakteristische Maxima der Fluoreszenzintensität ergeben, die durch 18S- bzw. 28S-ribosomale RNA hervorgerufen werden. Eine weitere Fluoreszenzspitze wird nach 26 Sekunden durch 5,8S-rRNA verursacht. 
Aufgrund der Zusammensetzung der mRNA aus vielen verschiedenen Transkripten, kann ihre Integrität nicht anhand eines spezifischen Maximums kontrolliert werden. Da beim Abbau von RNA aber mRNA und rRNA gleichermaßen betroffen sind, kann aus einer intakten ribosomalen RNA auf eine intakte mRNA geschlossen werden.

Um die verschiedenen Proben nacheinander messen zu können, müssen Ungenauigkeiten des Meßgeräts beim Beginn der Zeitmessung durch eine Eichung über einen zugegebenen Marker (RNA 6000 Ladder, Ambion Ltd., Huntingdon, UK) ausgeglichen werden. Er ist in Abbildung 3 als kleineres Maximum nach 23 Sekunden sichtbar.

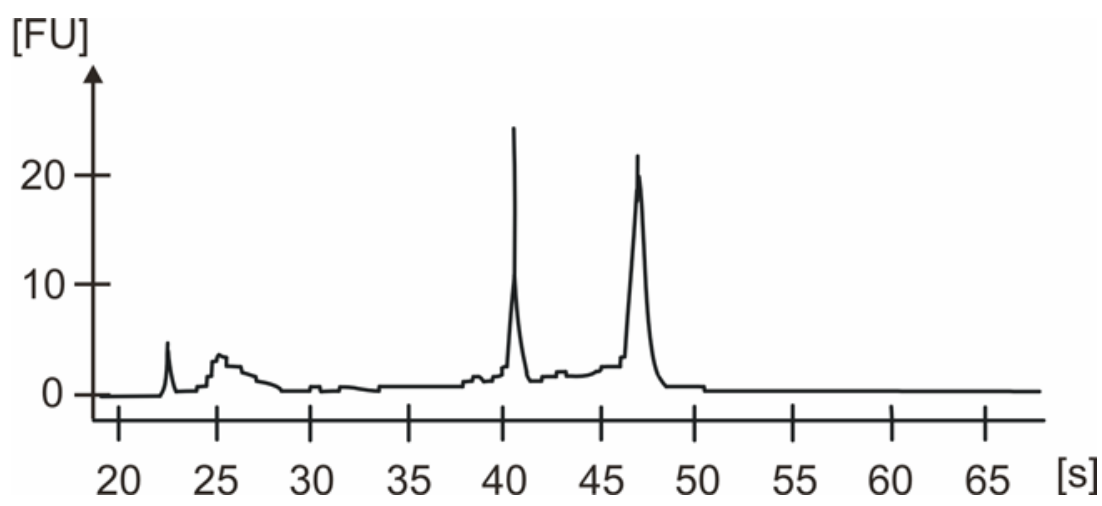

\section{Abbildung 3: Darstellung einer intakten RNA-Probe}

In dem dargestellten Elektropherogramm ist die Fluoreszenzintensität (FU) gegen die Zeit (in Sekunden) aufgetragen. Bei einer intakten RNA-Probe, wie sie hier zu sehen ist, zeigen sich nach 42 und nach 48 Sekunden charakteristische Maxima der Fluoreszenzintensität. Diese Fluoreszenzspitzen entstehen durch 18S- und 28S-rRNA, die in einer intakten Gesamt-RNALösung in großen Mengen enthalten sind. Aus der Integrität der rRNA kann auf eine intakte mRNA, die aufgrund ihrer Zusammensetzung aus vielen verschiedenen Transkripten als Basislinie zu erkennen ist, geschlossen werden. Eine weitere Fluoreszenzspitze wird nach 26 Sekunden durch 5,8S-rRNA verursacht. Das kleine Maximum nach 23 Sekunden wird durch den zugegebenen RNA-Marker, der zur Eichung der Messung verwendet wird, hervorgerufen.

Bei der Isolierung degradierte RNA läßt sich im Agilent 2100 Bioanalyzer dadurch erkennen, daß die charakteristischen Fluoreszenzspitzen fehlen und statt dessen ein breites Maximum nach 24-31 Sekunden sichtbar ist. Dieses Maximum wird durch kleine Bruchstücke der degradierten RNA hervorgerufen (s. Abbildung 4). 


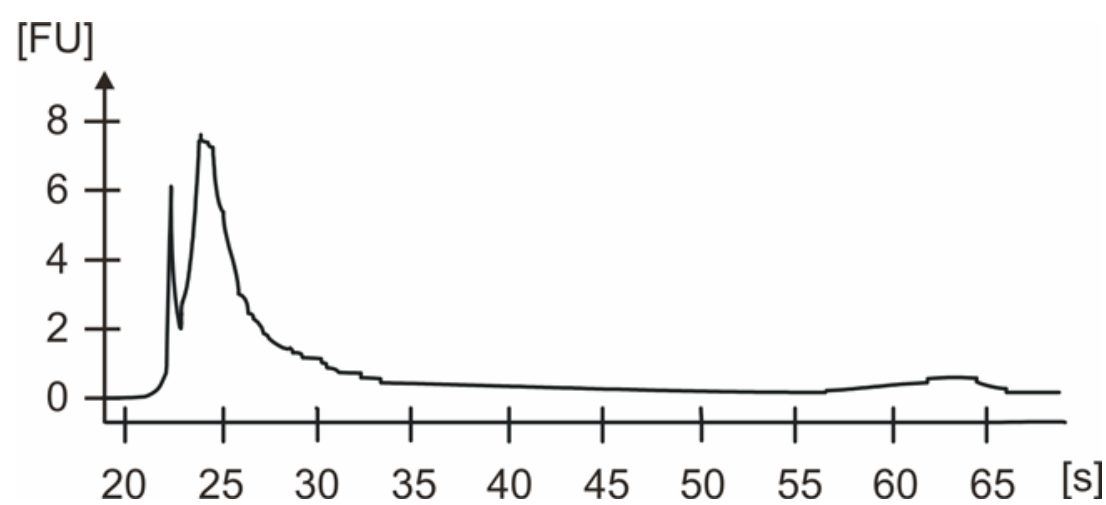

Abbildung 4: Darstellung einer degradierten RNA-Probe

In dem dargestellten Elektropherogramm ist die Fluoreszenzintensität (FU) gegen die Zeit (in Sekunden) aufgetragen. Bei der hier gezeigten degradierten RNA-Probe fehlen die typischen Fluoreszenzmaxima nach 42 und 48 Sekunden. Stattdessen ist ein breites Maximum nach 24-31 Sekunden sichtbar, das durch kleine Bruchstücke der degradierten RNA hervorgerufen wird. Das kleine Maximum nach 23 Sekunden wird durch den zugegebenen RNA-Marker, der zur Eichung der Messung verwendet wird, hervorgerufen.

Die Konzentration der Gesamt-RNA-Lösung wurde über einen RNA-Standard (RNA 6000 Ladder, Ambion Ltd., Huntingdon, UK) mit bekannter Konzentration (150 ng/ $\mu \mathrm{L}$ ) bestimmt, der zusammen mit den Proben auf einem Nano-Chip gemessen wurde. Für die Konzentrationsbestimmung wurde für jede Probe die insgesamt gemessene Fluoreszenz mit der Gesamtfluoreszenz des RNA-Standards verglichen.

Für die reverse Transkription wurde nur hochwertige RNA verwendet. Die Kriterien für gute Qualität sind hohe Fluoreszenzintensitäten für 18S- und 28S-rRNA. (Haller et al., 2004)

\subsubsection{Reverse Transkription}

Um RNA mittels PCR analysieren zu können, muß die Ribonukleinsäure zunächst mit dem Enzym reverse Transkriptase in cDNA umgeschrieben werden. Dazu werden Primer benutzt, die an die RNA binden und durch reverse Transkriptase verlängert werden. Gebräuchlich sind zwei Arten von Primern: Oligo-(dT)-Primer und randomHexamer-Primer. Oligo-(dT)-Primer hybridisieren mit den poly-(A)-Schwänzen der mRNA, so daß nur polyadenylierte mRNA in cDNA umgeschrieben wird, randomHexamer-Primer bestehen aus zufälligen Basen, die etwa alle 250 Basenpaare eine Paarung mit der RNA eingehen, so daß die gesamte RNA umgeschrieben wird. Das cDNA-Gemisch, das durch Verwendung von random-Hexamer-Primern entsteht, sollte 
in etwa der Zusammensetzung der Gesamt-RNA entsprechen. Deswegen und aufgrund der Tatsache, daß nicht alle Gene eine mRNA mit poly-(A)-Schwanz exprimieren, wurden in dieser Arbeit random-Hexamer-Primer verwendet.

Einzelstrang-cDNA wurde nach Vorschrift mit Superscript ${ }^{\mathrm{TM}}$ II RNAase H- Reverse Transcriptase (Invitrogen Life Technologies) aus jeweils $5 \mu \mathrm{g}$ Gesamt-RNA (ausgehend von der im Agilent 2100 Bioanalyzer gemessenen Konzentration) hergestellt. $5 \mu \mathrm{g}$ in DEPC-Wasser gelöste Gesamt-RNA wurden mit 0,5 $\mu \mathrm{L}$ randomHexamer-Primer $\quad(c=0,25 \mu \mathrm{g} / \mu \mathrm{L}$, Invitrogen Life Technologies, Karlsruhe, Deutschland) und $1 \mu \mathrm{L}$ dNTP-Mix (10 mM pro Nukleotid, PeqLab, Erlangen, Deutschland) gemischt und mit DEPC-Wasser auf ein Gesamtvolumen von $12 \mu \mathrm{L}$ aufgefüllt. Für die Primer-RNA-Hybridisierung wurden die Proben für 5 min auf $65^{\circ} \mathrm{C}$ erwärmt und anschließend 1 min lang auf Eis gekühlt. Dem Gemisch wurden $4 \mu \mathrm{L} 5 x$ first strand buffer (mitgeliefert), $2 \mu \mathrm{L}$ 0,1 M DTT (Invitrogen Life Technologies, Karlsruhe, Deutschland) und $1 \mu \mathrm{L}$ des RNAase-Inhibitors RNasIn $^{\mathrm{TM}}$ (40 U/ $\mu \mathrm{L}$; Promega, Mannheim, Deutschland) hinzugefügt. Die Zugabe von $1 \mu \mathrm{L}$ Superscript $^{\mathrm{TM}} I I$ RNAase H- Reverse Transkriptase (200 U/ $\mu \mathrm{L}$; Invitrogen Life Technologies, Karlsruhe, Deutschland) startete die Reaktion, die $10 \mathrm{~min}$ bei $25^{\circ} \mathrm{C}$ und $50 \mathrm{~min}$ bei $42^{\circ} \mathrm{C}$ ablief. Im Anschluß erfolgte eine Inaktivierung der reversen Transkriptase bei $70^{\circ} \mathrm{C}$ für 15 Minuten. Um die nicht-transkribierte RNA zu hydrolysieren, folgte der Zugabe von $10 \mu \mathrm{L} 1 \mathrm{M} \mathrm{NaOH}$ zu jeder Probe eine zehnminütige Inkubation bei $65^{\circ} \mathrm{C}$. Zur Neutralisation der Natronlauge wurden je $10 \mu \mathrm{L} 1 \mathrm{M} \mathrm{HCl}$ hinzugefügt und das

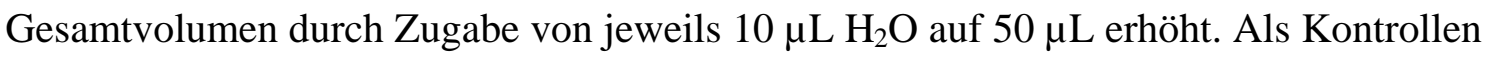
auf genomische Kontamination wurden drei Proben zufällig ausgewählt und zusätzlich den Bedingungen der reversen Transkription unterzogen, allerdings ohne die Zugabe von reverser Transkriptase. Falls diese Proben (,genomische Kontrollen“) in der PCR amplifiziert würden, wäre nachgewiesen, daß das Produkt aus genomischer DNA entstanden sein muß, da ohne Enzym keine cDNA hergestellt werden kann. Die cDNA wurde aliquotiert bei $-20^{\circ} \mathrm{C}$ gelagert. 


\subsubsection{Primerdesign für die quantitative RT-PCR}

Für die Analyse der mRNA-Expression verschiedener Histon H1-Subtypen mittels quantitativer RT-PCR wurden genspezifische 20-28 bp lange Primer für die unterschiedlichen Subtypen von H1 entworfen. Als Vorlage dienten die Sequenzinformationen aus cDNA-Einträgen der EMBL-Datenbank (EMBL acc. no. D64142 (H1x), BC000145 (H1º), BC069492 (H1.1), BC002649 (H1.2), BC104874 (H1.3), BC099632 (H1.4), BC101583 (H1.5), NM_001101(ß-Aktin), X03205 (18S-rRNA)). Die Primer wurden mit Hilfe der Primer3 Software (http://frodo.wi.mit.edu/cgibin/primer3/primer3_www.cgi) entwickelt und bei MWG (MWG Biotech, Ebersberg, Deutschland) gefertigt. Ihre durchschnittliche Schmelztemperatur betrug $60^{\circ} \mathrm{C}$, die Länge der Amplifikate lag im Durchschnitt bei 90 bp. Die Oligonukleotide sind in Tabelle 15 aufgelistet.

Tabelle 15: Primer

\begin{tabular}{|c|c|c|c|}
\hline Name & Gen & Sequenz fwd, rev & $\begin{array}{c}\text { Länge des } \\
\text { Transkripts in } \\
\text { bp }\end{array}$ \\
\hline Jw1H1FX for1 & \multirow{2}{*}{$H 1 x$} & 5' cccaacgatgtagcgttttt 3' & \multirow{2}{*}{80} \\
\hline Jw1H1FX rev1 & & 5' aaggccgagagccaataga 3' & \\
\hline Jw1H1F0 for2 & \multirow{2}{*}{$H 1^{\circ}$} & 5’ ctcgcagatcaagttgtcca 3' & \multirow{2}{*}{79} \\
\hline Jw1H1F0 rev1 & & 5' ggtcttcttgaaggccactg 3, & \\
\hline Jw1H1A for1 & \multirow{2}{*}{$H 1.1$} & 5' tcgtcaggtttataccactttatttg 3, & \multirow{2}{*}{99} \\
\hline Jw1H1A rev1 & & 5' aggtttctcaggagcagcag 3' & \\
\hline Jw1H1C for1 & \multirow{2}{*}{$H 1.2$} & 5’ gccacttgtacccgagtttt 3’ & \multirow{2}{*}{99} \\
\hline Jw1H1C rev1 & & 5 ' ttcttctttacaggggccttc 3 , & \\
\hline
\end{tabular}




\begin{tabular}{|c|c|c|c|}
\hline Name & Gen & Sequenz fwd, rev & $\begin{array}{c}\text { Länge des } \\
\text { Transkripts in } \\
\text { bp }\end{array}$ \\
\hline Jw1H1D for2 & \multirow{2}{*}{ H1.3 } & 5' cagtttgagattacttattgtcttttctg $3^{\prime}$ & \multirow{2}{*}{80} \\
\hline Jw1H1D for2 & & 5' gcaggaatggtaggagcaag 3' & \\
\hline Jw1H1E for1 & \multirow{2}{*}{ H1.4 } & 5' cgaattgctctcgctcac 3' & \multirow{2}{*}{101} \\
\hline Jw1H1E rev1 & & 5' ccttcttcttcacgggagtc $3^{\prime}$ & \\
\hline Jw1H1B for1 & \multirow{2}{*}{ H1.5 } & 5' ctgctctttagatttcgagcttatt 3, & \multirow{2}{*}{101} \\
\hline Jw1H1B rev2 & & 5' cttcttagccggggatt 3' & \\
\hline Aktin for & \multirow{2}{*}{ ß-Aktin } & 5' ctggaacggtgaaggtgaca 3' & \multirow{2}{*}{167} \\
\hline Aktin rev & & 5' aagggacttcctgtaacaatgca 3' & \\
\hline $18 \mathrm{~S}$ for & \multirow{2}{*}{$18 S$} & 5' acatccaaggaaggcagcag 3’ & \multirow{2}{*}{62} \\
\hline $18 \mathrm{~S}$ rev & & 5' tcgtcactacctccccgg 3, & \\
\hline
\end{tabular}

\subsubsection{Durchführung der quantitativen real-time RT-PCR}

Die quantitative real-time RT-PCR wurde Anfang der 1990er Jahre entwickelt (Higuchi et al., 1993; Schneeberger et al., 1995; Heid et al., 1996) und dient der Bestimmung der Genexpression in Geweben und Zellen. Bei dieser Art der PCR wird zunächst RNA mittels reverser Transkriptase in cDNA umgeschrieben (daher die Namensgebung RT) (s. Kapitel 3.1.6.4). Die cDNA wird anschließend in einer PCR amplifiziert. Die Vervielfachung der DNA läßt sich anhand eines Fluoreszenzfarbstoffes in Echtzeit (real time) verfolgen. Fluoreszenzfarbstoffe, wie zum Beispiel SYBR Green IM, binden sequenzunabhängig an doppelsträngige DNA. (Higuchi et al., 1993, Schneeberger et al., 1995). Im gebundenen Zustand können diese Farbstoffe durch Licht bestimmter 
Wellenlänge zur Fluoreszenz angeregt werden. Die zur Menge doppelsträngiger DNA im PCR-Ansatz proportionale Fluoreszenzintensität kann mit einem im PCR-Gerät (iCycler, Bio-Rad Laboratories GmbH, München, Deutschland) enthaltenen Detektor gemessen und über einen Computer ausgewertet werden.

PCR-Reaktionen mit einem Volumen von jeweils $20 \mu \mathrm{L}$ wurden in einem iCycler (BioRad Laboratories GmbH, München, Deutschland) dreimal wiederholt. Zur Durchführung und Verfolgung der Amplifikation wurden das Eurogentec qPCR Core Kit für SYBR Green I ${ }^{T M}$ No ROX (Eurogentec, Seraing, Belgium) und genspezifische Primer in einer Endkonzentration von $300 \mathrm{nmol} / \mathrm{L}$ eingesetzt. Nach Anleitung des Herstellers wurde $\mathrm{MgCl}_{2}$ in 3,5 mM Endkonzentration zu dem Ansatz gegeben.

Um unspezifische oder genomische Amplifikationen aufzudecken, wurden Negativkontrollen, die statt cDNA Wasser enthielten, oder „genomische Kontrollen“ (s. Kapitel 3.1.6.4) für jedes Gen durchgeführt.

Zur Durchführung der PCR wurde das Temperaturprofil wie in Tabelle 16 beschrieben verwendet.

Tabelle 16: Temperaturprofil RT-PCR

\begin{tabular}{|l|l|l|l|}
\hline Schritt & Temperatur & Zeit & Zyklen \\
\hline $\begin{array}{l}\text { Initiale } \\
\text { Denaturierung }\end{array}$ & $95^{\circ} \mathrm{C}$ & $10 \mathrm{~min}$ & \\
\hline Denaturierung & $95^{\circ} \mathrm{C}$ & $15 \mathrm{~s}$ & 40 \\
\hline $\begin{array}{l}\text { Annealing \& } \\
\text { Elongation }\end{array}$ & $60^{\circ} \mathrm{C}$ & $1 \mathrm{~min}$ & \\
\hline $\begin{array}{l}\text { Schmelzkurven- } \\
\text { analyse (s. Kapitel } \\
\text { 3.1.6.7) }\end{array}$ & $60-95^{\circ} \mathrm{C}$ & $3{ }^{\circ} \mathrm{C} / \mathrm{min}$ & \\
\hline
\end{tabular}




\subsubsection{Schmelzkurvenanalyse}

Bei der Schmelzkurvenanalyse (Ririe et al., 1997), die direkt im Anschluß an die RTPCR für jedes Gen durchgeführt wurde, wurden die Proben schrittweise von $60{ }^{\circ} \mathrm{C}$ auf $95^{\circ} \mathrm{C}$ erhitzt. Pro Minute wurde die Temperatur um $3{ }^{\circ} \mathrm{C}$ erhöht. Diese Erwärmung führte zu einem Aufschmelzen des DNA-Doppelstranges. Die gemessene Fluoreszenzintensität nahm ab, je weiter der Vorgang der Trennung beider Stränge fortschritt, da wie in Kapitel 3.1.6.6 beschrieben nur gebundener Farbstoff fluoresziert. Das Fluoreszenzminimum wurde bei $95{ }^{\circ} \mathrm{C}$ erreicht, da bei dieser Temperatur nur DNA-Einzelstränge existierten und folglich der gesamte Farbstoff ungebunden vorlag.

Jedem PCR-Produkt konnte eine spezifische Schmelztemperatur zugeordnet werden. Je länger und guanidin- und cytosinreicher die Sequenz war, desto höher war die Schmelztemperatur.

Mit dieser Methode konnte beurteilt werden, ob der Primer spezifisch gebunden hatte oder ein unspezifisches Amplifikat als Nebenprodukt hervorgebracht hatte. Auch die Bildung von Primerdimeren, d.h. die Hybridisierung der Primer miteinander durch unspezifische Wechselwirkungen, konnte mit Hilfe der Schmelzkurvenanalyse beobachtet bzw. ausgeschlossen werden. Beim Vorliegen zweier PCR-Produkte ergeben sich zwei unterschiedliche Schmelztemperaturen für die erhitzte DNA. Auch bei Primerdimeren ist dies der Fall.

\subsubsection{Bestimmung der Effizienz der PCR mittels Standardkurve}

Aus einer cDNA-Mischung, die aus allen auf einer 96-well-Platte im iCycler zu messenden cDNA-Proben bestand, wurde eine Verdünnungsreihe erstellt, um die Effizienz der eingesetzten Primerpaare für die unterschiedlichen H1-Subtypen zu testen. Die Effizienzen der Primerpaare in der PCR wurden anhand der Steigung der aus der Verdünnungsreihe hervorgehenden Standardkurve bestimmt.

\subsubsection{Berechnung nach $2^{-\Delta \Delta C_{T}}-$ Methode}

Es gibt generell zwei Möglichkeiten, RT-PCR-Daten auszuwerten: die absolute und die relative Quantifizierung der mRNA-Menge. 
Bei der absoluten Quantifizierung wird die eingesetzte Menge cDNA des zu untersuchenden Gens in jeder gemessenen Probe ermittelt. Diese entspricht der ursprünglich im Gewebe vorhandenen mRNA-Menge.

Bei der relativen Quantifizierung werden Änderungen der Expression eines Gens in den zu untersuchenden Proben im Verhältnis zu einer Referenzprobe (=Kalibrator) beschrieben. Die relative Quantifizierung reicht in den meisten Fällen aus, wenn ermittelt werden soll, um wievielfach höher oder niedriger ein Gen in bestimmten Proben im Vergleich zum Kalibrator exprimiert wird. Um relative Änderungen der Genexpression zu ermitteln, kann die von Livak und Schmittgen (2001) beschriebene $2^{-\Delta \Delta C_{T}}$-Methode angewandt werden. Bei dieser Methode wird ein Schwellenwertzyklus, der sogenannte $\mathrm{C}_{\mathrm{T}}$-Wert, für jede Probe bestimmt. Der $\mathrm{C}_{\mathrm{T}}$-Wert gibt den Zyklus an, bei dem die Anzahl amplifizierter Zielmoleküle einen Schwellenwert überschreitet. Dieser Schwellenwert wird vorher festgelegt, so daß nicht die Messung von Hintergrund die Ergebnisse verfälscht. Der Schwellenwert wurde für alle Gene auf 50 RFU (relative fluorescence units) gesetzt, so daß die Messung im exponentiellen Bereich der Amplifikation stattfand.

Voraussetzungen für die gültige Anwendung der $2^{-\Delta \Delta C_{T}}$-Methode sind gleiche Effizienzen von Ziel- und Referenzgenen $\left(E_{\mathrm{x}}=\mathrm{E}_{\mathrm{r}}\right)$. Werden die Differenzen der $\mathrm{C}_{\mathrm{T}^{-}}$ Werte des zu untersuchenden Gens und des Referenzgens gegen eine Verdünnungsreihe der cDNA aufgetragen, entsteht eine Gerade, deren Steigung nahe bei null sein sollte, wenn die Effizienzen der beiden untersuchten Gene über die Verdünnungsreihe hinweg ähnlich sind. Der Unterschied der beiden Gene sollte wenn sie gleich gut amplifizieren, gleich bleiben, egal, welche Konzentration die cDNA hat.

Das Referenzgen (z.B. ß-Aktin, 18S-rRNA oder GPDH) wird gemessen und verrechnet, um Unterschiede in der reversen Transkription auszugleichen, der Kalibrator, um eine Bezugsgröße für alle weiteren Proben zu haben, die mit dem Kalibrator und miteinander verglichen werden sollen. Als Kalibrator kann entweder eine Probe dienen, die nicht behandelt wurde, oder bei einer zeitabhängigen Analyse die Probe zum Zeitpunkt 0, wie bei den Zellzyklusversuchen geschehen. Falls die Expression in verschiedenen 
Geweben analysiert werden soll, kann auch ein Gewebe - in dieser Arbeit Normalgewebe aus Dünndarm - als Kalibrator definiert werden.

Um die $\mathrm{C}_{\mathrm{T}}$-Werte der Einzelmessungen innerhalb des Tumorkollektivs für einzelne Gene miteinander vergleichen zu können, wurde die $2^{-\Delta \Delta C_{T}}$-Methode angewandt (s. Gleichung 3 - Gleichung 5). 18S-rRNA und ß-Aktin wurden hier als interne Kontrollen verwendet und Normalgewebe aus Dünndarm als Kalibrator. Der $\mathrm{C}_{\mathrm{T}}$-Wert des zu untersuchenden Transkripts ( $\mathrm{H} 1 \mathrm{x}$ und andere $\mathrm{H1}$-Gene) wurde in Relation zu seinem $\mathrm{C}_{\mathrm{T}}$ Wert für normalen Dünndarm gesetzt. Die 18S-ribosomale RNA diente als endogene Kontrolle für alle Proben.

Gleichung 3: Berechnung der relativen Expression des Gens $\mathbf{x}$ in der Probe $\mathbf{n}$ $2^{-\left(\left(\Delta C_{T, q}\right)-\left(\Delta C_{T, c b}\right)\right)}=$ relative Expression $(\mathrm{n})_{\mathrm{x}}$

\section{Gleichung 4:}

$\Delta C_{T, q}=C_{T, X}(n)-C_{\bar{T}, q}(n)$

\section{Gleichung 5:}

$\Delta C_{T, c b}=C_{\bar{T}, x}(c b)-C_{\bar{T}, q}(c b)$

Erläuterungen: cb: Kalibratorprobe (hier Dünndarm), q: Referenzgen (hier 18SrRNA), x: untersuchtes Gen (z.B. $H 1 x$ ), n: untersuchte Probe (z.B. Lunge), $\bar{T}$ : Mittelwert der $\mathrm{C}_{\mathrm{T}}$-Werte eines Gens einer Probe

\subsection{Proteinbiochemische Methoden}

\subsubsection{Antikörperaffinitätsreinigung}

\section{M Natriumphosphatpuffer pH 7,5}

- $1 \mathrm{M} \mathrm{Na}_{2} \mathrm{HPO}_{4}$

- $1 \mathrm{M} \mathrm{NaH}_{2} \mathrm{PO}_{4}$

- $\mathrm{Na}_{2} \mathrm{HPO}_{4}$ vorlegen und mit $\mathrm{NaH}_{2} \mathrm{PO}_{4}$ einstellen. 
Um die Spezifität des polyklonalen Antiserums gegen H1x (Happel et al., 2005) zu erhöhen, wurde das Serum über eine mit dem als Antigen für die Immunisierung verwendeten Peptid gekoppelte Sulfo Link® Säule der Firma Pierce (Rockford, IL, USA) gereinigt.

Soweit nicht anders beschrieben, wurden die folgenden Schritte ohne Pumpe durchgeführt. Die Lösungen flossen durch Gravitation ab.

Zuerst wurde eine 1:10 Verdünnung des zu reinigenden Antikörpers mit sterilem PBS erstellt. Für einen späteren Vergleich der Spezifität des ungereinigten und des gereinigten Antikörpers wurden $50 \mu \mathrm{L}$ des ungereinigten Antikörpers vor der Verdünnung entnommen und bei $-20^{\circ} \mathrm{C}$ gelagert.

Die Säule wurde mit $20 \mathrm{~mL}$ sterilem PBS gewaschen. Anschließend wurden $4 \mathrm{~mL}$ der Antikörperverdünnung aufgetragen. Diese wurde $1 \mathrm{~h}$ bei RT über die Säule gereinigt. Dazu wurde die Lösung mit einer Schlauchförderpumpe („Peristaltic pump P-1“, Pharmacia Fine Chemicals, Uppsala, Schweden) im Kreislauf über die Säule geleitet. Die Fließgeschwindigkeit betrug $2 \mathrm{~mL} / \mathrm{min}$. Nach $1 \mathrm{~h}$ ließ man die Antikörperverdünnung durch Gravitation aus der Säule abfließen. Die Säule wurde mit $20 \mathrm{~mL}$ PBS gespült. Die Elution des an die Säule gebundenen Antikörpers wurde durch $100 \mathrm{mM}$ Glycin/HCl, pH 3,0 erreicht. Das Eluat wurde in Fraktionen à 1,0 mL in 1,5 mLReaktionsgefäßen, in denen $100 \mu \mathrm{L}$ Natriumphosphatpuffer vorgelegt waren, aufgefangen. Um das saure Antikörpereluat schnell zu neutralisieren, wurden Eluat und Natriumphosphatpuffer sofort gemischt. Die Eluate wurden bis zur Proteinbestimmung (Dot-Blot und Bradford, s. Kapitel 3.2.1.1 und 3.2.1.2) auf Eis gelagert. Gespült wurde

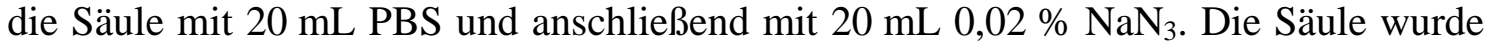
mit 2 mL Überstand $0,02 \% \mathrm{NaN}_{3}$ verschlossen und aufrecht bei $4{ }^{\circ} \mathrm{C}$ gelagert.

\subsubsection{Dot-Blot}

Um zu bestimmen, in welchen Eluaten sich Protein, d.h. Antikörper, befand, wurde ein sogenannter Dot-Blot angefertigt. Von jedem Eluat wurden 2-mal nacheinander 2,5 $\mu \mathrm{L}$ auf eine Nitrozellulosemembran getropft. Nach dem Trocknen wurde die Membran in Ponceau-S (s. Kapitel 3.2.5.1) gefärbt. Fraktionen mit ähnlich viel Protein wurden 
vereinigt. Mittels Bradford-Test (s. Kapitel 3.2.1.2) wurde die Proteinkonzentration der vereinigten Antikörperlösungen bestimmt. In dieser Arbeit wurden die Fraktionen 5-8 und 9-12 vereinigt und für spätere immunologische Fragestellungen verwendet.

Die Spezifität des gereinigten Antikörpers wurde im Vergleich zu der entnommenen Probe vor der Affinitätsreinigung mittels Western-Blot (s. Kapitel 3.2.5) getestet. Dazu wurden Gesamtzelllysate aus HeLa-Zellen (s. Kapitel 3.2.3.1) als Testprotein verwendet. Die Antikörper wurden in $5 \%$ Milch in TBS-T $1 \mu \mathrm{g} / \mathrm{mL}$ verdünnt, bzw. der ungereinigte Antikörper 1:1000 und 1 h bei RT mit der Blotmembran inkubiert.

\subsubsection{Proteinbestimmung nach Bradford}

\section{Bradford-Lösung:}

- 70 mg Coomassie Brilliant Blue G250

- $50 \mathrm{~mL} \mathrm{EtOH}$

Folgende Lösungen in angegebener Reihenfolge mischen:

- $500 \mathrm{~mL} \mathrm{H}_{2} \mathrm{O}$

- $100 \mathrm{~mL} 85 \%$ ortho $\mathrm{H}_{3} \mathrm{PO}_{4}$

- 50 mL Coomassie-EtOH-Lösung

- $350 \mathrm{~mL} \mathrm{H}_{2} \mathrm{O}$

Anhand einer BSA-in- $\mathrm{H}_{2} \mathrm{O}$-Standard-Reihe wurde eine Eichkurve für die BradfordLösung erstellt. Aus dieser Eichkurve ergibt sich der Verdünnungsfaktor, der zur Berechnung der Proteinkonzentration (s. Gleichung 6) benötigt wird.

$50 \mu \mathrm{L}$ einer Proteinlösung, deren Konzentration zu bestimmen war, wurden mit $1 \mathrm{~mL}$ Bradford-Lösung gemischt und 2 min bei RT inkubiert. Die Messung erfolgte in einem Photometer („Ultrospec 3000“, Pharmacia Biotech, Freiburg, Deutschland) bei 595 nm. Als Leerwert wurde die Lösung, in der das Protein gelöst war, verwendet. Die Proteinkonzentration wurde nach Gleichung 6 berechnet.

\section{Gleichung 6: Berechnung der Proteinkonzentration}

Konzentration $(\mu \mathrm{g} / \mathrm{mL})=$ Abs $(260 \mathrm{~nm}) \cdot$ Verdünnungsfaktor 


\subsubsection{Immunhistochemie}

Bei der Immunhistochemie werden Proteine in situ, also in der Zelle, mit Hilfe von Antikörpern nachgewiesen. Durch diese Methode ist es möglich, die Lokalisation der untersuchten Proteine innerhalb des Gewebeverbands zu bestimmen und festzustellen, welche Zellen oder Zellkompartimente das gesuchte Antigen enthalten.

\subsubsection{Silanisierte Objektträger}

Objektträger der Firma Knittel (Knittel Glasbearbeitungs-GmbH, Braunschweig, Deutschland) wurden in einem Automaten der Firma Vogel (Vogel, Gießen, Deutschland) silanisiert, um bessere Haftung des Gewebes am Objektträger zu gewährleisten.

Die Objektträger wurden jeweils für eine Minute mit folgenden Komponenten behandelt:

- einmal Aceton

- zweimal 3-Aminopropyltriethoxysilane in Aceton (1:40)

- fünfmal Aceton zum Trocknen

Anschließend wurden die Objektträger für 20 min bei $180{ }^{\circ} \mathrm{C}$ sterilisiert.

\subsubsection{Immunhistochemie mit der LSAB-Methode}

Bei der Labelled Streptavidin-Biotin-Methode, kurz LSAB, handelt es sich um eine Methode zur Detektion von Antigenen, die auf der hohen Affinität von Streptavidin (streptomyces avidinii) für Biotin basiert. Der Ablauf der LSAB-Methode sieht eine Inkubation mit Primärantikörper aus Maus oder Kaninchen, die darauf folgende Inkubation mit einem biotinylierten Immunglobulin gegen Maus oder Kaninchen und die abschließende Behandlung mit einem enzymmarkierten Streptavidin vor. Der Farbnachweis des Antigens erfolgt mittels Substrat-Chromogenlösung, die mit dem an Streptavidin gekoppelten Enzym reagiert. 


\section{0 mM Citratpuffer (pH 6,0):}

- 10 mM Citronensäuremonohydrat

- $\mathrm{pH}$ 6,0 mit $2 \mathrm{~N} \mathrm{NaOH}$ einstellen

In der vorliegenden Arbeit wurden zur immunhistochemischen Analyse $1 \mu \mathrm{m}$ dicke Paraffinschnitte verwendet, die auf silanisierte Objektträger nach Anweisung des Herstellers der Detektionsreagenzien (Dako, Glostrup, Dänemark) aufgezogen wurden. Bei der Fixierung und Einbettung des Gewebes in Paraffin kann es zum Verlust der antigenen Determinanten kommen, der durch enzymatische Behandlung oder Hitzevorbehandlung wieder rückgängig gemacht werden kann.

Die Schnitte wurden $20 \mathrm{~min}$ in Xylol entparaffiniert und anschließend in einer absteigenden Alkoholreihe rehydriert. Zur Antigendemaskierung folgte für 45 min eine Inkubation in $10 \mathrm{mM}$ Citratpuffer in einem Dampfgarer ("MultiGourmet" Braun, Deutschland).

Nach dieser Vorbehandlung erfolgte die weitere Versuchsdurchführung mit dem Dako Cytomation ChemMate Detection Kit Alkaline Phosphatase/Red Rabbit/Mouse (Dako, Glostrup, Dänemark) nach Angaben des Herstellers. Die Blockierung endogenen Biotins erfolgte mit $2 \%$ BSA in TBS-T für 10 min. Als primärer Antikörper zur Detektion des Histonsubtyps H1x diente anti-H1x (affinitätsgereinigt, Fraktion 9-12) in Antikörperverdünnungslösung (Zymed Diluent, Zymed Laboratories Invitrogen immunodetection, San Francisco, CA, USA) auf 1,5 $\mu \mathrm{g} / \mathrm{mL}$ verdünnt. Die Inkubationszeit betrug 30 min bei RT. Als primärer Antikörper zur Detektion der anderen H1Histonsubtypen im allgemeinen diente anti-H1 (MAB Clone 1415-1, Lab Vision, Fremont, CA, USA) $4 \mu \mathrm{g} / \mathrm{mL}$ in Zymed Diluent. Als Negativkontrolle wurde in Zymed Diluent 1:100 verdünntes Präimmunserum eingesetzt.

Um neuroendokrine Zellen zu identifizieren, wurde Chromogranin A als Markerprotein ausgewählt. Zum Nachweis von Chromogranin A wurde der monoklonale Antikörper DAK-A3 aus Maus (Dako, Glostrup, Dänemark) in einer 1:150 Verdünnung in Zymed Diluent eingesetzt. Das Gewebe wurde 30 min bei RT mit der Verdünnung behandelt. Der Nachweis von Vimentin erfolgte mit dem 1:400 in Zymed Diluent verdünnten 
Antikörper anti-Vimentin, Klon Vim 3B4 (Dako, Glostrup, Dänemark), der Nachweis von CEA (carcinoembryonic antigen) mit 1:400 verdünntem anti-CEA, Klon Col-1 (Zymed Laboratories, Invitrogen immunodetection, San Francisco, CA, USA). CD45 wurde mit anti-CD45, Klon 2B11 und Klon PD7/26, 1:300 in Zymed Diluent verdünnt nachgewiesen.

Bei RT wurde für jeweils 20 min mit biotinyliertem Immunglobulin gegen Maus oder Kaninchen und anschließend mit enzymmarkiertem Streptavidin inkubiert. Die 20minütige Farbreaktion erfolgte nach Anweisungen des Herstellers.

Um auch das übrige Gewebe, das keine Reaktion zeigte, im Mikroskop begutachten und die positiven Zellen besser einordnen zu können, wurden die mit anti-H1x behandelten Schnitte mit Anilinblau gegengefärbt, die anti-Chromogranin behandelten Schnitte mit Hämalaun.

\subsubsection{Färbung mit Anilinblau}

\section{Anilinblau-Färbelösung:}

(Romeis, 1989: Mikroskopische Technik, 17.Auflage)

- $1 \mathrm{~g} / \mathrm{L}$ Anilin

- $\quad$ in $1 \%$ Essigsäure

Anilinblau ist ein Triphenylmethan und dient zur Färbung von Bindegewebe.

Die hier angewandte Färbung wurde aus der Azanfärbung abgeleitet. In dieser Arbeit wurde auf die Komponente Orange G, die Nukleinsäuren orange-rot färbt, verzichtet, so daß nur eine Blaufärbung extranuklearer Strukturen übrig blieb.

Das Gewebe wurde für $5 \mathrm{~s}$ in die Anilinblaufärbelösung eingetaucht, mit $\mathrm{H}_{2} \mathrm{O}$ gespült und solange in 60 \% EtOH entfärbt, bis die rote Immunfärbung wieder gut erkennbar war. Der Vorgang des Entfärbens kann bis zu einer Minute dauern, abhängig von der Affinität des Gewebes für den Farbstoff.

In einer aufsteigenden Alkoholreihe wurde das Gewebe dehydriert und in Xylol eingedeckt. 


\subsubsection{Färbung mit Hämalaun}

\section{Hämalaun nach Meyer:}

- 3 g Haematoxilin

- 0,2 g Natriumiodat $\left(\mathrm{NaIO}_{3}\right)$

- 50 g Kaliumaluminiumsulfat

- $\quad$ in $1 \mathrm{~L}$ dd $\mathrm{H}_{2} \mathrm{O}$ lösen (über Nacht rühren)

- 50 g Chloralhydrat

- 1 g Zitronensäure

- über Nacht rühren, filtrieren

Die Schnitte wurden 2-3 min mit Meyers Hämalaun, ohne Eosin gegengefärbt und 35 min mit heißem Leitungswasser gebläut. In einer aufsteigenden Alkoholreihe wurde das Gewebe dehydriert und in Xylol eingedeckt.

\subsubsection{Immunhistochemie Doppelfärbung}

Die gleichzeitige Detektion zweier Proteine in einem Schnitt verläuft ähnlich wie die Immunfärbung eines Proteins. Im Unterschied dazu werden beide Primärantikörper in Zymed Diluent gemischt (unterschiedliche Verdünnungen sind möglich) und für $30 \mathrm{~min}$ bei RT auf den Schnitt einwirken gelassen. Zur Unterscheidung der beiden Antigene ist es notwendig, daß die Primärantikörper aus verschiedenen Spezies stammen. Bei den durchgeführten Versuchen wurden Antikörper aus Maus und Kaninchen verwendet.

Da Chromogene zum Teil schlecht voneinander zu unterscheiden sind, wurde hier auf fluoreszenzmarkierte Sekundärantikörper zurückgegriffen.

Bei den Sekundärantikörpern wurden Alexa-Fluor 488' anti-rabbit und Alexa-Fluor 555' anti-mouse (Molecular Probes, Invitrogen, Karlsruhe, Deutschland) in einer Verdünnung von 1:1000 in 2 \% BSA in TBS-T eingesetzt.

Die fertigen Schnitte wurden nicht rehydriert, um die Fluoreszenz nicht zu beeinträchtigen, sondern mit dem VECTASHIELD ${ }^{\circledR}$ mounting medium with DAPI (Vector Laboratories, Burlingame, CA, USA) eingedeckt. 
Tabelle 17: Antikörper für die Immunhistochemie

\begin{tabular}{|l|l|l|}
\hline Bezeichnung & Verdünung & Verdünnungsreagenz \\
\hline $\begin{array}{l}\text { Kaninchen-anti-H1x (affinitätsgereinigt, } \\
\text { Fraktion 9-12) }\end{array}$ & $1,5 \mu \mathrm{g} / \mathrm{mL}$ & Zymed Diluent \\
\hline Maus-anti-H1 (MAB Klon 1415-1) & $4 \mu \mathrm{g} / \mathrm{mL}$ & Zymed Diluent \\
\hline Präimmunserum aus Kaninchen & $1: 50$ & Zymed Diluent \\
\hline Maus-anti-Chromogranin (Klon DAK-A3) & $1: 150$ & Zymed Diluent \\
\hline Maus-anti-CEA (Klon Col-1) & $1: 400$ & Zymed Diluent \\
\hline Maus-anti-Vimentin (Klon Vim 3B4) & $1: 400$ & Zymed Diluent \\
\hline Maus-anti-CD45 (Klon 2B11 und Klon PD7/26) & $1: 300$ & Zymed Diluent \\
\hline Alexa-Fluor 488' anti-rabbit & $1: 1000$ & 2 \% BSA in TBS-T \\
\hline Alexa-Fluor 555' anti-mouse & $1: 1000$ & 2 \% BSA in TBS-T \\
\hline
\end{tabular}

\subsubsection{Tissue Microarray (TMA)}

Um mehrere in Paraffin eingebettete Gewebe gleichzeitig und unter gleichen Bedingungen untersuchen $\mathrm{zu}$ können, wurde ein sogenannter Tissue Microarray angefertigt, ein Paraffinblock, der 104 Punkte gestanztes Gewebe aus verschiedenen Proben enthielt.

Dieser TMA wurde mit Hilfe eines Manual Tissue Arrayers der Firma Beecher (Beecher Instruments, Sun Prairie, WI, USA) mit Stanzen von 1,0 mm Durchmesser gefertigt. Zur Unterstützung des Geräts von Beecher diente das Steuerinstrument MTABooster ${ }^{\circledR}$ Version 1.01 (APHELYS, Plaisir, Frankreich). Mit dem Programm Tissue arrays design software TMA-Designer ${ }^{\circledR}$ Version 1.1 der Firma Aphelys (APHELYS, Plaisir, Frankreich) wurde zuvor das Muster für den TMA entworfen. 
Zur Nachbehandlung wurde der TMA 30 min in einem Brutschrank (Memmert, Schwabach, Deutschland) bei $40^{\circ} \mathrm{C}$ erwärmt, um anschließend die überstehenden Gewebestanzen in den Paraffinblock drücken zu können. Erhitzen auf $60{ }^{\circ} \mathrm{C}$ für 20 min in Metallförmchen und Abkühlen für 10 min auf einer Kühlplatte (Medite Tissue Cool Plate COP20, Burgdorf, Deutschland) sorgten für die Wiederherstellung der Form des Paraffinblocks. Aus dem entstandenen TMA wurden Paraffinschnitte (s. Kapitel 3.1.5.1) in der Pathologie angefertigt und auf silanisierte Objektträger aufgezogen.

\subsubsection{Proteinextraktion aus Gewebe}

\subsubsection{Gesamtzelllysat aus Gewebe oder Zellen}

\section{Complete-Stammlösung:}

- 1 Tablette Complete (Roche, Mannheim, Deutschland)

- $1 \mathrm{~mL} \mathrm{H}_{2} \mathrm{O}$ dd

- $\quad$ Lagerung bei $-20^{\circ} \mathrm{C}$

\section{Pepstatin-Stammlösung:}

- 7 mg Pepstatin A

- $10 \mathrm{~mL} 100$ \% EtOH p.a.

- Lagerung bei $-20^{\circ} \mathrm{C}$

\section{PBS mit Protease-Inhibitoren:}

- Complete-Stammlösung 1:100

- Pepstatin-Stammlösung 1:1000

- in PBS

$100 \mathrm{mg}$ gefrorenes Gewebe, das bis zur Aufarbeitung bei $-80{ }^{\circ} \mathrm{C}$ gelagert wurde, wurde mit $380 \mu \mathrm{L}$ PBS mit Proteaseinhibitoren für 30 s mit einem Mikrodismembrator (Ultra Turrax T25, IKA-Werke GmbH, Staufen, Deutschland) bei 2400 rpm homogenisiert. $20 \mu \mathrm{L}$ des Homogenisats wurden entnommen und für eine anschließende Proteinkonzentrationsbestimmung nach Bradford (s. Kapitel 3.2.1.2) bei $-20{ }^{\circ} \mathrm{C}$ gelagert. Die verbliebenen $360 \mu \mathrm{L}$ wurden mit $51 \mu \mathrm{L}$ SDS (10 \%) durch Vortexen gemischt, so daß sich eine SDS-Endkonzentration von 1,2\% ergab. Nach Zugabe von $102 \mu \mathrm{L} 5 \mathrm{x}$ 
Laemmli-Probenauftragspuffer wurde die Probe $5 \mathrm{~min}$ bei $95^{\circ} \mathrm{C}$ denaturiert. Nach nochmaligem Mischen durch Vortexen wurde die Probe bis zur Lagerung bei $-20{ }^{\circ} \mathrm{C}$ auf Eis gekühlt.

Für Untersuchungen von Proteinen aus Zellen wurden die Proteine aus 2·10 ${ }^{6} \mathrm{HeLa}$ Zellen durch Zugabe von $100 \mu \mathrm{L}$ 5x Laemmli-Probenauftragspuffer und Erhitzen auf $95^{\circ} \mathrm{C}$ für 5 min gewonnen.

\subsubsection{Histonpräparation aus Gewebe oder Zellen mit Schwefelsäure $\left(\mathrm{H}_{2} \mathrm{SO}_{4}\right)$}

$100 \mathrm{mg}$ gefrorenes Gewebe, das bis zur Aufarbeitung bei $-80{ }^{\circ} \mathrm{C}$ gelagert wurde, wurde mit $1 \mathrm{~mL}$ PBS mit Proteaseinhibitoren für $30 \mathrm{~s}$ mit einem Mikrodismembrator (Ultra Turrax T25, IKA-Werke GmbH, Staufen, Deutschland) bei 2400 rpm homogenisiert. Durch sofortige Zugabe von $1 \mathrm{~mL} \mathrm{H}_{2} \mathrm{SO}_{4}$ (Endkonzentration 0,2 $\mathrm{M} \mathrm{H}_{2} \mathrm{SO}_{4}$ ) wurden die DNA und alle Proteine bis auf die säurelöslichen Histone durch Denaturierung gefällt. Die Probe wurde $5 \mathrm{~h}$ bei $4{ }^{\circ} \mathrm{C}$ auf einem Drehrad gemischt. Anschließend wurden die ausgefallenen Proteine bei $4^{\circ} \mathrm{C}$ für $10 \mathrm{~min}$ bei $18000 \mathrm{~g}$ in einer Tischzentrifuge sedimentiert. Durch Mischen von $1,6 \mathrm{~mL}$ des Überstands mit $400 \mu \mathrm{L}$ TCA (Endkonzentration $20 \%$ TCA) und Inkubation über Nacht bei $4{ }^{\circ} \mathrm{C}$, wurden die Histone gefällt. Das Sediment, das sich nach 20 min Zentrifugation bei $4{ }^{\circ} \mathrm{C}$ bei $18000 \mathrm{~g}$ gebildet hatte, wurde mit $1 \mathrm{~mL}$ eiskaltem Aceton gemischt und nochmals für 10 min bei $4{ }^{\circ} \mathrm{C}$ und $18000 \mathrm{~g}$ abzentrifugiert. Der Überstand wurde verworfen und das Sediment an der Luft nahezu vollständig getrocknet. Die sedimentierten, getrockneten Histone wurden in $100 \mu \mathrm{L} 30 \mathrm{mM} \mathrm{HCl}$ über Nacht bei $4{ }^{\circ} \mathrm{C}$ gelöst und anschließend bei $-80{ }^{\circ} \mathrm{C}$ gelagert.

Für Untersuchungen von Proteinen aus Zellen wurden die Proteine aus 30·10 $\mathrm{HeLa}$ Zellen gewonnen. Die Zellen wurden durch 5 min Zentrifugation bei $300 \mathrm{~g}$ geerntet (s Kapitel 3.3.1.4), das Medium wurde verworfen und das Zellsediment mit PBS gewaschen. Nach erneuter Sedimentierung wurden die Zellen wie für homogenisiertes Gewebe beschrieben behandelt (s.o.). 


\subsubsection{SDS-Polyacrylamidgelelektrophorese}

Proteine bzw. Peptide können durch die Natriumdodecylsulfat-Polyacrylamidgelelektrophorese (SDS-PAGE) unter denaturierenden Bedingungen nach Molekulargewicht aufgetrennt werden (Laemmli, 1970). Durch Anlagerung des anionischen Detergenzes SDS werden die Proteine denaturiert und alle proteineigenen Ladungen überdeckt. Die vollständige Denaturierung wird durch Zugabe von $\beta$-Mercaptoethanol, das als reduzierendes Agens Disulfidbrücken spaltet, und Erhitzung auf $95^{\circ} \mathrm{C}$ für $5 \mathrm{~min}$ unterstützt. Die SDS-Proteinkomplexe haben eine negative Nettoladung und ein konstantes Verhältnis von Ladung zu Masse. In einem elektrischen Feld wandern die ellipsoiden Komplexe zur Anode, wobei die poröse Polyacrylamidmatrix zu einer Auftrennung der Proteine nach Molekulargewicht führt.

Eine bessere Auflösung der Proteinauftrennung kann mit Hilfe eines diskontinuierlichen Gelsystems erreicht werden, das in der vorliegenden Arbeit verwendet wurde. Bei der diskontinuierlichen Auftrennung in einem Tris-HCl / Tris-Glycin-Puffersystem, die ursprünglich von Ornstein (1964) und Davis (1964) entwickelt wurde, werden zwei unterschiedlich zusammengesetzte Gele, ein Sammelgel (pH 6,8 mit 5 \% Acrylamid) und ein Trenngel (pH 8,9 mit $15 \%$ Acrylamid), benutzt. Die Proteine durchqueren zunächst das weitmaschige Sammelgel. Durch den pH-Wert des Sammelgels, der sehr nah am isoelektrischen Punkt des Glycins liegt, wandern die Proteinionen als Stapel zwischen Chlorid- und Glycinionen. Die Chloridionen haben unter den im Sammelgel herrschenden Bedingungen eine hohe elektrophoretische Mobilität (Leition), die Glycinionen eine sehr niedrige (Folgeion). Beim Anlegen eines elektrischen Feldes beginnen alle Ionen mit der gleichen Geschwindigkeit zu wandern. Der dadurch entstehende Feldstärkegradient, der sich zwischen Leit- und Folgeionen ausbildet, führt zu einer Sortierung der Proteinionen in der Reihenfolge ihrer Mobilitäten. Durch diesen Effekt wird eine Vortrennung und Aufkonzentrierung der Zonen beim Start bewirkt. Sobald die Proteine die Grenzschicht zwischen Sammel- und Trenngel erreichen, werden sie aufgrund des höheren Widerstandes durch die höhere Acrylamidkonzentration im Trenngel aufgestaut. Dieses Aufstauen führt wiederum zu schärferen Proteinbanden im Trenngel. Das niedermolekulare Glycin wird durch die engeren Poren nicht beeinflußt und überholt die Proteine. Diese befinden sich nun in einem 
homogenen Puffer. Dadurch löst sich der Stapel auf und die Folge der Proteinionen formiert sich neu, weil die Molekülgröße im engmaschigen Trenngel einen erheblichen Einfluß auf die Wanderungsgeschwindigkeit hat. Die Proteine werden nur noch nach Molekulargewicht aufgetrennt.

\subsubsection{Aufbau des SDS-Gels}

\section{Puffer A (Trenngelpuffer):}

- $\quad$ 1,5 M Tris/ $\mathrm{HCl}(\mathrm{pH} 8,9)$

\section{Puffer B (Sammelgelpuffer):}

- $\quad$ 0,5 M Tris/HCl (pH 6,8)

SDS-Gele wurden zwischen zwei Glasplatten, die einen Abstand von $1 \mathrm{~mm}$ hatten, gegossen. Zuerst wurde das Trenngel eingefüllt, so daß $2 \mathrm{~cm}$ für das Sammelgel übrigblieben. Die Trenngellösung wurde mit $100 \%$ EtOH überschichtet, um eine gerade Trennschicht zu erzeugen. Sobald das Trenngel polymerisiert war, wurde die Ethanolschicht vollständig entfernt und das Sammelgel darüber in die verbleibenden $2 \mathrm{~cm}$ gegossen. Taschen für die Proben wurden mit einem Geltaschenformer, der in das noch nicht polymerisierte Sammelgel gesteckt wurde, gebildet.

Die Zusammensetzung der Gele erfolgte nach Tabelle 18.

Tabelle 18: Zusammensetzung der Gele für SDS-PAGE

\begin{tabular}{|l|l|l|}
\hline & $\mathbf{1 5}$ \% Trenngel & $\mathbf{5}$ \% Sammelgel \\
\hline $\mathrm{H}_{2} \mathrm{O}$ dd & $1,08 \mathrm{~mL}$ & $1,35 \mathrm{~mL}$ \\
\hline Puffer A (pH 8,9) & $1,40 \mathrm{~mL}$ & - \\
\hline Puffer B (pH 6,8) & - & $0,625 \mathrm{~mL}$ \\
\hline $\begin{array}{l}\text { Acrylamid / Bisacrylamid } \\
(30 \% \text { (w/v) / 0,8 \% (w/v)) }\end{array}$ & $2,76 \mathrm{~mL}$ & $0,4 \mathrm{~mL}$ \\
\hline SDS-Lösung 10 \% (w/v) & $55 \mu \mathrm{L}$ & $25 \mu \mathrm{L}$ \\
\hline
\end{tabular}




\begin{tabular}{|l|l|l|}
\hline & $\mathbf{1 5} \%$ Trenngel & $\mathbf{5} \%$ Sammelgel \\
\hline APS $10 \%(\mathrm{w} / \mathrm{v})$ & $250 \mu \mathrm{L}$ & $100 \mu \mathrm{L}$ \\
\hline TEMED & $5 \mu \mathrm{L}$ & $2,5 \mu \mathrm{L}$ \\
\hline
\end{tabular}

Da APS und TEMED Polymerisationsstarter sind, empfiehlt es sich, diese beiden Komponenten zuletzt zu der Gelmischung zu geben und die Lösung dann rasch zwischen die Platten zu füllen, da sonst eine vorzeitige Polymerisation den Ansatz unbrauchbar machen könnte.

\subsubsection{Proteinauftrennung mit SDS-PAGE}

\section{5x Laemmli-Auftragspuffer:}

- $500 \mathrm{mM}$ Tris/HCl (pH 6,7)

- $38 \%(v / v)$ Glycerol

- $15 \%(\mathrm{w} / \mathrm{v})$ SDS

- $\quad 0,013 \%(\mathrm{w} / \mathrm{v})$ Bromphenolblau

- $5 \%$ (v/v) ß-Mecaptoethanol

Ohne ß-Mecaptoethanol läßt sich der Auftragspuffer bei $-20{ }^{\circ} \mathrm{C}$ lagern.

\section{5x Laemmli-Laufpuffer:}

- $\quad$ 0,25 M Tris/HCl (pH 8,7)

- 10 mM EDTA

- $\quad$ 1,9 M Glycin

- $0,5 \%(w / v)$ SDS

- Lagerung bei RT

Die Gelelektrophorese wurde in 1x Laemmli-Laufpuffer durchgeführt.

8-16 $\mu \mathrm{L}$ Proteinprobe wurden mit 2-4 $\mu \mathrm{L}$ reduzierendem 5x Auftragspuffer gemischt und bei $95{ }^{\circ} \mathrm{C} 3$ min denaturiert. Als Molekulargewichtsmarker wurde der Page Ruler $\AA$ Prestained Protein Ladder (Fermentas GmbH, Vilnius, Litauen) verwendet. Die Proben wurden zunächst bei einer Stromstärke von 15 mA im Sammelgel aufkonzentriert und 
anschließend bei $20 \mathrm{~mA}$ im Trenngel nach ihrer Größe aufgetrennt. Die SDS-PAGE wurde beendet, sobald der Farbstoff des Auftragspuffers aus dem Gel austrat.

Das Gel wurde entweder in Coomassie-Lösung gefärbt oder ungefärbt für den immunologischen Nachweis bestimmter Proteine mittels Western-Blot (s. Kapitel 3.2.5) verwendet.

\subsubsection{Coomassie-Färbung}

\section{Coomassie-Färbelösung:}

- $\quad 0,2 \%(\mathrm{w} / \mathrm{v})$ Coomassie Brilliant Blue R250

- $\quad 0,05 \%(\mathrm{w} / \mathrm{v})$ Coomassie Brilliant Blue G250

- $\quad 42,5 \%$ (v/v) EtOH p.a.

- $5 \%(\mathrm{v} / \mathrm{v}) \mathrm{MeOH}$

- 10 \% Essigsäure

\section{Starker Entfärber:}

- $50 \%(\mathrm{v} / \mathrm{v}) \mathrm{MeOH}$

- $10 \%(\mathrm{v} / \mathrm{v})$ Essigsäure

\section{Schwacher Entfärber:}

- $10 \%(\mathrm{v} / \mathrm{v}) \mathrm{MeOH}$

- $5 \%(v / v)$ Essigsäure

Beim Färben werden die Proteine im Gel fixiert, d.h. denaturiert und ausgefällt. Die Fixier-/Färbelösung enthält den Farbstoff Coomassie-Blau, der sich an proteinhaltige Bereiche des Gels anlagert. Dadurch bleiben die Proteinbanden nach einem Entfärbevorgang sichtbar, während das Gel wieder farblos wird.

Das Gel wurde 30 min in Färbelösung geschwenkt und anschließend in starkem Entfärber so lange inkubiert, bis die Banden gut erkennbar waren. Anschließend wurde das Gel in schwachem Entfärber geschwenkt, bis auch die letzten Farbreste aus dem Gel entfernt waren.

Zur Dokumentation wurde das Gel eingescannt und ausgedruckt. 


\subsubsection{Western-Blot}

\section{Blottransferpuffer:}

- $\quad 38,4$ mM Tris

- 31,2 mM Glycin

- $0,03 \%(\mathrm{v} / \mathrm{v})$ SDS

- $20 \%(\mathrm{v} / \mathrm{v}) \mathrm{MeOH}$

Beim Western-Blot (Towbin et al., 1979) werden Proteine, die zuvor per SDS-PAGE aufgetrennt wurden, elektrophoretisch im „semi-dry-Verfahren“ auf eine Membran übertragen. Die hier verwendete Nitrozellulosemembran bindet die Proteine durch hydrophobe Wechselwirkungen. Der Transfer aus dem Gel ermöglicht eine immunchemische Analyse der zu untersuchenden Proteine.

Filterpapier wurde in Blottransferpuffer befeuchtet, die Nitrozellulosemembran in $\mathrm{H}_{2} \mathrm{O}$ dd eingeweicht und das Gel ebenfalls in Blotpuffer equilibriert. Alle Schichten wurden nach dem unten abgebildetem Schema (Abbildung 5) luftblasenfrei aufeinander gelegt und die Apparatur mit einem Gewicht beschwert. Der Blotvorgang erfolgte über einen Zeitraum von 1 h bei $1,5 \mathrm{~mA} / \mathrm{cm}^{2}$ Gel.

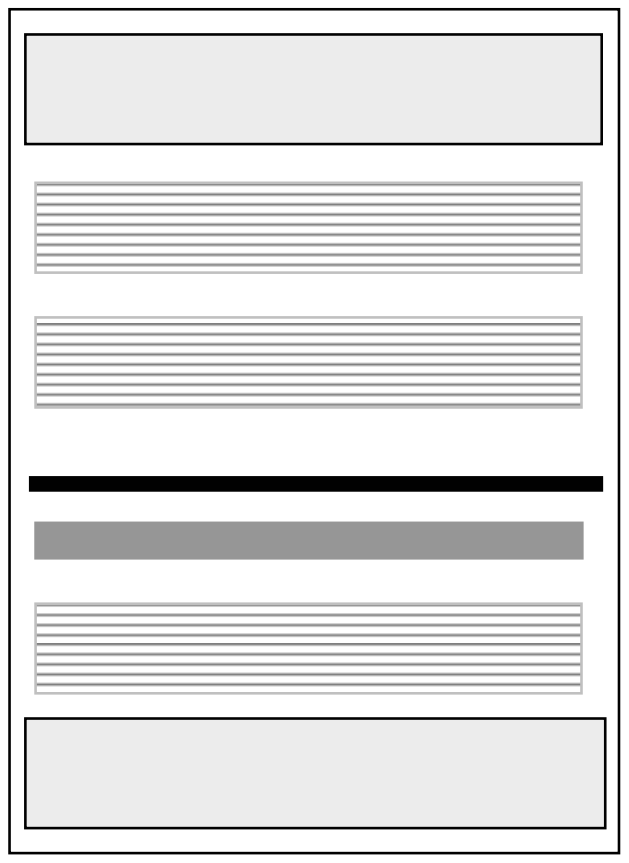

\section{Anode +}

3x Gelblottingpapier in Blotpuffer

Nitrozellulosemembran

SDS - GEL

3x Filterpapier in Blotpuffer

Kathode -

Abbildung 5: Aufbau eines Western-Blots 
Die immobilisierten Proteine wurden zunächst reversibel mit Ponceau-S angefärbt, um die Übertragungseffizienz zu überprüfen. Anschließend wurden bestimmte Proteine immunchemisch nachgewiesen.

\subsubsection{Proteinnachweis mit Ponceau-S}

Die Übertragungseffizienz der Proteine auf die Nitrozellulosemembran wurde durch Färbung der Membran mit Ponceau-S überprüft (Salinovich \& Montelaro, 1986). Die durch Ponceau-S hervorgerufene Rotfärbung der Proteine ist reversibel und beeinflußt die anschließende Immunreaktion nicht.

Die Membran wurde 5 min in 0,2\% (w/v) Ponceau-S-Lösung inkubiert und danach unter fließendem Wasser gespült, bis ein guter Kontrast zwischen Proteinbanden und Hintergrund erreicht war. Zur Dokumentation wurde die gefärbte Membran eingescannt und anschließend in TBS-T vollständig entfärbt.

\subsubsection{Proteinnachweis durch Immunfärbung}

\section{TBS/BSA/NaN -Puffer: $^{-}$}

- $5 \%$ BSA Fraktion V

- $0,02 \% \mathrm{NaN}_{3}$

- in TBS

Auf einer Membran immobilisierte Proteine lassen sich mit Antikörpern nachweisen. Zuvor ist eine Blockierung unspezifischer Bindungsstellen auf der Membran notwendig, um Hintergrundreaktionen zwischen dem Antikörper und der Membran zu verhindern. Die Sättigung unspezifischer Bindungsstellen wurde durch eine Inkubation für $1 \mathrm{~h}$ bei RT in $5 \%$ fettarmer Milch in TBS-T erreicht. Anschließend wurde die Membran mit einem Primärantikörper gegen das nachzuweisende Protein $1 \mathrm{~h}$ bei RT oder bei $4{ }^{\circ} \mathrm{C}$ über Nacht in entsprechender Verdünnung (s. Tabelle 19) inkubiert. Nach diesem Schritt wurde die Membran dreimal $10 \mathrm{~min}$ in TBS-T gewaschen, um ungebundenen Antikörper zu entfernen. Es folgte eine Inkubation mit Sekundärantikörper in $5 \%$ fettarmer Milch in TBS-T für 1 h bei RT. Nach drei weiteren Waschschritten in TBS-T 
für jeweils 10 min wurden die Proteine über die Peroxidasemarkierung des Sekundärantikörpers mittels Chemolumineszenz nachgewiesen.

Tabelle 19: Antikörperverdünnungen

\begin{tabular}{|l|l|l|l|}
\hline Antikörper & Verdünnung & Puffer & Inkubation \\
\hline $\begin{array}{l}\text { Kaninchen-anti H1x (Bezeichnung „305“, } \\
\text { 3. Blutung, Happel et al., 2005) }\end{array}$ & $1: 1000$ & $5 \%$ Milch & 1 h RT \\
\hline $\begin{array}{l}\text { Kaninchen-anti-H1.2 (Abcam, } \\
\text { Cambridge, England) }\end{array}$ & $1: 2000$ & TBS/BSA/NaN 3 & $4{ }^{\circ} \mathrm{C}$ üN \\
\hline $\begin{array}{l}\text { Maus-anti H1 }{ }^{\circ} \text { (freundlicherweise von } \\
\text { Prof. Dr. Zentgraf, DKFZ, Heidelberg, }\end{array}$ & $1: 50$ & $5 \%$ Milch & $1 \mathrm{~h} \mathrm{RT}$ \\
\hline $\begin{array}{l}\text { Maus-anti-H1 Klon AE-4 (Upstate, Lake } \\
\text { Placid, NY, USA) }\end{array}$ & $1: 5000$ & $5 \%$ Milch & $4{ }^{\circ} \mathrm{C}$ üN \\
\hline $\begin{array}{l}\text { Ziege-anti-Maus IgG + HRP (Sigma, } \\
\text { Taufkirchen, Deutschland) }\end{array}$ & $1: 12500$ & $5 \%$ Milch & $1 \mathrm{~h} \mathrm{RT}$ \\
\hline $\begin{array}{l}\text { Ziege-anti-Kaninchen IgG +HRP (Sigma, } \\
\text { Taufkirchen, Deutschland) }\end{array}$ & $1: 100000$ & $5 \%$ Milch & $1 \mathrm{~h} \mathrm{RT}$ \\
\hline
\end{tabular}

\subsubsection{Nachweis mittels Chemolumineszenz}

Mit Meerrettichperoxidase gekoppelte Antikörper wurden mittels ECL Plus Western Blotting Detction Reagent Kit (GE Healthcare, Buckinghamshire, England) nach Angaben des Herstellers nachgewiesen. Die Peroxidase katalysiert die Oxidation von Luminol und löst damit Chemolumineszenz aus. Das emittierte Licht wurde durch Auflegen eines High-Performance-Chemolumineszenz-Films (GE Healthcare, Buckinghamshire, England) detektiert. Die Expositionszeit des Films wurde an die Stärke des Signals angepaßt und betrug $30 \mathrm{~s}$ bis $30 \mathrm{~min}$. Nach der Belichtung wurde der Film in 
Entwicklerlösung LX24 (Kodak, Paris, Frankreich) 1 min entwickelt und 1 min in Fixierer (Kodak, Paris, Frankreich) lichtbeständig gemacht. Zur Dokumentation wurden die Filme eingescannt.

\subsubsection{Wiederverwendung einer Blotmembran nach Immunfärbung („Strippen“)}

\section{Strippuffer:}

- $62,5 \mathrm{mM}$ Tris/HCl (pH 6,7)

- $100 \mathrm{mM} \beta$-Mercaptoethanol

- $2 \%(w / v)$ SDS

Bei einigen Western-Blots, bei denen die Proteinproben limitiert waren, wurden die Nitrozellulosemembranen nach erfolgreicher Immunfärbung wiederverwendet, um ein anderes Protein nachzuweisen. Mit Strippuffer behandelt wurde die Membran nur, wenn das Protein, das nachgewiesen werden sollte, eine ähnliche Größe wie das zuvor detektierte Protein aufwies. Bei unterschiedlich großen Proteinen war eine zweite Immunreaktion möglich, ohne die Membran vorher mit Strippuffer zu behandeln. Die Proteine konnten anhand des Größenstandards auseinandergehalten werden.

Die Membran wurde in Strippuffer $15 \mathrm{~min}$ bei $65^{\circ} \mathrm{C}$ geschwenkt und anschließend durch mehrmaliges Waschen in TBS-T von den $\beta$-Mercaptoethanolresten aus dem Puffer befreit. Durch die Inkubation in Strippuffer wurden sowohl der primäre als auch der sekundäre Antikörper von der Membran abgelöst. Die Membran wurde für $1 \mathrm{~h}$ in 5 \% Milchlösung geblockt und anschließend für die Immundetektion wiederverwendet wie in Kapitel 3.2.5.2 beschrieben.

\subsection{Zellbiologische Methoden}

\subsubsection{Kultivierung von humanen Tumorzellinien}

Arbeiten mit humanen Zellen wurden unter sterilen Bedingungen unter einer dafür vorgesehenen Sicherheitsarbeitsbank („Hera Safe Sterilbank“, Heraeus, Hanau, Deutschland) durchgeführt. Die Kultivierung in speziellem Zellkulturmedium erfolgte in Zellkulturflaschen bei $37^{\circ} \mathrm{C}, 5 \% \mathrm{CO}_{2}, 21 \% \mathrm{O}_{2}$ und einer relativen Luftfeuchtigkeit 
von 96-100\%. Verwendete Materialien und Lösungen wurden steril gehalten und ausschließlich für die Zellkultur verwendet.

Die verwendeten Zellen wurden nur für eine begrenzte Zeit kultiviert, um Veränderungen des Genotyps ausschließen zu können. Nach maximal 20 Teilungszyklen wurden die Zellen vernichtet und durch frisch aufgetaute Zellen ersetzt.

\subsubsection{Kultivierung und Passagieren von Suspensionszellen (Raji)}

\section{RPMI-Medium (pH 7,3):}

- 10,41 g/L Biochrom T 121-05 RPMI 1640 mit L-Lysin, ohne $\mathrm{NaHCO}_{3}$ (Berlin, Deutschland)

- $24 \mathrm{mM} \mathrm{NaHCO}$

- 15 mM HEPES

- in $\mathrm{H}_{2} \mathrm{O}$ dd, sterilfiltriert

- Lagerung bei $4{ }^{\circ} \mathrm{C}$

Raji-Zellen sind Blutzellen, die aus einem Burkitt-Lymphom stammen, und werden seit 1963 kultiviert (Pulvertaft, 1964). Es handelt sich dabei - wie bei allen Blutzellen - um Suspensionszellen, die nicht am Boden der Kulturflasche wachsen. Die Zellen wurden in einer Dichte von $5 \cdot 10^{4}$ bis $1 \cdot 10^{5}$ Zellen/mL RPMI-Medium mit $10 \%$ (v/v) FCS (Biochrom, Berlin, Deutschland) und $50 \mu \mathrm{g} / \mathrm{L}$ Gentamycin (Ratiopharm, Ulm, Deutschland) ausgesät und bei einer maximalen Dichte von $1 \cdot 10^{6} / \mathrm{mL}$ geteilt. Vor der Teilung wurden die Zellen gezählt (s. Kapitel 3.3.1.3) und anschließend ein Bruchteil der Zellen mit frischem Medium aufgefüllt, so daß sie wieder eine Dichte von $5 \cdot 10^{4}$ bis $1 \cdot 10^{5}$ Zellen/mL erreichten. Die restlichen Zellen wurden verworfen oder zur Analyse geerntet (s. Kapitel 3.3.1.4). Raji-Zellen haben unter den genannten Bedingungen eine Verdopplungszeit von $24 \mathrm{~h}$.

\subsubsection{Kultivierung und Passagieren von adhärenten Zellen (HeLa und 293)}

\section{MEM-Medium (pH 7,4):}

- 9,76 g/L Biochrom T 437-05 MEM Eagle mit L-Glutamin, ohne $\mathrm{NaHCO}_{3}$ (Berlin, Deutschland) 
- $27 \mathrm{mM} \mathrm{NaHCO}$

- 10 mM HEPES

- in $\mathrm{H}_{2} \mathrm{O}$ dd, sterilfiltriert

- Lagerung bei $4{ }^{\circ} \mathrm{C}$

\section{DMEM-Medium(pH 7,5):}

- 13,54 g/L Biochrom T 043-05 DMEM mit 4,5g D-Glucose, mit L-Glutamin, ohne $\mathrm{NaHCO}_{3}$ (Berlin, Deutschland)

- $\quad 44,4 \mathrm{mM} \mathrm{NaHCO} 3$

- in $\mathrm{H}_{2} \mathrm{O}$ dd, sterilfiltriert

- Lagerung bei $4{ }^{\circ} \mathrm{C}$

HeLa- und 293-Zellen wachsen wie die meisten aus Gewebe stammenden Zellen adhärent, sie heften sich am Boden der Zellkulturflasche an.

HeLa-Zellen wurden ursprünglich aus einem epitheloiden Cervix-Adenocarcinom gewonnen.

293-Zellen stammen aus menschlichen embryonalen Nierenzellen (HEK) und enthalten Teile des Genoms des Adenovirus Typ 5. Die Etablierung der Zellinie wurde 1977 von Graham (Graham et al., 1977) publiziert.

HeLa-Zellen wurden in MEM-Medium mit $10 \%$ (v/v) FCS (Biochrom, Berlin, Deutschland) und $50 \mu \mathrm{g} / \mathrm{L}$ Gentamycin (Ratiopharm, Ulm, Deutschland) kultiviert, 293Zellen in DMEM mit 10 \% (v/v) FCS und 50 pg/L Gentamycin. Sowohl HeLa- als auch 293-Zellen wurden mit einer Dichte von $2 \cdot 10^{6} / \mathrm{mL}$ ausgesät und bis zu einer Besiedlung von 80-90 \% der Flasche kultiviert. Die anschließende Teilung erfolgte nach Ablösen der Zellen durch Trypsin/EDTA-Lösung (0,05\%/0,02 \% (w/v)). Dazu wurde das Medium der adhärenten Zellen verworfen, die Zellen wurden einmal mit PBS gewaschen, um das restliche FCS zu entfernen, und mit der Trypsin/EDTA-Lösung überschichtet. Es wurde nur soviel Trypsin/EDTA-Lösung eingesetzt, daß die Zellen gerade befeuchtet waren (2-3 mL/650 mL-Flasche). Die Zellen wurden mit Trypsin 25 min bei $37^{\circ} \mathrm{C}$ im Brutschrank inkubiert, bis sie sich vom Boden der Kulturflasche gelöst hatten. Die Ablösung wurde durch vorsichtiges Abklopfen erleichtert. Die 
Trypsinaktivität wurde durch 10 mL Medium mit FCS gestoppt, da FCS Proteaseinhibitoren enthält. Die Zellsuspension wurde maschinell gezählt (s. Kapitel 3.3.1.3). Aus der Suspension wurden der Zählung entsprechend $2 \cdot 10^{6}$ Zellen/mL mit frischem Medium zur Weiterkultivierung ausgesät. Die restlichen Zellen wurden verworfen oder zur Analyse geerntet.

\subsubsection{Zellzählung}

Alle Zellen wurden in einem CASY 1TT-Zellzählgerät (Schärfe System, Reutlingen, Deutschland) gezählt. Für die Messung wurde die Zellsuspension 1:100 in isotoner Lösung (Beckman Coulter, Krefeld, Deutschland) (100 $\mu \mathrm{L}$ Zellen in $10 \mathrm{~mL}$ Lösung) verdünnt.

\subsubsection{Ernte von Zellen}

Sowohl Suspensions- als auch Adhäsionszellen wurden zur Analyse in $50 \mathrm{~mL}$ Reaktionsgefäßen geerntet. Die Zellen wurden bei $300 \mathrm{~g}$ bei RT für 5 min sedimentiert, mit $10 \mathrm{~mL}$ PBS gewaschen und nochmals unter gleichen Bedingungen zentrifugiert. Das Zellsediment wurde sofort verarbeitet oder bei $-20{ }^{\circ} \mathrm{C}$ gelagert.

\subsubsection{Präparation der Zellen für die Fluoreszenzmikroskopie}

Adhärente Zellen, die mittels Fluoreszenzmikroskopie analysiert werden sollten, wurden in 6-well-Platten mit 4 Deckgläschen pro Vertiefung ausgesät. Es wurden $1,5 \cdot 10^{5}$ Zellen in $2 \mathrm{~mL}$ Medium/Vertiefung ausgesät bzw. bei Ernte nach $48 \mathrm{~h}$ nur $0,75 \cdot 10^{5}$ Zellen in $2 \mathrm{~mL}$ Medium/Vertiefung. Nach $24 \mathrm{~h}$ oder $48 \mathrm{~h}$ wurden die Deckgläschen entnommen und für die Fluoreszenzmikroskopie (s. Kapitel 3.3.4) vorbereitet.

Suspensionszellen konnten aufgrund der fehlenden Adhäsion an Deckgläschen nicht wie HeLa-Zellen kultiviert werden, sondern mußten aus der Suspension per Zentrifugalkraft auf die Deckgläschen transferiert werden. Diese Methode ist als „Spindown“ bekannt. Pro Deckgläschen wurden $1 \cdot 10^{5}$ Zellen geerntet. Die Zentrifugation erfolgte in einer speziellen Vorrichtung, so daß die Zellen aus einem 0,75 mL-Gefäß durch ein Loch im Boden des Gefäßes auf das Deckgläschen tropfen konnten. Der Erfolg wurde 
im Lichtmikroskop überprüft und das Deckglas nach gelungener Zentrifugation für die Fluoreszenzmikroskopie (s. Kapitel 3.3.4) vorbereitet.

\subsubsection{Langzeitlagerung von Zellen}

Zellen können über Jahre in flüssigem Stickstoff gelagert werden. Zur Erstellung solcher Dauerkulturen wurden adhärente Zellen bis zu einer Dichte von 2/3 der Kulturflasche kultiviert, mit Trypsin abgelöst und durch Sedimentierung bei $300 \mathrm{~g}$ geerntet. Die Zellen wurden mit Kulturmedium, das 20 \% FCS und 10 \% DMSO zum Schutz der Zellen enthielt, so resuspendiert, daß eine Konzentration von 1,875.10 ${ }^{6}$ Zellen/mL erreicht wurde. Je $1,6 \mathrm{~mL}$ mit $3 \cdot 10^{6}$ Zellen wurden in Kryoröhrchen mit Schraubdeckel überführt. Die aliquotierten Zellen wurden in Papier und Styropor isoliert für $24 \mathrm{~h}$ bei $-80{ }^{\circ} \mathrm{C}$ langsam eingefroren und anschließend in flüssigem Stickstoff gelagert.

\subsubsection{Auftauen von Zellen}

Um Zellen neu in Kultur zu nehmen, wurden die in flüssigem Stickstoff gelagerten „Kryostocks“ kurz in 100 \% MeOH getaucht, um Kontaminationen mit Mykoplasmen vorzubeugen und dann schnell bei $37^{\circ} \mathrm{C}$ im Wasserbad aufgetaut. Sobald die Zellen aufgetaut waren, wurden sie in eine Zellkulturflasche mit entsprechendem Medium überführt und bei Standardbedingungen (s. Kapitel 3.3.1.1 oder Kapitel 3.3.1.2) kultiviert.

\subsubsection{Synchronisation von HeLa-Zellen und Zellzyklusarrest}

HeLa-Zellen in Kultur wachsen asynchron, das heißt, daß sich die Zellen in verschiedenen Zellzyklusphasen befinden. Durch Zugabe von Aphidicolin (QbiogeneAlexis, Grünberg, Deutschland) bzw. Natriumbutyrat (Sigma, Taufkirchen, Deutschland) läßt sich der Zellzyklus in bestimmten Phasen arretieren. Eine Behandlung der Zellen mit $10 \mu \mathrm{M}$ Aphidicolin für $24 \mathrm{~h}$ hemmt DNA-Polymerasen und hat somit zu einem Arrest am G1/S-Übergang zur Folge (Ikegami et al., 1978, Perrino und Loeb, 1990). Die Inkubation der Zellen mit $5 \mathrm{mM}$ Natriumbutyrat führt zur Differenzierung der Zellen oder zum Zellzyklusarrest und zeichnet sich durch eine Akkumulation der 
Zellen in der G1-Phase aus (Leder 1975, Chabanas 1985, Kress et al., 1986). Die Entlassung aus dem reversiblen Arrest durch $10 \mu \mathrm{M}$ Aphidicolin erfolgte durch Waschen der Zellen mit PBS und Zugabe von frischem MEM-Medium mit 10 \% FCS. Die Zellen wurden zu bestimmten Zeitpunkten nach der Entlassung aus dem Arrest geerntet $^{3}$, mittels FACS analysiert und bei $-20^{\circ} \mathrm{C}$ gelagert oder direkt für die RT-PCR verarbeitet (s. Kapitel 3.1.6.2).

\subsubsection{Transiente Transfektion}

Bei der transienten Transfektion wird DNA in die Zelle eingeschleust, aber nicht dauerhaft in das Zellgenom integriert. Da die ungeschützte, aufgenommene DNA schnell abgebaut wird und außerdem nicht im folgenden Teilungszyklus vermehrt wird, lassen sich Untersuchungen mit transient transfizierten Zellen nur über wenige Tage durchführen.

\subsubsection{Transiente Transfektion von Suspensionszellen}

Am Tag der Transfektion wurden $1 \cdot 10^{6}$ Zellen in 1,4 mL Medium/Vertiefung einer 6well-Platte ausgesät. Direkt im Anschluß erfolgte die Transfektion mit dem Effectene Transfection Reagent Kit der Firma Qiagen (Qiagen, Hilden, Deutschland) nach Standardprotokoll des Herstellers. 400 ng DNA wurden mit 3,2 $\mu \mathrm{L}$ Enhancer gemischt und mit $10 \mu \mathrm{L}$ Effectene und 0,6 mL Kulturmedium zu den Zellen gegeben, so daß eine Zelldichte von $0,5 \cdot 10^{6} / \mathrm{mL}$ Medium herrschte. Die Zellen wurden $22 \mathrm{~h}$ nach Transfektion geerntet. Für eine Ernte nach $24 \mathrm{~h}$ wurden die transfizierten Zellen 1:2 geteilt und mit $1 \mathrm{~mL}$ neuem Medium versehen.

\footnotetext{
${ }^{3}$ Die Behandlung der Zellen mit Aphidicolin und Natriumbutyrat sowie die Ernte und die Analyse mittels FACS wurden freundlicherweise von Kristina Hänecke durchgeführt.
} 


\subsubsection{Transiente Transfektion von Adhäsionszellen}

Für die Transfektion von HeLa- und 293-Zellen wurde das Effectene Transfection Reagent Kit der Firma Qiagen (Qiagen, Hilden, Deutschland) verwendet. Die Durchführung erfolgte nach Angaben des Herstellers bei ca. 40-80 \% Konfluenz der Zellen in Bezug auf die Oberfläche der Vertiefungen der 6-well-Platte. Diese Besiedlungsdichte wurde nach $24 \mathrm{~h}$ erreicht, wenn zuvor $1,5 \cdot 10^{5}$ Zellen in $2 \mathrm{~mL}$ Medium pro Vertiefung einer 6-well-Platte ausgesät wurden. Für fluoreszenzmikroskopische Analysen der HeLa-Zellen wurden diese in gleicher Konzentration in 6-well-Platten, die Deckgläschen enthielten, ausgesät. Bei der Transfektion von HeLa-Zellen mit GFPKonstrukten wurden nach Standardprotokoll des Effectene Transfection Reagent Kits 400 ng DNA-Konstrukt mit 3,2 $\mu \mathrm{L}$ Enhancer gemischt und mit $10 \mu \mathrm{L}$ Effectene und 0,6 mL Kulturmedium zu den Zellen gegeben. Die Ernte erfolgte $22 \mathrm{~h}$ nach Transfektion.

\subsubsection{Transiente Transfektion von HeLa-Zellen mit siRNA-Konstrukten ${ }^{i}$}

Für die transiente Transfektion mit Polyfect (Qiagen, Hilden, Deutschland) sollten die Zellen 50-80 \% konfluent sein. Diese Dichte wurde durch Aussaat von 1,5·10 Zellen in $1 \mathrm{~mL}$ Medium pro Vertiefung einer 12-well-Platte am Vortag erreicht.

Pro Vertiefung wurden 0,75 $\mu \mathrm{g}$ bzw. 1,5 $\mu \mathrm{g}$ DNA auf $50 \mu \mathrm{L}$ mit serumfreiem MEMMedium in einem 1,5 mL-Reaktionsgefäß aufgefüllt. Nach Zugabe von $6 \mu \mathrm{L}$ Polyfect wurde für $10 \mathrm{~s}$ auf dem Vortex gut gemischt. Einer Inkubationszeit von $10 \mathrm{~min}$ bei RT folgte die Zugabe von 150 $\mu \mathrm{L}$ MEM mit FCS, ohne Antibiotikum. Der gesamte Ansatz wurde sofort zu den HeLa-Zellen, die zuvor $800 \mu \mathrm{L}$ frisches MEM-Medium mit FCS bekommen hatten, gegeben.

Nach einmaliger Transfektion mit siRNA-Konstrukten $\left(0,75 \mu \mathrm{g}\right.$ X2 in pSilencer ${ }^{\mathrm{TM}}$, 0,75 $\mu$ g T1 in pSilencer ${ }^{\mathrm{TM}}$, 1,5 $\mu$ g pSilencer $^{\mathrm{TM}}$ ), wurden die Zellen wie gewöhnlich (s. Kapitel 3.3.1.2) geteilt. 


\subsubsection{RNA- / Proteinextraktion aus transfizierten HeLa-Zellen ${ }^{i}$}

Für die Analyse der mit siRNA transfizierten Zellen wurden RNA und Protein aus einer Probe aufgereinigt. Dieses Verfahren ermöglicht es, aus wenig Material Informationen über Expression und Translation eines Gens zu bekommen. Die Durchführung der Isolierung erfolgte nach Angaben des Herstellers des Nucleospin ${ }^{\circledR}$ RNA/Protein-Kits (Macherey-Nagel, Düren, Deutschland).

\subsubsection{Stabile Transfektion von HeLa-Zellen mit siRNA}

Bei der stabilen Transfektion werden Zellen selektiert, die das transfizierte Plasmid in ihr Genom aufgenommen haben. Um selektieren zu können, muß das aufgenommene Plasmid eine Resistenz für ein bestimmtes Antibiotikum aufweisen. Nur stabil transfizierte Zellen, die Plasmid-DNA in aktive Teile ihres Chromatins integriert haben, sind in der Lage, über längere Zeit in Selektionsmedium zu überleben.

Die stabile Transfektion mit siRNA wurde wie die in Kapitel 3.3.2.3 beschriebene transiente Transfektion mit Polyfect der Firma Qiagen durchgeführt. Der einzige Unterschied bestand darin, daß ein Kontrollplasmid kotransfiziert wurde, das nicht nur die Überprüfung der Transfektionseffizienz ermöglichte, sondern auch die stabile Transfektion aufgrund einer Resistenz gegen G418. Als Kontrollplasmid wurde pEGFPN1 (Biosciences Clontech, Mountain View, CA, USA) eingesetzt, da die Expression von GFP leicht zu überprüfen ist und das Plasmid eine Resistenz gegen Neomycin (G418) aufweist. 0,5 $\mu \mathrm{g}$ pEGFP-N1 wurden direkt mit den siRNA-Konstrukten auf $50 \mu \mathrm{L}$ mit serumfreiem MEM-Medium in einem 1,5 mL-Reaktionsgefäß aufgefüllt.

Die transfizierten HeLa-Zellen wurden direkt nach der Transfektion in MEM-Medium mit $10 \%$ (v/v) FCS (Biochrom, Berlin, Deutschland), $50 \mu \mathrm{g} / \mathrm{L}$ Gentamycin (Ratiopharm, Ulm, Deutschland) und 400 g/mL G418 (Sigma, München, Deutschland) kultiviert. Durch die Zugabe von G418 wurde sichergestellt, daß sich nur Zellen, die das Plasmid in ihr Genom aufgenommen haben, vermehren konnten. Das Medium wurde alle $48 \mathrm{~h}$ gewechselt, um abgestorbene Zellen $\mathrm{zu}$ entfernen und immer für eine gleichbleibende Konzentration an G418 zu sorgen. Bei 2/3 Besiedlung der Kultur- 
flasche wurden die Zellen wie unter 3.3.1.2 beschrieben geteilt und mit Medium mit G418 weiterkultiviert oder zur Analyse geerntet.

\subsubsection{Fluoreszenzmikroskopische Analyse von Zellen}

Die Vorbereitung der Deckgläschen für die Fluoreszenzmikroskopie erfolgte in einer feuchten Kammer. Alle Lösungen wurden vorsichtig mittels Pipette aufgetropft und mit Hilfe einer Wasserstrahlpumpe abgesaugt. Die Zellen auf den Deckgläschen wurden konstant feucht gehalten. Soweit nicht anders beschrieben, wurden alle Schritte bei RT durchgeführt.

\subsubsection{Fluoreszenzmikroskopische Analyse von Zellen mit GFP-Konstrukten}

Deckgläschen mit HeLa-Zellen, die mit GFP-Konstrukten transfiziert worden waren (s. Tabelle 20) ${ }^{4}$, wurden dreimal mit je $100 \mu \mathrm{L}$ PBS gewaschen. Die Zellen wurden 15 min in $100 \mu \mathrm{L}$ einer $3 \%$ (w/v) Paraformaldehydlösung in PBS fixiert, danach dreimal mit je $100 \mu \mathrm{L}$ PBS gewaschen und anschließend mit VectaShield $\circledast$ Mounting Medium mit DAPI (Vector Laboratories, Burlingame, CA, USA) auf Objektträgern eingedeckelt. Die Präparate konnten entweder sofort im Fluoreszenzmikroskop angeschaut werden oder bei $-20^{\circ} \mathrm{C}$ für die spätere Auswertung und Dokumentation gelagert werden.

\footnotetext{
${ }^{4}$ Die Plasmide pJW 9 - 34 wurden wie in Kapitel 3.1.3.10 und 4.1.3 beschrieben gefertigt.
} 
Tabelle 20: Für die Fluoreszenzmikroskopie zur Transfektion verwendete

\section{Plasmide}

\begin{tabular}{|l|l|}
\hline Name & Beschreibung \\
\hline pJW 9 & H1x kodierender Bereich in pEGFP-N1, GFP C-terminal \\
\hline pJW 33 & H1 $x$ kodierender Bereich in pEGFP-1, GFP C-terminal \\
\hline pJW 34 & $\begin{array}{l}\text { Promotorkonstrukt 55 }-56+H 1 x \text { kodierender Bereich in pEGFP-N1, GFP } \\
\text { C-terminal }\end{array}$ \\
\hline
\end{tabular}

\subsubsection{Dokumentation am Fluoreszenzmikroskop}

Fluoreszenzmarkierte Zellen und Gewebe wurden an einem Fluoreszenzmikroskop („Axioskop“, Zeiss, Göttingen, Deutschland) mit der Kamera Axio Cam MRm der Firma Zeiss mit dem Programm AxioVision Rel.4.5 von Zeiss aufgenommen.

i Dieser Ansatz wurde durchgeführt, ist aber im Ergebnisteil nicht erwähnt, da die Resultate noch nicht aussagekräftig waren. (s. Kapitel 5.5) 



\section{Ergebnisse}

Bisher wurden elf verschiedene Subtypus-Gene des Linkerhistons H1 im Genom des Menschen beschrieben. Der Histonsubtyp H1x wurde bisher nur in wenigen Veröffentlichungen erwähnt (Yamamoto \& Horikoshi, 1996; Sulimova et al., 2002; Happel et al., 2005). Yamamoto und Horikoshi (1996) beschreiben die cDNA-Sequenz dieses Subtyps und leiten aus dieser Sequenz den für H1-Histone charakteristischen strukturellen Aufbau aus einer zentralen globulären Domäne und zwei terminalen Domänen her. Sie untersuchten die Verteilung von H1x-mRNA in humanem Gewebe und stellten mittels Northern-Blot-Analyse fest, daß $H 1 x$ in allen von ihnen untersuchten Geweben exprimiert wird. Bei Happel et al. (2005) werden die Ähnlichkeit zur Sequenz anderer H1-Subtypen bzw. zu Proteinen orthologer Gene und diverse biochemische Eigenschaften des Proteins sowie die Expression von H1x in humanen Tumorzellinien beschrieben.

Die bereits erschienenen Publikationen geben einen ersten Einblick in verschiedene Eigenschaften von H1x. Für H1x ist aber, wie für die anderen H1-Subtypen auch, weiter ungeklärt, wie seine Expression reguliert wird und inwiefern das untersuchte H1-Histon an der Regulation der Genexpression beteiligt ist. Die vorliegende Arbeit hatte das Ziel, am Beispiel H1x einen Beitrag zur Aufklärung der Expression von H1-Histongenen und der Zusammensetzung der einzelnen H1-Histonsubtypen in verschiedenen Geweben und Entwicklungsstadien zu leisten. Für die genauere Charakterisierung von $H 1 x$ wurden die genomische Sequenz mit dem Ziel einer Promotoranalyse, die Expression im Verlauf des Zellzyklus, die Expression in humanen Tumorzellinien und das Auftreten von H1x in unterschiedlichen Entwicklungsstadien humanen Gewebes und in Tumoren analysiert. 


\subsection{Promotoranalyse von $\mathrm{H1x}$}

\subsubsection{In silico Vergleich des H1x-Promotors mit Promotoren anderer H1-Gene}

In der Diversität der Promotorstrukturen spiegelt sich die vielfältige Kontrolle der Expression verschiedener H1-Gene wider. Die in silico Betrachtung der genomischen Sequenz von $H 1 x$ zeigte oberhalb des Startcodons ATG eine ungewöhnlich lange untranslatierte Region von 381 Nukleotiden und oberhalb des Transkriptionsstarts das Vorkommen von Konsensussequenzen im Vergleich zu existierenden Daten von H1Promotoren (Doenecke et al., 1994). Die folgenden Promotorelemente (s. Abbildung 6 und Tabelle 21) wurden für $H 1 x$ aus der Promotorsequenz vorhergesagt:

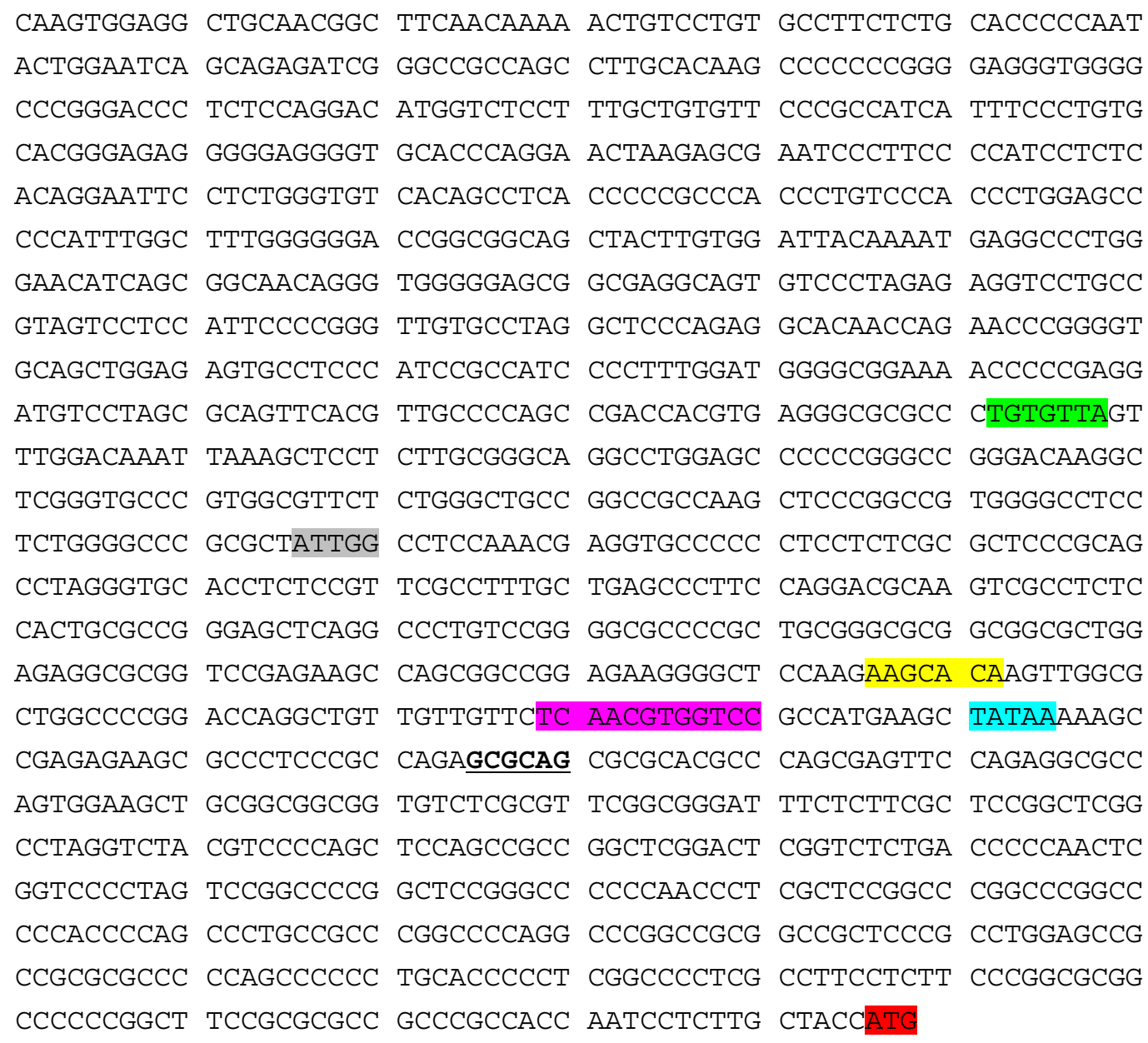

Abbildung 6: Sequenz des $H 1 x$-Genabschnitts, $1,0 \mathrm{~kb}$ vor dem Transkriptionsstart beginnend, mit putativen Promotorelementen

Die hier gezeigte Sequenz von H1x beginnt etwa 1,0 kb vor dem Transkriptionsstart, der fettgedruckt und unterstrichen ist. Die putativen Promotorelemente oberhalb der kodierenden 
Region sind farblich unterlegt. Grün: CH1UE; grau: „umgedrehte CCAAT-Box“; gelb: H1-Box (statt AAACACA lautet hier die Sequenz AAGGCACA); pink: UPE H4; türkis: TATA-Box; fettgedruckt und unterstrichen: Transkriptionsstart; rot: Beginn des proteincodierenden Bereichs (Translationsstart)

Tabelle 21: Auflistung der putativen Promotorelemente von $H 1 x$

\begin{tabular}{|l|l|}
\hline Element & Länge \\
\hline CH1UE & 453 bp bis Transkriptionsstart \\
\hline „umgedrehte CCAAT-Box“ & 309 bp bis Transkriptionsstart \\
\hline H1-Box & 103 bp bis Transkriptionsstart \\
\hline UPE H4 & 56 bp bis Transkriptionsstart \\
\hline TATA-Box & 34 bp bis Transkriptionsstart \\
\hline Transkriptionsstart bis Translationsstart & 381 bp \\
\hline
\end{tabular}

Die bisher in den verschiedenen Genen der H1-Subtypen beschriebenen regulatorischen Promotorelemente werden in Abbildung 7 mit den für $H 1 x$ vorausgesagten Elementen verglichen. Das von Khochbin und Wolffe (1993) für $H 1^{\circ}$ beschriebene UCE (upstream conserved element) befindet sich etwa -450 bp vom Transkriptionsstart entfernt und ist in Kooperation mit proximalen Promotorelementen für die basale Expression von $H 1^{\circ}$ verantwortlich (Khochbin \& Wolffe, 1993). Es enthält die bei Meergans et al. (1998) für H1.3 und bei Eilers et al. (1994) für H1.2 beschriebene Sequenz TGTGTTA des CH1UEs (conserved H1 gene upstream element). In dieser Sequenz ist das Kernmotiv der H1-Box (AAACACA) fast perfekt invertiert (Duncliffe et al., 1995). Das distal lokalisierte CH1UE bindet nukleäre Proteine, die bei H1.3 in die zellzyklusabhängige Regulation involviert sind (Meergans et al., 1998). In dem Sequenzabschnitt des $H 1 x-$ Gens liegt das putative CH1UE 453 bp oberhalb des Transkriptionsstarts. 
Die H1-Box hat das Kernmotiv AAACACA (Coles \& Wells, 1985) und wurde ursprünglich für die S-Phase-abhängige Expression verantwortlich gemacht (Dalton \& Wells, 1988). Im $H 1 x$-Genabschnitt ist ein Motiv mit der Sequenz AAGCACA zu finden, das aufgrund seiner Position relativ zum Transkriptionsstart (103 bp oberhalb des Transkriptionsstarts) der H1-Box entsprechen könnte.

Die CCAAT-Box bindet im Falle von H1-Promotoren den H1-spezifischen Transkriptionsfaktor H1TF2 (van Wijnen et al., 1988 a, b; Gallinari et al., 1989; Martinelli \& Heintz, 1994) und wird in H1-Histon-Gen-Promotoren von einem weiteren CA gefolgt, d.h., die Sequenz CCAATCA liegt vor. Bei $H 1^{\circ}$ fehlt die CCAAT-Box in der 5'flankierenden Region. Ergebnisse aus Bindungsstudien lassen vermuten, daß die CCAAT-Box-bindenden Faktoren eine wichtige Rolle bei der S-Phase-Regulation spielen, da die Aktivität von H1TF2 in Kernextrakten aus S-Phase-Zellen erhöht ist (La Bella et al., 1989; Heintz 1991). Die putative CCAAT-Box liegt im H1x-Gen auf dem anti-sense Strang 309 bp oberhalb des Transkriptionsstarts und wird deshalb hier als „umgedrehte CCAAT-Box“ bezeichnet.

Das UPE H4TF2 (upstream positive element) wurde nur in replikationsunabhängigen Histonen ( $\mathrm{H} 1^{\circ}$ und $\left.\mathrm{H} 5\right)$ gefunden, nicht in somatischen H1-Histonen (Bouterfa et al., 1993). Das upstream positive element wurde bei $H 1^{\circ}$ etwa 40 bp oberhalb des Transkriptionsstarts beschrieben (Bouterfa et al., 1993; Khochbin \& Wolffe, 1993) und enthält die H4-Gentranskriptionsfaktorbindungsstelle H4TF2 (TCANNNNG GTCC), die an der Expressionskontrolle von H4-Genen beteiligt ist (Dailey et al., 1988). Im $H 1 x$-Promotor wurde ein Element mit der Sequenz TCAACGTGGTCCT 56 bp oberhalb des Transkriptionsstarts gefunden, das dem UPE H4TF2 entsprechen könnte.

Die TATA-Box ist die Bindungsstelle für das TBP-Protein (TATA-box binding protein), das Bestandteil des Transkriptionsfaktors TFIID ist. Die TATA-Box ist für den Aufbau und die korrekte Positionierung des RNA-Polymerase II-Initiationskomplexes zuständig, der die Synthese von mRNA und weniger kleiner snRNAs katalysiert. Die TATABox ist spezifisch für H1-Gen-Promotoren (Martinelli \& Heintz, 1994; Gallinari et al., 1989). Die putative TATA-Box des H1x-Promotors befindet sich 34 bp oberhalb des Transkriptionsstarts. 


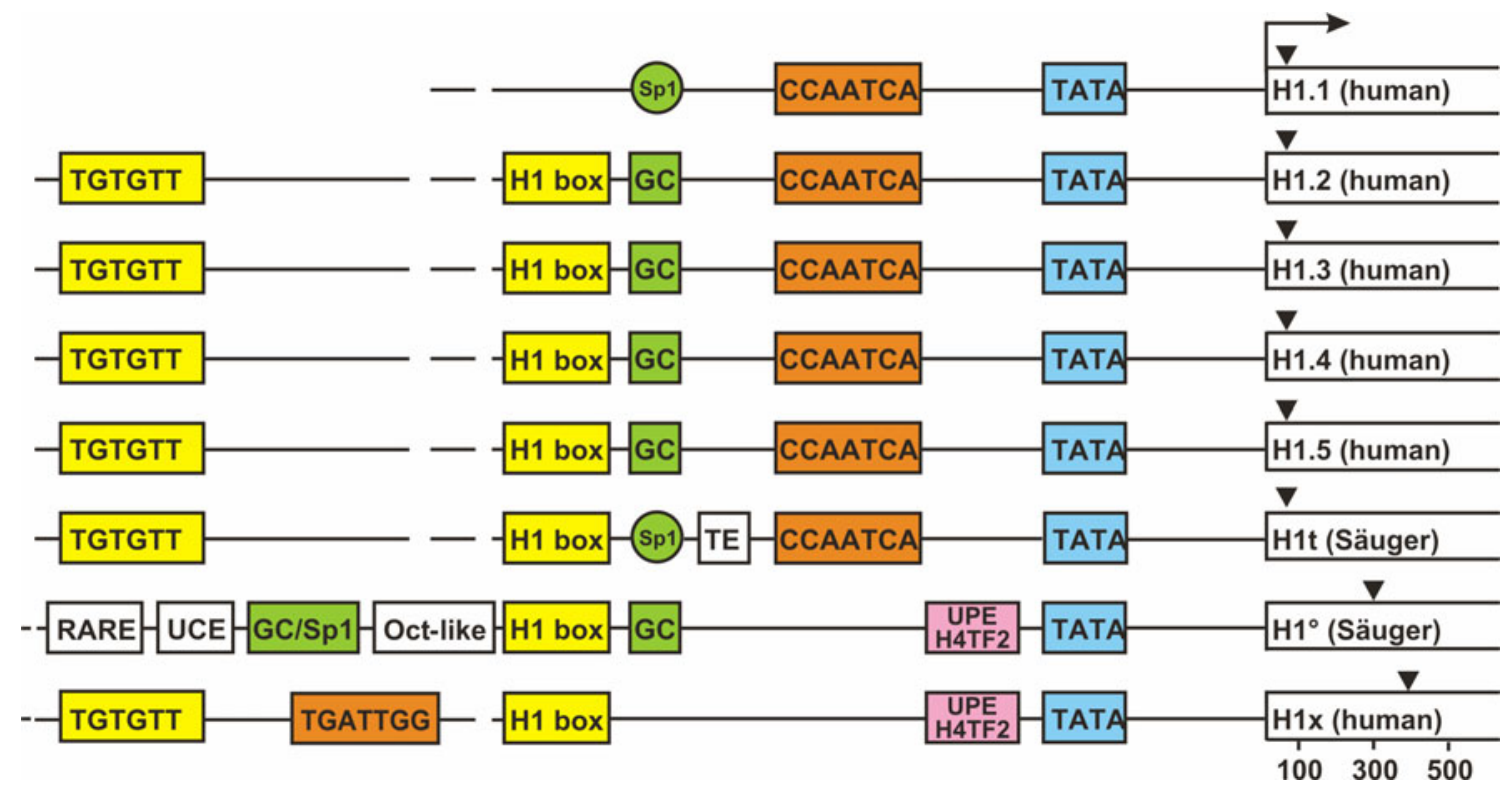

Abbildung 7: H1-Gen-Promotoren im Vergleich ${ }^{5}$

Dargestellt sind regulatorische Promotorelemente der H1-Histongene. Zusätzlich zu der H1-Box (gelb), der CCAAT-Box (orange, CCAATCA, bzw. TGATTG bei der putativen ,umgedrehten CCAAT-Box“ im H1x-Promotor), dem UPE H4 (pink) und der TATA-Box (hellblau) sind weitere Elemente der H1-Gen-Promotoren abgebildet: Sp1: Bindungsstelle für den Transkriptionsfaktor Sp1 (Briggs et al., 1986); Oct-like: Bindungsmotiv für OTF1 (Fletcher et al., 1987); RARE: retinoic acid receptor binding element (Evans, 1988; Bouterfa et al., 1995); TE: testis specific element (Grimes et al., 1992); GC: GC-reiche Region; TGTGTT: conserved H1 gene upstream element (CH1UE) (Eilers et al., 1994; Meergans et al., 1998); Pfeil: Transkriptionsstart; Pfeilspitze: Translationsstart

Ziel der Promotoranalyse war, regulatorische Abschnitte des $H 1 x$-Promotors zu identifizieren und herauszufinden, ob die Region, auf der die bekannten regulatorischen Elemente liegen, ausreicht, um $H 1 x$ funktionell in Transfektionsexperimenten zu exprimieren.

\subsubsection{Luciferase-Assay}

Auf der Grundlage der aus der Promotorsequenz vorausgesagten Elemente (Tabelle 21) wurden Konstrukte verschiedener Länge entworfen und in den Expressionsvektor pGL3-basic eingefügt. Die so gefertigten Plasmide enthielten dementsprechend

\footnotetext{
${ }^{5}$ Erweiterte und angepaßte Version der Abbildung 1 aus Doenecke et al., 1994
} 
Teilsequenzen des in Abbildung 6 gezeigten $H 1 x$-Genabschnitts und das Gen für die Firefly-Luciferase (s. Abbildung 8). Der $H 1 x$-Genabschnitt wurde um jeweils ein regulatorisches Element verkürzt, ausgehend von einem Konstrukt, das 591 bp vor dem CH1UE begann (Konstrukt 55). Das Konstrukt 18 beginnt wie Konstrukt 55, geht aber unmittelbar nach dem Transkriptionsstart in den Translationsstart über. Die Deletion dieses im 5'-UTR (untranslated region) gelegenen Sequenzabschnitts sollte zeigen, ob der gegenüber anderen H1-Subtypen vergleichsweise lange Bereich des $H 1 x$-Promotors zwischen Transkriptions- und Translationsstart für den $H 1 x$-Promotor von Bedeutung ist.

Aufgrund einer Aktivitätszunahme des Konstrukts 8 gegenüber dem Konstrukt 7 (s. Abbildung 9) wurden weitere Deletionsmutanten erstellt, die den Bereich zwischen den Konstrukten 7 und 8 in 50 bp-Schritten abdeckten (Konstrukte 19 - 22). Die Erstellung dieser Konstrukte war darin begründet, daß eine Aktivitätszunahme nicht erwartet worden war. Konstrukt 8 fehlt im Vergleich zu Konstrukt 7 die „umgedrehte CCAATBox“, von der angenommen wurde, daß sie aktivierend wirkt.

Einen Überblick über die erstellten Konstrukte gibt Abbildung 8: 


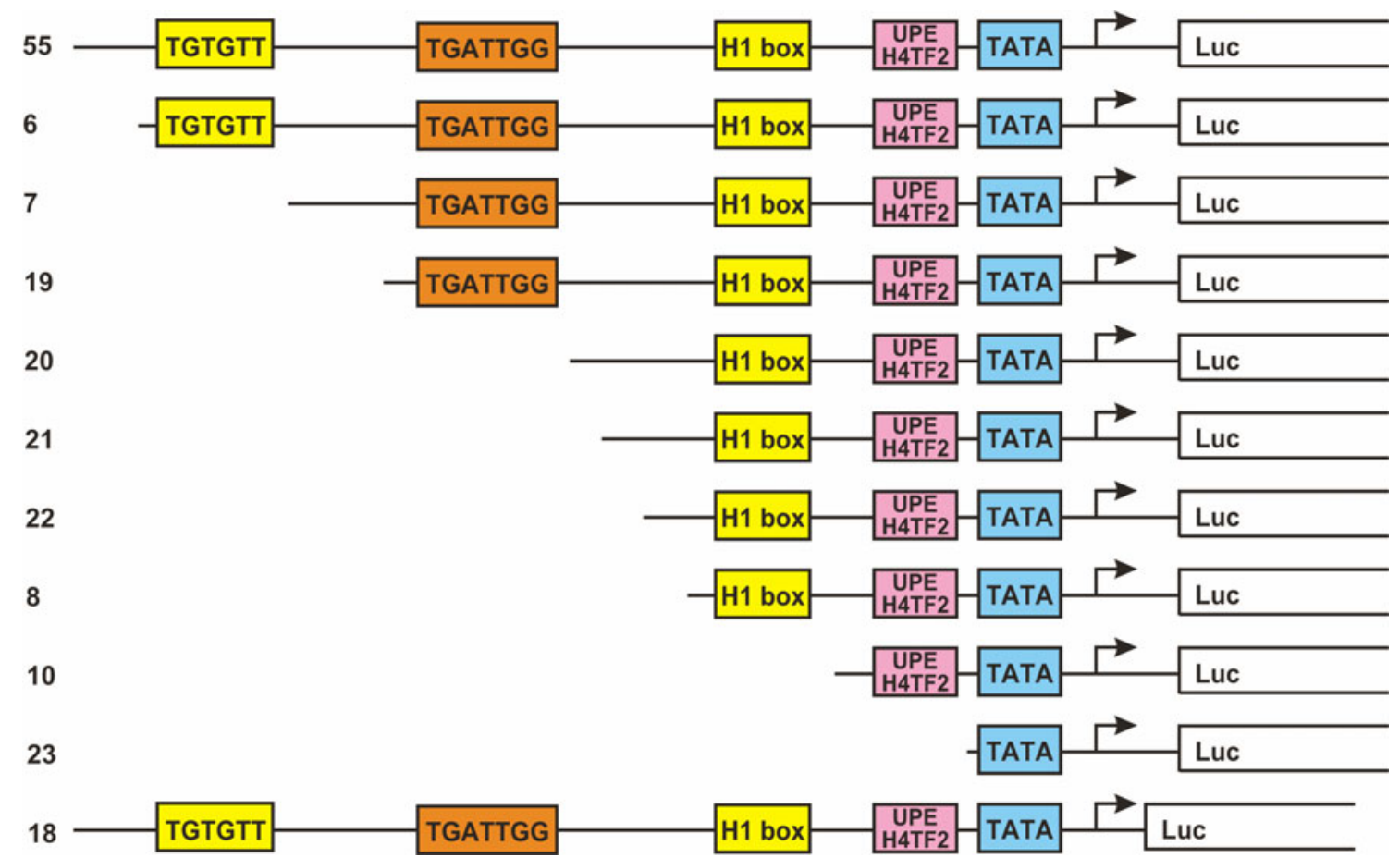

Abbildung 8: Schematische Darstellung der untersuchten Konstrukte zur Aktivitätsbestimmung des $\mathrm{H} 1 \mathrm{x}$-Promotors

Anhand der vorausgesagten Elemente wurden Konstrukte erstellt, die jeweils um ein putatives Promotorelement verkürzt wurden. Das CH1UE ist als gelbe Box mit der Beschriftung TGTGTT dargestellt, die mögliche „umgedrehte CCAAT-Box“ in orange mit der Beschriftung TGATTG, die H1-Box als gelber Kasten „H1 box“, das UPE in pink mit der Beschriftung UPE H4TF2 und die TATA-Box als blauer Kasten „TATA“. Die Zahlen vor den gezeigten Ausschnitten der erstellen Plasmide geben die Bezeichnungen der Konstrukte an. Das längste Konstrukt (Konstrukt 55) beginnt 591 bp vor dem CH1UE (gelbe Box, TGTGTT). Bei Konstrukt 18 sind alle vorhergesagten Elemente vorhanden, doch wurde die Sequenz zwischen Transkriptionsstart (Pfeil) und Translationsstart um 340 Nukleotide verkürzt. Mit dem LucAbschnitt beginnt der proteincodierende Bereich (Translationsstart).

Für die unterschiedlichen Konstrukte wurden Reportergenassays (s. Kapitel 3.1.4.2) durchgeführt, bei denen die Messung der Firefly-Luciferaseenzymaktivität als Maß der Promotorstärke diente. Die konstitutiv unter der Kontrolle eines CMV-Promotors koexprimierte Renilla-Luciferase wurde als interner Standard verwendet. Bei der Bestimmung der Promotoraktivität wurde das Verhältnis aus der Lumineszenz der Firefly-Luciferase und der Lumineszenz der koexprimierten Renilla-Luciferase gebildet. Mittelwerte aus drei unabhängig voneinander durchgeführten Experimenten mit je drei Meßreihen wurden berechnet und aufgetragen (s. Abbildung 9). 


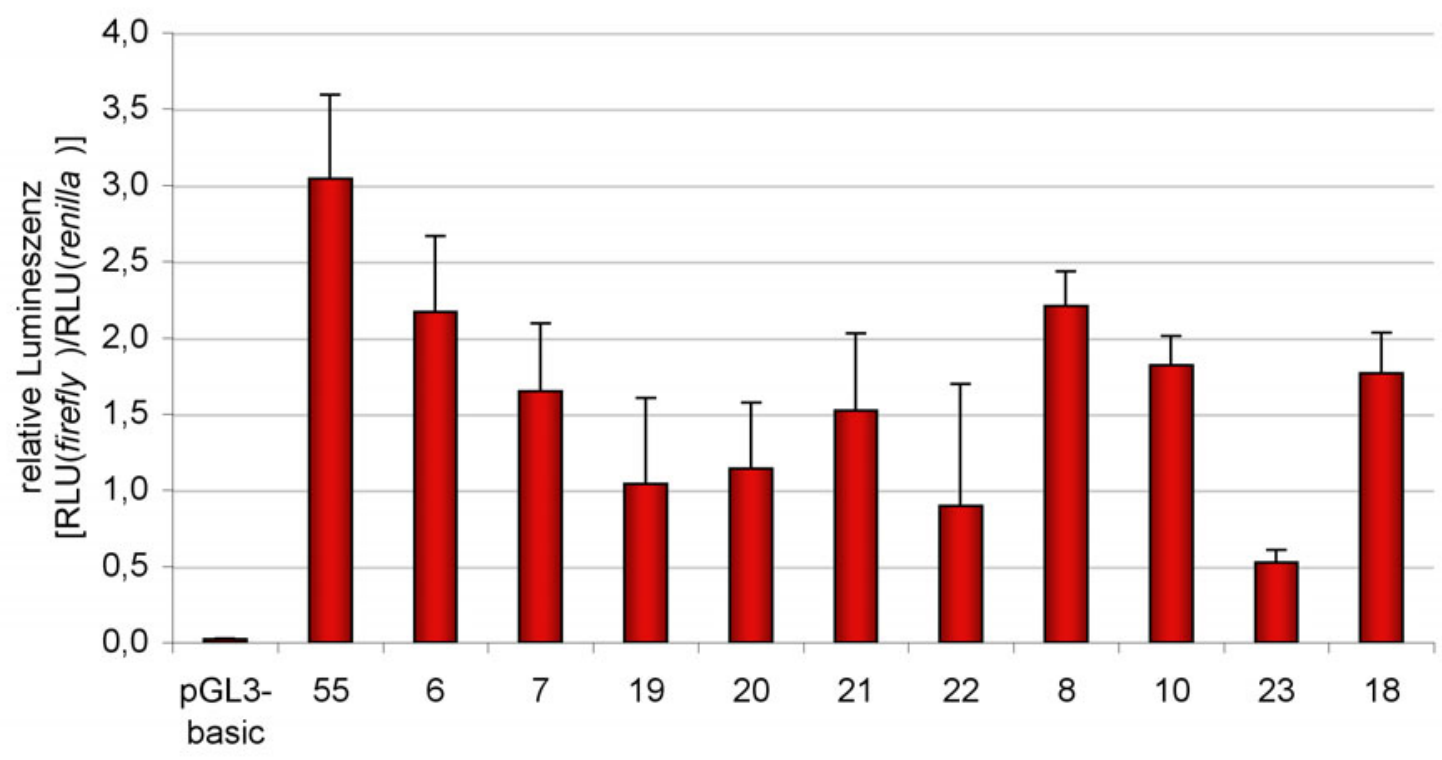

Konstrukte

\section{Abbildung 9: Auswertung der Luciferaseassays zur Aktivitätsbestimmung der H1X-Promotorkonstrukte}

Aufgetragen ist die dimensionslose relative Lumineszenz der Firefly-Luciferase im Verhältnis zur Lumineszenz der konstitutiv koexprimierten Renilla-Luciferase [RLU(firefly)/RLU(renilla)] für die einzelnen Konstrukte. Der Originalvektor pGL3-basic, der keinen Promotor enthält, fungiert als Negativkontrolle. Das längste Konstrukt (Konstrukt 55) weist die höchste Luciferaseenzymaktivität auf. Konstrukt 23, das nur die TATA-Box enthält, zeigt etwa $20 \%$ der Aktivität des Konstrukts 55. Die Standardabweichung von drei unabhängig voneinander durchgeführten Experimenten mit je drei Meßreihen ist angegeben.

Das Konstrukt 55, das 1,0 kb vor dem $H 1 x$-Transkriptionsstart beginnt, zeigte die höchste Luciferaseaktivität und damit auch die stärkste Expression von H1x. Die Konstrukte 7, 19, 20, 21 und 22, denen im Vergleich zu Konstrukt 55 das CH1UE fehlt, weisen eine geringere Aktivität auf als Konstrukt 55. Zwischen Konstrukt 55, das das conserved H1 gene upstream element und zusätzlich 591 Nukleotide oberhalb des CH1UE enthält, und Konstrukt 7 ist ein Aktivitätsunterschied von fast $50 \%$ zu beobachten. Das Konstrukt 6 weist trotz vorhandenem CH1UE nur 71 \% der Aktivität des Konstrukts 55 auf. Diese Daten lassen darauf schließen, daß das CH1UE für den $H 1 x$-Promotor ein wichtiges regulatorisches Element ist und daß die Sequenz oberhalb des CH1UE ebenfalls für die Expression von $H 1 x$ von Bedeutung ist.

Der Aktivitätsanstieg um etwa 20 \% von Konstrukt 7, das 227 bp länger als Konstrukt 8 ist und die putative „umgedrehte CCAAT-Box“ enthält, zu Konstrukt 8, das 55 bp vor der H1-Box beginnt, konnte auch durch die Deletionsmutanten 19-22 nicht geklärt 
werden. Die Messung der Konstrukte 19-22, die zwischen Konstrukt 7 und 8 lagen, brachte keinen Aufschluß über eventuell vorhandene repressive oder aktivierende Elemente zwischen der „umgedrehten CCAAT-Box“ und der H1-Box. Daraus kann geschlossen werden, daß die vorausgesagte „umgedrehte CCAAT-Box“, die zudem noch an anderer Stelle als die CCAAT-Boxen anderer H1-Subtypen liegt, kein funktionell aktives Promotorelement des $H 1 x$-Gens ist.

Zwischen Konstrukt 8 und 10 ist ein sehr geringer Aktivitätsunterschied von $13 \%$ in der Expression der Firefly-Luciferase erkennbar. Die H1-Box scheint in den vorliegenden Konstrukten keinen starken Einfluß auf die Promotoraktivität zu haben.

Das Konstrukt 23 enthält als einziges Promotorelement die TATA-Box und zeigte eine geringere Promotoraktivität als alle anderen Konstrukte. Im Vergleich zu Konstrukt 55 sank die Aktivität des Konstrukts 23 auf 17 \%. Im Vergleich zu Konstrukt 10, das sich von Konstrukt 23 allein durch das Vorhandensein des UPE H4 (upstream positive element) unterscheidet, sank die Aktivität auf $29 \%$. Dieser signifikante Unterschied von Konstrukt 23 zu Konstrukt 10 macht den Einfluß des UPE H4 für den H1x-Promotor deutlich.

Die Verkürzung der Sequenz zwischen Transkriptions- und Translationsstart (Konstrukt 18) führte $\mathrm{zu}$ einem Rückgang der Promotoraktivität auf $60 \%$ gemessen an der Aktivität des Konstrukts 55. Die zu anderen H1-Histonen vergleichsweise lange Sequenz des H1x-Promotors zwischen Transkriptions- und Translationsstart [381 bp gegenüber 43 bp im H1.2-Promotor (Eilers et al., 1994), 55 bp im H1.3-Promotor (Meergans et al., 1998) und 284 bp im $H 1^{\circ}$-Promotor (Bouterfa et al., 1993)] hat folglich einen gewissen Einfluß auf die Stärke des Promotors.

Um zu klären, ob das Konstrukt 55 ein geeigneter Promotor zur funktionellen Expression von $H 1 x$ in humanen Tumorzellen ist, wurde dieses Konstrukt zur Expression von H1x-GFP-Plasmiden in HeLa-Zellen verwendet. 


\subsubsection{Funktionalität des H1x-Promotors: Erstellung und Expression von H1x-GFP- Konstrukten}

Ausgehend von den Ergebnissen der Reportergenassays wurden H1x-GFP-Fusionskonstrukte erstellt, die entweder unter der Kontrolle eines konstitutiv exprimierenden CMV-Promotors oder unter der Kontrolle des Konstrukts 55, das im folgenden H1XPromotor genannt wird, standen. Die Funktionalität des $H 1 x$-Promotors wurde anhand der Expression des H1x-GFP-Fusionsproteins mittels Fluoreszenzmikroskopie überprüft.

Als Positivkontrollen für einen aktiven Promotor dienten das Plasmid pJW 9 (H1xGFP-Fusionsprotein unter CMV-Promotorkontrolle) (s. Abbildung 10) und der käuflich erworbene Vektor pEGFP-N1 (GFP unter CMV-Promotorkontrolle) (s. Kapitel 3.1.3.10). Zur Erstellung des Plasmids pJW 9 wurden Schnittstellen für Hind III und Bam HI an die kodierende Sequenz von H1x durch Amplifikation mit den Primern oNH53 und oNH54 (s. Tabelle 23) angefügt. Als Vorlage wurde das Plasmid IM28 in pOTB7 (H1x cDNA im Vektor pOTB7) (Happel et al., 2005) verwendet. Das PCRProdukt wurde durch Ligation in den Vektor pGEM-T Easy (Promega, Madison, USA) eingefügt, transformiert und mittels Miniprep aufgereinigt (s. Kapitel 3.1.2.2, 3.1.3.3, 3.1.3.4). Aus dem entstandenen Übergangskonstrukt wurde die cDNA mit den Restriktionsenzymen Hind III und Bam HI herausgeschnitten und mit dem zuvor ebenfalls mit Hind III und Bam HI linearisierten Vektor pEGFP-N1 zusammengefügt. Ein Ausschnitt der Vektorsequenz mit dem einklonierten $H 1 x$-Genabschnitt ist im Anhang (s. Kapitel 7.2.7) zu finden. 


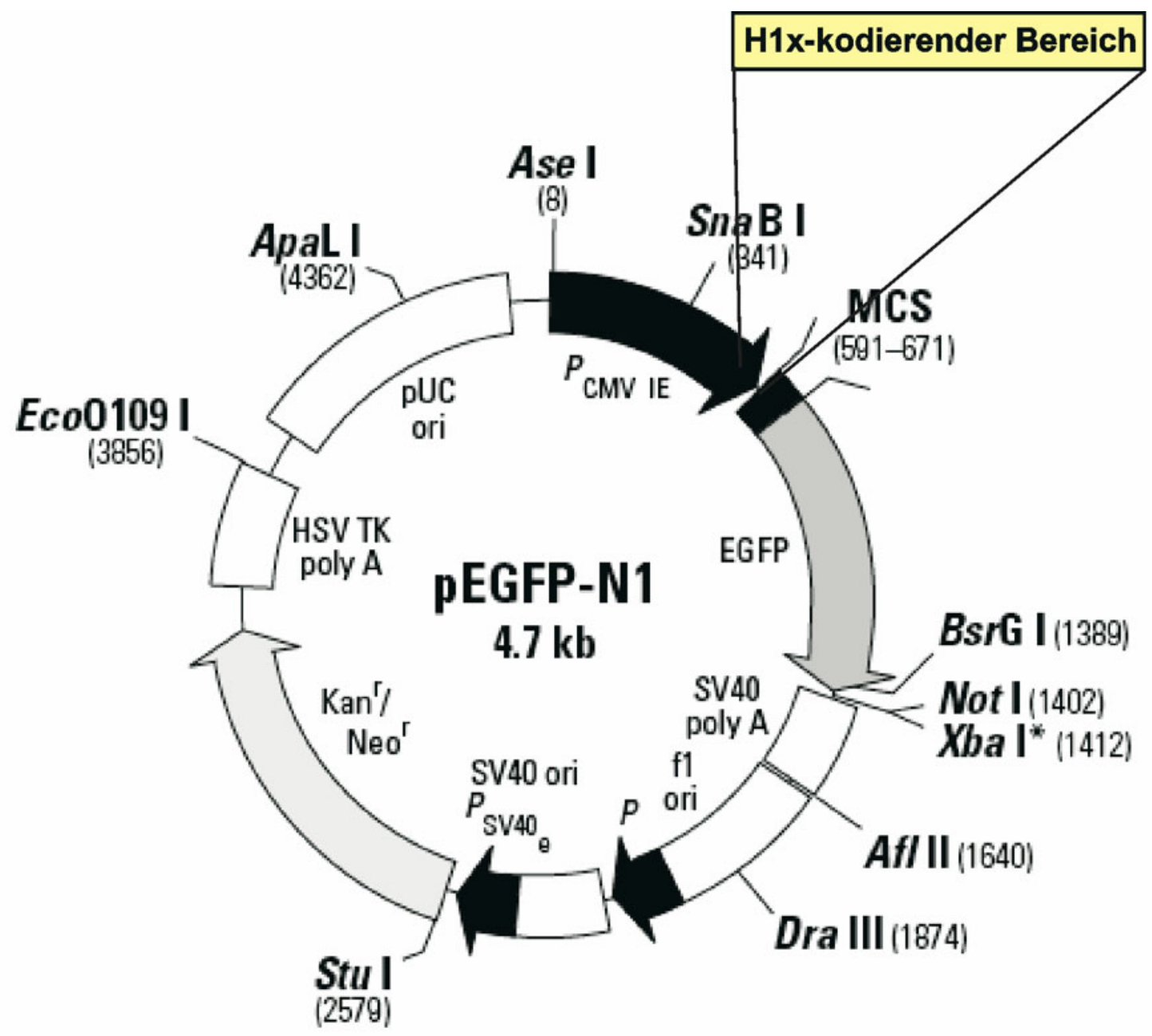

Abbildung 10: Darstellung des GFP-Plasmids pJW 9 mit CMV-Promotor ${ }^{6}$

In die Klonierungsstelle (MCS, multiple cloning site) des Vektors pEGFP-N1 wurde durch Restriktionsverdau mit Hind III und Bam HI und anschließende Ligation die kodierende Sequenz von $H 1 x$ eingesetzt. Der eingefügte $H 1 x$-Genabschnitt hat den gleichen Leserahmen wie das GFP-Gen, so daß ein H1x-GFP-Fusionskonstrukt mit GFP am C-Terminus des H1x entstand. Das SV40 Polyadenylierungssignal (SV40 poly A) unterhalb des GFP-Gens ist für die korrekte Prozessierung des 3'-Endes der GFP-mRNA zuständig. Das Plasmid wurde pJW 9 genannt und steht unter der Kontrolle eines CMV-Promotors ( $\mathrm{P}_{\mathrm{CMV}}$ IE). Der Vektor enthält außerdem einen SV40 Replikationsursprung (SV40 ori) zur Expression des SV40 T Antigens in Säugerzellen. Die Neomycinresistenzkassette, die aus dem SV40-Pomotor $\left(\mathrm{P}_{\mathrm{Sv} 40}\right)$, dem Neomycin- / Kanamycin-Resistenzgen $\left(\mathrm{Kan}^{\mathrm{r}} / \mathrm{Neo}^{\mathrm{r}}\right.$ ) und dem Polyadenylierungssignal aus der Thymidinkinase des Herpes simplex Virus (HSV TK poly A) besteht, ermöglicht die Selektion stabil transfizierter eukaryotischer Zellen mit G418. Ein bakterieller Promotor (P) oberhalb

\footnotetext{
${ }^{6}$ Der hier gezeigte Vektor sowie der Vektor in Abbildung 11 wurde aus den Handbüchern der GFPVektoren pEGFP-1 und pEGFP-N1 (DB Biosciences Clontech, Mountain View, CA, USA) entnommen und erweitert.
} 
dieser Kassette exprimiert das Kanamycinresistenzgen in E. coli. Der pUC-Replikationsursprung (pUC ori) ist für die Verbreitung in E. coli zuständig, der f1-Ursprung (f1 ori) für die DNA-Einzelstrangproduktion.

Als Negativkontrollen ohne Promotorsequenz wurden das Plasmid pJW 33 und der Vektor pEGFP-1 verwendet. Der Vektor pEGFP-1 weist keinen Promotor auf und kann deshalb GFP nicht exprimieren. Das Plasmid pJW 33 besteht aus der kodierenden Sequenz von $H 1 x$ im Vektor pEGFP-1. Dieses Plasmid hat - wie der ursprüngliche Vektor pEGFP-1 - keinen Promotor, so daß das Fusionsprotein H1x-GFP nicht synthetisiert wird. pJW 33 wurde aus pJW 9 und dem Vektor pEGFP-1 durch Linearisierung mit Bam HI und Hind III und Ligation von geschnittenem Vektor pEGFP-1 und Insert (H1x-Sequenz aus pJW 9) erstellt.

Das Konstrukt 55 wurde samt kodierender Sequenz für H1x in den GFP-Vektor pEGFP-1 kloniert, um die Funktionalität des $H 1 x$-Promotors anhand der Expression des H1x-GFP-Fusionsproteins mittels Fluoreszenzmikroskopie zu überprüfen. Es entstand das H1x-GFP-Fusionsplasmid pJW 34 unter der Kontrolle des H1x-Promotors (s. Abbildung 11).

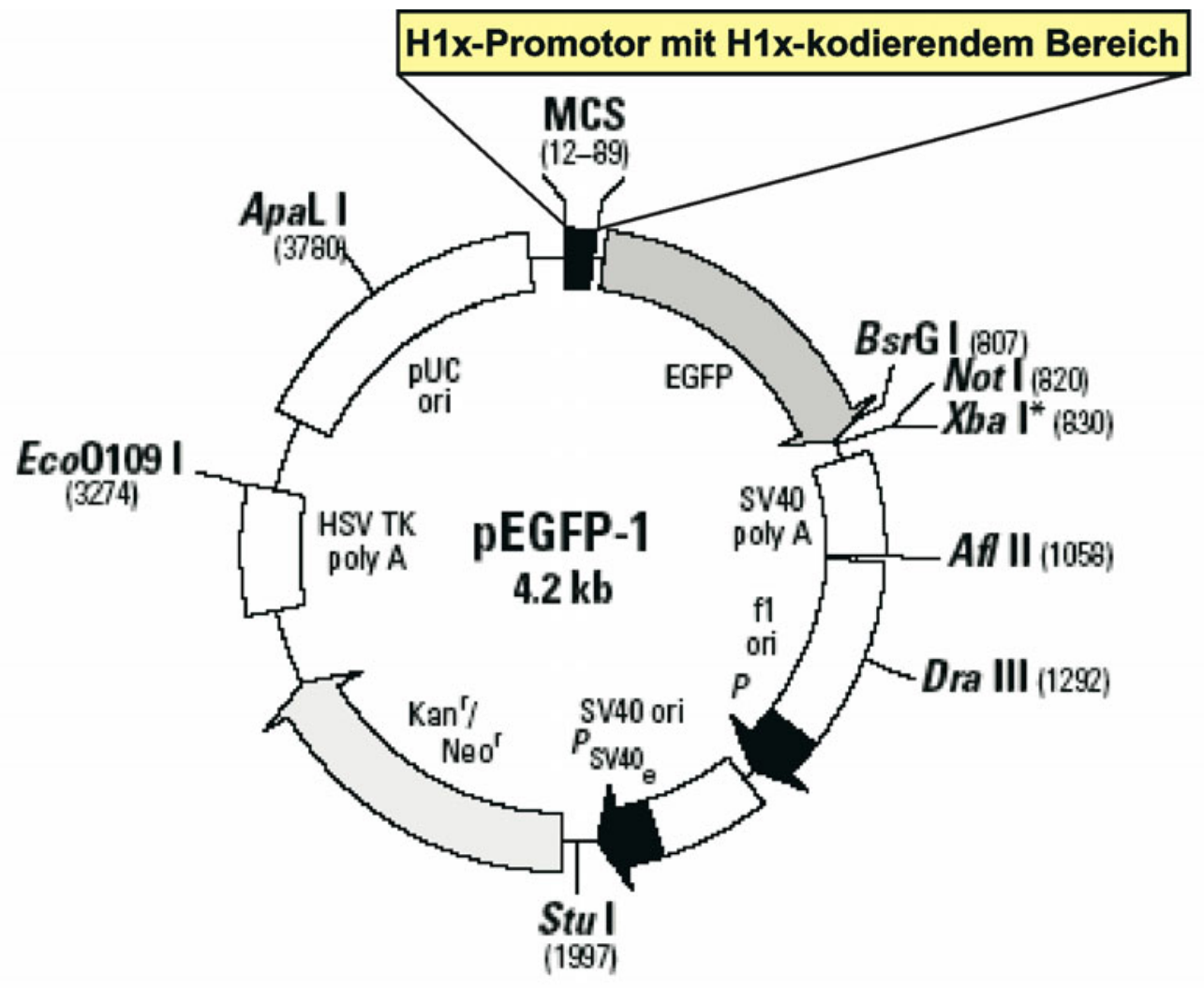

Abbildung 11: Darstellung des GFP-Plasmids pJW 34 mit H1x-Promotor 
In die Klonierungsstelle (MCS, multiple cloning site) des Vektors pEGFP-1 wurde durch Linearisierung des Vektors mit Bgl II und Bam HI und anschließende Ligation das H1xPromotorkonstrukt 55 und die kodierende Sequenz von $H 1 x$ eingefügt. Der eingesetzte $H 1 x$ Genabschnitt hat den gleichen Leserahmen wie das GFP-Gen, so daß ein H1x-GFPFusionskonstrukt mit GFP am C-Terminus des H1x entstand. Das Plasmid wurde pJW 34 genannt und stand unter der Kontrolle des $H 1 x$-Promotors. Das SV40 Polyadenylierungssignal (SV40 poly A) unterhalb des GFP-Gens ist für die korrekte Prozessierung des 3'-Endes der GFP-mRNA zuständig. Der Vektor enthält den SV40 Replikationsursprung (SV40 ori) zur Expression des SV40 T Antigens in Säugerzellen. Die Neomycinresistenzkassette, die aus dem SV40-Pomotor $\left(\mathrm{P}_{\mathrm{SV} 40}\right)$, dem Neomycin- / Kanamycin-Resistenzgen $\left(\mathrm{Kan}^{\mathrm{r}} / \mathrm{Neo}^{\mathrm{r}}\right)$ und dem Polyadenylierungssignal aus der Thymidinkinase des Herpes simplex Virus (HSV TK poly A) besteht, ermöglicht die Selektion stabil transfizierter eukaryotischer Zellen mit G418. Ein bakterieller Promotor (P) oberhalb dieser Kassette exprimiert das Kanamycinresistenzgen in E. coli. Der pUC-Replikationsursprung (pUC ori) ist für die Verbreitung in E. coli zuständig, der f1-Ursprung (f1 ori) für die DNA-Einzelstrangproduktion.

Zur Fertigung des Plasmids pJW 34 wurde zunächst der Vektor pEGFP-1 mit Bgl II und Bam HI linearisiert und mit alkalischer Phosphatase behandelt. Der H1x-Promotor wurde aus dem pGL3-basic-Plasmid, das das Konstrukt 55 enthält, mit den Restriktionsendonukleasen Bgl II und Nco I herausgeschnitten. Die kodierende Sequenz für H1x wurde mittels PCR mit den Schnittstellen Nco I und Bam HI versehen (s. Kapitel 3.1.3.10) Das $H 1 x$-Fragment $(0,65 \mathrm{~kb})$, der linearisierte Vektor pEGFP-1 (4,2 kb) und der $H 1 x$-Promotor (1,5 kb) wurden in einem Ligationsansatz miteinander verbunden. Zur Kontrolle der Ligationserfolgs wurden die Klone mit dem Restriktionsenzym Eco47 III geschnitten. Eco47 III schneidet die Plasmide, die das Insert (Promotor und H1x) enthalten, zweimal, so daß ein Fragment von etwa $2 \mathrm{~kb}$ entsteht. Die Klone 3 und 20 enthalten das Insert (s. Abbildung 12). Die Klone 1 und 19 enthalten zwar ebenfalls ein 2 kb großes Insert, wurden aber aufgrund der in Abbildung 12 erkennbaren Doppelbande ausgeschlossen. 


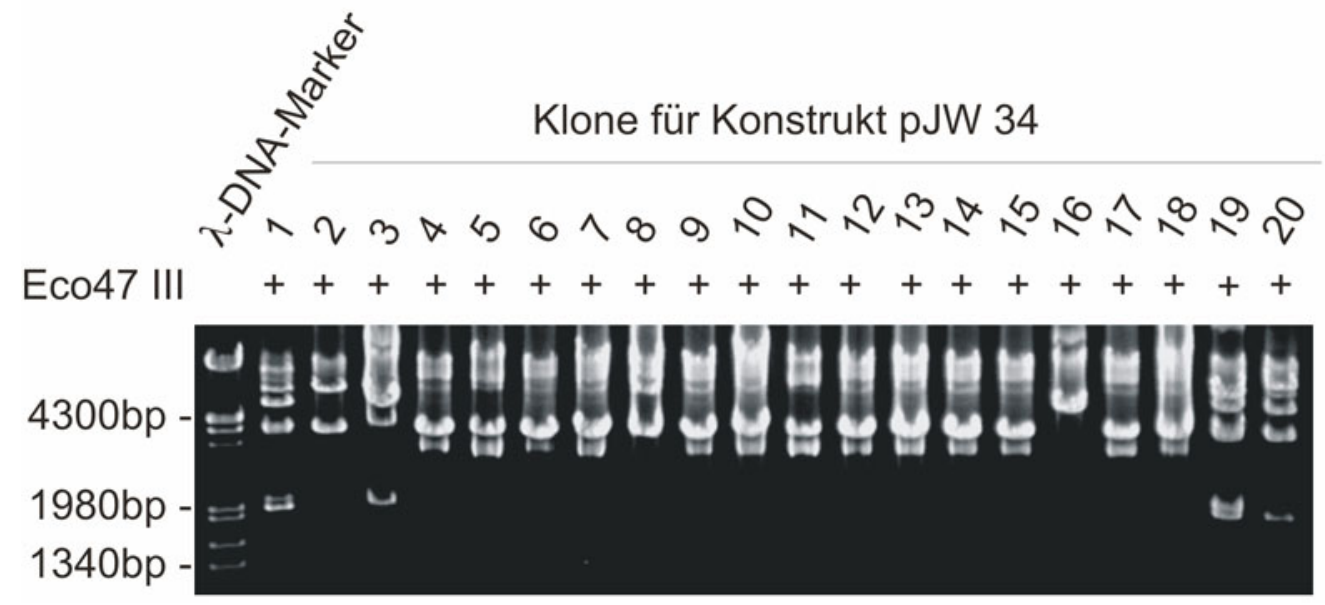

\section{Abbildung 12: Restriktionsanalyse der Klone für das Plasmid pJW 34}

Zur Kontrolle der Ligationserfolgs wurden 20 Klone, die das Insert aus H1x-Promotor und $H 1 x$ Gen im Vektor pEGFP-1 enthalten sollten, mit dem Restriktionsenzym Eco47 III geschnitten. Die Klone sind von 1 bis 20 benannt. Als Marker-DNA wurde eine mit Eco RI und Hind III verdaute $\lambda$-DNA verwendet. Bei Klonen, die das Insert trugen, wurde durch Restriktionsanalyse mit Eco47 III ein etwa 2 kb langes DNA-Fragment aus dem Vektor geschnitten. Dies ist der Fall bei den Klonen 3 und 20. Die Klone 1 und 19 wurden aufgrund der deutlich erkennbaren Doppelbande im Bereich um $2 \mathrm{~kb}$ als mögliche positive Klone ausgeschlossen.

Die Konstrukte 3 und 20 wurden durch Sequenzierung überprüft. Als Plasmid pJW 34 wurde nach der Sequenzierung der Klon 3 verwendet.

Die erstellten Plasmide pJW 9, pJW 33, pJW 34 sowie die Vektoren pEGFP-N1 und pEGFP-1 wurden in HeLa-Zellen transient exprimiert und die Zellen mit dem Fluoreszenzmikroskop analysiert. Die Negativkontrollen pJW 33 und pEGFP-1 zeigten keine Fluoreszenz in den Zellen (Abbildung nicht gezeigt). Die mit pEGFP-N1 transfizierten Zellen wiesen GFP sowohl im Zytoplasma als auch im Kern auf. Die HeLa-Zellen, die mit pJW 9 und pJW 34 transfiziert worden waren, zeigten ausschließlich im Kern Fluoreszenz. In einem Teil der Zellen war H1x-GFP in den Nukleoli angereichert. Da GFP nach der Transfektion mit pJW 34 in den transfizierten Zellen synthetisiert wurde, ist die Funktionalität des erstellten $H 1 x$-Promotors bewiesen. 


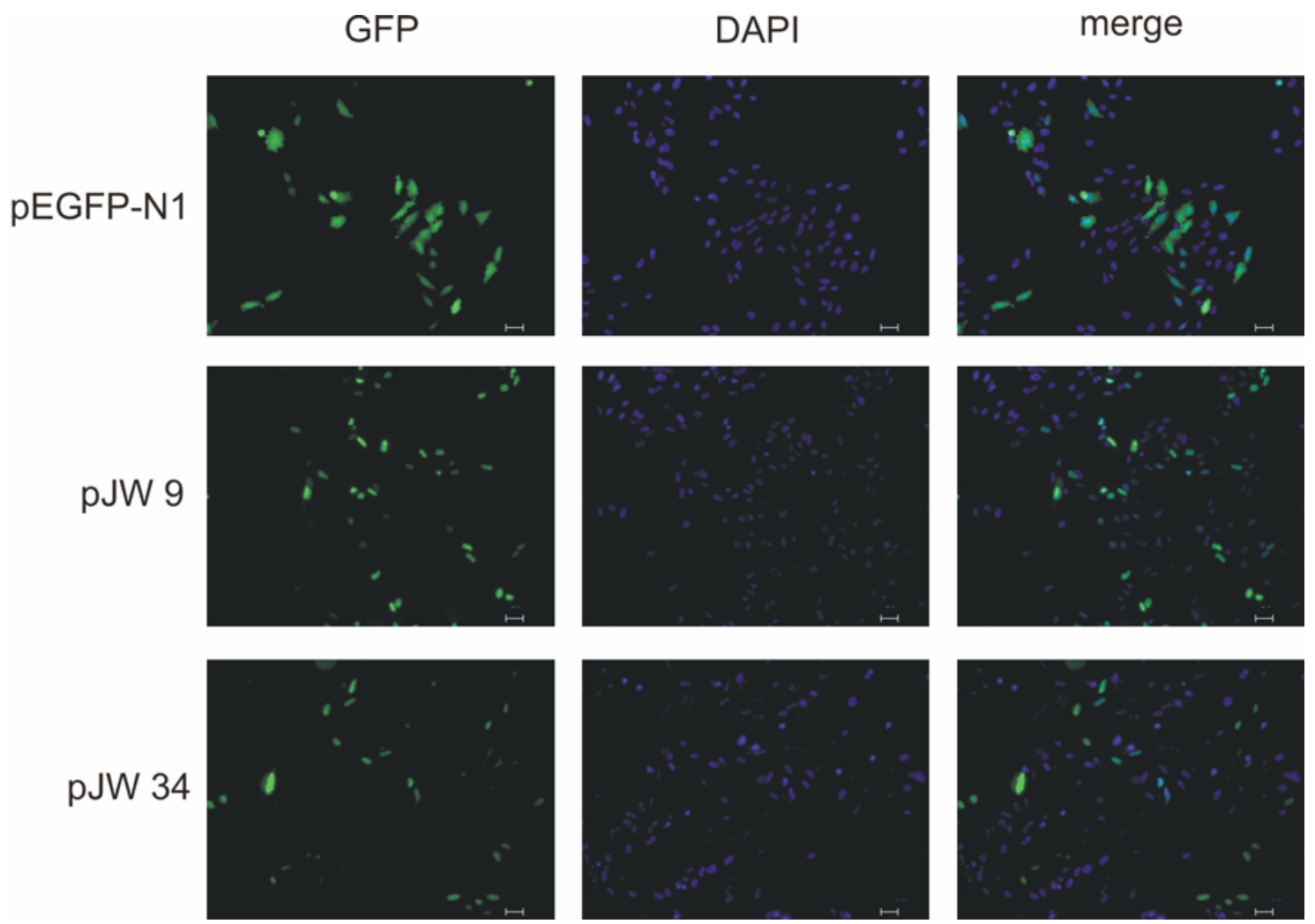

Abbildung 13: 20-30 \% Transfektionseffizienz der GFP-Konstrukte in HeLa-

\section{Zellen}

HeLa-Zellen wurden mit den GFP-Plasmiden pEGFP-N1, pJW 9 und pJW 34 transient transfiziert. Der Vektor pJW 9 enthält ein H1x-GFP-Fusionsgen, dessen Expression durch einen CMV-Promotor kontrolliert wird. Das Plasmid pJW 34 enthält den H1x-Promotor und die kodierende Sequenz von $H 1 x$ in dem GFP-Vektor pEGFP-1. Die transfizierten Zellen erscheinen durch die Synthese von GFP bei einer Anregung mit einer Wellenlänge von $488 \mathrm{~nm}$ grün. Die Kerne sind mit dem Farbstoff DAPI angefärbt und erscheinen blau. Die rechte Spalte („merge“) zeigt die Überlagerung der mit DAPI angefärbten Kerne und den transfizierten HeLaZellen. Die Konstrukte pEGFP-N1 und pJW 9 zeigen eine Transfektionseffizienz von etwa $30 \%$, das Konstrukt pJW 34 eine Effizienz von etwa $20 \%$. Der in den Bildern angezeigte Größenbalken entspricht $50 \mu \mathrm{m}$. 

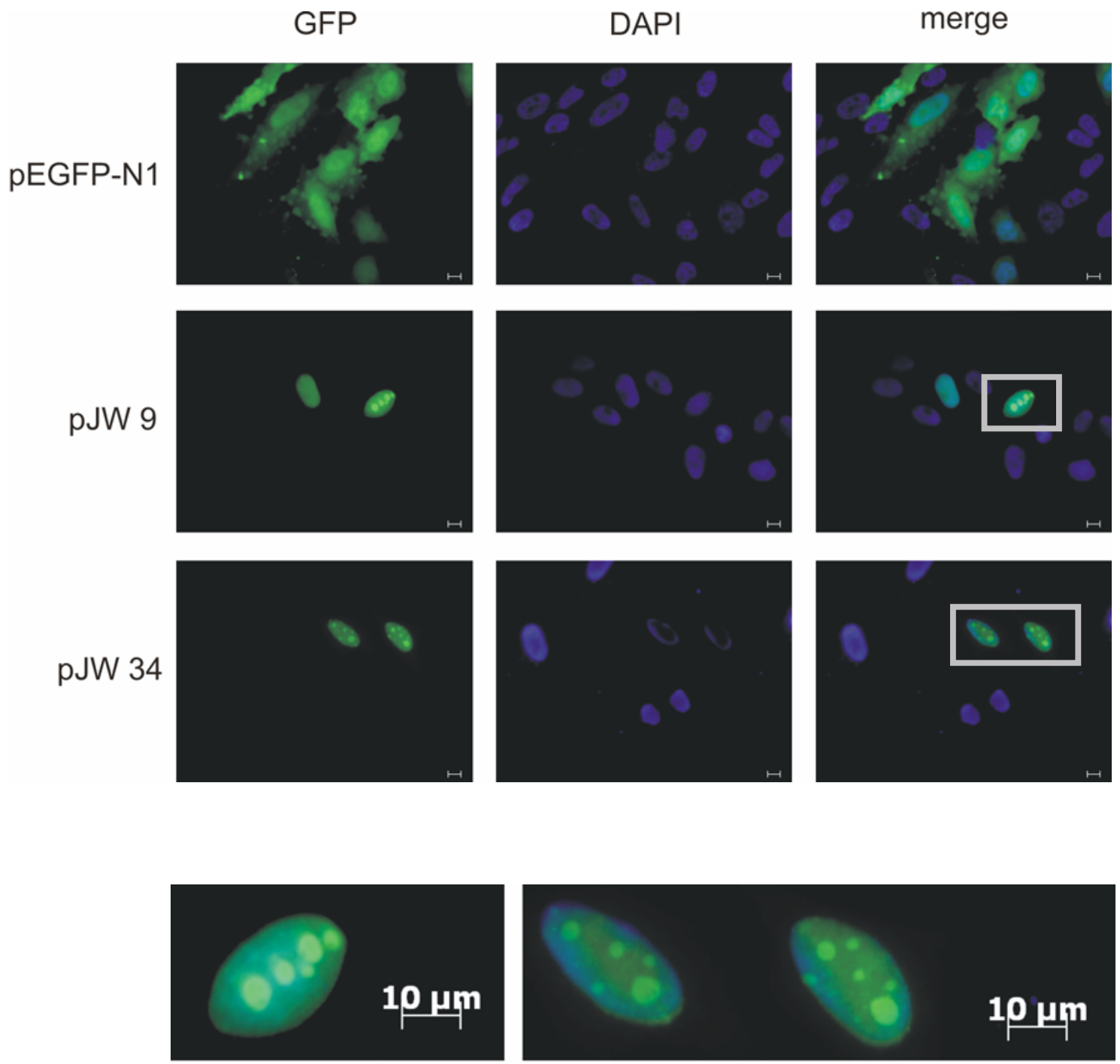

pJW 9

pJW 34

\section{Abbildung 14: Mit GFP-Konstrukten transfizierte HeLa-Zellen}

HeLa-Zellen wurden mit den GFP-Plasmiden pEGFP-N1, pJW 9 und pJW 34 transient transfiziert. Der Vektor pJW 9 enthält ein H1x-GFP-Fusionsgen, dessen Expression durch einen CMV-Promotor kontrolliert wird. Das Plasmid pJW 34 besteht aus dem H1x-Promotor und der kodierenden Sequenz von $H 1 x$ in dem GFP-Vektor pEGFP-1. Die transfizierten Zellen erscheinen bei einer Anregungswellenlänge von $488 \mathrm{~nm}$ grün. Die Kerne sind mit dem Farbstoff DAPI angefärbt und erscheinen blau. Die rechte Spalte (,merge“) zeigt die Überlagerung der mit DAPI angefärbten Kerne und der transfizierten HeLa-Zellen. Mit pEGFP-N1 transfizierte Zellen weisen GFP sowohl im Zytoplasma als auch im Kern auf. Die mit pJW 9 und pJW 34 transfizierten HeLa-Zellen zeigen ausschließlich im Kern Fluoreszenz. In einem Teil der Zellen war GFP in den Nukleoli angereichert (Ausschnittsvergrößerung in der unteren Zeile). Der in den Bildern angezeigte Größenbalken entspricht $10 \mu \mathrm{m}$. 
Die Überexpression von $H 1 x$ in HeLa-Zellen zeigte, daß $H 1 x$ durch den gewählten Promotor (Konstrukt 55) exprimiert wird und das H1x-Protein zum Teil in den Nukleoli angereichert ist. Die Morphologie der transfizierten Zellen veränderte sich nicht durch die durch Transfektion hervorgerufene Synthese von H1x. Zwischen den Konstrukten pJW 9 und pJW 34 konnte kein Unterschied bezüglich der Lokalisation von H1x-GFP in den Zellen festgestellt werden.

\subsection{Vergleichende Expressionsanalyse von H1-Subtypen im Verlauf des Zellzyklus mittels quantitativer real-time RT-PCR}

Die replikationsabhängigen Subtypen H1.1-H1.5 werden in Abhängigkeit der DNA Replikation, d. h. in der S-Phase synthetisiert (Heintz et al., 1983; Plumb et al., 1983; Osley, 1991), während das Gen des replikationsunabhängigen Subtyps $\mathrm{H} 1^{\circ}$ vermehrt in nicht-proliferierenden und in terminal differenzierten Zellen exprimiert wird (Zlatanova, 1980; Khochbin \& Wolffe, 1994; Zlatanova \& Doenecke, 1994; Doenecke et al., 1994). Smith beschreibt $\mathrm{H} 1^{\circ}$ als Replacementhiston, da $\mathrm{H} 1^{\circ}$ - wie $\mathrm{H} 5$ in Vogelerythrozyten anscheinend andere H1-Histone ersetzen kann (Smith et al., 1984). Da der Histonsubtyp $H 1 x$ einige gemeinsame Merkmale mit dem Replacementhiston $H 1^{\circ}$ teilt, wie zum Beispiel die solitäre chromosomale Lokalisation (Sulimova et al., 2002) und eine polyadenylierte mRNA (Yamamoto \& Horikoshi, 1996), stellte sich die Frage, ob die Expression von $H 1 x$ ähnlich reguliert wird wie die des Replacement-Histons $H 1^{\circ}$. Daraufhin wurde in der vorliegenden Arbeit die Expression von H1x-mRNA im Vergleich zu somatischen H1-Histonsubtypen und dem Replacementhiston $\mathrm{H}^{\circ}{ }^{\circ}$ mittels quantitativer RT-PCR in synchronisierten Zellen im Verlauf des Zellzyklus untersucht.

Für die quantitative RT-PCR wurden H1-Subtyp-spezifische Primer entworfen (s. Kapitel 3.1.6.5) und an einer cDNA-Verdünnungsreihe, wie in Kapitel 3.1.6.8 beschrieben, getestet, um sicherzustellen, daß sie sich mit ähnlichen Effizienzen an die cDNA anlagerten. Die ermittelten Effizienzen waren für alle Primerpaare nahezu identisch und lagen im Bereich von 90-100\%. Die einzige Ausnahme bildete das Primerpaar für H1.3 mit 84 \%. Die Effizienz für die H1x-Primer lag bei 93 \%. Da die Werte aller Primer bei nahezu 100 \% lagen, waren die notwendigen Voraussetzungen daß die Effizienzen von Ziel- und Referenzgenen in etwa gleich sind $\left(E_{x}=E_{q}\right)$ - für die 
Berechnung der relativen Expressionen mit der $2^{-\Delta \Delta C_{T}}$-Methode (Livak \& Schmittgen, 2001) (s. Kapitel 3.1.6.9) erfüllt. Die Regressionskoeffizienten überschritten für alle gemessenen Gene den Wert 0,96. Der Regressionskoeffizient $r^{2}$ gibt an, wie gut sich die gemessenen Daten mit den Werten der Geradengleichung decken $\left(r_{\max }^{2}=1\right)$.

Die genspezifische Amplifikation konnte mittels Schmelzkurvenanalyse überprüft und bestätigt werden. Hierbei wird die Änderung der Fluoreszenzintensität pro Zeitintervall gegen die Temperatur (-dRFU/dT vs. Temperatur) aufgetragen. Alle Amplifikate mit subtypspezifischen Primerpaaren präsentierten sich in der Schmelzkurvenanalyse als Einzelmaximum (s. Abbildung 15 und Kapitel 7.2.2). Zusätzlich konnte bei spezifischer Amplifikation eine DNA-Einzelbande der vorausgesagten Länge mittels Agarosegelelektrophorese nachgewiesen werden. Negativkontrollen, die Wasser statt cDNA enthielten, ergaben genau wie Kontrollen auf genomische Verunreinigung (s. Kapitel 3.1.6.4) keine PCR-Produkte. Daraus ließ sich schließen, daß weder Primerdimerisierung noch unspezifische Amplifikation stattgefunden hatten.

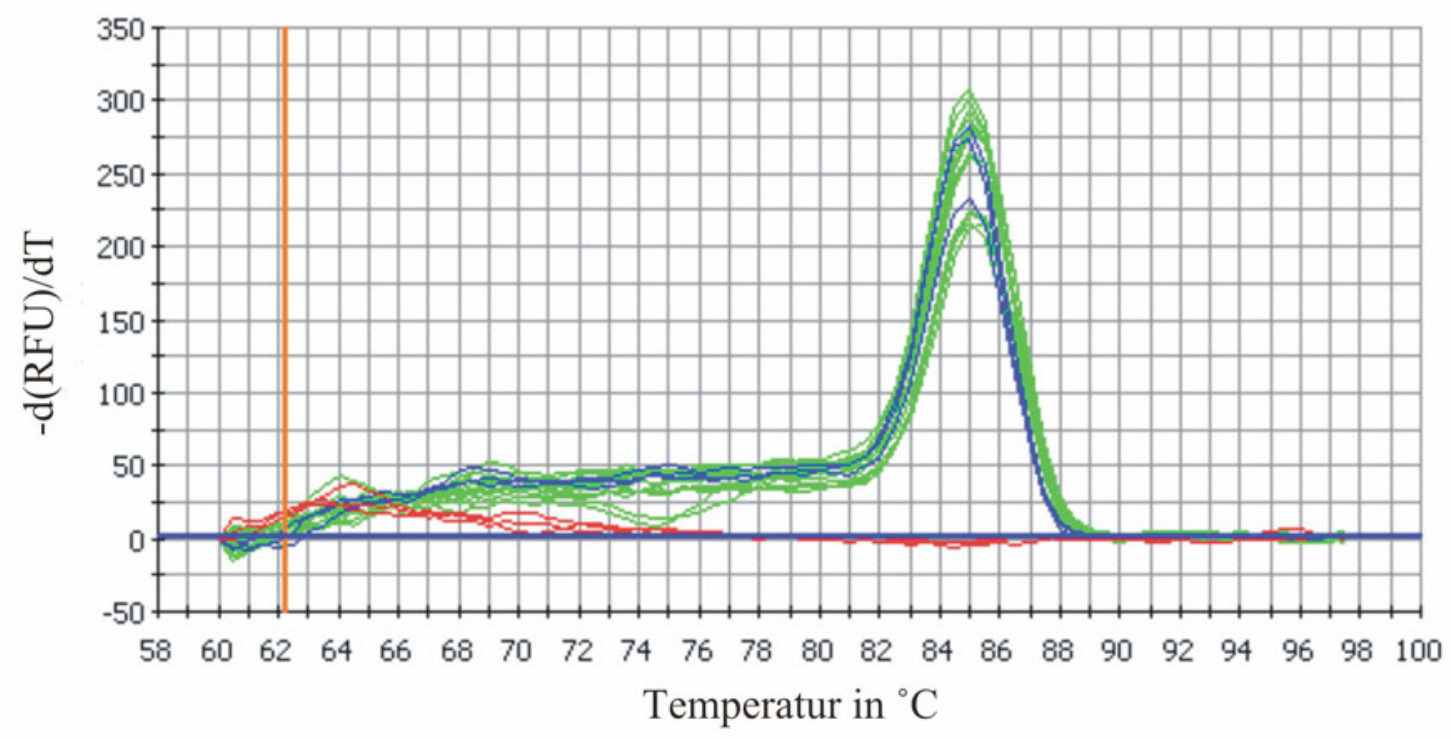

\section{Abbildung 15: exemplarische Schmelzkurvenanalyse für H1x-Primer}

Schmelzkurven von 15 cDNA-Proben von mRNA aus humanem Lungengewebe, die mit $H 1 x$ spezifischen Primern amplifiziert wurden; grün und blau: cDNA-Proben, rot: Negativkontrollen (keine Amplifikation). Die PCR-Produkte zeigen ein einzelnes Maximum bei $85^{\circ} \mathrm{C}$, d.h., die Produkte sind spezifisch und rein (keine Primerdimere oder andere unspezifische Amplifikationen enthalten).

Die Ergebnisse der RT-PCR wurden nach der $2^{-\Delta \Delta C_{T}}$-Methode (Livak \& Schmittgen, 2001) ausgewertet. 18S-rRNA diente als Referenz-RNA, mit deren Hilfe mögliche 
Unterschiede in der Transkriptionseffizienz der reversen Transkriptase in den verschiedenen Geweben ausgeglichen werden konnten. Als Kalibrator wurde für die Zellzyklusanalysen der $\mathrm{C}_{\mathrm{T}}$-Wert der unsynchronisierten Zellen („Kontrolle“) verwendet.

Vor der Bestimmung des relativen mRNA-Gehalts der einzelnen Subtypen mittels RTPCR wurden die untersuchten, synchronisierten HeLa-Zellen (s. Kapitel 3.3.1.8) im Durchflußzytometer gemessen, um zu verifizieren, daß sich die Zellen in den beschriebenen Zellzyklusphasen befanden.

Eine Behandlung der Zellen mit Aphidicolin hemmt DNA-Polymerasen und hat somit einen Arrest am G1/S-Übergang zur Folge (Ikegami et al., 1978; Perrino \& Loeb, 1990). 2 h nach der Entlassung aus dem Arrest waren alle Zellen in der frühen S-Phase akkumuliert, nach $4 \mathrm{~h}$ und $6 \mathrm{~h}$ in der mittleren S-Phase. $8 \mathrm{~h}$ nach Entlassung aus dem Zellzyklusblock lagen die Zellen in der späten S-Phase vor. Die letzte Probe wurde nach $10 \mathrm{~h}$ entnommen und enthielt Zellen, die sich am Übergang von der G2- zur M-Phase befanden. Die Behandlung der Zellen mit Natriumbutyrat führte zu einem Zellzyklusarrest in der G1-Phase (s. Abbildung 16).

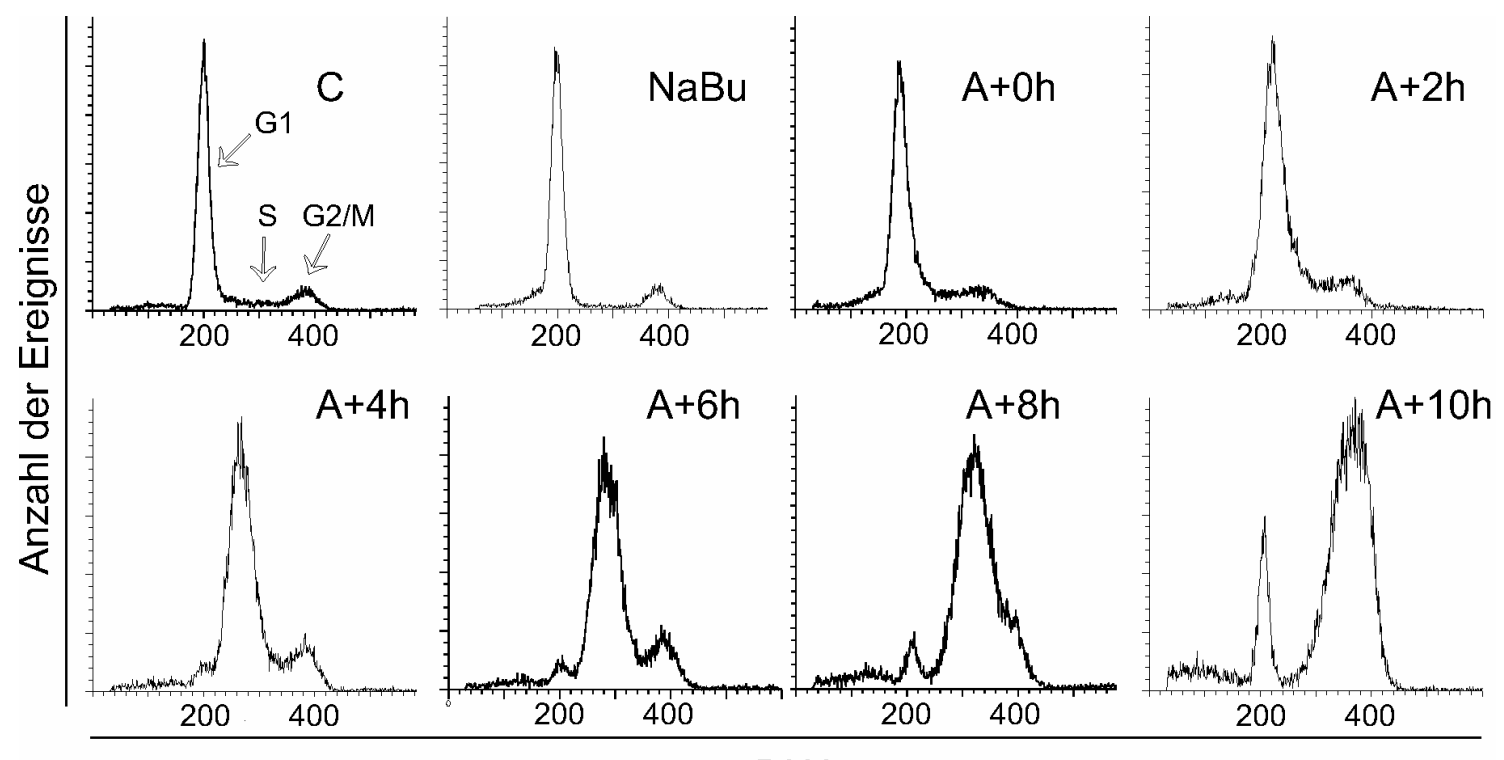

DNA

Abbildung 16: DNA-Gehalt in synchronisierten HeLa-Zellen - Verifizierung der Zellzyklusphasen

Um zu verifizieren, daß sich die Zellen in den für die Analyse vorgesehenen Zellzyklusphasen befanden, wurde der DNA-Gehalt synchronisierter HeLa-Zellen mittels Durchflußzytometrie gemessen. Die Zellen wurden mit Natriumbutyrat $(\mathrm{NaBu})$ oder mit Aphidicolin $(\mathrm{A})$ behandelt, 
um einen Zellzykusarrest in G1 oder am Übergang von G1 zur S-Phase zu induzieren. Bei den mit C gekennzeichneten Zellen handelt es sich um unsynchronisierte Kontrollzellen. Die Angabe von $0-10 \mathrm{~h}$ beschreibt, nach welcher Zeit die Zellen nach der Entlassung aus dem Aphidicolinblock geerntet und untersucht wurden.

Zur Klärung der Frage, ob das $H 1 x$-Gen replikationsabhängig oder -unabhängig exprimiert wird, wurde die relative Expression von $\mathrm{H} 1 \mathrm{x}, \mathrm{H} 1^{\circ}$ und replikationsabhängigen H1-Subtypen mittels RT-PCR in den synchronisierten Zellen ermittelt (s. Kapitel 3.1.6). Mittelwerte aus drei unabhängig voneinander durchgeführten Experimenten mit je drei Meßreihen wurden für jeden Subtyp berechnet und aufgetragen (s. Abbildung 17). Die Standardabweichung für die Meßwerte ergibt sich aus den neun Einzelmessungen pro Subtyp. 


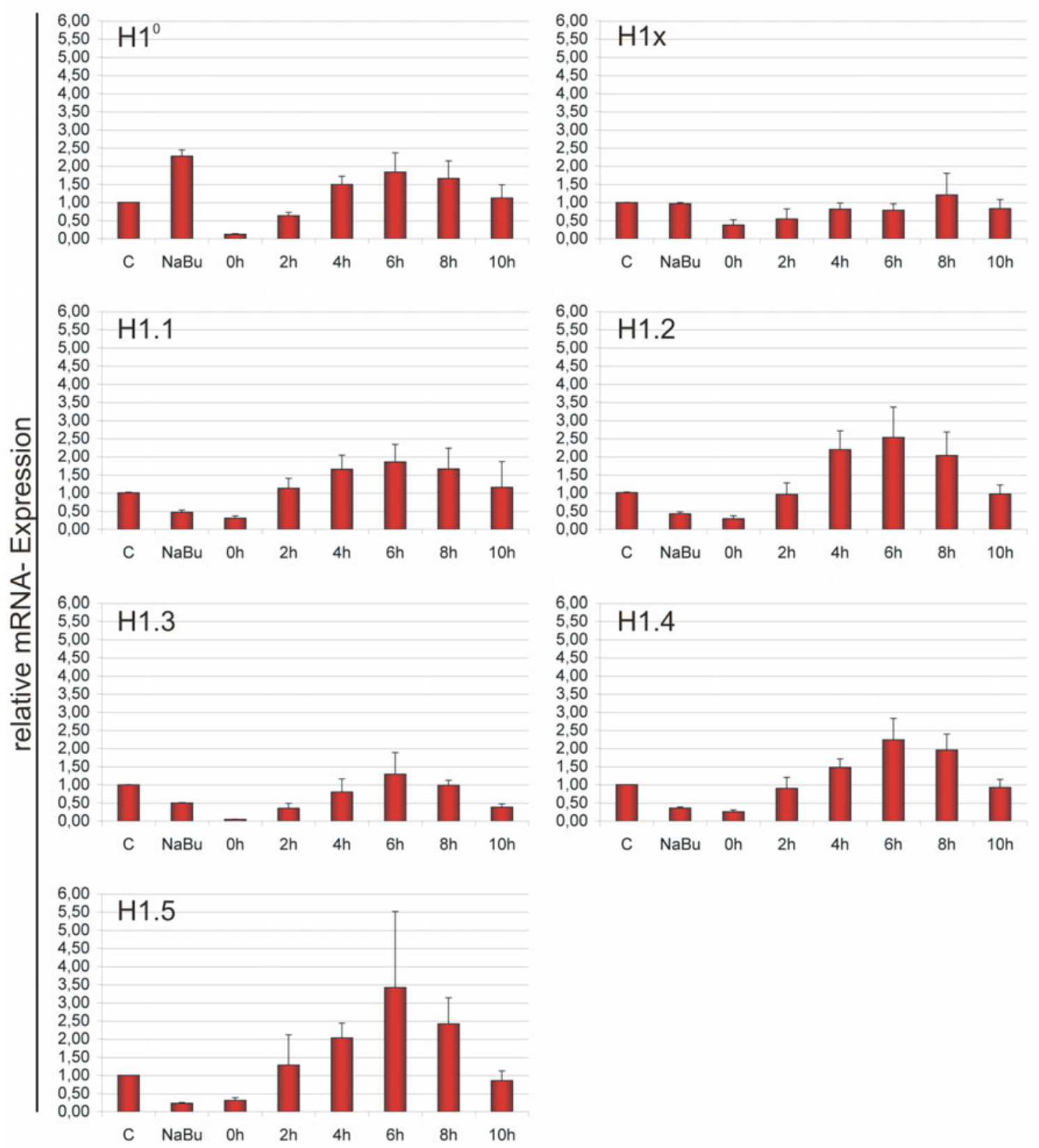

Abbildung 17: Expression der $H 1$-Subtypen $H 1^{\circ}, H 1 x, H 1.1-H 1.5$ im Verlauf des Zellzyklus

Aufgetragen ist die relative mRNA-Expression der untersuchten H1-Subtypen in synchronisierten HeLa-Zellen verschiedener Zellzyklusphasen. 18S-rRNA diente als Referenz, unsynchronisierte Zellen wurden als Kalibrator bei der Berechnung nach der $2^{-\Delta \Delta C_{T}}$-Methode (Livak \& Schmittgen, 2001) eingesetzt. C: unsynchronisierte HeLa-Zellen; NaBu: mit $5 \mathrm{mM}$ Natriumbutyrat in der G1-Phase akkumulierte HeLa-Zellen; 0h: HeLa-Zellen am G1/SÜbergang direkt nach der Entlassung aus einem Arrest mit $10 \mu \mathrm{M}$ Aphidicolin (Ikegami et al., 1978; Perrino \& Loeb, 1990); 2h: 2h nach der Entlassung aus dem Aphidicolinblock, frühe SPhase; 4h und 6h: mittlere S-Phase; 8h: späte S-Phase; 10h: Übergang von der G2- zur MPhase. Die Standardabweichungen wurden aus drei unabhängigen Experimenten mit je drei Meßreihen ermittelt. 
In den Graphen sind die Werte für die Kontrollproben (C) gleich 1,00 gesetzt. Dadurch ist ein relativer Vergleich innerhalb eines Graphen möglich jedoch nicht ein Vergleich als Absolutwerte zwischen den einzelnen Graphen.

Der Arrest der Zellen in der G1-Phase durch Natriumbutyrat führte zu einer um mindestens den Faktor 2 verringerten Expression der replikationsabhängigen Histone im Vergleich zu den unsynchronisierten Zellen (Kontrolle) (s. Abbildung 17, H1.1 H1.5). Dabei zeigte H1.5 die stärkste Abnahme der mRNA-Menge auf etwa ein Fünftel der RNA-Menge in Kontrollzellen (s. Abbildung 17, H1.5). Bei $H 1^{\circ}$ war nach Zellzyklusarrest durch Natriumbutyrat ein deutlicher Anstieg der Transkripte auf das 2,3-fache der Menge in Kontrollzellen zu verzeichnen (s. Abbildung 17, H1 ${ }^{\circ}$ ). Die Genexpression von $H 1 x$ wurde im Vergleich zu den unsynchronisierten Zellen durch Natriumbutyrat nicht beeinflußt (s. Abbildung 17, H1x). Die im Vergleich zu unsynchronisierten Zellen gleichbleibende H1x-mRNA-Menge nach Zellzyklusarrest in der G1-Phase impliziert, daß H1x replikationsunabhängig exprimiert wird.

Die Gene aller Subtypen einschließlich $H 1^{\circ}$ und $H 1 x$ zeigten direkt nach Entlassung (0 h) aus dem Aphidicolin-induzierten Arrest am G1/S-Übergang eine verminderte Expression im Vergleich zu den unsynchronisierten Kontrollzellen (s. Abbildung 17). Dieser Effekt war bei $H 1^{\circ}$ und $H 1.3$ am deutlichsten. Für beide Subtypen konnten nur noch etwa ein Zehntel der in den Kontrollzellen vorhandenen mRNA nachgewiesen werden. Bei allen anderen Subtypen sank die Zahl der Transkripte auf etwa ein Drittel. Mit zunehmender Dauer der Entlassung, d.h. mit Fortschreiten der S-Phase, stieg die Expression aller Subtypen im Vergleich zu ihrem 0 h-Wert an.

Im Unterschied zu Genen anderer Histonsubtypen, die $6 \mathrm{~h}$ nach Entlassung aus dem Aphidicolin-induzierten Arrest in der mittleren S-Phase ihre höchste Expression erreichten, wurde die maximale Menge an H1x-mRNA erst in der späten S-Phase nach 8 h erlangt (s. Abbildung 17, H1x).

Bei Abbildung 17 ist zu beachten, daß es sich um relative mRNA-Mengen der Subtypen handelt. Die Verwendung der Kontrollzellen als Kalibrator führt zu einer relativen RNA-Menge von eins für alle Kontrollen. Das heißt nicht, daß alle H1Subtypen in gleicher Menge in den unsynchronisierten Zellen vorlagen. Um das Verhältnis der RNA-Mengen der einzelnen Subtypen zueinander zu zeigen, wurde in 
einer weiteren Berechnung die relative mRNA-Menge der einzelnen Subtypen in unsynchronisierten HeLa-Zellen unter Verwendung der Kontrollprobe von H1.3 als Kalibrator ermittelt (s. Abbildung 18). Die aufgetragenen Mittelwerte und Standardabweichungen errechneten sich wiederum aus neun Messungen pro Subtyp.

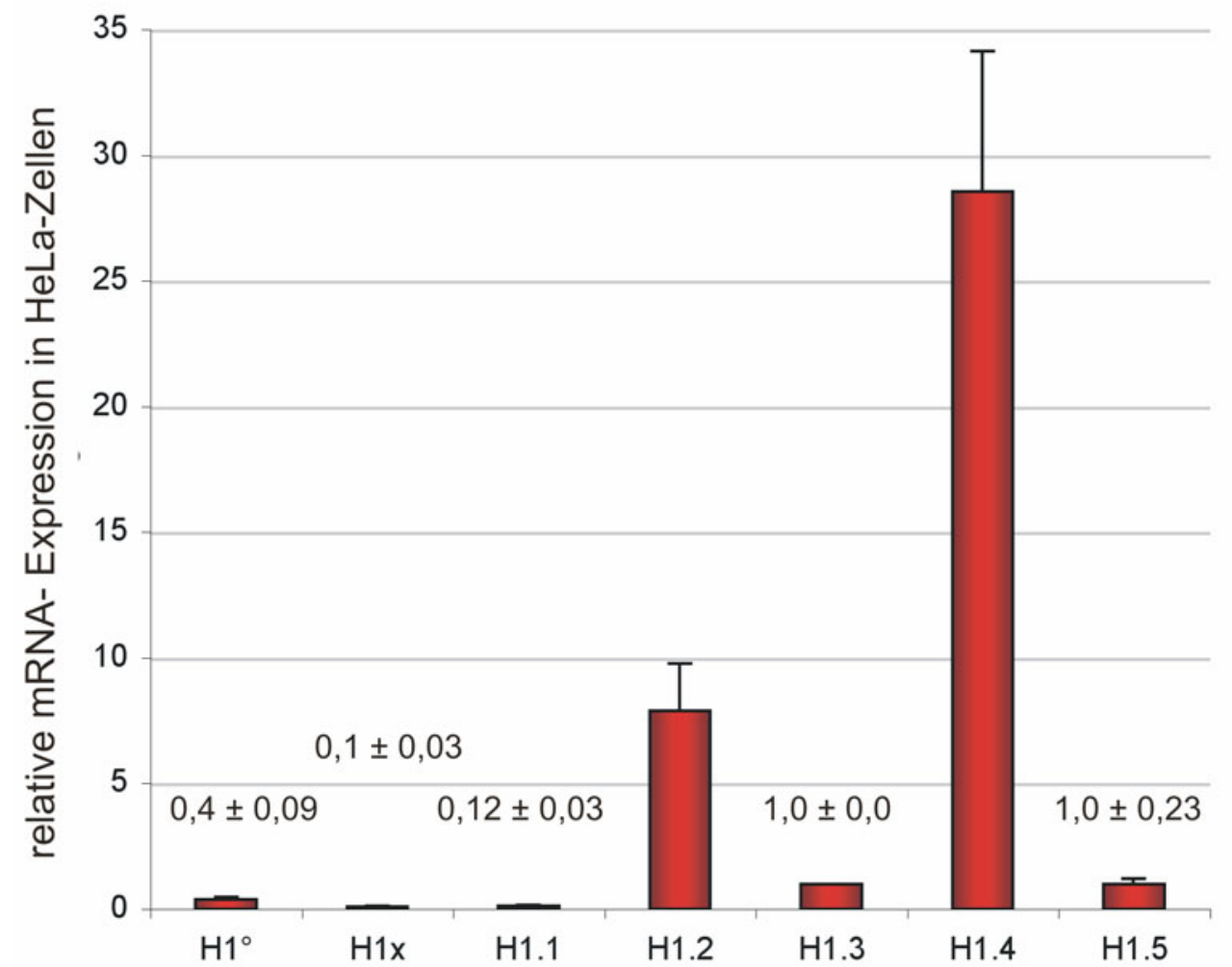

Abbildung 18: Vergleich der relativen mRNA-Mengen der untersuchten $H 1$ Subtypen in unsynchronisierten HeLa-Zellen

Als Referenz-RNA wurde bei der Berechnung mittels $2^{-\Delta \Delta C_{T}}$-Methode (Livak \& Schmittgen, 2001) 18S-rRNA eingesetzt, als Kalibrator diente der $\mathrm{C}_{\mathrm{T}}$-Wert von H1.3 der Kontrollzellen. Da die relativen mRNA-Mengen von H1.2 und H1.4 deutlich größer sind als die der anderen H1Subtypen, wurde die Skalierung der Ordinate an die übrigen Subtypen angepaßt. Für H1.2 ergab sich eine relative Expression von 7,9 $\pm 1,9$, für H1.4 ergab sich ein Wert von 28,6 $\pm 5,6$. Die Standardabweichungen wurden aus drei unabhängigen Experimenten mit je drei Meßreihen ermittelt.

Beim Vergleich der relativen mRNA-Mengen der unterschiedlichen H1-Subtypen in HeLa-Zellen zeigt sich, daß $H 1 x$ und $H 1.1$ am geringsten exprimiert werden. Ihre relative mRNA-Menge beträgt etwa ein Zehntel der Menge von $\mathrm{H} 1.3$. Auch $H 1^{\circ}$ wird mit etwa einem Drittel im Vergleich zu H1.3 und H1.5 schwach exprimiert. H1.2 und H1.4 dagegen konnten mit einer achtfach bzw. knapp dreißigfach höheren Expression 
im Vergleich zu H1.3 als die hauptsächlich vorhandenen H1-Subtypen in HeLa-Zellen identifiziert werden.

Zusammengefaßt ist zu beobachten, daß $H 1 x$ - wie auch $H 1.1$ - nur sehr schwach exprimiert wird. Die mittels RT-PCR durchgeführten Expressionsanalysen zeigten, daß der Subtyp H1x replikationsunabhängig exprimiert wird. Nach Zellzyklusarrest in der G1-Phase konnte keine verringerte Expression von $H 1 x$ im Vergleich zu den unsynchronisierten Zellen festgestellt werden. Dieser G1-Arrest hatte allerdings auch keine Zunahme der H1x-mRNA zur Folge. Während der S-Phase ist im Gegensatz zu allen anderen untersuchten H1-Subtypen keine vermehrte Expression des $H 1 x$-Gens zu verzeichnen. Die Regulierung der $H 1 x$-Expression weicht damit sowohl von der Regulierung der replikationsunabhängig exprimierten H1-Subtypen als auch von der des replikationsunabhängig exprimierten $H 1^{\circ}$ ab.

\subsection{Differentielle Expression von H1x in Tumoren}

Histone spielen nicht nur eine entscheidende Rolle bei der Kondensierung von DNA, sondern auch bei der Steuerung der Genexpression, der DNA-Replikation und der DNA-Reparatur (Brown, 2003; Harvey \& Downs, 2004). Angesichts der häufig veränderten Chromatinmorphologie und der veränderten Genexpression und Replikationsregulation in Tumoren stellte sich daher die Frage, inwieweit Expressionsmuster und Verteilung der H1-Histone, im Speziellen des Subtyps H1x, zu den Charakteristika von Tumorzellen gehören oder von funktioneller Bedeutung für die Tumorzellen sind. Eine Analyse in BLAST (Altschul et al., 1997) zeigte gehäuft EST-Einträge (expressed sequence tags) in Genbanken neuroendokriner Tumore für den Subtyp H1x. Von 500 angezeigten ESTs mit einem E value (expect value) von 0,0 waren 225 ESTs Einträge aus den Genbanken LU24 und LU5 (Happel, persönliche Mitteilung). Diese Genbanken stammen aus neuroendokrinen Lungenkarzinoiden. Der E value gibt an, wie hoch die Anzahl der Treffer ist, die durch Zufall entstanden sind. Das heißt, je niedriger der E value ist, desto höher ist die Signifikanz des Treffers, deshalb wurden nur Einträge mit $\mathrm{E}=0,0$ betrachtet. 
Die Bezeichnung der Tumore als neuroendokrin beruht auf der phänotypischen Verwandtschaft mit neuralen Zellen bezüglich der Expression bestimmter Proteine wie Synaptophysin, neuronspezifische Enolase und Chromogranin A (Klöppel et al., 2004).

Um der Frage nachzugehen, ob $H 1 x$ generell in neuroendokrinen Tumoren (NETs) überexprimiert wird und sich eventuell als Marker für bestimmte Tumorentitäten eignet, wurden zunächst Untersuchungen an Gewebedünnschnitten aus NETs mittels in situ Hybridisierung durchgeführt.

\subsubsection{Nachweis von H1x-mRNA in neuroendokrinen Tumoren durch in situ Hybridisierung}

Die in situ Hybridisierung zum Nachweis von H1x-RNA zeigte eine positive Reaktion einer H1x-Sonde mit den Tumorzellen eines neuroendokrinen Bronchialkarzinoms (s. Abbildung 19). Die H1x-sense-Sonde wurde als Negativkontrolle eingesetzt, um unspezifische Reaktionen der Färbelösung mit dem Gewebe ausschließen zu können. Die sense-Sonde ist nicht komplementär zur im Gewebe vorkommenden mRNA und kann deshalb nicht binden.
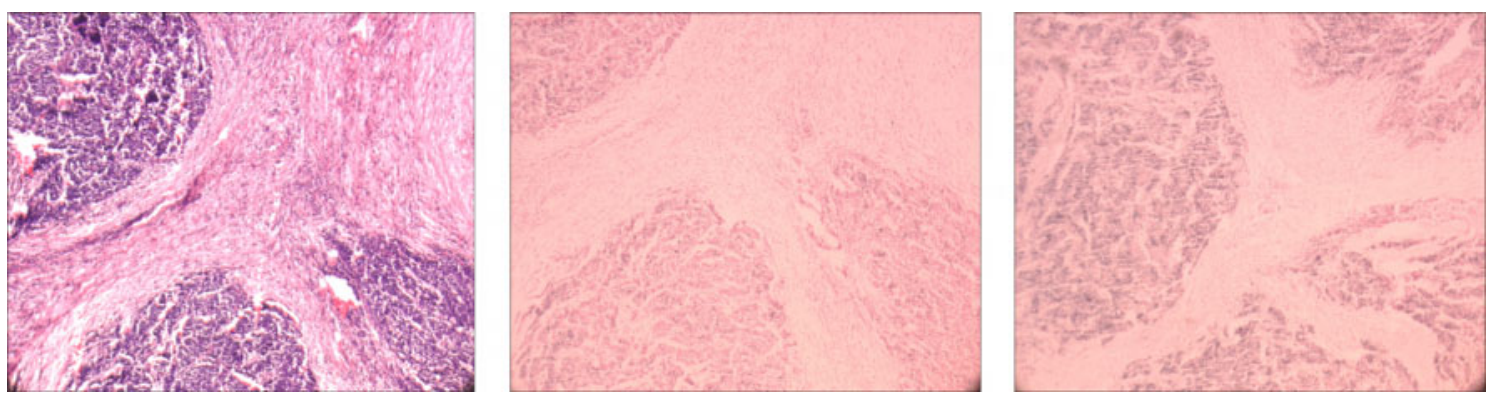

\section{Abbildung 19: in situ Hybridisierung an neuroendokrinem Bronchialkarzinom}

Links: HE-Färbung des Bronchialkarzinoms (Tumorinfiltrationen sind dunkel gefärbt); Mitte: Negativkontrolle mit H1x-sense-Sonde; rechts: positive Reaktion der H1x-anti-sense-Sonde S2 im Tumorbereich; die gebundene, mit DIG-UTP markierte Sonde zeigt eine bräunliche Farbreaktion mit BCIP/NBT.

\subsubsection{Nachweis von H1x-mRNA in neuroendokrinen Tumoren durch RT-PCR}

Die in situ Hybridisierung war an dem vorhandenen Schnittmaterial nicht zuverlässig reproduzierbar. Das lag möglicherweise an einer RNA-Degradierung innerhalb des Gewebes oder an der Fixierung der Schnitte. Daher wurden unfixierte Gewebeproben, 
die unmittelbar nach Entnahme bei $-80^{\circ} \mathrm{C}$ gelagert worden waren, mittels RT-PCR untersucht. Das für die RT-PCR oder die Untersuchung des Proteingehalts mittels Western-Blot zur Verfügung stehende Material ist in Tabelle 22 aufgelistet. Im Gegensatz zur in situ Hybridisierung ist es bei der RT-PCR nicht möglich, RNA im Gewebe zu lokalisieren. Allerdings bietet die RT-PCR den Vorteil, die RNA unterschiedlicher Proben quantitativ vergleichen zu können.

Tabelle 22: Neuroendokrine Tumore für die RT-PCR-Analyse bzw. für die Proteinanalyse

\begin{tabular}{|l|l|l|l|}
\hline $\begin{array}{l}\text { Proben- } \\
\text { nummer (ID) }\end{array}$ & $\begin{array}{l}\text { E-Nummer } \\
\text { (Pathologie) }\end{array}$ & Klassifizierung & Lokalisation \\
\hline 1 & 99-U00922-T & Neuroendokrines Karzinoid & Lunge \\
\hline 2 & 99-U00922-N & Normalgewebe & Lunge \\
\hline 4 & 00-U02725-T & $\begin{array}{l}\text { Weuroendokrines Karzinom, } \\
\text { kleinzelliger Typ }\end{array}$ & Dünndarm \\
\hline 6 & 04-P00402-T & $\begin{array}{l}\text { Wenig differenziertes } \\
\text { neuroendokrines Karzinom }\end{array}$ & Dickdarm \\
\hline 7 & 04-P00402-N & Normalgewebe & Pankreas \\
\hline 9 & 01-U03827-T & $\begin{array}{l}\text { Wenig differenziertes } \\
\text { neuroendokrines Karzinom, } \\
\text { kleinzelliger Typ }\end{array}$ & Lunge \\
\hline Normalgewebe & $\begin{array}{l}\text { Wenig differenziertes } \\
\text { neuroendokrines Karzinom, } \\
\text { großzelliger Typ }\end{array}$ \\
\hline
\end{tabular}




\begin{tabular}{|c|c|c|c|}
\hline $\begin{array}{l}\text { Proben- } \\
\text { nummer (ID) }\end{array}$ & $\begin{array}{l}\text { E-Nummer } \\
\text { (Pathologie) }\end{array}$ & Klassifizierung & Lokalisation \\
\hline 13 & 01-U09573-T & $\begin{array}{l}\text { Wenig differenziertes } \\
\text { neuroendokrines Karzinom, } \\
\text { kleinzelliger Тур }\end{array}$ & Magen \\
\hline 18 & 05-U00628-T & Rezidiv eines Leiomyosarkoms & Retroperitoneum \\
\hline 19 & 03-U01213-T & $\begin{array}{l}\text { Gut differenziertes } \\
\text { neuroendokrines Karzinom }\end{array}$ & Pankreas \\
\hline $24 a$ & $97-11021-\mathrm{T}$ & $\begin{array}{l}\text { Gut differenziertes } \\
\text { neuroendokrines Karzinom }\end{array}$ & Pankreas \\
\hline $24 b$ & $97-11021-\mathrm{N}$ & Normalgewebe & Pankreas \\
\hline 25 & 99-U10403-N & Normalgewebe & Pankreas \\
\hline 26 & 01-U06888-N & Normalgewebe & Dünndarm (Ileum) \\
\hline 27 & 04-P07502-N & Normalgewebe & Dünndarm \\
\hline 28 & 06-P2203-T & $\begin{array}{l}\text { Gut differenziertes } \\
\text { neuroendokrines Karzinoid }\end{array}$ & $\begin{array}{l}\text { Dünndarm } \\
\text { (Duodenum) }\end{array}$ \\
\hline 29 & 06-U00585-T & $\begin{array}{l}\text { Gut differenziertes } \\
\text { neuroendokrines Karzinom }\end{array}$ & Dünndarm (Ileum) \\
\hline 30 & 06-U00585-N & Normalgewebe & $\begin{array}{l}\text { Dickdarm } \\
\text { (Schleimhaut) }\end{array}$ \\
\hline 31 & 06-U00585-N & Normalgewebe & Dünndarm \\
\hline R1 & 04-P09001-T & $\begin{array}{l}\text { Gut differenziertes } \\
\text { neuroendokrines Karzinom }\end{array}$ & $\begin{array}{l}\text { Dünndarm } \\
\text { (Duodenum) }\end{array}$ \\
\hline
\end{tabular}




\begin{tabular}{|l|l|l|l|}
\hline $\begin{array}{l}\text { Proben- } \\
\text { nummer (ID) }\end{array}$ & $\begin{array}{l}\text { E-Nummer } \\
\text { (Pathologie) }\end{array}$ & Klassifizierung & Lokalisation \\
\hline R2 & 03-U05459 & Rezidiv eines Leiomyosarkoms & Retroperitoneum \\
\hline R3 & 99-U04304-T & $\begin{array}{l}\text { Gut differenziertes } \\
\text { neuroendokrines Karzinom }\end{array}$ & $\begin{array}{l}\text { Dünndarm } \\
\text { (Appendix }+ \\
\text { Jejunum) }\end{array}$ \\
\hline
\end{tabular}

Neuroendokrine Tumore werden entsprechend der WHO-Klassifikation aus dem Jahr 2000 eingeteilt in:

- hochdifferenzierten neuroendokrinen Tumor, der synonym als neuroendokrines Karzinoid bezeichnet wird,

- hoch differenziertes neuroendokrines Karzinom und

- $\quad$ niedrig differenziertes neuroendokrines Karzinom (Klöppel et al., 2004).

Die Klassifizierung der Tumore erfolgte durch einen Pathologen (Universitätsklinikum Göttingen, Abteilung Gastroenteropathologie, Prof. Dr. Füzesi). Der hochdifferenzierte neuroendokrine Tumor zeichnet sich durch ein benignes Verhalten oder eine fragliche Dignität ohne Befall der Lymphknoten aus, das hoch differenzierte neuroendokrine Karzinom ist durch ein niedrigmalignes Verhalten charakterisiert und das niedrig differenzierte, meist kleinzellige neuroendokrine Karzinom durch hohe Malignität. Die Beurteilung erfolgt nach morphologisch-biologischen Kriterien wie beispielsweise Tumorgröße, Angioinvasion, Anwesenheit von Metastasen und Invasion von benachbarten Organen (Klöppel et al., 2004).

Für die quantitative RT-PCR wurden H1-Subtyp-spezifische Primer verwendet (s. Kapitel 3.1.6.5). Die Ergebnisse wurden nach der $2^{-\Delta \Delta C_{T}}$-Methode ausgewertet. 18SrRNA diente als Referenz-RNA, mit deren Hilfe mögliche Unterschiede in der Transkriptionseffizienz der reversen Transkriptase in den verschiedenen Geweben ausgeglichen werden konnten. Als Kalibrator wurde der $\mathrm{C}_{\mathrm{T}}$-Wert der Normalprobe aus Dünndarm (ID 27) verwendet. 


\section{$\square$ Normalgewebe $\boldsymbol{\square}$ Karzinom $\square$ Karzinoid}

$\mathrm{H} 1^{\circ}$

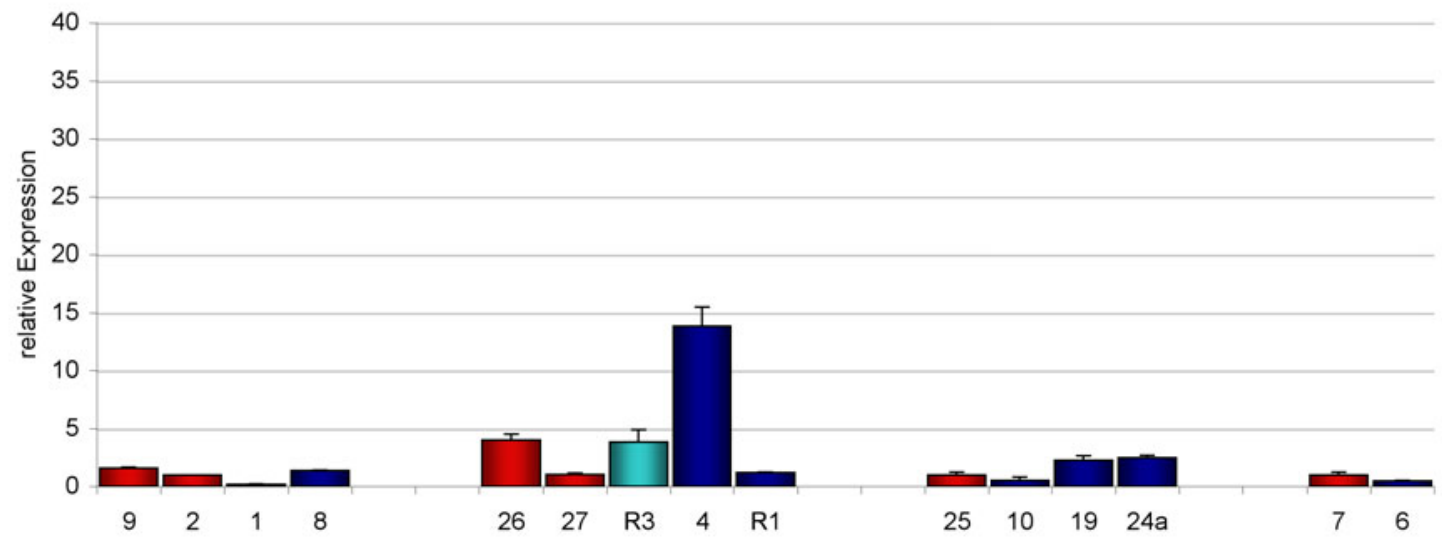

$\mathrm{H} 1 \mathrm{x}$

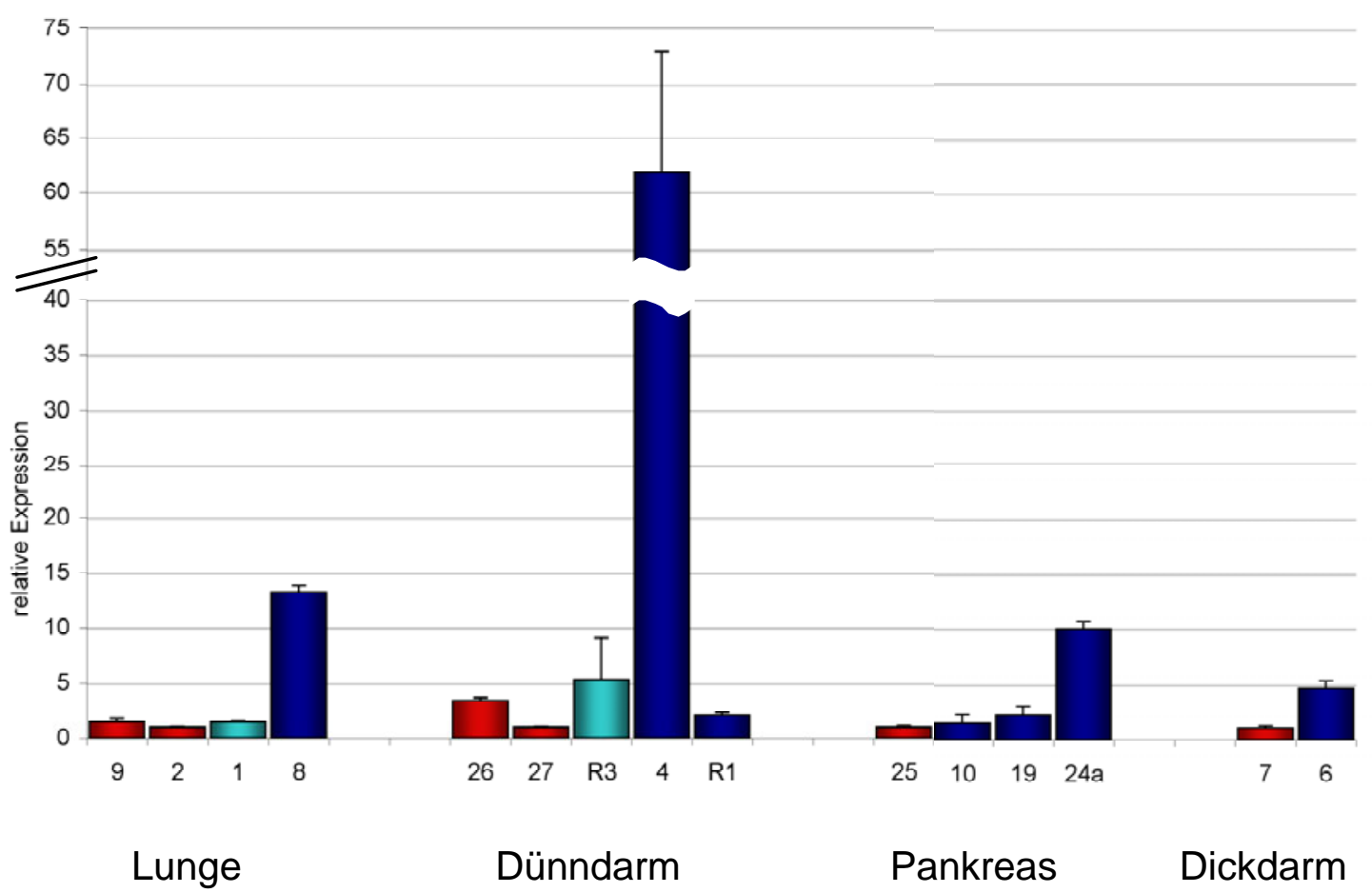


$\square$ Normalgewebe $\mathbf{M}$ Karzinom $\square$ Karzinoid

H1.1

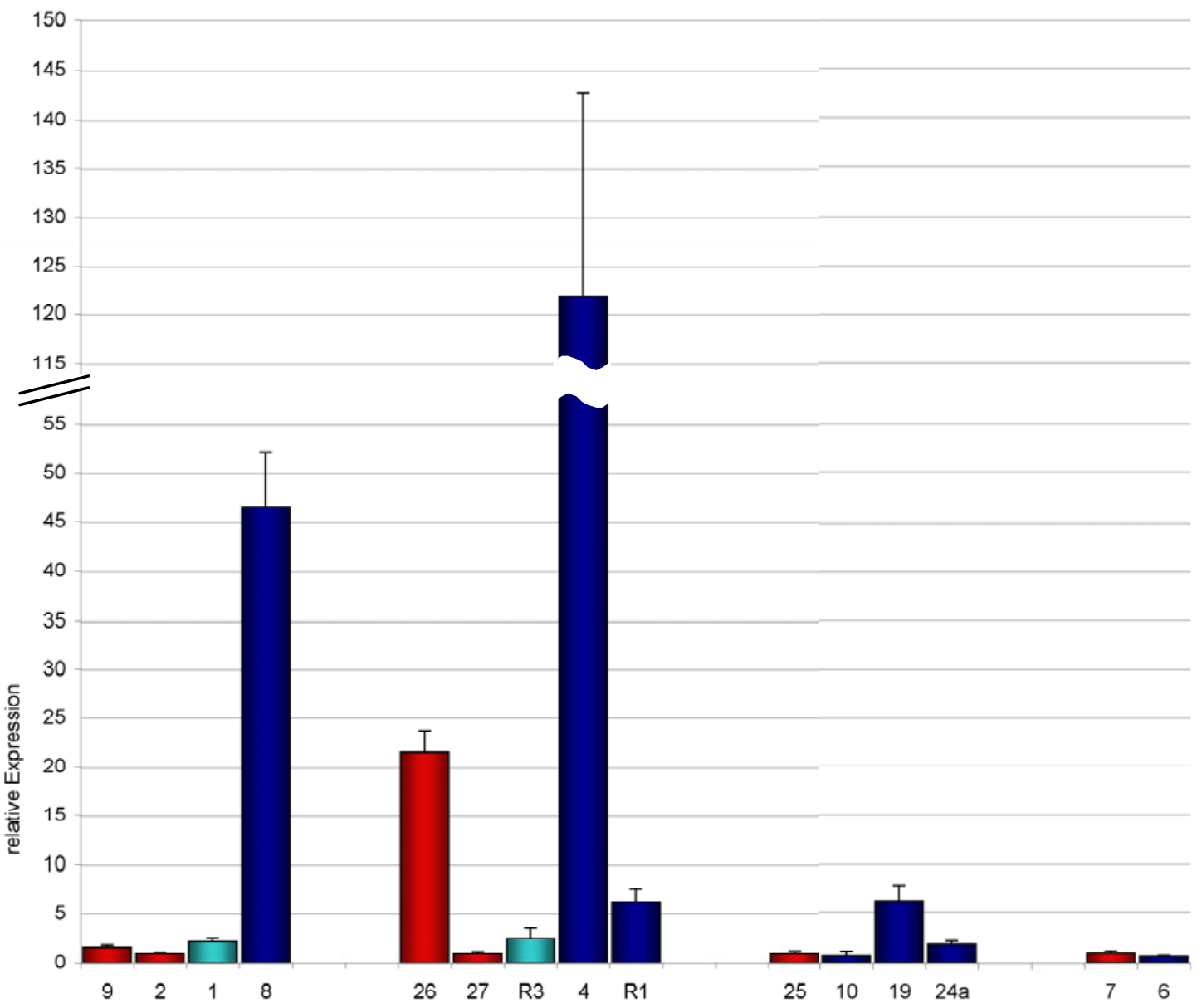

$\mathrm{H} 1.2$

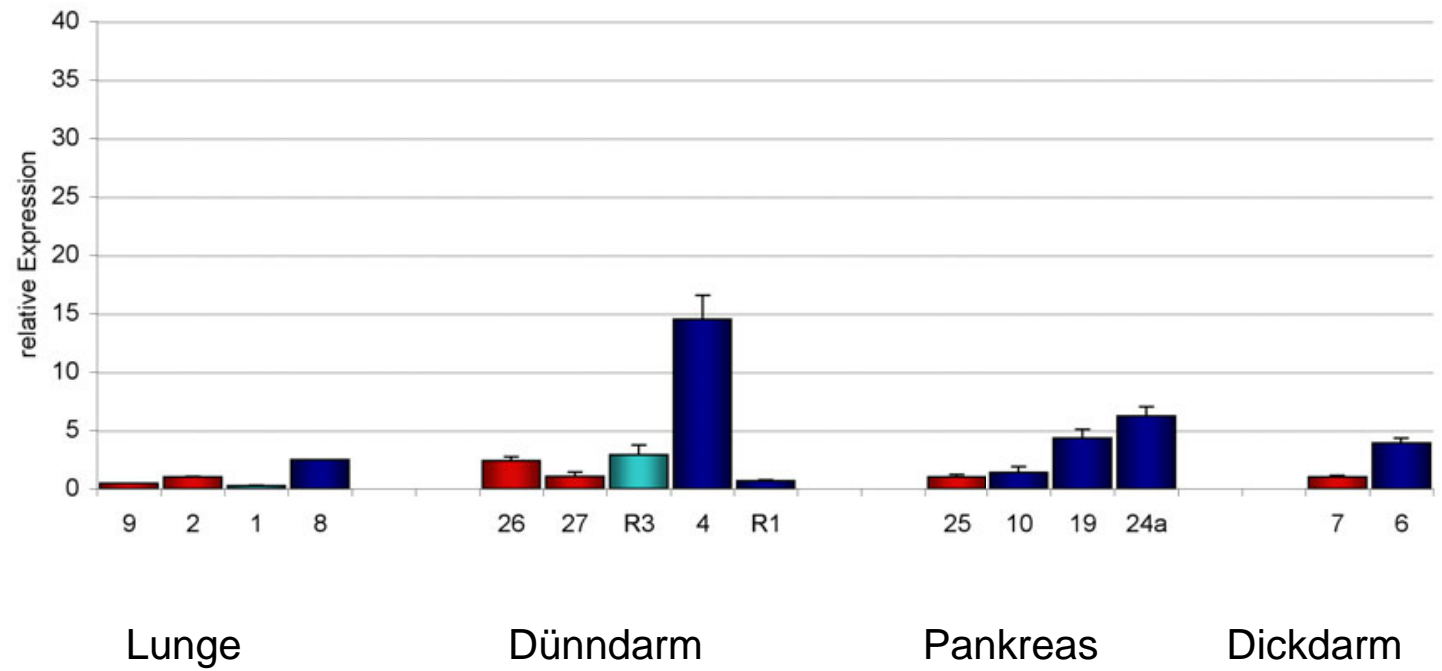


$\square$ Normalgewebe $\mathbf{M}$ Karzinom $\square$ Karzinoid

$\mathrm{H} 1.3$

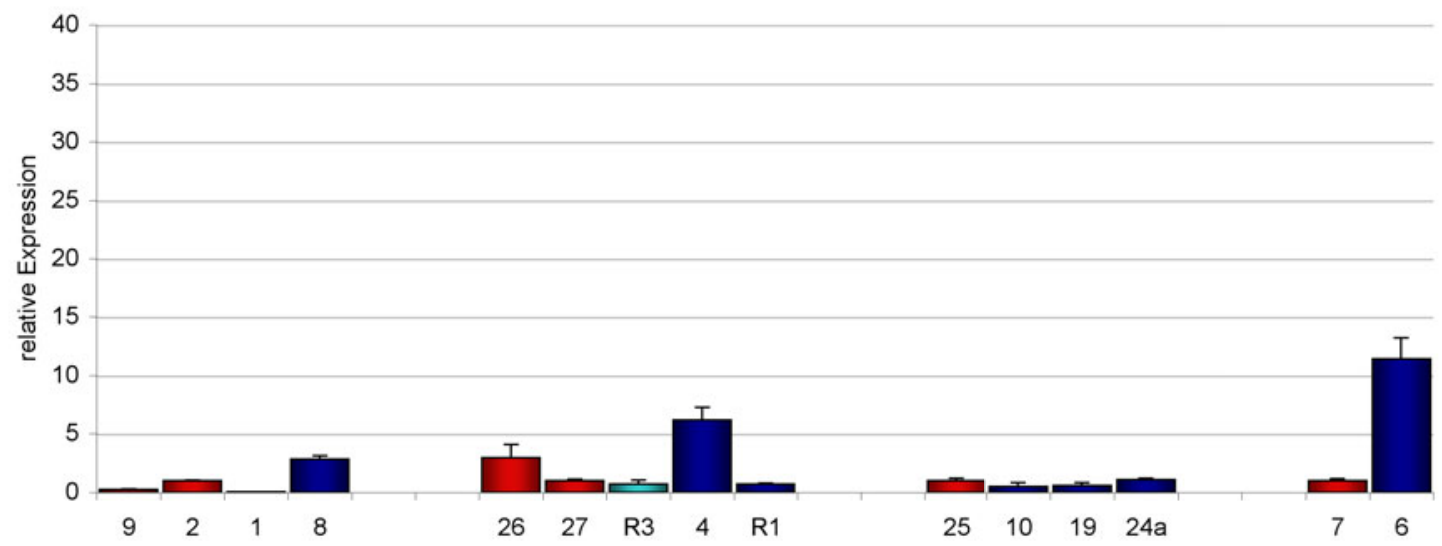

$\mathrm{H} 1.4$

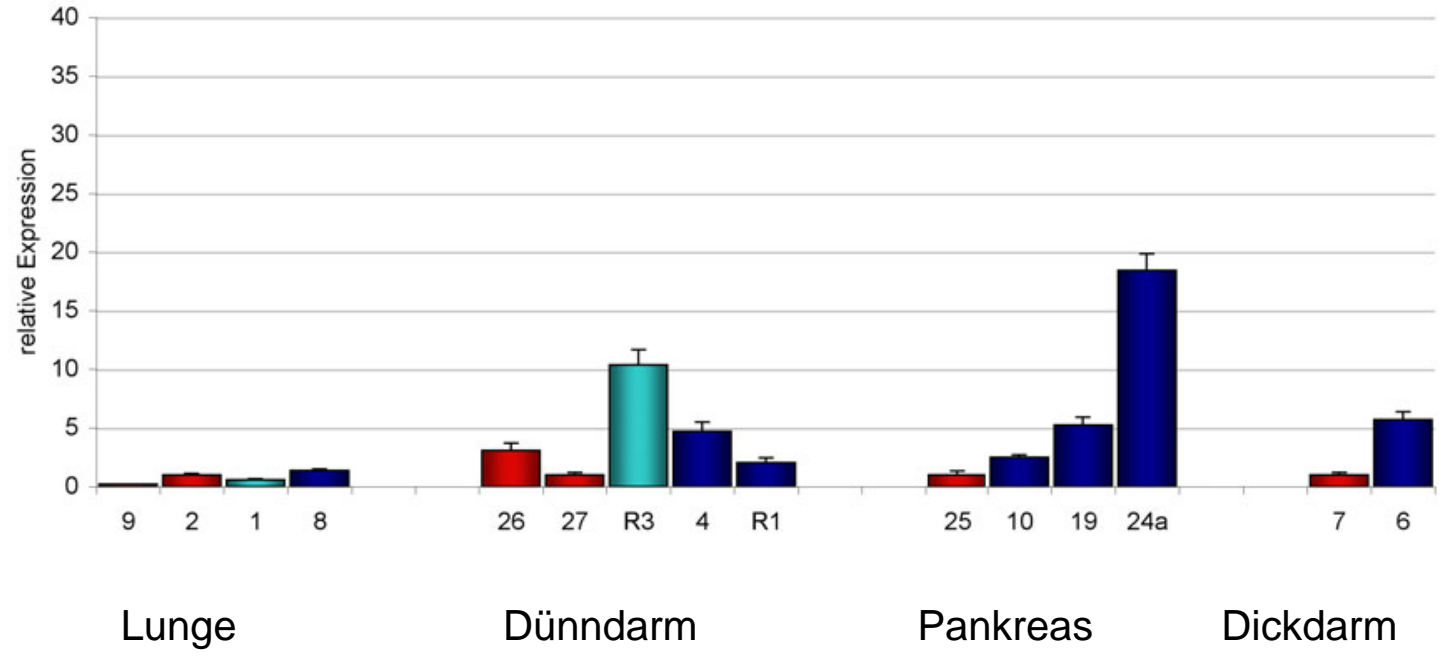




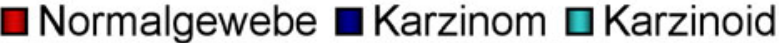

$\mathrm{H} 1.5$

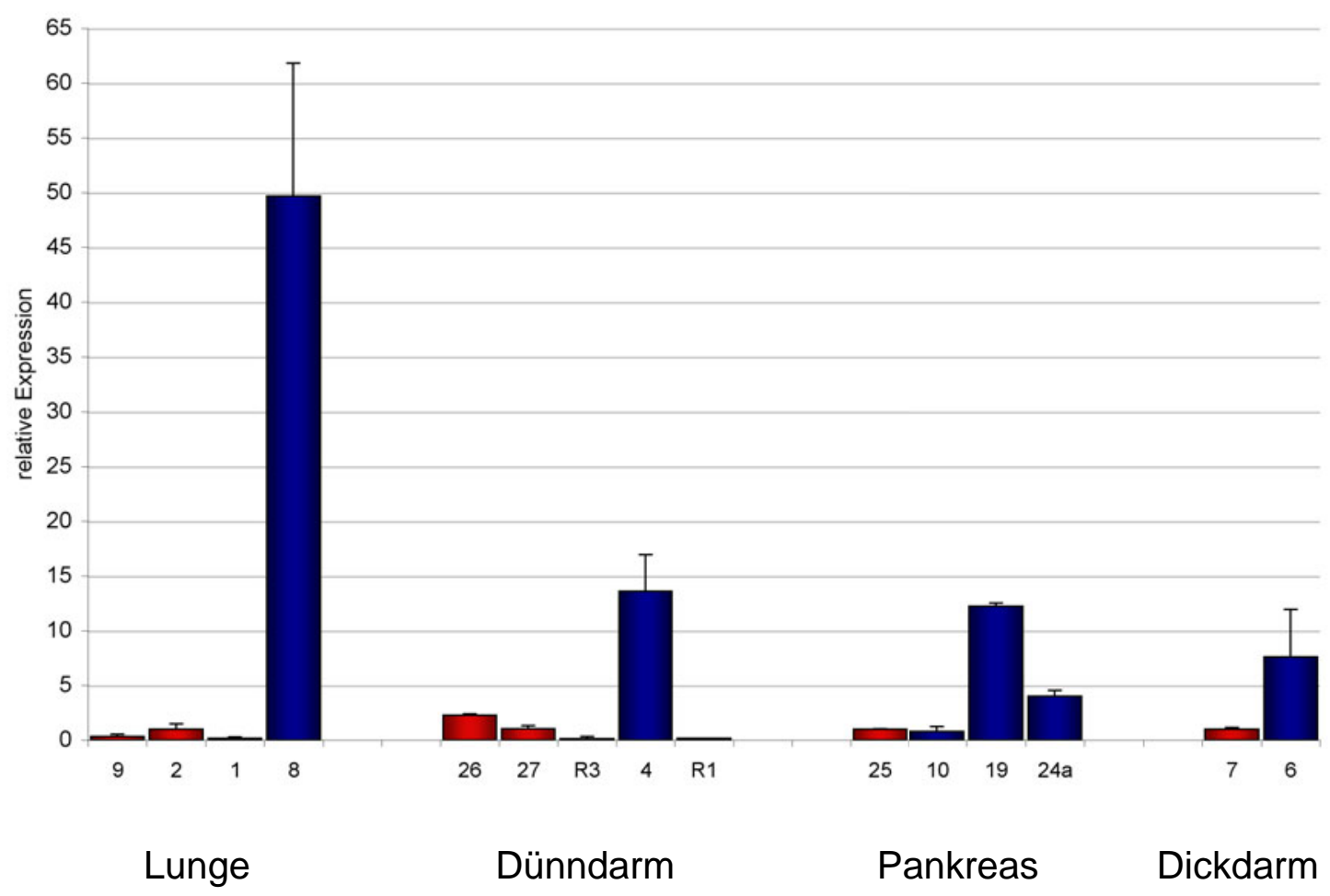

Abbildung 20: relative mRNA-Expression der H1-Histonsubtypen in RNA-Proben aus Lunge, Dünndarm, Pankreas und Dickdarm

Die relative mRNA-Menge der verschiedenen H1-Subtypen in nicht-neoplastischem und neoplastischem Gewebe wurde mittels RT-PCR bestimmt. Als Referenz diente 18S-rRNA, als Kalibrator die Dünndarmprobe mit der ID-Numer 27. Die Standardabweichungen wurden aus je drei Messungen ermittelt.

Die Expressionsanalyse mittels RT-PCR zeigte, daß H1x-mRNA in allen untersuchten Geweben nachweisbar war. Der Vergleich der nach der $2^{-\Delta \Delta C_{T}}$-Methode berechneten Ergebnisse ergab, daß $H 1 x$ im untersuchten wenig differenzierten neuroendokrinen Karzinom der Lunge stärker exprimiert wurde als in Normalgewebe (13-mal soviel H1x-mRNA in Karzinom gegenüber Normalgewebe, s. Abbildung 20). Im neuroendokrinen Karzinoid hingegen konnte keine erhöhte Menge an H1x-mRNA gemessen werden. Eine extrem hohe mRNA-Menge des Subtyps H1.1 wurde in der untersuchten Probe aus neuroendokrinem Karzinom festgestellt. Sie enthielt das knapp fünfzigfache an H1.1-mRNA im Vergleich zu der Normalprobe (s. Abbildung 20). Auch H1.5 zeigte 
in dieser Karzinomprobe (ID 8) eine fünfzigfach erhöhte Expression im Vergleich zu Normalgewebe.

In Dünndarm war die $H 1 x$-Expression im neuroendokrinen Karzinom 20-mal höher als im Karzinoid und 62-mal höher als in Normalgewebe. Allerdings zeigte sich dieser deutliche Unterschied nur in einer der beiden Karzinomproben (ID-Nummer 4). Das andere Karzinom (ID-Nummer R1) wies eine $H 1 x$-Expression auf, die vergleichbar mit den Werten aus Karzinoid und gesundem Gewebe war (s. Abbildung 20). Auch hier war - ähnlich wie bei Lungenprobe Nummer 8 - die Karzinomprobe Nummer 4, die eine vergleichsweise hohe $H 1 x$-Expression gezeigt hatte, im Hinblick auf H1.1 auffällig: sie enthielt 61-mal soviel H1.1-mRNA wie das neuroendokrine Dünndarmkarzinoid (s. Abbildung 20). Der Unterschied zwischen den beiden Karzinomproben 4 und R1, die untersucht worden waren, liegt im Differenzierungsgrad. Probe 4, die sowohl für $\mathrm{H} 1 \mathrm{x}$ als auch für $\mathrm{H} 1.1$ relativ $\mathrm{zu}$ den anderen Proben aus Dünndarm eine deutlich höhere mRNA-Menge aufwies, ist wenig differenziert, das Vergleichskarzinom mit der ID-Nummer R1 wurde als gut differenziert eingestuft (s. Tabelle 22).

In Pankreas ließ sich ein ähnliches Bild wie bei den Dünndarmproben erkennen: eine Probe eines neuroendokrinen Karzinoms (ID-Nummer 24a) zeichnete sich durch eine gegenüber nicht-neoplastischem Gewebe erhöhte $H 1 x$-Expression aus (zehnmal mehr als in Normalgewebe). Die anderen Karzinomproben (ID-Nummern 10 und 19) zeigten nur geringfügig stärkere Expressionen von $\mathrm{H} 1 \mathrm{x}$ im Vergleich zu der Normalprobe (s. Abbildung 20). Bei der Probe 10 handelt es sich um ein wenig differenziertes Karzinom, während die Proben mit den ID-Nummern 19 und 24a als gut differenziert eingestuft wurden. Im Gegensatz zu 19 und 24a gehört die Probe 10 jedoch zum großzelligen Typ, was die geringe $H 1 x$-Expression erklären könnte.

In den untersuchten Proben aus Dickdarm war die mRNA-Menge der meisten H1Subtypen in Tumorgewebe fünf- bis zehnfach erhöht. $H 1.1$ und $H 1^{\circ}$ zeigten in den Dickdarmproben eine niedrigere Expression in Tumor als in Normalgewebe (s. Abbildung 20). Für H1x war im Tumor eine fünffach erhöhte Expression im Vergleich zu Normalgewebe erkennbar (s. Abbildung 20). 
Zusammengefaßt läßt sich aussagen, daß die somatischen H1-Subtypen H1.2-H1.5 ebenso wie das Replacementhiston $\mathrm{H} 1^{\circ}$ im größten Teil der Tumorproben eine erhöhte Expression im Vergleich zum Normalgewebe zeigten (s. Abbildung 20), jedoch - mit Ausnahme von H1.5 in Lunge - nicht in dem Ausmaß wie H1x und H1.1. So zeigte sich in den untersuchten Proben, daß $H 1 x$ in neuroendokrinen Tumoren mit schlechterer Prognose, d.h. in wenig differenzierten, kleinzelligen neuroendokrinen Karzinomen, vermehrt exprimiert wird. Auch die Expression von H1.1 ist in den wenig differenzierten Karzinomen der Lunge und des Dünndarm gegenüber den dazugehörigen Normalgeweben erhöht.

Bei der Darstellung der relativen mRNA-Mengen der H1-Subtypen in Tumor und Normalgewebe ist zu beachten, daß es sich um relative mRNA-Mengen der Subtypen handelt. Die Verwendung der Normalprobe 27 als Kalibrator und die Umrechnung je einer Normalprobe pro Organ auf eins heißt nicht, daß alle H1-Subtypen in gleicher Menge in den Geweben vorlagen.

\subsubsection{Proteinanalyse mittels Western-Blot bestätigt Ergebnisse aus RT-PCR: H1x ist auch auf Proteinebene in neuroendokrinen Tumoren vermehrt nachzuweisen}

Nach den vorliegenden Ergebnissen des mRNA-Nachweises durch RT-PCR, bei dem sich gezeigt hatte, daß die Expression des $H 1 x$-Gens in wenig differenzierten neuroendokrinen Tumoren im Vergleich zu gesundem Gewebe erhöht war, sollte ermittelt werden, ob dieses Ergebnis auch auf Proteinebene festzustellen ist. Daraufhin wurden die relativen Proteinmengen von H1x und anderen H1-Subtypen mittels Western-Blot in Tumoren und den zugehörigen Normalgeweben untersucht. Da die Proteine durch Extraktion mit Schwefelsäure aus den gefrorenen Geweben isoliert worden waren und sich deshalb nur säurelösliche Proteine in dem Extrakt befanden, war ein Vergleich der H1x-Proteinmenge mit ß-Aktin nicht möglich. Stattdessen wurde H1.2 als Bezugsgröße genutzt, da H1.2 ein basal exprimiertes Histon ist, das in allen bisher untersuchten Zellen nachgewiesen werden konnte (Meergans et al., 1997). Es wurden Gewebeproben verwendet, die auch mittels RT-PCR untersucht worden waren. Die Western-BlotAnalysen wurden für die abgebildeten Proben mindestens dreimal durchgeführt und zeigten reproduzierbare Ergebnisse. Der in dieser Arbeit verwendete Antikörper gegen 
H1x wurde durch Happel et al. (2005) in Western-Blots und in affinitätsgereinigter Form durch Stoldt et al. (2007) in Immunfluoreszenz- und immunhistochemischen Untersuchungen auf seine Spezifität getestet.

Der anti-H1x-Antikörper zeigte stärkere Signale bei den meisten Tumorproben im Vergleich zu den zugehörigen Proben aus gesundem Gewebe (s. Abbildung 21). Besonders ausgeprägt war dies bei NET aus Lunge (Probe 1 vs. 2), neuroendokrinem Karzinom des Pankreas (Probe Nummer 24a vs. 24b) und neuroendokrinem Dünndarmkarzinom (Probe Nummer 4 vs. 26). Für $\mathrm{H}^{\circ}{ }^{\circ}$ war kein klares Muster erkennbar: in einigen Proben war die Proteinmenge von $\mathrm{H}^{\circ}$ in Tumor- und Normalgewebe gleich, zum Teil war $\mathrm{H}^{\circ}{ }^{\circ}$ in Normalgewebe mehr, zum Teil weniger vorhanden als in den Tumorproben. So zeigte beispielsweise der $\mathrm{H} 1^{\circ}$-Antikörper in der Probe aus Normalgewebe aus Lunge eine deutliche Bande, während sich in der dazugehörigen Tumorprobe anscheinend kein $\mathrm{H} 1^{\circ}$-Protein nachweisen ließ (s. Abbildung 21). Im Unterschied zu der durch RT-PCR ermittelten mRNA-Expression von $H 1 x$, die sich in neuroendokrinem Lungenkarzinom als deutlich, aber in neuroendokrinem Karzinoid der Lunge nur als geringfügig erhöht dargestellt hatte, konnte bei der Proteinanalyse mittels Western-Blot auch in Lungenkarzinoid ein stärkeres Signal als in der Normalprobe für H1x beobachtet werden (Probe 1 vs. 2).

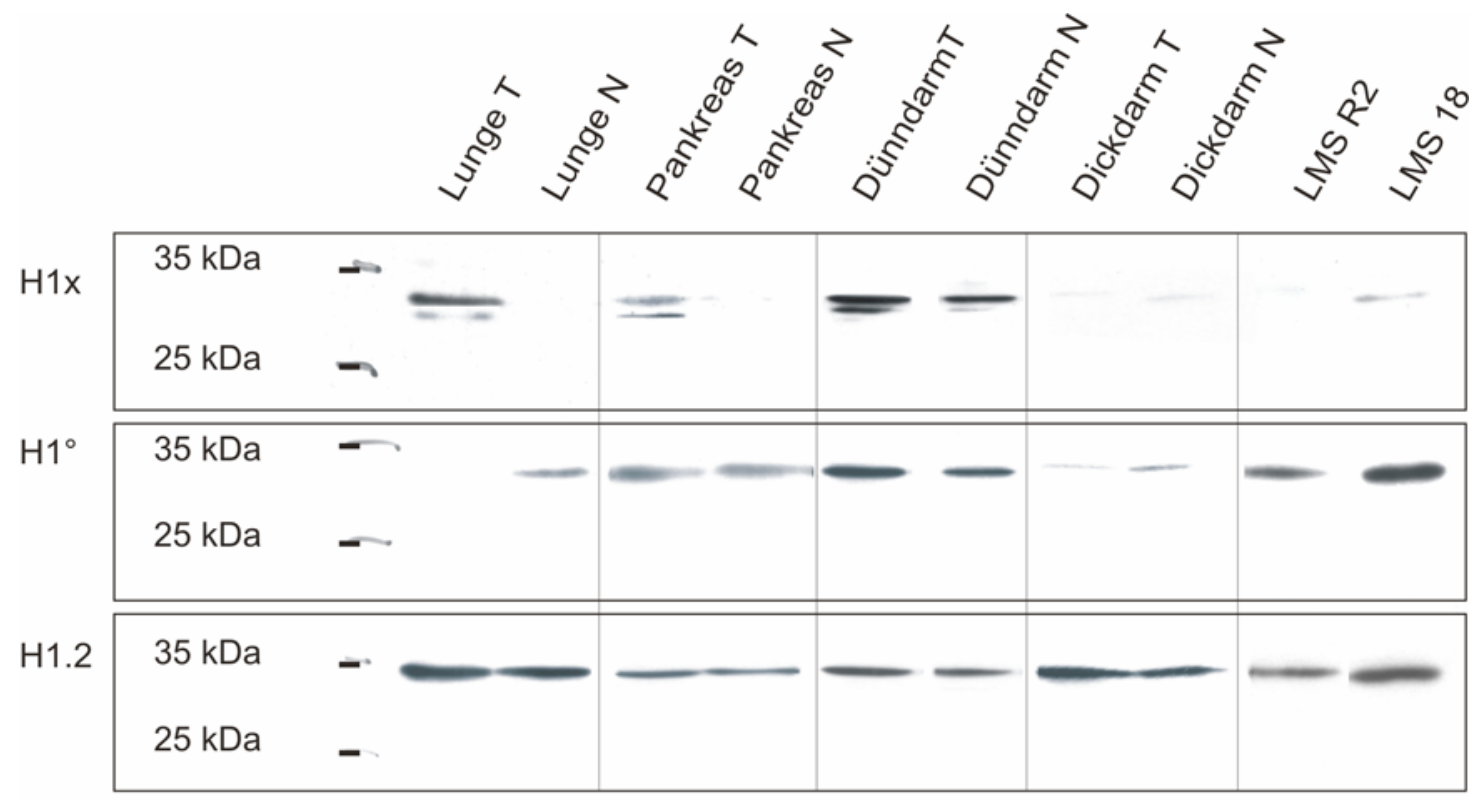

Abbildung 21: Western-Blot von Tumor- und Normalproben 
Durch Schwefelsäureextraktion gewonnene Proteine aus verschiedenen Tumor- und Normalproben wurden mittels SDS-Gelelektrophorese aufgetrennt, auf eine Nitrozellulosemembran übertragen und mit Antikörpern gegen $\mathrm{H} 1 \mathrm{x}, \mathrm{H} 1^{\circ}$ oder $\mathrm{H} 1.2$ nachgewiesen. Der H1Histonsubtyp H1.2 wurde als Bezugsgröße verwendet. T: Tumor; N: gesundes Gewebe; LMS R2: Leiomyosarkom mit der ID-Nummer R2; LMS 18: Leiomyosarkom mit der ID-Nummer 18. Die Proben haben von links nach rechts die folgenden ID-Nummern: 1, 2, 24a, 24b, 4, 26, 6, 7, R2, 18. Mit Ausnahme von Probe 2 (neuroendokrines Karzinoid) handelt es sich bei den untersuchten Tumorproben um neuroendokrine Karzinome.

Bei der Untersuchung der Proteinmenge der H1-Histone $\mathrm{H} 1 \mathrm{x}, \mathrm{H} 1^{\circ}$ und $\mathrm{H} 1.2$ mittels Western-Blot konnte zusätzlich zu den neuroendokrinen Tumoren auch auf Leiomyosarkome als Vergleichstumoren anderen Ursprungs zurückgegriffen werden, die für die RT-PCR nicht zur Verfügung standen. Leiomyosarkome leiten sich aus glatten Muskelzellen ab. Bei den untersuchten Leiomyosarkomen handelte es sich um Rezidive des Retroperitoneums. Im Bereich des Retroperitoneums sind Leiomyosarkome die dritthäufigsten Sarkome und führen zu einer massiven Zelldegeneration (Hashimoto et al., 1985). In den untersuchten Leiomyosarkomen war H1x-Protein kaum nachweisbar.

Zusammengefaßt zeigen die Ergebnisse aus dem Western-Blot, daß das H1x-Protein in neuroendokrinen Tumoren in größerer Menge als in gesundem Gewebe, dagegen aber kaum in Leiomyosarkomen nachzuweisen ist.

\subsubsection{Immunhistochemischer Nachweis von H1x in neuroendokrinen Tumorzellen}

Um die im Western-Blot erhaltenen Ergebnisse zu stützen und eine Zuordnung des H1x-Proteins zu neuroendokrinen Zellen zu ermöglichen oder eine anderweitige zellspezifische Expression von H1x festzustellen, wurden neben dem Nachweis von H1x immunhistochemische Nachweise der Markerproteine Chromogranin A, Vimentin, CEA und CD45 durchgeführt. Chromogranin A ist ein Markerprotein für neuroendokrine Tumore und kommt hauptsächlich in chromaffinen Granula vor. Immunhistochemisch läßt sich Chromogranin A in neuroendokrinen Zellen, Karzinoiden und allen Tumoren, die Peptidhormone synthetisieren, sowie in endokrinen Zellen des Darms (enteroendokrine Zellen) nachweisen (Wilander, 1989). Das Intermediärfilament Vimentin kommt im Zytoplasma aller Zellen mesenchymalen Ursprungs vor. Nicht-muskuläre Sarkome werden mittels Vimentin charakterisiert (Osborn, 1983; Osborn \& Weber, 1983). Das carcinoembryonic antigen (CEA) gehört 
zur Familie der Glykoproteine und ist ein Marker für Adenokarzinome (Neville et al., 1975). CD45 ist ein Transmembranglykoprotein, das in den meisten kernhaltigen Zellen hämatopoetischen Ursprungs exprimiert wird. CD45 wird zur Identifizierung von Tumorzellen lymphoider Herkunft genutzt (Mason \& Gatter, 1987; Huelin, 1988). Der Antikörper gegen CD45 wurde zusätzlich zu der optischen Beurteilung der H1xpositiven Zellen durch einen Pathologen genutzt, um sicherzustellen, daß es sich bei den H1x-positiven Zellen nicht um Lymphozyten handelte.

Wie in Kapitel 3.2.2.6 beschrieben, wurde zur besseren Vergleichbarkeit der Proben ein sogenannter Tissue microarray (TMA) angefertigt, der es ermöglichte, alle untersuchten Gewebestücke gleichzeitig, d.h. unter gleichen Bedingungen, zu behandeln und am Mikroskop zu beurteilen. Der TMA enthielt Proben aus zehn verschiedenen Tumoren und die zugehörigen Proben aus gesundem Gewebe. Die Paraffinschnitte aus dem TMA wurden mit anti-H1x oder anti-Gesamt-H1, als Positivkontrolle, inkubiert. Ein Präimmunserum diente als Negativkontrolle. Abgesehen von vereinzelten Kernen zeigte das Präimmunserum nachweislich keine Reaktion auf den Schnitten.

Die resultierenden Signale auf den Schnitten waren für alle H1-Histone in den Kernen lokalisiert. Die Gegenüberstellung von H1x- und H1-positiven Zellen erfolgte falls möglich in Nachbarschnitten, die direkt nacheinander aus dem Paraffinblock geschnitten worden waren. Dieser Vergleich zeigte, daß im allgemeinen mehr H1x-positive Zellen im Bereich des Tumors als im Normalgewebe zu finden waren. Im Gegensatz dazu waren die H1-positiven Zellen wie zu erwarten gleichmäßig in Tumor und Normalgewebe verteilt (s. Abbildung 22-Abbildung 26).

Die Markierungen von H1x und Chromogranin A in Nachbarschnitten deutete auf eine ähnliche Verteilung von H1x und Chromogranin A in einigen der untersuchten Proben hin, waren jedoch für die Fragestellung der Kolokalisation zu ungenau. Mit den Antikörpern gegen Vimentin, CEA und CD45 konnte anhand von Immunreaktionen in Nachbarschnitten keine Korrelation mit H1x festgestellt werden (s. Abbildung 22). 


\section{H1x Gesamt-H1 Cg A Vimentin CEA CD45}

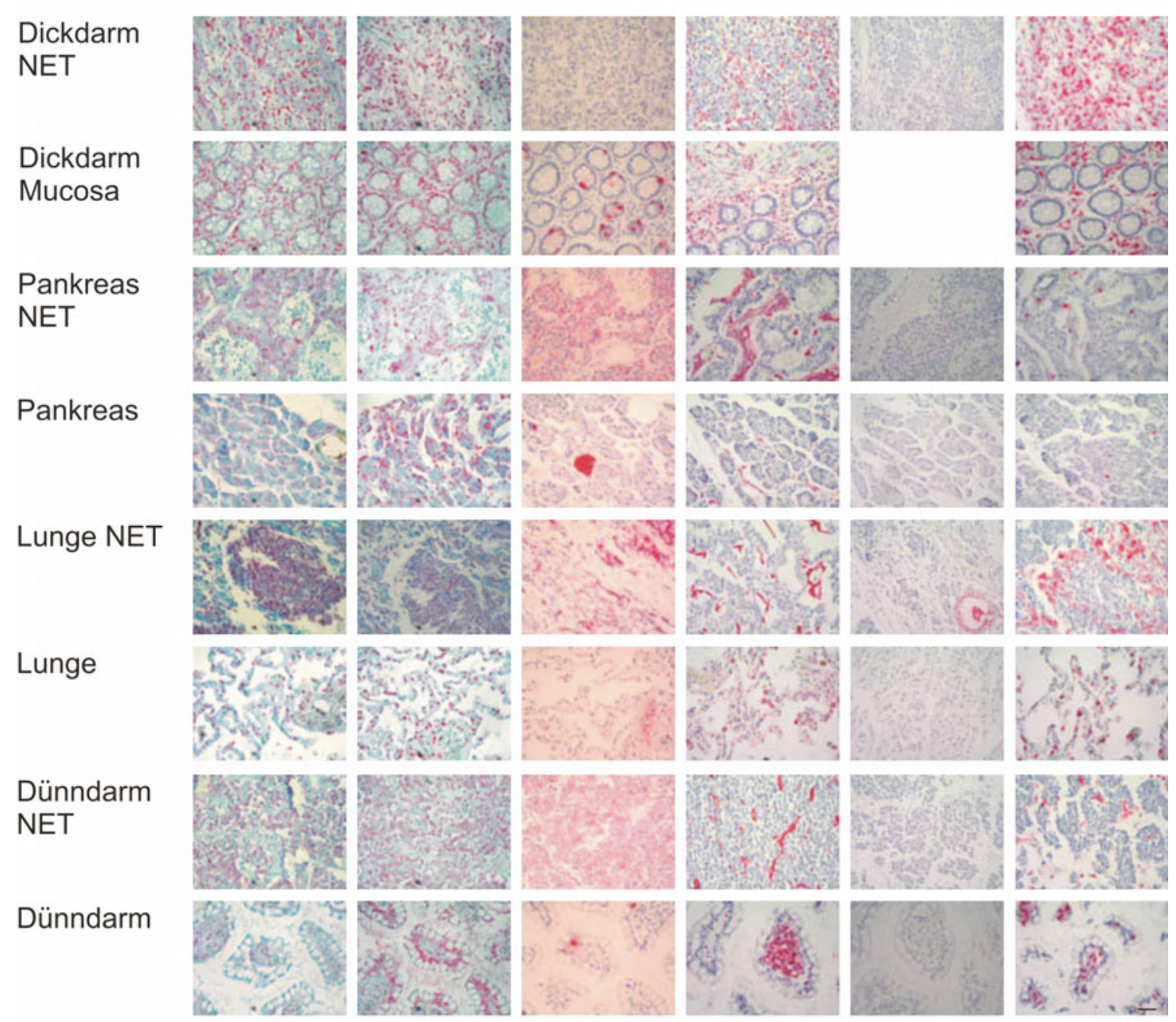

Abbildung 22: Zusammenstellung der immunhistochemischen Nachweise

Übersicht über die mit Antikörpern gegen H1x, Gesamt-H1, Chromogranin A (Cg A), Vimentin, CEA und CD45 untersuchten Gewebeproben. Der Nachweis der Proteine erfolgte mit dem Chromogen Red, so daß eine positive Immunfärbung rot erscheint. Der Hintergrund wurde mit Anilinblau gefärbt und ist bläulich. Von oben nach unten abgebildet haben die Proben die folgenden ID-Nummern: 6T, 7N, 19T, 19N, 8T, 9N, 4T, 4N (s. Tabelle 22). Der schwarze Balken entspricht $50 \mu \mathrm{m}$.

Die detaillierte Betrachtung der Immunhistologie zeigte folgendes:

Die Antikörper gegen H1x und gegen Gesamt-H1 zeigten starke immunhistochemische Reaktionen in Zellen des neuroendokrinen Dickdarmkarzinoms (s. Abbildung 23, linke Spalte), besonders in kleinen Zellkernen. Die Zellen des Tumors, die größere und damit weniger kondensierte Kerne hatten, zeigten eine vergleichsweise schwache Färbung für H1x. In der Mucosa des Dickdarms (Normalgewebe) konnten positive Immunantworten 
auf H1x in Zellen des umgebenden Gewebes beobachtet werden (Pfeile, Abbildung 23, H1x, N). Diese H1x-positiven Zellen hatten allerdings keinen lang ausgezogenen Zellkern und waren damit wohl keine Bindegewebszellen. Es ist daher zu vermuten, daß es sich um mobile Zellen, wie zum Beispiel Lymphozyten oder Mastzellen handelt (persönliche Mitteilung von Prof. Füzesi). Die vorwiegende Zellpopulation des Dickdarmepithels, die Becherzellen, zeigten keine H1x-Expression. Gesamt-H1-Histone konnten sowohl in Bindegewebe als auch in Becherzellen (Pfeile, Abbildung 23, H1, N) nachgewiesen werden.

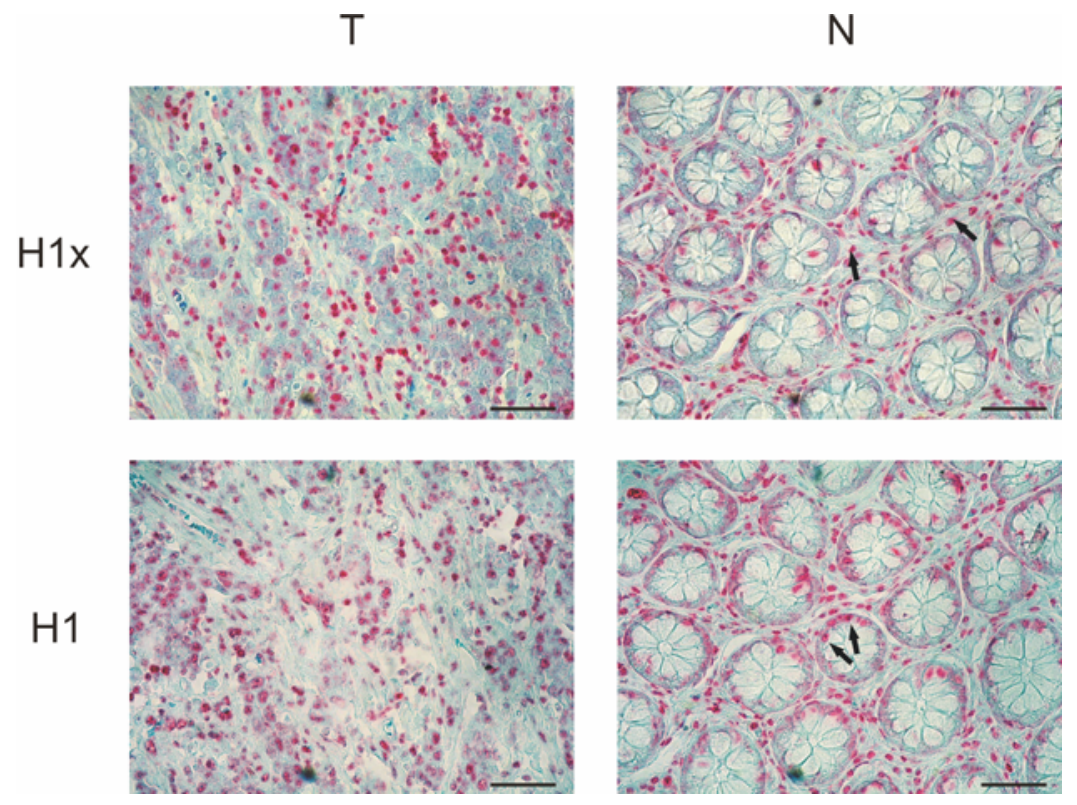

\section{Abbildung 23: Immunhistochemie der Dickdarmproben (ID-Nummern 6 und 7)}

T: Tumorproben (linke Spalte), N: Dickdarmschleimhaut (rechte Spalte), H1x: als Primärantikörper wurde anti-H1x eingesetzt (obere Zeile), H1: als Primärantikörper wurde antiGesamt-H1 verwendet (untere Zeile). Der schwarze Balken entspricht $50 \mu \mathrm{m}$.

Im Tumorgewebe aus neuroendokrinem Karzinom ist sowohl bei $\mathrm{H} 1 \mathrm{x}$ als auch bei $\mathrm{H} 1$ eine deutliche positive Immunreaktion (rot) zu erkennen. Im Normalgewebe zeigt sich, daß H1x nur in gewissen Zellen außerhalb des Dickdarmepithels vorkommt (Pfeile), während Gesamt-H1 praktisch in jedem Zelltyp zu finden ist. Die Becherzellen der Darmschleimhaut sind H1-positiv (Pfeile). 


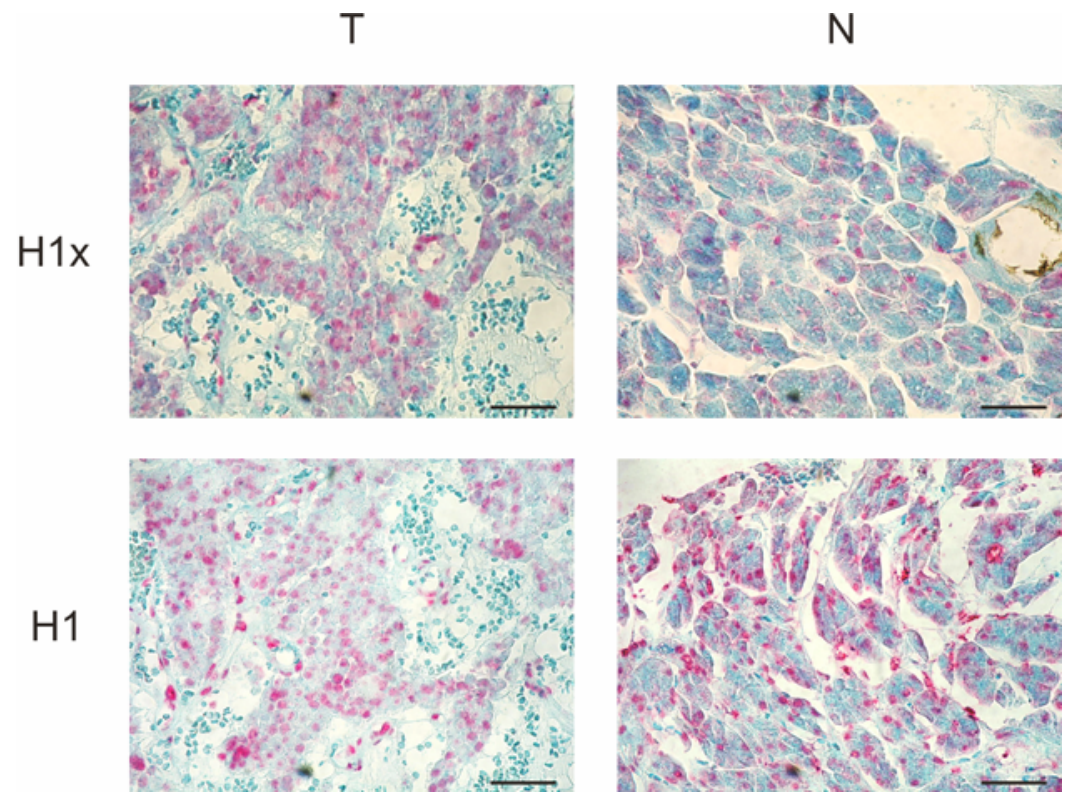

Abbildung 24: Immunhistochemie der Pankreasschnitte (ID-Nummer 19)

T: Tumor, N: gesundes Pankreasgewebe, H1x: als Primärantikörper wurde anti-H1x eingesetzt, H1: als Primärantikörper wurde anti-Gesamt-H1 verwendet. Der schwarze Balken entspricht $50 \mu \mathrm{m}$.

Im neuroendokrinen Karzinom des Pankreas ist kein Unterschied in den Immunreaktionen der Antikörper gegen H1x und Gesamt-H1 erkennbar. Die Tumorzellen (rot gefärbt) reagierten positiv mit den Antikörpern, während die kernlosen Erythrozyten (türkisblaue, kleine Zellen) kein $\mathrm{H} 1$ enthalten. Im Normalgewebe des exokrinen Pankreas ist H1x in einigen Azinuszellen nachzuweisen, Gesamt-H1 wird in allen Azinuszellen synthetisiert.

Eine deutliche Immunreaktion für H1x und Gesamt-H1 konnte in den Tumorzellen des neuroendokrinen Pankreaskarzinoms beobachtet werden, jedoch nicht in den kernlosen Erythrozyten (blau, in Gefäßen). In einigen wenigen zentroazinären Zellen des gesunden exokrinen Pankreas konnte H1x nachgewiesen werden. Die Gesamt-H1Reaktion in diesen Zellen war vergleichsweise stark (s. Abbildung 24). 


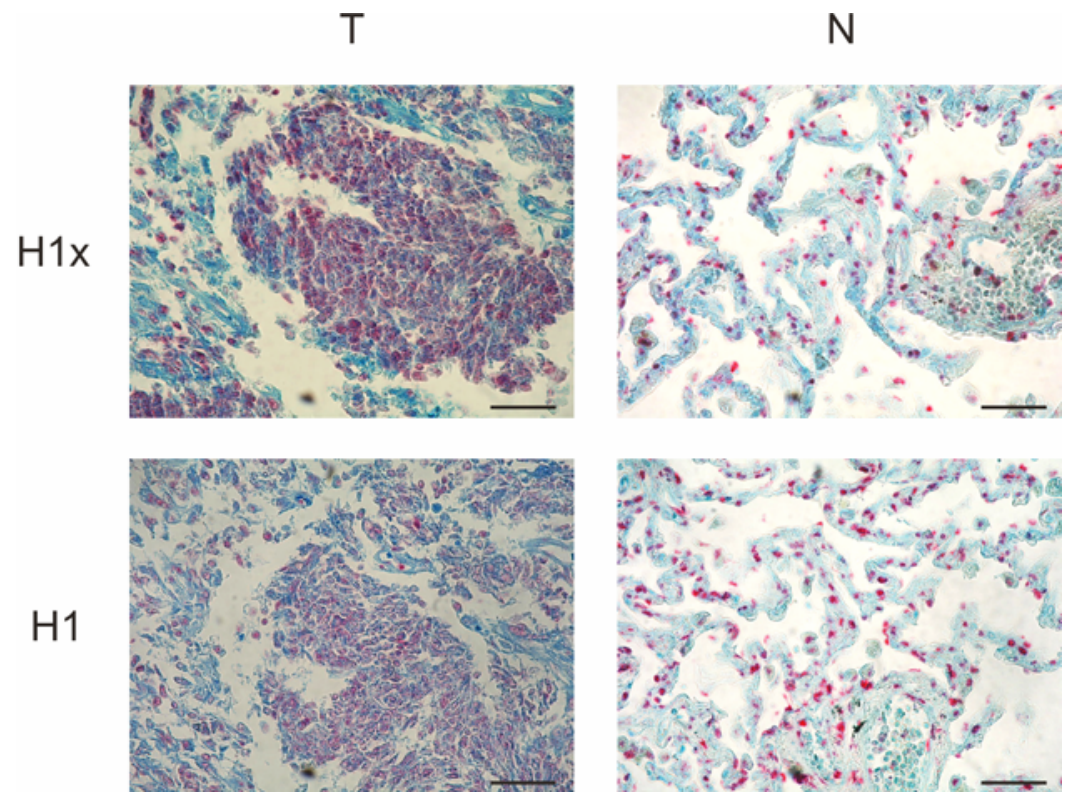

Abbildung 25: Immunhistochemie der Lungenproben (ID-Nummern 8 und 9)

T: Tumor, N: gesundes Lungengewebe, H1x: als Primärantikörper wurde anti-H1x eingesetzt, H1: als Primärantikörper wurde anti-Gesamt-H1 verwendet. Der schwarze Balken entspricht $50 \mu \mathrm{m}$.

Im Tumorgewebe des neuroendokrinen Karzinoms der Lunge ist bei der immunhistochemischen Reaktion kein Unterschied zwischen dem Vorkommen von H1x und Gesamt-H1 zu erkennen. Beide Primärantikörper riefen eine deutliche positive Immunreaktion (rot) in den Tumorzellkernen hervor. Im Normalgewebe zeigt sich, daß mehr Zellen Gesamt-H1 enthalten als H1x.

Sowohl der anti-H1x-Antikörper als auch der Antikörper gegen Gesamt-H1 zeigten eine deutliche Reaktion mit den Kernen der Tumorzellen des neuroendokrinen Lungenkarzinoms. In Schnitten aus gesunder Lunge konnten H1x und Gesamt-H1 in den unterschiedlichen Zellen des Lungengewebes nachgewiesen werden. Fast alle Zellen der gesunden Lunge waren H1-positiv, während nur einige Zellen der Lunge H1x-positiv waren (s. Abbildung 25). 

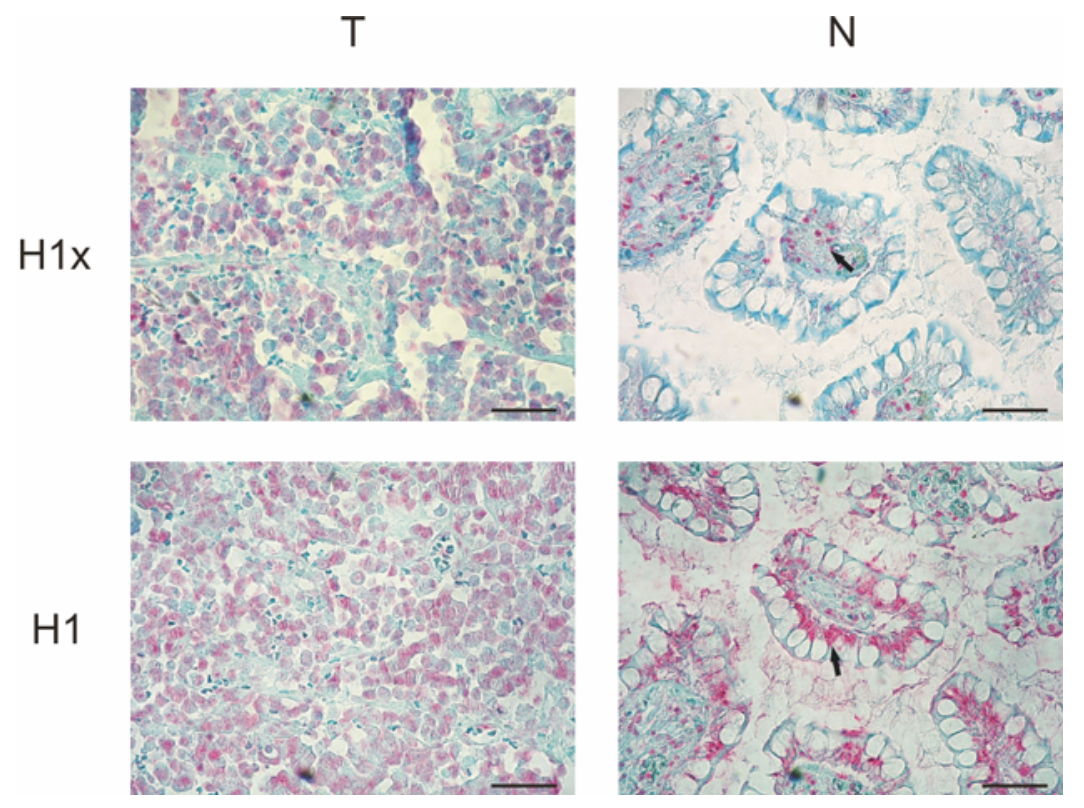

Abbildung 26: Immunhistochemie der Dünndarmproben (ID-Nummer 4)

T: Tumor, N: gesundes Lungengewebe, H1x: als Primärantikörper wurde anti-H1x eingesetzt, H1: als Primärantikörper wurde anti-Gesamt-H1 verwendet. Der schwarze Balken entspricht $50 \mu \mathrm{m}$.

Im Tumorgewebe aus neuroendokrinem Karzinom des Dünndarms ist sowohl für H1x als auch für Gesamt-H1 eine deutliche positive Immunreaktion (rot) zu erkennen. Im Normalgewebe zeigt sich, daß H1x nur in wenigen Zellen außerhalb des Dickdarmepithels vorkommt (Pfeil), während Gesamt-H1 in allen Zellen der Darmschleimhaut nachweisbar ist (Pfeil).

Eine deutliche Immunreaktion für $\mathrm{H} 1 \mathrm{x}$ und Gesamt-H1 kann in den Zellen des neuroendokrinen Tumors des Dünndarms beobachtet werden (s. Abbildung 26, linke Spalte). Im untersuchten Dünndarmepithel ist keine H1x-Antikörperreaktion erkennbar. Wenige Zellen des Bindegewebes (Pfeil, Abbildung 26, H1x, N) sind H1x positiv. Somatische H1-Histone konnten dagegen sowohl in Bindegewebe als auch in den Epithelzellen (Pfeil, Abbildung 26, H1, N) nachgewiesen werden.

Der Vergleich der Gesamt-H1-Histone mit H1x zeigt, daß H1x nur in wenigen Zellen des gesunden Gewebes nachweisbar ist, dafür aber in fast allen Tumorzellen.

Die Immunhistochemie bestätigte die Ergebnisse des Western-Blots: in den Proben aus nicht-neoplastischem Gewebe ist $\mathrm{H} 1 \mathrm{x}$ nur in einigen Zellen nachweisbar. In den Tumorzellen neuroendokriner Tumore der Lunge, des Pankreas und des Darms ist dagegen eine starke Immunreaktion des anti-H1x-Antikörpers erkennbar. Gesamt-H1- 
Histone ließen sich sowohl in den Kernen der Tumorzellen als auch in den Kernen der Zellen des nicht-neoplastischen Gewebes nachweisen.

\subsubsection{Chromogranin A-positive Zellen enthalten H1x}

Die vorliegenden Ergebnisse aus RT-PCR, Western-Blot und Immunhistochemie zeigten, daß sowohl die Transkription als auch die Proteinmenge von $\mathrm{H} 1 \mathrm{x}$ in neuroendokrinen Tumoren im Vergleich zu Normalgewebe, aber auch im Vergleich zu Gesamt-H1, erhöht war. Es zeichnete sich darüber hinaus eine Korrelation von H1x und neuroendokrinen Zellen ab. Daher stellte sich die Frage, ob eine starke $H 1 x$-Expression spezifisch für neuroendokrine Zellen ist. Eine immunhistochemische Doppelmarkierung mit fluoreszenzmarkierten Antikörpern gegen H1x und Chromogranin A - als Marker für neuroendokrine Zellen - wurde an den Paraffinschnitten vorgenommen, um diese Frage zu klären (s. Kapitel 3.2.2.5).

Die Untersuchungen ergaben, daß der Zustand nur einer einzigen Probe aus dem Kollektiv den Nachweis mit fluoreszenzmarkierten Antikörpern zuließ. Alle anderen Proben wiesen auch nach diversen Veränderungen der Bedingungen zu viel Hintergrundfärbung auf und konnten nicht bewertet werden. Die einzige zu bewertende Probe (ID-Nummer 28) stammte aus Darmgewebe und zeigte, daß die meisten Chromogranin A-positiven Zellen H1x exprimierten, aber nicht alle H1x-positiven Zellen Chromogranin A-positiv waren. Insbesondere gab es viele Zellen im gesunden Gewebe, die eine Immunreaktion mit dem H1x-Antikörper zeigten, in denen sich aber kein Chromogranin A nachweisen ließ (s. Abbildung 27). Das heißt, daß H1x nicht als spezifisch für neuroendokrine Zellen anzusehen ist. Die Zellen, die sowohl Chromogranin A- als auch H1x-positiv sind, fallen durch einen grünen Kern (Signal für H1x) mit rot granuliertem Zytoplasma (Signal für Chromogranin A) auf (s. Abbildung 28). Es gibt keine Überlagerung der beiden Farben zu gelb, da die beiden untersuchten Proteine in unterschiedlichen Kompartimenten der Zelle lokalisiert sind. 
Chromogranin A
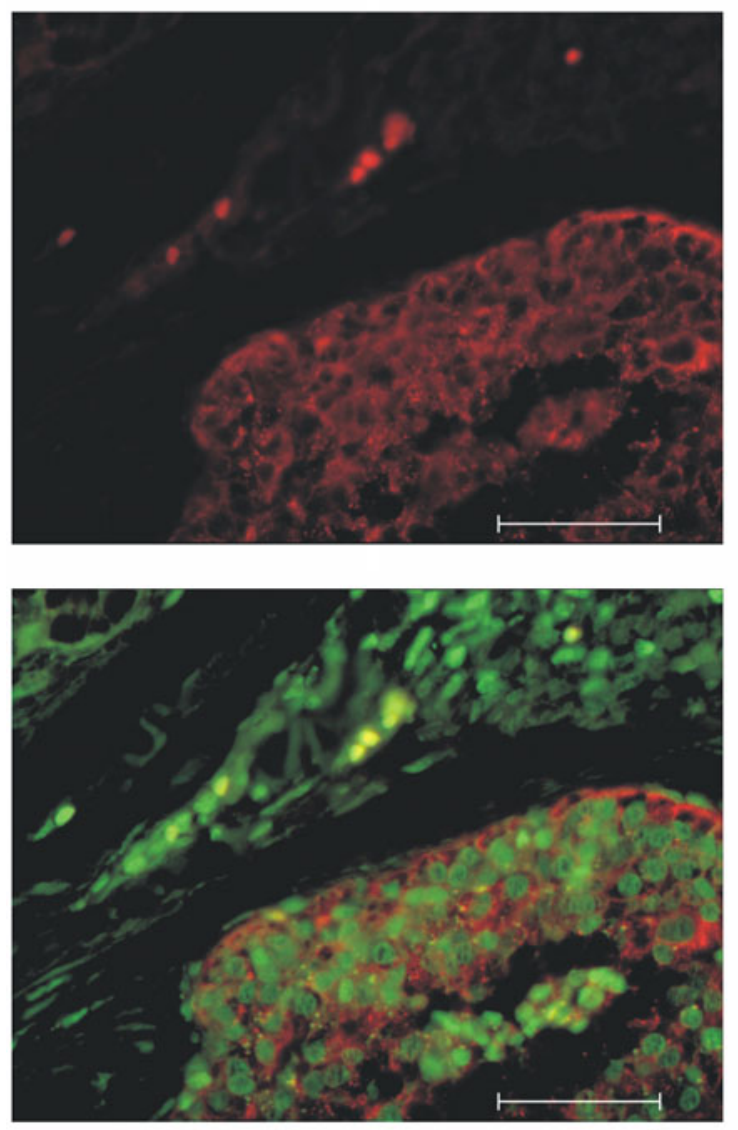

Überlagerung Chromogranin $\mathrm{A}$ und $\mathrm{H} 1 \mathrm{x}$
$\mathrm{H} 1 \mathrm{x}$
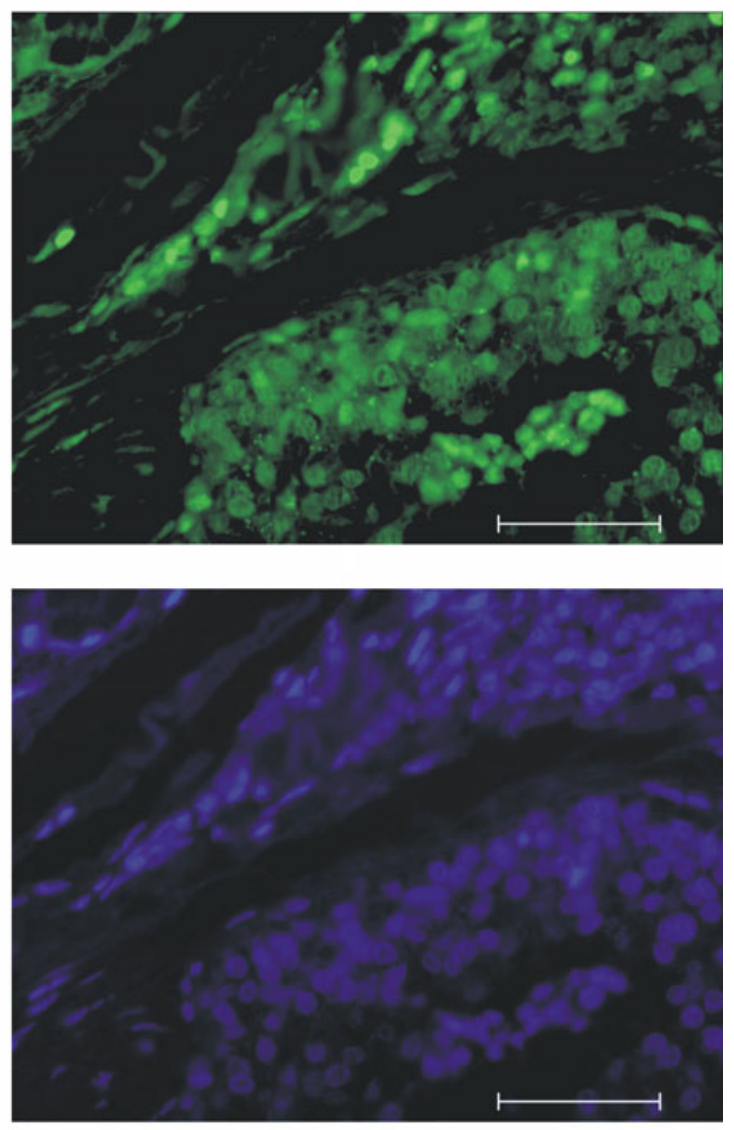

Dapi

\section{Abbildung 27: Übersicht Fluoreszenzdoppelmarkierung in Darmgewebe (ID 28)}

Chromogranin A zeigt rote Fluoreszenz, H1x fluoresziert grün, die Kerne wurden mit DAPI (blau) gefärbt. Unten rechts in jedem Bild: Tumor, oben links in allen drei Bildern: Normalgewebe. Der weiße Größenbalken entspricht $50 \mu \mathrm{m}$.

Chromogranin A ist in Granula im Cytoplasma enthalten, H1x in den Kernen. Deshalb gibt es keine Überlagerung von rot und grün zu gelb. Im Tumorbereich sind Übereinstimmungen zwischen H1x- und Chromogranin A-positiven Zellen zu sehen. H1x ist aber auch in Zellen des Normalgewebes vorhanden, die nicht Chromogranin A-positiv sind. 
Chromogranin A
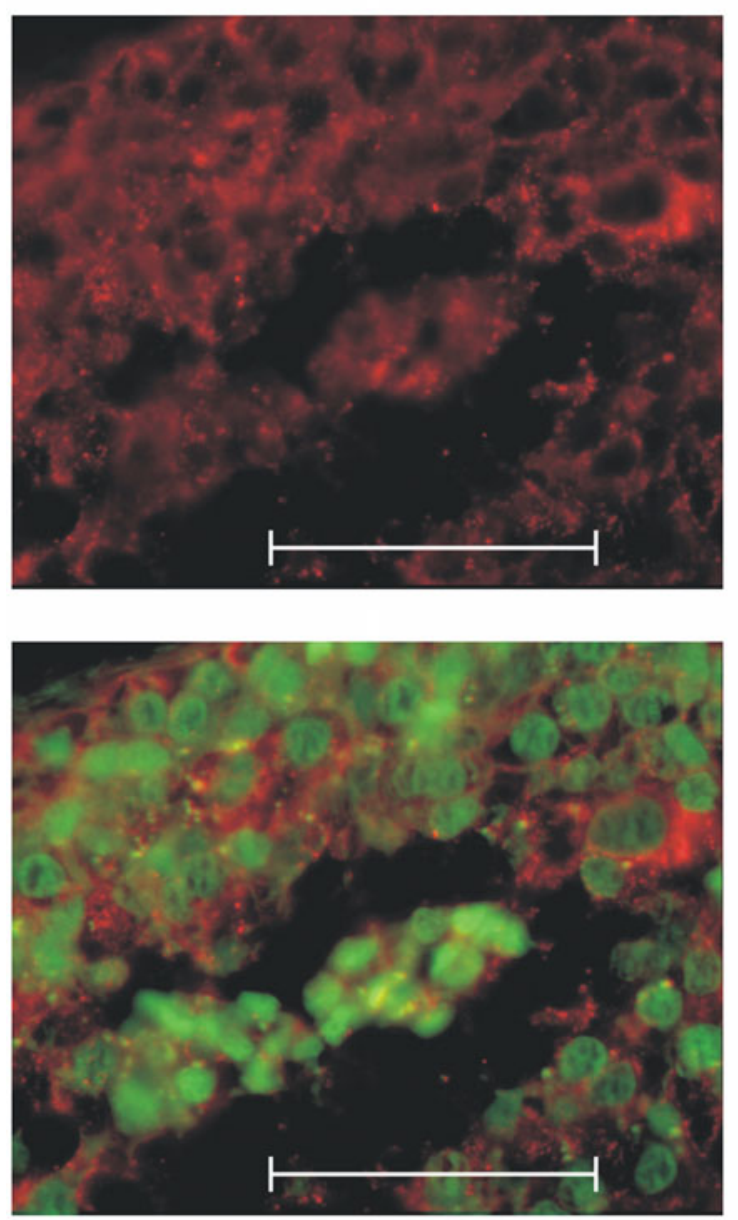

Überlagerung Chromogranin $\mathrm{A}$ und $\mathrm{H} 1 \mathrm{x}$
$\mathrm{H} 1 \mathrm{x}$
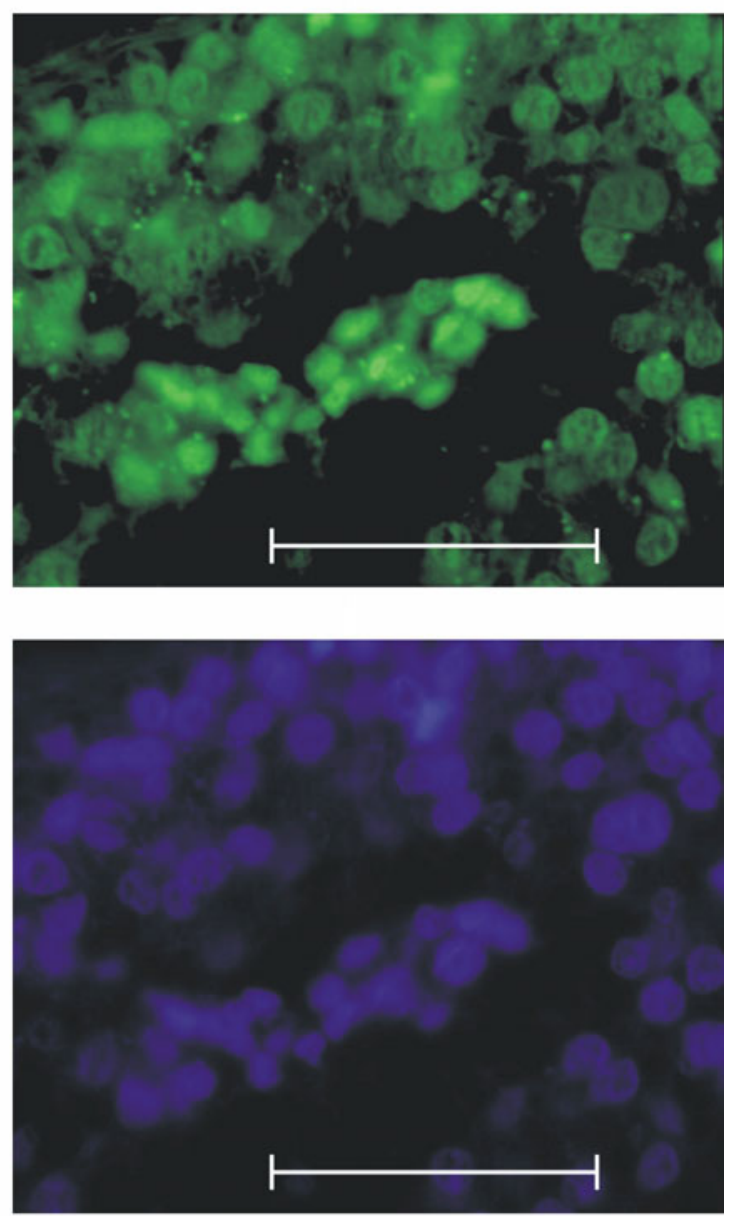

Dapi

Abbildung 28: Ausschnittvergrößerung des Tumorbereichs der Probe 28 aus

\section{Darm}

Ein Ausschnitt aus dem unteren rechten Bereich der in Abbildung 27 abgebildeten Probe zeigt deutlich, daß die Chromogranin A-positiven Zellen (rote Granula im Zytoplasma) H1x enthalten (grüne Kernfärbung). Der weiße Größenbalken entspricht $50 \mu \mathrm{m}$.

Zusammenfassend ergaben die Untersuchungen mittels RT-PCR, Western-Blot und Immunhistochemie, daß die erhöhte Expression von $H 1 x$ in neuroendokrinen Tumoren anscheinend auf die unterschiedliche Dignität der Tumore (wenig differenziertes Karzinom vs. Karzinoid) zurückgeführt werden kann und es einen Zusammenhang zwischen dem Vorkommen von Chromogranin A und $\mathrm{H} 1 \mathrm{x}$ gibt. H1x wird in neuroendokrinen Zellen exprimiert. 


\subsection{H1-mRNA Expression in Abhängigkeit des Entwicklungsstadiums}

Histongene gehörten zu den ersten Genen, die isoliert und charakterisiert wurden. Die Gene wurden aus Seeigelembryonen isoliert, da in diesen marinen Invertebraten während der Embryonalentwicklung durch die schnell aufeinanderfolgenden Zellteilungen sehr viel Histon-mRNA vorkommt (Kedes et al., 1975). Die Anhäufung von Histon-mRNA läßt sich durch die rasche Entwicklung der Embryonen erklären, bei der große Histonmengen für neues Chromatin synthetisiert werden müssen. Verschiedene Histongruppen werden abhängig von Gewebe und Zeitpunkt der Entwicklung unterschiedlich stark exprimiert (Kedes et al., 1975). Lennox und Cohen (1983) beschreiben weiterhin, daß sich das Verhältnis der unterschiedlichen H1Subtypen in den ersten Lebenswochen von Mäusen deutlich verändert und einige Subtypen (H1.1 und H1.5) mit zunehmendem Alter der Tiere fast nicht mehr nachzuweisen sind.

Aufgrund dieser Publikationen und da sich die Menge von H1x-mRNA in neuroendokrinen Tumoren im Vergleich zu nicht-neoplastischem Gewebe als erhöht dargestellt hatte, wurde untersucht, ob die Expression von $H 1 x$ mit intensivem Zellwachstum korreliert und dementsprechend in fötalem stärker als in adultem Gewebe exprimiert wird. Daraufhin wurde die relative H1x-mRNA-Menge in fötalem Gewebe ermittelt und mit der Transkriptmenge von H1x in adultem Gewebe verglichen. Um die Expressionsrate von $H 1 x$ mit den replikationsabhängigen und -unabhängigen Subtypen vergleichen zu können, wurden die Expressionsmuster der verschiedenen humanen H1-Subtypen mittels RT-PCR in adultem und fötalem Gewebe aus Lunge und Dickdarm untersucht. Die dazu verwendete Gesamt-RNA wurde von der Firma Stratagene bezogen und wie in Kapitel 3.1.6.3 beschrieben auf Qualität überprüft und in cDNA umgeschrieben. Die Auswertung der RT-PCR-Daten erfolgte mittels $2^{-\Delta \Delta C_{T}}$-Methode. 18S-rRNA diente als Referenz, als Kalibrator wurde der $\mathrm{C}_{\mathrm{T}}$-Wert von $\mathrm{H} 1.3$ aus adulter Lunge bzw. für die Darmproben der $\mathrm{C}_{\mathrm{T}}$-Wert von $\mathrm{H} 1.3$ aus adultem Kolon eingesetzt. Da bei dieser Untersuchung auch die Expressionsunterschiede zwischen den H1-Subtypen in adultem Gewebe festgestellt werden sollten, wurde H1.3 als Kalibrator ausgewählt anstelle der $\mathrm{C}_{\mathrm{T}}$-Werte aus adultem Gewebe. Bei der Verwendung der $\mathrm{C}_{\mathrm{T}}$-Werte der adultem RNA hätte sich für adultes Gewebe aller Subtypen ein Wert von eins ergeben. 
Für alle H1-Subtypen wurde eine erhöhte Expressionsrate in fötalem Gewebe festgestellt. Die einzige Ausnahme bildete H1.4 in Kolon. Hier war zwar eine sehr hohe Expression im Vergleich zu den anderen H1-Subtypen sowohl in adultem als auch in fötalem Gewebe zu verzeichnen (s. Abbildung 29), jedoch wies die adulte Probe 1,5mal mehr H1.4 mRNA auf als die fötale. Auch in Lungengewebe war eine hohe Expression von H1.4 erkennbar. Das fötale Gewebe wies eine 3,3-fach höhere H1.4mRNA-Menge auf als das adulte Gewebe (s. Abbildung 30). $H 1 x$ und $H 1.1$ zeigten sowohl in Lunge als auch in Kolon eine im Vergleich zu anderen H1-Subtypen sehr schwache Expression.

In adulter Lunge war H1.5 sehr schwach exprimiert. Die Expression von H1.5 in fötaler Lunge war dafür um so deutlicher erkennbar (s. Abbildung 30). Ansonsten zeigten $H 1^{\circ}$ in Kolon (neunfache Expression in fötal) und H1.3 in Lunge (7,6-fache Expression in fötal) große Expressionsunterschiede zwischen adulten und fötalen Proben auf. Das im Vergleich zu H1.2 und H1.4 sehr wenig exprimierte $H 1 x$ wies eine fünf- bzw. 2,5-fach höhere Expression in fötalem gegenüber adultem Gewebe auf, zeigte damit aber einen eher geringen Unterschied zwischen adultem und fötalem Gewebe (s. Abbildung 29 und Abbildung 30). 


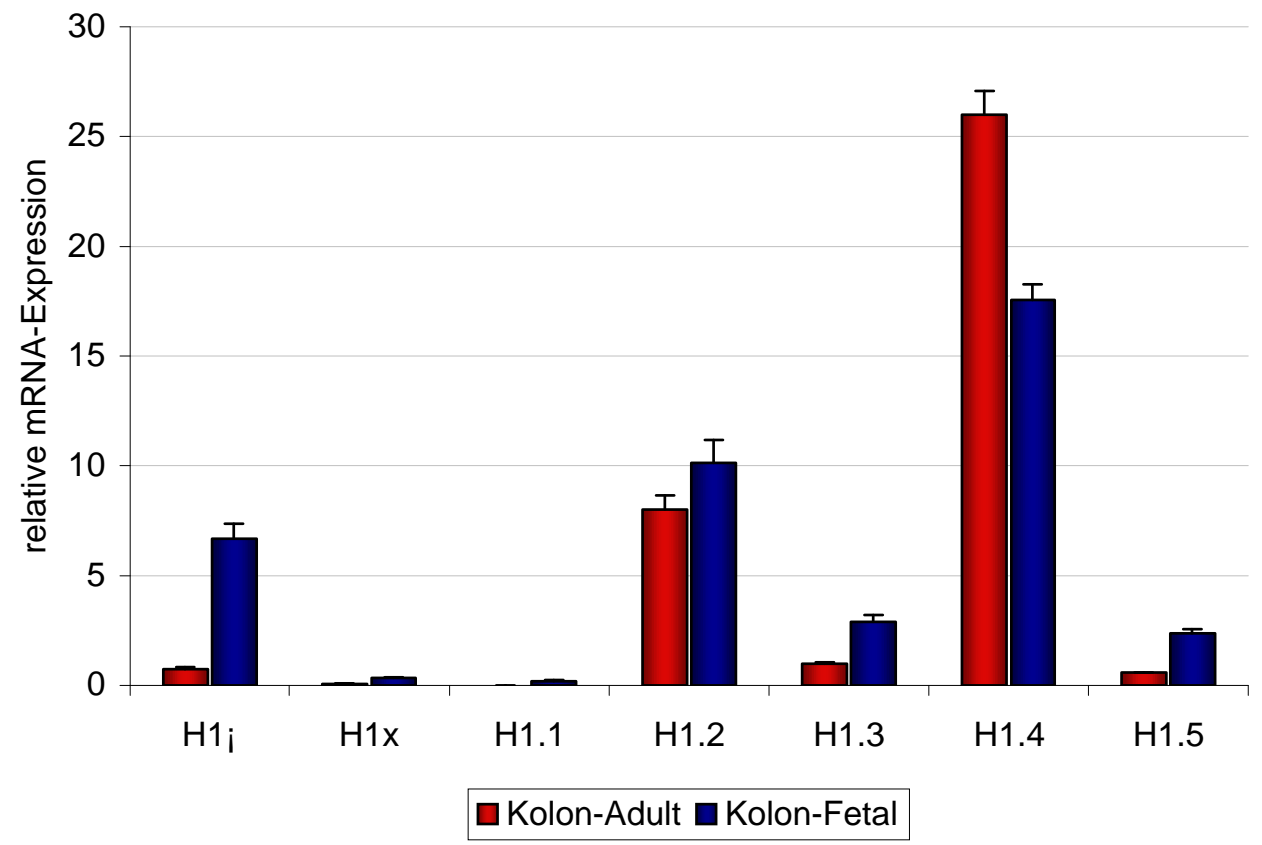

Abbildung 29: Vergleich der mRNA-Expression der $H 1$-Histonsubtypen $H 1^{\circ}, H 1 x$ und H1.1-H1.5 in adultem und fötalem Dickdarm

RNA-Proben aus adultem und fötalem Dickdarm wurden mittels quantitativer RT-PCR auf ihren H1-Histongehalt untersucht. Die Subtypen H1 ${ }^{\circ}, \mathrm{H} 1 \mathrm{x}$ und H1.1-H1.5 wurden jeweils in adultem und fötalem Gewebe verglichen. Die Ergebnisse wurden nach der $2^{-\Delta \Delta C_{T}}$-Methode ausgewertet. 18S-rRNA diente als Referenz-RNA, der $\mathrm{C}_{\mathrm{T}}$-Wert von $\mathrm{H} 1.3$ aus adultem Dickdarm als Kalibrator. Die Standardabweichungen ergeben sich aus drei Messungen. 


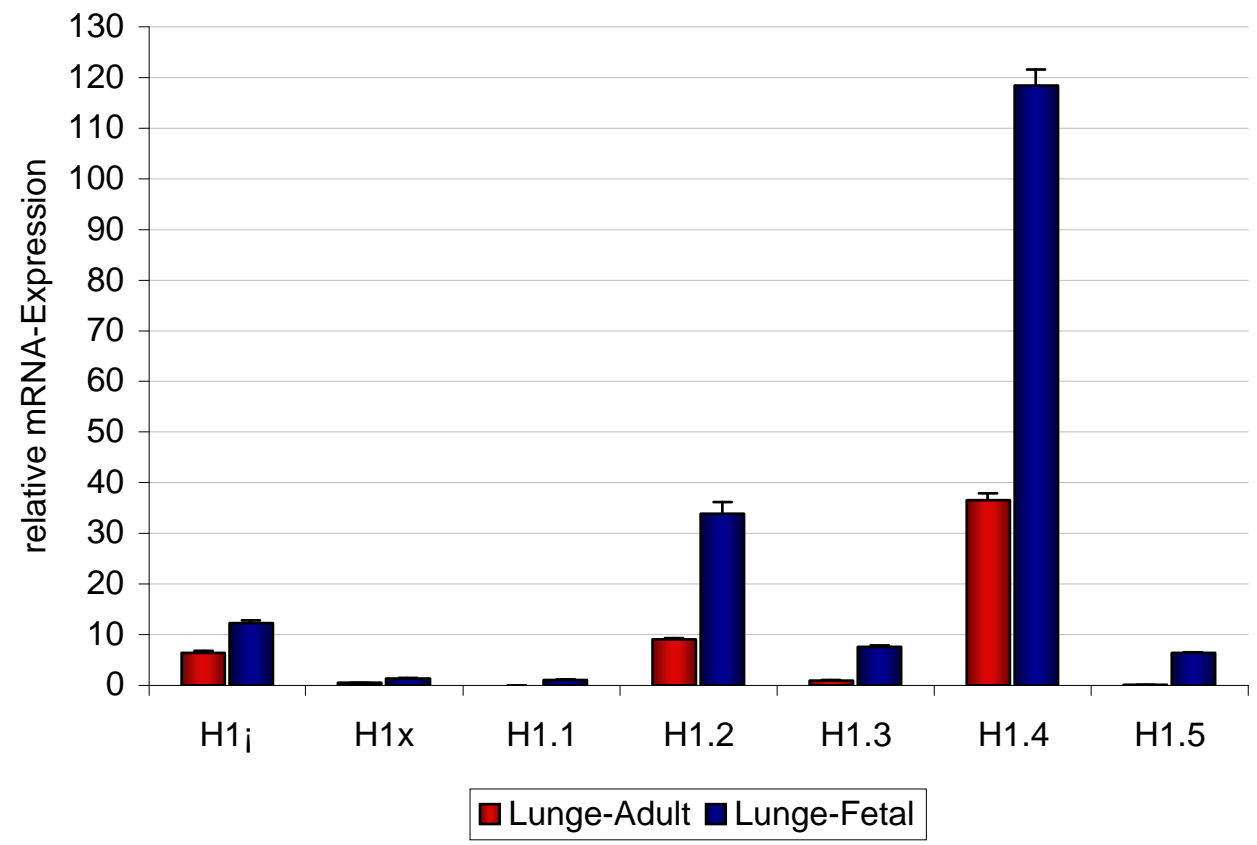

\section{Abbildung 30: Vergleich der mRNA-Expression der $\mathrm{H1}$-Histonsubtypen $\mathrm{H1}{ }^{\circ}, \mathrm{H1x}$ und H1.1-H1.5 in adulter und fötaler Lunge}

RNA-Proben aus adulter und fötaler Lunge wurden mittels quantitativer RT-PCR auf ihren H1Histongehalt untersucht. Die Subtypen $\mathrm{H}^{\circ}$, H1x und H1.1-H1.5 wurden jeweils in adultem und fötalem Gewebe verglichen. Die Ergebnisse wurden nach der $2^{-\Delta \Delta C_{T}}$-Methode ausgewertet. 18S-rRNA diente als Referenz, der $\mathrm{C}_{\mathrm{T}}$-Wert von H1.3 aus adulter Lunge als Kalibrator. Die Standardabweichungen wurden aus drei Messungen ermittelt.

Zusammenfassend ist für den Vergleich der H1-Expressionen in adultem und fötalem Gewebe festzustellen, daß die mRNA-Expression von H1x in den untersuchten Proben aus fötaler Lunge und fötalem Dickdarm gegenüber adultem Gewebe nur leicht erhöht ist. Mit Ausnahme des Subtyps H1.4 in Kolon sind die relativen mRNA-Mengen aller untersuchten Subtypen sowohl in Lunge als auch in Kolon in fötalem Gewebe größer als in adultem Gewebe. 



\section{Diskussion}

Im Jahr 1966 beschrieben Kinkade \& Cole (1966) zum ersten Mal die Existenz von verschiedenen H1-Histonsubtypen. Obwohl das Wissen um diese Diversität also schon seit mehr als 40 Jahren besteht, ist bis heute weitestgehend ungeklärt, wie die Expression der H1-Subtypen reguliert wird und welche spezifischen Funktionen die einzelnen Subtypen haben.

H1-Histongene werden im Verlauf des Zellzyklus (Heintz et al., 1983; Plumb et al., 1983; Zlatanova, 1980; Zlatanova \& Doenecke, 1994; Doenecke et al., 1994) und in verschiedenen Zelltypen (Tan et al., 1982; Goodlad \& Clark, 1995; Kostova et al., 2005) unterschiedlich stark exprimiert. Während die Hauptklassesubtypen H1.1, H1.2, H1.3, H1.4 und H1.5 während der S-Phase exprimiert werden (Heintz et al., 1983; Plumb et al., 1983), wenn Histone für die Verpackung neu replizierter DNA benötigt werden, ist $H 1^{\circ}$ ein replikationsunabhängig exprimiertes Gen, das vermehrt in arretierten und terminal differenzierten Zellen exprimiert wird (Zlatanova, 1980; Zlatanova \& Doenecke, 1994; Doenecke et al., 1994). Über die Regulierung der Expression des bisher wenig untersuchten H1-Histons H1x (Yamamoto \& Horikoshi, 1996) während verschiedener Zellzyklusphasen und in Zellen unterschiedlichen Ursprungs war zu Beginn der vorliegenden Arbeit kaum etwas bekannt. Gemeinsamkeiten von $H 1 x$ mit dem replikationsunabhängigen $H 1^{\circ}$, wie beispielsweise eine polyadenylierte mRNA, eine solitäre chromosomale Lokalisation (Sulimova et al., 2002) und die Ähnlichkeit der Verteilung von Sequenzmotiven im H1x-Promotor mit dem $H 1^{\circ}$-Promotor (s. Kapitel 4.1.1), führten zu der Frage, ob es sich bei $H 1 x$ ebenfalls um ein replikationsunabhängig exprimiertes Gen handelt. Weiterhin gab eine erhöhten Trefferrate von H1x-ESTs (expressed sequence tags) in Tumordatenbanken neuroendokriner Tumore (s. Kapitel 4.3) Hinweise darauf, daß $H 1 x$ in bestimmten Tumoren vermehrt exprimiert sein könnte.

Um diese Fragen zu klären, wurde in der vorliegenden Arbeit eine vergleichende Expressionsanalyse der H1-Subtypen im Verlauf des Zellzyklus, in neuroendokrinen Tumoren und in unterschiedlichen Entwicklungsstadien humanen Gewebes durchgeführt. 


\subsection{Promotoranalyse von $\mathrm{H} 1 x$}

Die variable Zusammensetzung der H1-Histone während unterschiedlicher Entwicklungs- und Differenzierungsphasen von Geweben und Zellen deutet auf eine vielfältige und komplexe Kontrolle der Expression und Synthese der H1-Gene hin (Lennox \& Cohen, 1982; Brown et al. 1996). Um einen Einblick in die Regulation der Expression des H1-Subtyps $H 1 x$ zu bekommen, wurde in der vorliegenden Arbeit eine Promotoranalyse der genomischen Sequenz von $H 1 x$ durchgeführt.

Das Ziel dieser Promotoranalyse war, einen zur funktionellen Expression von $H 1 x$ geeigneten Promotor zu finden. Zunächst wurden potentielle Transkriptionsfaktorbindungsstellen für $H 1 x$ durch Vergleich der genomischen Sequenz von $H 1 x$ mit regulatorischen Konsensuselementen anderer H1-Gene vorhergesagt. Anhand der Verteilung potentieller Promotorelemente wurden unterschiedlich lange Expressionskonstrukte erstellt, deren Aktivität in Luciferase-Assays gemessen wurde. Wie aus den Ergebnissen der Luciferasemessungen (s. Kapitel 4.1.2) und der transienten Transfektion in HeLa-Zellen (s. Kapitel 4.1.3) hervorgeht, war das Konstrukt 55, das die Elemente CH1UE, H1-Box, UPE und TATA-Box enthält, zur funktionellen Expression von $H 1 x$ in Tumorzellinien geeignet. Es zeigte in Luciferase-Assays gegenüber kürzeren Konstrukten die höchste Aktivität. Da die Promotorelemente der bisher untersuchten H1-Histongene in der Regel nicht weiter als 500 bp oberhalb desjenigen Promotorelements begannen, das am weitesten oberhalb des Transkriptionsstarts lag (Bouterfa et al., 1993; Khochbin \& Wolffe, 1993, Meergans et al. 1998), wurde in der vorliegenden Arbeit der untersuchte Bereich der 5'-flankierenden Region auf eine Länge von 1,5 kb oberhalb des Translationsstarts begrenzt. Die längste hier untersuchte $H 1 x$-Promotorsequenz (Konstrukt 55) beinhaltete dementsprechend ein 591 bp langes Stück oberhalb des ersten aus der Sequenz vorausgesagten Promotorelements.

Allerdings wurde für das Linkerhistongen $H 5$ des Huhns gezeigt, daß die transkriptionelle Aktivierung dieses Gens durch zwei Enhancer (DNA-Sequenzen, die das Ablesen eines Gens verstärken) oberhalb sowie einen Enhancer unterhalb des Transkriptionsstarts beeinflußt wird (Rousseau et al., 1993; Trainor et al., 1987). Dementsprechend ist 
es nicht auszuschließen, daß auch im $H 1 x$-Gen außerhalb der hier untersuchten Region Enhancer vorhanden sind. Es bleibt zu klären, ob eine weitere Ausdehnung der Promotorsequenz in die 5'-flankierende Richtung zu noch stärkerer Expression von $\mathrm{H} 1 x$ geführt hätte.

Bei der Untersuchung der für die Promotoranalyse angefertigten Deletionsmutanten (s. Kapitel 4.1) zeichnete sich durch Luciferaseaktivitätsmessungen nicht nur die Eignung des Konstrukts 55 für die funktionelle Expression von $H 1 x$ ab, sondern auch, daß die meisten der vorausgesagten Promotorelemente (s. Abbildung 6, Tabelle 21) in der untersuchten $H 1 x$-Gensequenz funktionell aktiv waren. Es konnte gezeigt werden, daß das $453 \mathrm{bp}$ oberhalb des Transkriptionsstarts gelegene CH1UE für die $H 1 x$ Promotoraktivität von Bedeutung ist. Ob dieses Element wie das bei Khochbin und Wolffe (Khochbin \& Wolffe, 1993) für $H 1^{\circ}$ beschriebene UCE (upstream conserved element) in Kooperation mit proximalen Promotorelementen für die basale Expression von $H 1 x$ verantwortlich ist, bliebe bei einer genaueren Charakterisierung des $H 1 x$ Promotors zu klären.

Die Luciferaseaktivitätsmessungen zeigten weiterhin, daß die für $H 1 x$ vorausgesagte „umgedrehte CCAAT-Box“, die zudem noch an anderer Stelle als die CCAAT-Boxen anderer H1-Subtypen liegt (s. Abbildung 7), kein regulatorisches Promotorelement ist. Auch dem $\mathrm{H}^{\circ}{ }^{\circ}$-Gen fehlt die CCAAT-Box in der 5'-flankierenden Region (Meergans et al., 1998). Damit sind folgende Übereinstimmungen zwischen den Promotorelementen von $\mathrm{H} 1 \mathrm{x}$ und $H 1^{\circ} \mathrm{zu}$ verzeichnen: beide Promotoren enthalten ein upstream positive element und eine TATA-Box (s. Abbildung 7), aber keine funktionelle CCAAT-Box. Laut La Bella et al. (1989) und Heintz (1991) spielen die CCAAT-Box-bindendenFaktoren eine wichtige Rolle bei der Regulierung der Expression während der S-Phase. Dementsprechend sind auch die Daten der zellzyklusabhängigen Expressionsanalyse für H1x mit dem Fehlen einer funktionellen CCAAT-Box vereinbar, da bei diesen Untersuchungen gezeigt wurde, daß $H 1 x$ während der S-Phase nicht gesteigert exprimiert wird (s. Kapitel 4.2, Abbildung 17).

In den untersuchten $\mathrm{H} 1 \mathrm{x}$-Promotorkonstrukten konnte nur ein geringer Einfluß der H1Box auf die Promotoraktivität festgestellt werden (s. Kapitel 4.1.2). Da jedoch schon mehrfach ein Zusammenspiel zwischen verschiedenen Promotorelementen, wie zum 
Beispiel zwischen der H1-Box und dem CH1UE bzw. UCE (in $\mathrm{H}^{\circ}{ }^{\circ}$ ) sowie der H4-Box (in $H 1^{\circ}$ ), gefunden wurde (Khochbin \& Wolffe, 1993; Khochbin \& Lawrence, 1994; Meergans et al., 1998), ist eine Beteiligung der H1-Box an der Aktivität des $H 1 x$ Promotors nicht auszuschließen. Auch bei Khochbin \& Wolffe (1993) konnte kein signifikanter Unterschied zwischen Konstrukten, die die H1-Box und die H4-Box, aber kein UCE enthielten, und Konstrukten, die nur die H4-Box, und kein UCE enthielten, beobachtet werden. Die Bedeutung der Elemente wurde erst durch Deletion in einem langen Promotorkonstrukt, das das upstream conserved element enthielt, deutlich (Khochbin \& Wolffe, 1993). Für die genauere Aufklärung der H1x-Regulation auf Promotorebene, wären weitere Analysen mit Kombinationen deletierter oder mutierter Elemente unerläßlich.

Der Einfluß des UPE H4 (upstream positive element) auf die Aktivität des $H 1 x$ Promotors wurde beim Vergleich der Aktivität des Konstrukts 10, das das UPE H4 und die TATA-Box enthält, und des Konstrukts 23, das nur die TATA-Box enthält, ersichtlich. Dies ist ein Indiz dafür, daß $H 1 x$ replikationsunabhängig exprimiert wird, da das UPE H4 bisher nur in replikationsunabhängigen Histonen $\left(\mathrm{H} 1^{\circ}\right.$ und $\left.\mathrm{H5}\right)$ gefunden wurde (Bouterfa et al., 1993).

Das Konstrukt 18, dem ein in 5'-UTR (untranslated region) gelegener Sequenzabschnitt fehlte, zeigte einen Aktivitätsverlust von etwa 40 \% gegenüber dem Konstrukt 55. Demzufolge hat die gegenüber anderen H1-Subtypen vergleichsweise lange Sequenz der 5'-untranslatierten Region zwischen Transkriptions- und Translationsstart einen Einfluß auf die Aktivität des $H 1 x$-Promotors. Ein ähnlicher Aufbau wurde für den Promotor des replikationsunabhängig exprimierten H3.3-Gens geschildert. Für diesen Promotor beschreiben Frank et al. (2003) ein Initiationselement oberhalb des Translationsstarts. Bei Hurt et al. (1989) konnte gezeigt werden, daß das Fehlen eines Sequenzabschnitts innerhalb der kodierenden Region einen großen Einfluß auf die Expression des H3-Gens hat.

Für eine funktionelle Expression von $H 1 x$ war das Promotorkonstrukt 55, das alle vorhergesagten regulatorischen Elemente einschließlich des CH1UE und weiteren 591 bp in 5'-Richtung enthielt, geeignet. Die Funktionalität des erstellten $H 1 x$ Promotors konnte im Vergleich zu CMV-Promotoren mit Hilfe von GFP-Fusions- 
plasmiden gezeigt werden. Beide Promotoren führten gleichermaßen zu einer $H 1 x$ GFP-Expression in den transient transfizierten HeLa-Zellen (s. Abbildung 13, Abbildung 14). Zwischen den Konstrukten pJW 9 mit CMV-Promotor und pJW 34 mit $H 1 x$-Promotor konnte kein Unterschied bezüglich der Morphologie der transfizierten Zellen beobachtet werden.

Bei dieser Expressionsanalyse der GFP-Konstrukte in HeLa-Zellen fiel auf, daß H1x teilweise in den Nukleoli der transfizierten Zellen akkumuliert ist (s. Abbildung 14). Dabei konnte zwischen den Konstrukten mit CMV-Promotor und mit H1x-Promotor kein Unterschied in Bezug auf die Lokalisation von H1x-GFP in den Zellen festgestellt werden. Eine nukleoläre Anreicherung von H1x wurde auch bei Stoldt und Mitarbeitern (Stoldt et al., 2007) beschrieben. Diese konnten mittels Doppelimmunfluoreszenz- und Synchronisationsstudien zeigen, daß H1x während der G1-Phase in HeLa-Zellen nukleolär akkumuliert ist. Damit bleibt im vorliegenden Ansatz zu klären, ob das verwendete GFP-Konstrukt ebenso G1-Phase-abhängig in den Nukleoli angereichert wird.

\subsection{Vergleichende Expressionsanalyse von H1-Subtypen im Verlauf des Zellzyklus mittels quantitativer real-time RT-PCR}

Während der S-Phase des Zellzyklus müssen Histone in stöchiomerischen Mengen für die Bildung von Chromatin mit neu replizierter DNA zur Verfügung stehen. Obwohl die meisten Core- und H1-Histone parallel zur DNA-Replikation synthetisiert werden (Osley, 1991), wurde aber auch gezeigt, daß einige der Histonsubtypen, unter anderem der H1-Subtyp $\mathrm{H}^{\circ}{ }^{\circ}$ (Zlatanova, 1980), in nicht-proliferierenden Zellen, d.h. replikationsunabhängig, exprimiert werden. Zur Klärung der Frage, ob der Subtyp $H 1 x$ replikationsabhängig oder -unabhängig exprimiert wird, wurde in der vorliegenden Arbeit die Expression von H1x-mRNA im Vergleich zu somatischen H1Histonsubtypen und dem Replacementhiston $\mathrm{H} 1^{\circ}$ mittels quantitativer RT-PCR in synchronisierten HeLa-Zellen im Verlauf des Zellzyklus untersucht.

Die RT-PCR wurde Anfang der 90er Jahre als Methode zur Amplifikation von cDNA beschrieben (Higuchi et al., 1993; Schneeberger et al., 1995; Heid et al., 1996) und stellt zur Zeit die sensitivste und spezifischste Methode zur Bestimmung der 
Genexpression dar (Bustin, 2000). Für eine korrekte Anwendung der quantitativen RTPCR gibt es jedoch eine Reihe von Faktoren, die beachtet werden müssen (Bustin, 2002; Freeman et al., 1999). Im einzelnen sind dies die Konzentration der eingesetzten Gesamt-RNA, die Bestimmung der Effizienz der PCR, die Normalisierung auf Referenzgene sowie die Spezifität der PCR. In der vorliegenden Arbeit wurden daher die Konzentration und Integrität der Gesamt-RNA für jede Probe fluorometrisch bestimmt. Dies stellte einerseits sicher, daß nur intakte RNA für die weiteren Analysen verwendet wurde, andererseits gewährleistete die Konzentrationsbestimmung der Gesamt-RNA, daß für jede Probe die gleiche absolute Menge an Gesamt-RNA eingesetzt wurde. Die Effizienz der reversen Transkriptase für verschiedene Proben kann jedoch durch viele Faktoren beeinflußt werden (Zhang \& Byrne, 1999). Da davon auszugehen ist, daß die reverse Transkriptase innerhalb einer Probe die gesamte RNA mit gleicher Effizienz kopiert, kann die Expressionsrate eines Gens auf ein Referenzgen bezogen werden (Thellin et al., 1999). Als Referenzgene lassen sich Gene wie zum Beispiel $ß-A k t i n$, GAPDH und 18S-rRNA verwenden, da davon ausgegangen wird, daß sie im Idealfall in allen Zellen unter allen Bedingungen gleich stark exprimiert werden. Zahlreiche Studien zeigten jedoch, daß die Expression einiger dieser als Referenzgene verwendeten Gene abhängig von verschiedenen Bedingungen stark schwanken kann (Bereta \& Bereta, 1995; Bas et al., 2004; Roge et al., 2007, Port et al., 2007). In der vorliegenden Arbeit wurde 18S-rRNA als Referenz für die Berechnung der relativen mRNA-Menge mittels $2^{-\Delta \Delta C_{T}}$-Methode (Livak \& Schmittgen, 2001) gewählt, da mehrfach belegt werden konnte, daß 18S-rRNA eine sehr stabile Referenz-RNA darstellt, die in unterschiedlichen Geweben und Zellen zuverlässig die eingesetzte Menge an mRNA widerspiegelt (Bas et al., 2004; Roge et al., 2007, Port et al., 2007). Da die untersuchten H1-Histonsubtypen ähnliche Sequenzen haben (s. Kapitel 7.2.9), mußte die Spezifität der verwendeten Primer sichergestellt werden, um einen zuverlässigen Vergleich der mRNA-Mengen gewährleisten zu können. Die Spezifität der Primer wurde anhand von Schmelzkurvenanalysen nachgewiesen (s. Abbildung 15,

\section{Abbildung 31).}

Die mittels RT-PCR durchgeführten Expressionsanalysen zeigten, daß der Subtyp $H 1 x$ replikationsunabhängig exprimiert wird. Nach Zellzyklusarrest in der G1-Phase durch Natriumbutyratzugabe konnte in den arretierten Zellen keine verringerte Expression von 
H1x im Vergleich zu den unsynchronisierten Zellen festgestellt werden (s. Abbildung 17). Allerdings führte der G1-Arrest - im Gegensatz zur Expression von $H 1^{\circ}$ - nicht zu einer Zunahme der H1x-mRNA. Diese Ergebnisse sind vereinbar mit der von Happel et al. (2005) beschriebenen Proteinsynthese von H1x nach Natriumbutyratzugabe. Die Autoren konnten zeigen, daß die Proteinsynthese von H1x durch einen Zellzyklusarrest in der G1-Phase nicht induziert wurde.

In der vorliegenden Arbeit war für den Subtyp $\mathrm{H} 1^{\circ}$ nach Natriumbutyratzugabe ein Anstieg der Transkripte um mehr als $100 \%$ relativ zu der mRNA-Menge in Kontrollzellen zu verzeichnen. Dieser Expressionsanstieg deckt sich mit bereits publizierten Ergebnissen: Chemikalien, die Zelldifferenzierung oder Zellzyklusarrest hervorrufen, können zur Akkumulation von $\mathrm{H}^{\circ}{ }^{\circ}$-mRNA und -Protein führen (Keppel, 1977; Smith et al., 1984; Kress et al., 1986; Alonso, 1988). Insbesondere Natriumbutyrat ruft eine gesteigerte Expression von $\mathrm{H} 1^{\circ}$-mRNA hervor (Kress et al., 1986). In den erwähnten Arbeiten konnte allerdings im Gegensatz zu der vorliegenden Arbeit noch keine quantitative Mengenabschätzung durch RT-PCR vorgenommen werden.

Der RNA-Gehalt der Hauptklassesubtypen H1.1-H1.5 war nach Zellzyklusarrest in G1 durch Natriumbutyratzugabe mindestens auf die Hälfte gesunken (s. Abbildung 17). Dies stimmt mit der Einteilung überein, wonach H1.1-H1.5 replikationsabhängig exprimiert werden.

Die Beobachtung, daß die Expression von $H 1^{\circ}$ im Verlauf der S-Phase nach Aphidicolinarrest und anschließender Entlassung aus dem Arrest anstieg (s. Abbildung 17), stellt keinen Widerspruch zu der Bezeichnung „replikationsunabhängig“ dar, da dieser Terminus nur beschreibt, daß die Gene auch außerhalb der S-Phase oder während eines Zellzyklusarrests exprimiert werden. Ein Transkriptionsanstieg von $\mathrm{H}^{\circ}{ }^{\text {im }}$ Verlauf der S-Phase wurde schon 1991 von Grunwald et al. (1991) in Erythroleukämiezellen der Maus und von Khochbin et al. (1991) in sich teilenden Rattenhepatocyten beobachtet. Dieser Anstieg während der S-Phase konnte nun quantitativ mittels real-time RT-PCR bestätigt werden. Darüberhinaus wurde für $\mathrm{H} 1^{\circ}$ in der genannten Publikation von Khochbin et al. (1991) sowie bei Cuisset et al. (1999) und Tönjes et al. (1997) auch gezeigt, daß Transkription und Translation für $\mathrm{H}^{\circ}{ }^{\circ}$ 
voneinander entkoppelt sein können. Da die Synthese von Histonen sowohl auf Transkriptions- als auch auf Translationsebene kontrolliert wird (Heintz, 1991; Doenecke et al., 1994), und die Entkopplung der Synthese von mRNA und Protein für H1ํㅡㄹ nachgewiesen wurde (Khochbin et al., 1991; Cuisset et al., 1999), wäre es möglich, daß für H1x ein ähnlicher Regulationsmechanismus zum Tragen kommt. Stoldt und Mitarbeiter (2007) zeigten, daß sich die Menge an H1x-Protein mit Fortschreiten der SPhase nicht wesentlich ändert. In der vorliegenden Arbeit wurde ein dazu analoger Verlauf in der H1x-mRNA-Menge gefunden (s. Abbildung 17). Das Fortschreiten der S-Phase wirkte sich nicht wesentlich auf die H1x-mRNA Menge aus. Dementsprechend scheint für H1x keine entkoppelte Synthese von mRNA und Protein vorzuliegen. Aus den vorliegenden Resultaten kann geschlossen werden, daß sich die Regulierung der $H 1 x$-Expression von der Regulierung der replikationsunabhängig exprimierten H1Subtypen unterscheidet.

Für die weiteren untersuchten H1-Subtypen zeigte sich in der vorliegenden Arbeit eine Zunahme der mRNA-Menge, die ihr Maximum sechs Stunden nach Entlassung aus dem Aphidicolinarrest, d.h. in der mittleren S-Phase des Zellzyklus, erreichte. Eine deutliche Abnahme der H1-Transkripte zehn Stunden nach Entlassung aus dem Aphidicolinarrest entsprach dem G2/M-Übergang des Zellzyklus. Diese Abnahme weist auf eine schnelle RNA-Degradierung und eine reduzierte Transkriptionsrate hin, die bei Heintz (1991) und bei Osley (1991) als ein für replikationsabhängige Histone charakteristisches Merkmal beschrieben wird. Die in der vorliegenden Arbeit ermittelten Ergebnisse für die somatischen H1-Subtypen stimmen mit den von Meergans et al. (1997) publizierten Daten überein.

Beim quantitativen Vergleich der relativen mRNA-Mengen der verschiedenen H1Histonsubtypen mittels qRT-PCR konnten H1.2 und H1.4 als die vorherrschenden H1Subtypen in unsynchronisierten HeLa-Zellen identifiziert werden (s. Abbildung 18). $H 1^{\circ}, H 1 x$ und $H 1.1$ waren dagegen nur sehr schwach exprimiert. Dieses Ergebnis deckt sich mit den Befunden von D’ Incalci et al. (1986) und Parseghian et al. (1994), die hohe Proteinmengen für H1.2 und H1.4 im Verhältnis zu den übrigen H1-Subtypen ermittelten, was mit der in der vorliegenden Arbeit gemessenen mRNA-Menge korreliert. Auch mit den Resultaten der von Meergans et al. (1997) durchgeführten 
Untersuchungen der unterschiedlichen Expressionsmuster humaner H1-Histone in verschiedenen Zellinien mittels RNAase protection assay sind die vorliegenden Ergebnisse aus HeLa-Zellen vereinbar. In den Untersuchungen von Meergans et al. (1997) wurde allerdings der Subtyp H1x noch nicht berücksichtigt.

Zusammengefaßt zeigen die vorliegenden Ergebnisse der Expressionsanalyse von $H 1 x$, daß sich die H1x-mRNA-Menge weder durch einen Zellzyklusarrest in der G1-Phase noch im Verlauf der S-Phase wesentlich verändert. Die Regulierung der $H 1 x$ Expression weicht damit sowohl von der Regulierung der replikationsunabhängig exprimierten H1-Subtypen als auch von der des replikationsunabhängig exprimierten $H 1^{\circ}$ ab.

\subsection{Differentielle Expression von H1x in Tumoren}

In diversen Publikationen wurde eine Änderung des H1-Subtypverhältnisses während maligner Transformation beschrieben (s. beispielsweise Tan et al., 1982; Goodlad \& Clark, 1995; Kostova et al., 2005) Viele dieser Untersuchungen bezogen sich auf den replikationsunabhängigen Subtyp $\mathrm{H}^{\circ}{ }^{\circ}$. In einigen Tumoren wurde ein Anstieg der Konzentration von $\mathrm{H} 1^{\circ}$ nachgewiesen, in anderen dagegen eine Abnahme im Vergleich zu der Konzentration in ihren Herkunftsgeweben (Zlatanova \& Doenecke, 1994).

Aufgrund einer erhöhten Trefferrate von H1x-ESTs in Tumordatenbanken neuroendokriner Tumore (s. Kapitel 4.3) wurden RNA-Expression und Proteinsynthese von H1x in neuroendokrinen Tumoren aus verschiedenen Geweben untersucht. Dabei zeigte sich, daß die Analysen mittels in situ Hybridisierung nicht zuverlässig zu reproduzieren und deshalb nicht für eine umfassende Betrachtung geeignet waren. Möglicherweise war entweder die Fixierung der Proben oder eine RNA-Degradierung innerhalb des Gewebes für die schlechte Reproduzierbarkeit verantwortlich. Aus diesem Grund wurde für weitere Untersuchungen unfixiertes Gewebe, das unmittelbar nach Entnahme bei $80^{\circ} \mathrm{C}$ gelagert worden war, verwendet und seine mRNA mittels RT-PCR analysiert.

Die mRNA-Mengen der einzelnen Subtypen in verschiedenen Geweben wurden quantitativ verglichen. 
Die Analyse mittels RT-PCR ergab, daß $H 1 x$ in allen untersuchten Geweben exprimiert wird, und bestätigt damit das bei Yamamoto und Horikoshi (1996) mittels Northern-Blot erhaltene Ergebnis, daß $\mathrm{H} 1 \mathrm{x}$ in allen von diesen Autoren untersuchten Geweben nachzuweisen ist. Es zeigte sich, daß $\mathrm{H} 1 \mathrm{x}$ in wenig differenzierten, kleinzelligen neuroendokrinen Karzinomen im Vergleich zu nicht-neoplastischem Gewebe deutlich vermehrt exprimiert wird. Auch im Vergleich $\mathrm{zu}$ der H1x-mRNA-Menge in Karzinoiden ist die Expression von $\mathrm{H1x}$ in wenig differenzierten Karzinomen sehr hoch. In Karzinoiden war höchstens die fünffache mRNA-Menge im Vergleich zu nicht-neoplastischem Gewebe meßbar, in Karzinomen eine bis zu 62-fache. Es scheint folglich einen spezifischen Zusammenhang zwischen der vermehrten H1x-Expression und der malignen Entartung von Zellen zu wenig differenzierten neuroendokrinen Karzinomen zu geben.

Parallel zu den in der vorliegenden Arbeit erhaltenen Ergebnissen zum Anstieg von H1x fiel bei bestimmten Karzinomen - aus Lunge und Dünndarm - ein extremer Anstieg von H1.1 im Vergleich zu Karzinoiden und nicht-neoplastischem Gewebe auf. Der Mengenunterschied der H1.1-mRNA zwischen Lungenkarzinom und Lungenkarzinoid war 23-fach, zwischen Dünndarmkarzinoid und -karzinom sogar 61-fach. Diese Beobachtung, daß H1.1 in neoplastischem, stark proliferierendem Gewebe vermehrt exprimiert wird, steht im Einklang mit der Aussage von Lennox und Cohen (1983), daß sich die Zusammensetzung der H1-Histone in sich teilenden Zellen zugunsten des H1.1Subtyps verschiebt. Überdies wiesen Franke et al. (1998) eine erhöhte H1.1 Expression in Spermatogonien und Teratokarzinomzellen der Maus, d.h. ebenfalls in Zellen mit hoher DNA Replikation, nach.

$\mathrm{Ob}$ die beobachteten Veränderungen der H1x-Expression spezifisch für wenig differenzierte neuroendokrine Karzinome sind, müßte mit einer umfangreicheren Untersuchung an einem deutlich größeren Probenkollektiv bestätigt werden. Die Schwierigkeit weiterer Untersuchungen zur Rolle von H1x, bzw. des veränderten Expressionsmusters der H1-Subtypen, liegt darin, daß bei den seltenen neuroendokrinen Tumoren nur wenige Fälle für molekularbiochemische Untersuchungen zur Verfügung stehen und das Probenmaterial daher sehr begrenzt ist. 
Da eine Entkopplung der Synthese von mRNA und Protein für $\mathrm{H}^{\circ}$ gezeigt wurde (Khochbin et al., 1991; Tönjes et al., 1997; Cuisset et al., 1999), wurden die neuroendokrinen Tumore zusätzlich zu den durchgeführten Expressionsanalysen auf ihren Proteingehalt an H1x untersucht. Die ermittelten Daten zeigten eine starke Korrelation zwischen H1x-mRNA- und H1x-Proteinmenge: H1x-Protein wird in neuroendokrinen Tumoren stärker synthetisiert als in Normalgewebe. Im Unterschied zu der durch RT-PCR ermittelten mRNA-Expression von $H 1 x$, die sich in neuroendokrinem Lungenkarzinom als deutlich, aber in neuroendokrinem Karzinoid der Lunge nur als geringfügig erhöht dargestellt hatte, konnte bei der Proteinanalyse mittels Western-Blot auch in Lungenkarzinoid ein stärkeres Signal als in der Normalprobe für $\mathrm{H} 1 \mathrm{x}$ beobachtet werden (s. Abbildung 21, Probe 1 vs. 2). Bei diesem Vergleich der Daten der RT-PCR mit den Daten des Western-Blots ist allerdings zu beachten, daß bei der Berechnung der mRNA-Mengen 18S-rRNA als Referenz diente, im Western-Blot aber die Proteinmenge von H1x auf H1.2 bezogen wurde. Da sich für H1.2 eine Erniedrigung der mRNA-Menge in Lungenkarzinoid gegenüber der Normalprobe aus Lunge zeigte, kann davon ausgegangen werden, daß bei der Verwendung von H1.2 als Bezugsgröße im Western-Blot, im Verhältnis zu den übrigen Proben, mehr Protein der Tumorprobe aufgetragen wurde. Damit ließe sich der deutlich erkennbare Unterschied der Proteinmengen von H1x in nicht-neoplastischem Lungengewebe und Lungenkarzinoid erklären.

Um eine Zuordnung der Synthese des H1x-Proteins zu neuroendokrinen Zellen zu ermöglichen oder eine anderweitige zellspezifische Synthese von H1x detektieren zu können, wurden immunhistochemische Nachweise von H1x und diversen Markerproteinen an Paraffinschnitten der untersuchten Proben durchgeführt. Die Immunhistochemie wurde an einem Tissue microarray (TMA) vorgenommen, bei dem alle untersuchten Proben als Stanzen auf einem Objektträger parallel behandelt werden, um die Gewebe besser miteinander vergleichen zu können. Die Immunhistochemie ergab, daß H1x deutlich stärker in den Tumorzellen neuroendokriner Tumore der Lunge, des Pankreas und des Darms synthetisiert wird als in den Zellen des gesunden Gewebes, und bestätigte damit die Ergebnisse der Western-Blot-Analyse. Außerdem gelang es, mittels Immunhistochemie zu zeigen, daß das durch Western-Blot nachgewiesene H1x in der Tat in Tumorzellen lokalisiert war. Da sich H1x auch in einigen Zellen des nicht- 
neoplastischen Gewebes nachweisen ließ (s. Abbildung 22-Abbildung 26), stellte sich die Frage, ob es sich bei diesen Zellen vornehmlich um neuroendokrine Zellen handelt. Um diese Frage zu klären, wurden immunhistochemische Doppelmarkierungen mit fluoreszenzmarkierten Antikörpern durchgeführt.

Die immunhistochemischen Untersuchungen zur Kolokalisation von $\mathrm{H} 1 \mathrm{x}$ und Chromogranin A ergaben, daß nur der Zustand einer einzigen Probe aus dem Kollektiv den Nachweis mit fluoreszenzmarkierten Antikörpern zuließ. Alle anderen Proben wiesen auch nach diversen Veränderungen der Bedingungen zu viel Hintergrundfärbung auf und ließen sich daher nicht bewerten. Eine mögliche Ursache für diese Hintergrundreaktion könnte in der Art der Fixierung der vorhandenen Proben liegen. Es ist nicht auszuschließen, daß die Fluoreszenzfarbstoffe mit den Fixierungsagenzien interagieren.

In der analysierten Probe aus Dünndarm ließen sich sowohl Chromogranin A als auch H1x in den Zellen des Tumorgewebes nachweisen. Die meisten Chromogranin Apositiven Zellen waren auch H1x-positiv. Dennoch ist H1x nicht als spezifisch für neuroendokrine Zellen anzusehen, da die Immunfluoreszenz gezeigt hatte, daß nicht alle H1x-positiven Zellen Chromogranin A-positiv sind: in den H1x-positiven nichtneoplastischen Zellen der untersuchten Probe ließ sich im Gegensatz zu den Zellen des Tumors kein Chromogranin A nachweisen (s. Abbildung 27, Abbildung 28).

Zusammengefaßt zeigen die vorliegenden Ergebnisse der Untersuchung neuroendokriner Tumore, daß H1x sowohl auf RNA- als auch auf Proteinebene im Vergleich zu nicht-neoplastischem Gewebe in wenig differenzierten neuroendokrinen Karzinomen hochreguliert wird. Dies konnte mit drei voneinander unabhängigen Methoden (RTPCR, Western-Blot und Immunhistochemie) sicher gezeigt werden.

\subsection{H1-mRNA Expression in Abhängigkeit des Entwicklungsstadiums}

Die erhöhte Menge von H1x in neuroendokrinen Tumoren im Vergleich zu nichtneoplastischem Gewebe (s. Kapitel 4.3) und die Ergebnisse zahlreicher Studien zur H1Subtypzusammensetzung in unterschiedlichen Differenzierungsstadien von Zellen (Lennox et al., 1982; Lennox \& Cohen, 1983; Khochbin \& Wolffe, 1994; Franke et al., 
1998) führten zu der Frage, ob die Expression von $H 1 x$ mit intensivem Zellwachstum korreliert. Eine derartige Korrelation mit sich entwickelnden Zellen wurde bei Franke et al. (1998) für den Subtyp H1.1 gezeigt. Aus diesem Grund wurde die relative H1xmRNA-Menge in fötalem Gewebe mit der relativen mRNA-Menge von H1x in adultem Gewebe mittels RT-PCR verglichen. Darüber hinaus wurde die relative Expression von $\mathrm{H} 1 \mathrm{x}$ in fötalem und adultem Gewebe mit der Expression sowohl der replikationsabhängigen Subtypen als auch des replikationsunabhängigen Subtyps $\mathrm{H} 1^{\circ}$ verglichen.

In den untersuchten mRNA-Proben aus Lunge und Dickdarm zeigten sich nur geringe Unterschiede in der Expressionsrate von $H 1 x$ zwischen dem adulten und dem fötalen Gewebe. Es fiel auf, daß $H 1 x$ in adulter Lunge und in adultem Kolon - ähnlich wie H1.1 und H1.5 - sehr gering exprimiert ist. Im Unterschied zu H1.1, das in den Proben aus fötalem Gewebe eine deutlich höhere Expression als im adulten Gewebe aufweist, ist die mRNA-Menge von H1x auch in fötalem Gewebe sehr gering.

Die hohe Expression von H1.2 und H1.4 relativ zu allen anderen untersuchten H1Subtypen wurde nicht nur aus den in Kapitel 4.2 beschriebenen Ergebnissen für HeLaZellen ersichtlich, auch in den untersuchten Organen adulter und fötaler Herkunft zeigten H1.2 und H1.4 einen hohen Anteil an der Histon-mRNA.

Für alle H1-Subtypen wurde in Bezug auf 18S-rRNA als Referenz eine erhöhte mRNAExpression in fötalem gegenüber adultem Gewebe festgestellt. Die erhöhte Expression der Hauptklassesubtypen H1.1-H1.5 in den schnell wachsenden fötalen Zellen läßt sich mit der Abhängigkeit ihrer Expression von der S-Phase erklären. Die einzige Ausnahme unter allen untersuchten H1-Subtypen bildete H1.4 in Kolon. Hier wies die adulte Probe 1,5-mal mehr H1.4-mRNA auf als die fötale. Ob diese differentielle Expression eine funktionelle Bedeutung hat, bleibt zu klären.

Der Histonsubtyp $\mathrm{H}^{\circ}{ }^{\circ}$ wurde bisher in der Literatur hauptsächlich in arretierten und terminal differenzierten Zellen beschrieben. Es wird angenommen, daß die Menge an $\mathrm{H} 1^{\circ}$ direkt mit geringer Proliferationsrate korreliert (Lea, 1987; Khochbin \& Wolffe, 1994; Zlatanova \& Doenecke, 1994). Demnach erscheint die beobachtete höhere Expressionsrate von $\mathrm{H} 1^{\circ}$ in dem stark wachsenden fötalen Gewebe im Vergleich zu 
adultem Gewebe auf den ersten Blick erstaunlich. Jedoch ist zu beachten, daß es sich bei der Beschreibung der $\mathrm{H}^{\circ}$-Menge in der Literatur um die Proteinmenge handelt, während hier ein Vergleich der mRNA-Mengen stattfand. Khochbin beschreibt die $\mathrm{H} 1^{\circ}$ mRNA-Expression als ein proliferationsabhängiges Ereignis und betont den Zusammenhang zwischen gesteigerter $\mathrm{H}^{\circ}{ }^{\circ}$-Expression und der DNA-Replikation. Weiterhin wurde bei Khochbin anhand von partiell hepatektomierten Ratten dargestellt, daß die mRNA-Akkumulation von der Proteinsynthese entkoppelt ist (Khochbin et al., 1991). Auch Cuisset (1999) konnte zeigen, daß die Menge an H1º-Protein nicht unbedingt die mRNA-Menge widerspiegelt. So gesehen steht die in der vorliegenden Arbeit in fötalem Gewebe beobachtete höhere $H 1^{\circ}$-Expression gegenüber adultem Gewebe nicht im Widerspruch zu den bisherigen Erkenntnissen zur Expression und Synthese von H1.

Zusammengefaßt zeigt sich, daß in fötalem Gewebe im Vergleich zu adultem Gewebe erhöhte Expressionsraten der untersuchten H1-Histonsubtypen mit Ausnahme von H1.4 in Kolon nachweisbar sind. Der Unterschied in der Expressionsrate von H1x zwischen dem adulten und dem fötalen Gewebe ist in den untersuchten mRNA-Proben aus Lunge und Dickdarm nur gering. Es scheint demzufolge keine generelle Korrelation zwischen der vermehrten Expression von H1x und intensivem Zellwachstum zu bestehen, sondern ein spezifischer Regulationsmechanismus in neuroendokrinen Tumoren, der für eine Erhöhung der mRNA-Menge von H1x sorgt.

\subsection{Ausblick}

Die in der vorliegenden Arbeit durchgeführten Analysen zur Charakterisierung und Expression von H1x leisten einen Beitrag dazu, die Frage nach der Expressionsregulation und der Zusammensetzung von H1-Histonsubtypen in Abhängigkeit des Gewebes oder des Entwicklungsstadiums zu beantworten. Mit dem Entwurf eines zur funktionellen Expression von H1x geeigneten Promotorkonstrukts ist es nun möglich, Untersuchungen zur Aufklärung der Funktion des Subtyps H1x durchzuführen. Dabei muß nicht mehr auf einen konstitutiv stark exprimierenden Promotor zurückgegriffen werden, der unter Umständen durch zu starke Expression des $H 1 x$-Gens zu nicht einschätzbaren Artefakten führen könnte. Weiterhin ist die hier durchgeführte Identifizierung von Promotorelementen ein erster Schritt zur Charakterisierung von für 
die Expression von H1x entscheidenden Transkriptionsfaktoren. In Bezug auf die Rolle von H1x in Tumoren wäre die daraus folgende Konsequenz, zu untersuchen, ob diese Transkriptionsfaktoren in den Tumoren hochreguliert sind, die mehr H1x-mRNA enthalten.

Da die mRNA-Menge von H1x im Vergleich zu Normalgewebe vornehmlich in schlecht differenzierten neuroendokrinen Karzinomen, nicht aber in neuroendokrinen Karzinoiden hochreguliert war, könnte $\mathrm{H} 1 \mathrm{x}$ zur Klassifizierung der vielfältigen und schlecht charakterisierten neuroendokrinen Tumore oder zur Beurteilung ihrer Dignität beitragen. Zur genaueren Analyse der Verteilung von $\mathrm{H} 1 \mathrm{x}$ wäre es sinnvoll, die Expression in neuroendokrinen Tumoren mit der Expression von $\mathrm{H} 1 \mathrm{x}$ in neuroendokrinem Gewebe (beispielsweise Nebenniere oder Adenohypophyse) zu vergleichen. Eine derartige Gegenüberstellung könnte zeigen, ob H1x generell in neuroendokrinen Zellen vermehrt exprimiert wird oder nur in neoplastischen Zellen aus neuroendokrinen Tumoren. Eine weitere Frage wäre, ob H1x die primäre Ursache für die Entstehung dieser Tumore oder eine sekundäre Auswirkung der malignen Entartung der Zellen zu den vorhandenen Karzinomen darstellt. Zur weiteren Analyse könnten mittels Immunpräzipitation mögliche Interaktionspartner von H1x identifiziert werden (s. auch Lee et al., 2004), um somit Hinweise auf spezifische Funktionen dieses Subtyps zu bekommen.

Für eine funktionelle Interpretation des Subtyps H1x können auch Versuche zur Expression von H1x in Zellen, die kein natives H1x enthalten, wie zum Beispiel RajiZellen (Happel et al., 2005), oder aber vorzugsweise in undifferenzierten Stammzellen beitragen. Würden sich die undifferenzierten Zellen in eine bestimmte Richtung entwickeln, ihre Morphologie verändern oder sogar Eigenschaften von Tumorzellen aufweisen?

Eine andere Möglichkeit könnte darin bestehen, $\mathrm{H1x}$ in humanen Zellinien herunterzuregulieren. Dieser Ansatz wurde in der vorliegenden Arbeit mittels transient und stabil exprimierter siRNA in HeLa-Zellen verfolgt, führte jedoch bisher nicht zu einer Reduzierung von H1x. Alternativ zum bisherigen experimentellen Vorgehen wäre es möglich, siRNAs mit Hilfe von viralen Vektoren in die Zellen einzubringen, um so eine Reduzierung von H1x zu erreichen. 
Darüber hinaus könnten knockout-Mäuse erstellt werden, die kein $H 1 x$ enthalten. Diese $H 1 x$-defizienten Mäuse wären zu phänotypisieren und mittels Stimulantien, die das Wachstum von Tumoren induzieren oder hemmen, genauer zu charakterisieren. Mit sehr großer Wahrscheinlichkeit wären $H 1 x$-defiziente Mäuse lebensfähig, da bei Sirotkin et al. (1995), Drabent et al. (2000), Rabini et al. (2000) und Fan et al. (2001) gezeigt werden konnte, daß sich Mäuse, denen ein oder zwei der H1-Subtypen fehlen, normal entwickeln. Für den Fall, daß eine $H 1 x^{-/-}$-Maus keinen erkennbaren Phänotyp zeigen sollte, wäre ein Doppel- oder Dreifach-knockout in Kombination mit weiteren H1-Subtypen denkbar. Jedoch ist dabei zu beachten, daß ein Dreifach-knockout letal sein könnte. Fan et al. (2003) konnten zeigen, daß H1-Histone für die Entwicklung essentiell sind und daß Embryonen, denen die Gene für die replikationsabhängigen Subtypen H1.2, H1.3 und H1.4 fehlen, nicht lebensfähig sind. Mit Ausnahme der Arbeit von Sirotkin et al. (1995), in der $H 1^{\circ}$-defiziente Mäuse untersucht wurden, wurden in den Arbeiten der anderen genannten Arbeitsgruppen replikationsabhängige H1Subtypen (Rabini et al., 2000; Fan et al, 2001) bzw. der gewebespezifische Subtyp H1t (Drabent et al., 2000) eliminiert. Eine spätere Untersuchung $H 1^{\circ}$-defizienter Mäuse brachte die Erkenntnis, daß sich die $H 1^{\circ /}$-Mäuse zwar anscheinend normal entwickeln, aber dennoch eine verringerte Produktion dendritischer Zellen aufweisen (Gabrilovich et al. 2002). Dieser Defekt im Immunsystem von $H 1^{\circ}$-knockout-Mäusen macht deutlich, daß das Fehlen replikationsunabhängiger H1-Histonsubtypen funktionelle Konsequenzen haben kann. Dementsprechend sollte der replikationsunabhängig exprimierte Histonsubtyp H1x von besonderem Interesse für weitere Untersuchungen sein. 


\section{Zusammenfassung}

H1-Histone sind chromosomale Proteine, die nicht nur an der Kondensierung der DNA beteiligt sind, sondern auch eine entscheidende Rolle bei der Steuerung der Genexpression, der DNA-Replikation und der DNA-Reparatur spielen. Seit mehr als 40 Jahren sind die Existenz verschiedener H1-Histonsubtypen und ihre Diversität in Bezug auf Expression und Verteilung in unterschiedlichen Zellen bekannt. Dennoch ist bis heute weitgehend ungeklärt, wie die Expression der H1-Gene reguliert wird und welche spezifischen Funktionen die einzelnen Subtypen haben.

In der vorliegenden Arbeit wurde die Expression des bisher wenig untersuchten humanen Histonsubtyps H1x genauer analysiert. Es konnte gezeigt werden, daß H1x ein H1-Histon mit besonderen Expressionseigenschaften ist, die auf spezielle Funktionen dieses Subtyps hindeuten. So zeigte sich in Untersuchungen zur Expression von $H 1 x$ im Verlauf des Zellzyklus, daß $H 1 x$ replikationsunabhängig exprimiert wird. Eine Promotoranalyse der genomischen Sequenz von $H 1 x$ ergab, daß der Promotor von $H 1 x$ in Bezug auf Art und Position der regulatorischen Elemente Ähnlichkeit mit dem des replikationsunabhängig exprimierten $\mathrm{H} 1^{\circ}$ aufweist. Beide Gene enthalten ein upstream positive element und eine TATA-Box, aber keine funktionelle CCAAT-Box. Die Expressionsanalyse von $H 1 x$ im Verlauf des Zellzyklus zeigte, daß sich die H1xmRNA-Menge weder während der S-Phase verändert noch durch einen Zellzyklusarrest in der G1-Phase induzierbar ist. Da nach Zellzyklusarrest in der G1-Phase jedoch keine verringerte Expression von $H 1 x$ im Vergleich $\mathrm{zu}$ den unsynchronisierten Zellen festgestellt werden konnte, wird $\mathrm{H} 1 \mathrm{x}$ den replikationsunabhängigen H1-Histonen zugeordnet. Dennoch unterscheidet sich das Expressionsmuster dieses Subtyps vom ebenfalls replikationsunabhängig exprimierten Replacementhiston $\mathrm{H} 1^{\circ}$.

Dies wird durch Untersuchungen der mRNA-Mengen von H1x aus adultem und fötalem Gewebe in Proben aus Lunge und Dickdarm gestützt. Hier zeigten sich nur geringe Unterschiede zwischen den H1x-mRNA-Mengen. Damit bestätigte sich, daß keine generelle Korrelation zwischen der vermehrten Expression von $\mathrm{H} 1 \mathrm{x}$ und Zellproliferation besteht. 
Eine Expressionsanalyse des Subtyps H1x in Zellen unterschiedlichen Ursprungs ergab, daß sowohl H1x-mRNA als auch H1x-Protein in wenig differenzierten neuroendokrinen Karzinomen im Vergleich zu nicht-neoplastischem Gewebe vermehrt exprimiert werden. Dies konnte sowohl mittels quantitativer RT-PCR als auch durch Western-Blot und Immunhistochemie gezeigt werden. Diese Ergebnisse machen deutlich, daß H1x eventuell zur Klassifizierung der vielfältigen und schlecht charakterisierten neuroendokrinen Tumore oder zur Beurteilung ihrer Dignität beitragen könnte. Weitere Untersuchungen zur genaueren Charakterisierung dieses Subtyps müßten durchgeführt werden, um zu klären, ob H1x besondere Funktionen im Zusammenhang mit maligner Transformation hat. 


\section{Abkürzungsverzeichnis und Anhang}

\subsection{Abkürzungsverzeichnis}

\#

Anzahl

$\mu$

mikro

A

Ampère

$\mathrm{A}_{260}$

Absorption, gemessen bei $260 \mathrm{~nm}$

Acc. no.

Accession number

Amp

Ampicillin

APS

Ammoniumperoxodisulfat

ATP

Adenosintriphosphat

BCIP

5-Brom-4-chlor-3-indoxylphosphat

bp

Basenpaare

BSA

Bovine serum albumine (Rinderserumalbumin)

C

Konzentration

$\mathrm{cb}$

Kalibrator

cDNA

Complementary DNA

CEA

Carcinoembryonic antigen

CH1UE

Conserved H1 gene upstream element

CLS

Cell lines service

CMV

Cytomegalovirus

$\mathrm{C}_{\mathrm{T}}$

Threshold cycle (Schwellenwert)

CTP

Cytidintriphosphat

d

destilliert

Da

Dalton

DAPI

4',6-Diamino-2-phenylindol

DEPC

Diethylpyrocarbonat

DMEM

Dulbecco's MEM

DMF

Dimethylformamid

DMSO

Dimethylsulfoxid

DNA

Desoxyribonukleinsäure 
dNTP

DSMZ

DTT

E value

E. coli

ECL

EDTA

EMBL

EST

$\mathrm{EtOH}$

$\mathrm{E}_{\mathrm{x}}$

FACS

FCS

FU

fwd

$g$

g

G0/G1/G2

GFP

GPDH

GTP

H1TF2

H4TF2

HEPES

HRP

HSV

IgG

$\mathrm{k}$

Kan

$\operatorname{Kan}^{\mathrm{r}}$

$\mathrm{kb}$

$\mathrm{L}$
Desoxynukleosidtriphosphat

Deutsche Sammlung von Mikroorganismen und Zellkulturen

Dithiothreitol

Expect value

Escherichia coli

Enhanced chemiluminescence

Ethylendiaminotetraacetat

European molecular biology laboratory

Expressed sequence tag

Ethanol

Effizienz einer Probe $\mathrm{x}$

Fluorescence activated cell sorter

Fetal calf serum (fötales Kälberserum)

Fluorescence unit

forward

Multipliziert mit der Erdbeschleunigung

Gramm

Gap0/Gap1/Gap2

Green fluorescent protein

Glycerol-3-phosphat-dehydrogenase

Guanosintriphosphat

H1-spezifischer Transkriptionsfaktor

H4-Gentranskriptionsfaktorbindungsstelle

4-(2-Hydroxyethyl)-1-piperazinethansulfonsäure

Horseradish-peroxidase (Meerrettichperoxidase)

Herpes simplex Virus

Immunglobulin G

kilo

Kanamycin

Kanamycin-Resistenzgen

Kilobasenpaare

Liter 
LB

LSAB

Luc $^{+}$

m

M

MCS

MEM

$\mathrm{MeOH}$

M-Phase

mRNA

n

$\mathrm{N}$

NBT

Neo

$\mathrm{Neo}^{\mathrm{r}}$

NET

OD

ori

p

P

p.a.

PAGE

PBS

PCA

PCR

PMSF

$\mathrm{P}_{\mathrm{SV} 40}$

PVP

RARE

rev

RFU

$\mathrm{RL}$
Luria-Bertani

Labelled streptavidin biotin

Luciferase kodierende Sequenz

milli

molar $[\mathrm{mol} / \mathrm{L}]$

Multiple cloning site (multiple Klonierungsstelle)

Minimum essential medium

Methanol

Mitose-Phase

Messenger RNA (Boten-RNA)

nano

Nicht-neoplastisches Gewebe

Nitroblau-Tetrazoliumchlorid

Neomycin

Neomycin-Resistenzgen

Neuroendokriner Tumor

Optische Dichte

Origin of replication (Replikationsursprung)

piko

Promotor

pro analysi

Polyacrylamidgelelektrophorese

Phosphate buffered saline

Perchlorsäure

Polymerase chain reaction

Phenylmethylsulfonylfluorid

SV40-Pomotor

Polyvinylpyrrolidon

Retinoic acid receptor binding element

Reverse

Relative fluorescence unit

Renilla Luciferase 
RLU

Relative luminescence unit

RNA

Ribonukleinsäure

RNAase

Ribonuklease

RNasIn

Ribonukleaseinhibitor

rpm

Rounds per minute (Umdrehungen pro Minute)

RPMI

Roswell Park Memorial Institute

rRNA

Ribosomale RNA

RT

Raumtemperatur

RT-

Reverse Transkriptase-

S

Svedberg unit

SDS

Sodiumdodecylsulfat

S-Phase

Synthese-Phase

SSC

Standard saline citrat

SV40

Simianvirus 40

$\mathrm{T}$

Tumor

TBP

TATA-box binding protein

TBS

Tris buffered saline

TBS-T

TBS mit Tween-20

TCA

Trichloressigsäure

TE

Tris-EDTA

TEMED

N,N,N',N'-Tetramehylethylendiamin

TK

Thymidinkinase

$\mathrm{T}_{\mathrm{m}}$

Schmelztemperatur

TMA

Tissue microarray

Tris

Tris-(hydroxymethyl)-aminomethan

tRNA

Transfer-RNA

Tween-20

Polyoxyethylenesorbitanmonolaurat

$\mathrm{U}$

Unit

UCE

Upstream conserved element

üN

über Nacht

UPE

Upstream positive element

UTP

Uridintriphosphat 


$\begin{array}{ll}\text { UTR } & \text { untranslated region (untranslatierte Region) } \\ \text { UV } & \text { Ultraviolett } \\ \text { V } & \text { Volt } \\ \text { v/v } & \text { Volumen pro Volumen } \\ \text { w/v } & \text { Gewicht pro Volumen }\end{array}$

\subsection{Anhang}

\subsubsection{Primer}

Tabelle 23: Primer für pJW 9

\begin{tabular}{|l|l|l|l|l|}
\hline Name & Sequenz & $\begin{array}{l}\# G C / \\
\text { Gesamtlänge }\end{array}$ & $\mathbf{T}_{\mathbf{m}}$ in ${ }^{\circ} \mathbf{C}$ & Schnittstelle \\
\hline oNH53 & 5' caagcttatgtccgtggagctcgagg 3, & $15 / 26$ & 68 & Hind III \\
\hline oNH54 & 5' aggatccttgcggcccttgggcac 3, & $16 / 24$ & 69 & Bam HI \\
\hline
\end{tabular}

\subsubsection{Primerspezifität für H1-Subtypen}

Primer: alle H1-Subtypprimer (in Klammern stehen die Primerkombinationen (f,r))

$\begin{array}{lll}\text { H1 }{ }^{\circ}(2,1) & \text { rot } & \text { 136bp } \\ \text { H1.1 }(1,1) & \text { hellgrün } & \text { 99bp } \\ \text { H1.2 }(1,1) & \text { dunkelgrün } & \text { 99bp } \\ \text { H1.3 (2,2) } & \text { blau } & \text { 80bp } \\ \text { H1.4 (1,1) } & \text { pink } & 101 b p \\ \text { H1.5 (1,2) } & \text { gelb } & 117 b p \\ \text { H1x (1,1) } & \text { hellblau/türkis } & \text { 80bp }\end{array}$


Schmelzkurve

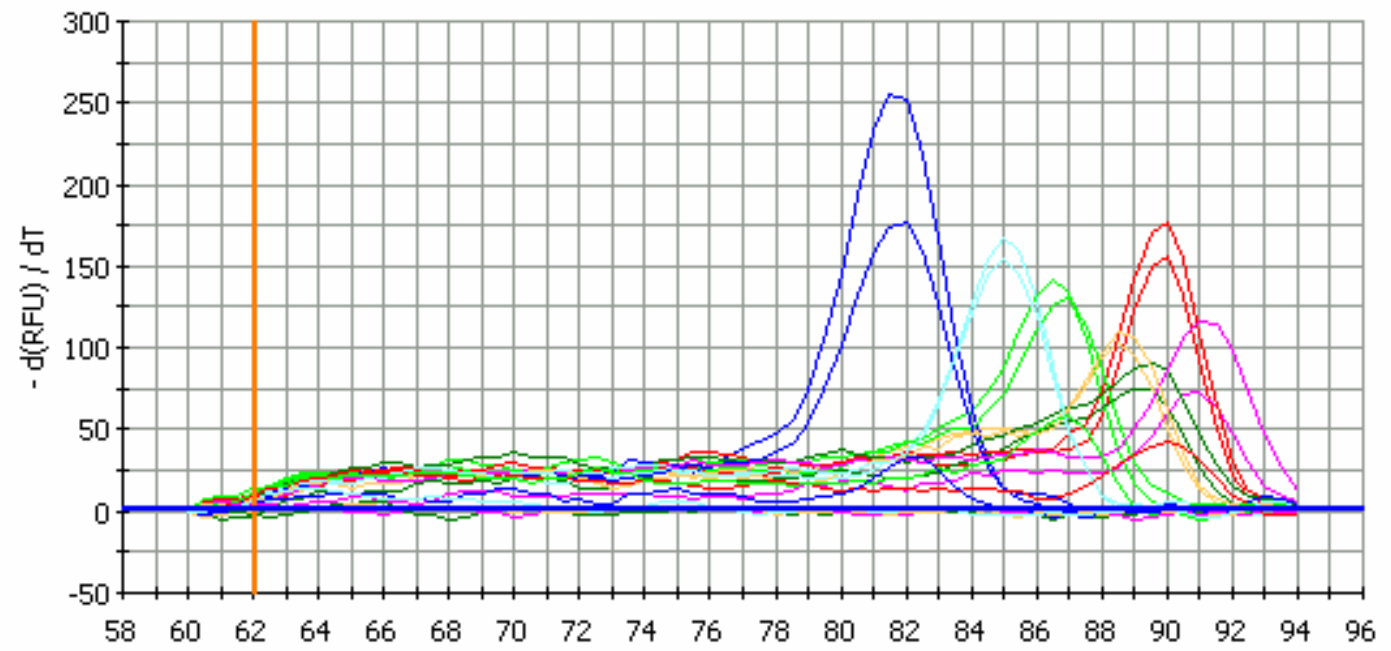

Temperatur in ${ }^{\circ} \mathrm{C}$

\section{Abbildung 31: Schmelzkurven der veschiedenen H1-Subtyp-Primer}

Schmelzkurven von je zwei cDNA-Proben von mRNA aus HeLa- und HL60-Zellen, die mit H1-spezifischen Primern amplifiziert wurden. Die PCR-Produkte zeigen je Subtyp ein einzelnes Maximum, d.h., die Produkte sind spezifisch und rein (keine Primerdimere oder andere unspezifische Amplifikationen enthalten).

\subsubsection{Originaldaten aus RT-PCR fötal / adult}

Tabelle 24: Original $\mathrm{C}_{\mathrm{T}}$-Werte aus RT-PCR adult / fötal (Kolon)

\begin{tabular}{|l|l|l|l|l|l|l|l|l|l|l|}
\hline & $\mathrm{C}_{\mathrm{t}}-18 \mathrm{~S}$ & $\mathrm{C}_{\mathrm{t}}-\mathrm{Act} \Omega$ & $\mathrm{C}_{\mathrm{t}}-\mathrm{H} 1 \mathrm{x}$ & $\mathrm{C}_{\mathrm{t}}-\mathrm{H} 1^{\circ}$ & $\mathrm{C}_{\mathrm{t}}-\mathrm{H} 1.1$ & $\mathrm{C}_{\mathrm{t}}-\mathrm{H} 1.2$ & $\mathrm{C}_{\mathrm{t}}-\mathrm{H} 1.3$ & $\mathrm{C}_{\mathrm{t}}-\mathrm{H} 1.4$ & $\mathrm{C}_{\mathrm{t}}-\mathrm{H} 1.5$ & $\mathrm{C}_{\mathrm{t}}-\mathrm{H} 3$ \\
\hline AC & 7,2 & 21,6 & 25,5 & 22,5 & 31,8 & 18,8 & 21,9 & 17,2 & 22,6 & 21,4 \\
\hline AC & 7,2 & 20 & 25,9 & 22,2 & 31,5 & 18,8 & 21,8 & 17,1 & 22,6 & 21,3 \\
\hline AC & 7,4 & 20,3 & 26 & 22,2 & 31,5 & 19 & 21,9 & 17,2 & 22,6 & 21,3 \\
\hline FC & 7,2 & 18,7 & 23,1 & 19,1 & 23,8 & 18,3 & 20 & 17,6 & 20,5 & 20,5 \\
\hline FC & 7,2 & 18,3 & 23,2 & 18,9 & 23,7 & 18,2 & 20,3 & 17,5 & 20,5 & 20,2 \\
\hline FC & 6,8 & 18,6 & 23,5 & 18,8 & 24,5 & 18,5 & 20,1 & 17,5 & 20,3 & 20,4 \\
\hline
\end{tabular}


Tabelle 25: Original $\mathrm{C}_{\mathrm{T}}$-Werte aus RT-PCR adult / fötal (Lunge)

\begin{tabular}{|c|c|c|c|c|c|c|c|c|c|c|}
\hline & $\mathrm{C}_{\mathrm{t}}-18 \mathrm{~S}$ & $\mathrm{C}_{\mathrm{t}}-\mathrm{Act} ß$ & $\mathrm{C}_{\mathrm{t}}-\mathrm{H} 1 \mathrm{x}$ & $\mathrm{C}_{\mathrm{t}}-\mathrm{H} 1^{\circ}$ & $\mathrm{C}_{\mathrm{t}}-\mathrm{H} 1.1$ & $\mathrm{C}_{\mathrm{t}}-\mathrm{H} 1.2$ & $\mathrm{C}_{\mathrm{t}}-\mathrm{H} 1.3$ & $\mathrm{C}_{\mathrm{t}}-\mathrm{H} 1.4$ & $\mathrm{C}_{\mathrm{t}}-\mathrm{H} 1.5$ & $\mathrm{C}_{\mathrm{t}}-\mathrm{H} 3$ \\
\hline AL & 7,61 & 18,82 & 23,65 & 20,06 & 30,22 & 19,69 & 22,75 & 17,58 & 26,44 & 25,94 \\
\hline AL & 7,59 & 18,91 & 23,77 & 20,18 & 30,34 & 19,59 & 22,84 & 17,67 & 26,03 & 25,4 \\
\hline AL & 7,62 & 19,09 & 23,89 & 20,23 & 30,5 & 19,69 & 22,9 & 17,67 & 26,33 & 26,17 \\
\hline FL & 7,57 & 19,32 & 22,51 & 19,21 & 22,68 & 17,79 & 19,91 & 15,93 & 20,11 & 20,81 \\
\hline FL & 7,51 & 19,66 & 22,46 & 19,13 & 22,52 & 17,67 & 19,79 & 15,86 & 20,08 & 20,96 \\
\hline FL & 7,56 & 19,44 & 22,26 & 19,11 & 22,64 & 17,6 & 19,83 & 15,86 & 20,06 & 20,93 \\
\hline
\end{tabular}

Anmerkg. AC: Colon adult, FC: Colon fätal; AL: Lunge adult, FL: Lunge fötal

\subsubsection{Originaldaten RT-PCR für Tumorkollektiv}

Tabelle 26; RT-PCR für Tumorkollektiv

\begin{tabular}{|l|l|l|l|l|l|l|l|l|l|l|l|}
\hline ID & Typ & $\mathrm{C}_{\mathrm{t}}-18 \mathrm{~S}$ & $\mathrm{C}_{\mathrm{t}}-\mathrm{Act} \Omega$ & $\mathrm{C}_{\mathrm{t}}-\mathrm{H} 1{ }^{\circ}$ & $\mathrm{C}_{\mathrm{t}}-\mathrm{H} 1 \times$ & $\mathrm{C}_{\mathrm{t}}-\mathrm{H} 1.1$ & $\mathrm{C}_{\mathrm{t}}-\mathrm{H} 1.2$ & $\mathrm{C}_{\mathrm{t}}-\mathrm{H} 1.3$ & $\mathrm{C}_{\mathrm{t}}-\mathrm{H} 1.4$ & $\mathrm{C}_{\mathrm{t}}-\mathrm{H} 1.5$ & $\mathrm{C}_{\mathrm{t}}-\mathrm{H} 3$ \\
\hline 26 & S.I. & 6,74 & 20,25 & 20,4 & 26,04 & 28,72 & 20,93 & 25,58 & 19,01 & 27,32 & 23,83 \\
\hline 26 & S.I. & 6,61 & 21,32 & 20,29 & 25,85 & 28,47 & 20,6 & 24,57 & 19,02 & 27,3 & 23,53 \\
\hline 26 & S.I. & 6,46 & 20,8 & 20,06 & 25,9 & 28,43 & 20,52 & 24,39 & 19,59 & 27,44 & 23,89 \\
\hline 27 & S.I. & 6,61 & 23,15 & 22,28 & 27,93 & 33,38 & 21,56 & 26,36 & 20,75 & 28,33 & 24,12 \\
\hline 27 & S.I. & 7 & 24,09 & 22,5 & 27,86 & 32,88 & 22,38 & 26,59 & 20,95 & 28,93 & 24,73 \\
\hline 27 & S.I. & 6,84 & 24,08 & 22,63 & 27,96 & 33,27 & 22,51 & 26,69 & 21,37 & 29,04 & 24,94 \\
\hline R3 & S.I. Kd & 9,63 & 28,72 & 23,11 & 27,5 & 34,12 & 23,01 & 29,24 & 20,26 & 36,82 & 29,43 \\
\hline
\end{tabular}




\begin{tabular}{|c|c|c|c|c|c|c|c|c|c|c|c|}
\hline ID & Тур & $\mathrm{C}_{\mathrm{t}}-18$ & $\mathrm{C}_{\mathrm{t}}-\mathrm{Act} \Omega$ & $\mathrm{C}_{\mathrm{t}}-\mathrm{H} 1$ & $\mathrm{C}_{\mathrm{t}}-\mathrm{H} 1 \mathrm{x}$ & $\mathrm{C}_{\mathrm{t}}-\mathrm{H} 1.1$ & $\mathrm{C}_{\mathrm{t}}-\mathrm{H} 1.2$ & $\mathrm{C}_{\mathrm{t}}-\mathrm{H} 1.3$ & $\mathrm{C}_{\mathrm{t}}-\mathrm{H} 1.4$ & $\mathrm{C}_{\mathrm{t}}-\mathrm{H} 1.5$ & $\mathrm{C}_{\mathrm{t}}-\mathrm{H} 3$ \\
\hline R3 & S.I. Kd & 9,62 & 28 & 23,13 & 28,42 & 35,57 & 23,9 & 30,67 & 20,49 & 38,33 & 29,72 \\
\hline R3 & S.I. Kd & 9,6 & 27,35 & 23,87 & 29,92 & 34,8 & 23,5 & 30 & 20,61 & 33 & 29,33 \\
\hline 4 & S.I. Km & 5,69 & 22,87 & 17,38 & 20,61 & 25,05 & 16,95 & 22,76 & 17,82 & 23,48 & 20,25 \\
\hline 4 & S.I. Km & 5,65 & 23,32 & 17,71 & 21,11 & 25,36 & 17,37 & 23,01 & 17,7 & 24,21 & 20,37 \\
\hline 4 & S.I. Km & 5,59 & 22,69 & 17,43 & 20,69 & 24,85 & 17,05 & 22,5 & 17,35 & 23,88 & 20,41 \\
\hline R1 & S.I. Km & 6,79 & 21,91 & 21,64 & 26,3 & 29,76 & 22,07 & 26,4 & 19,42 & 30,76 & 26,52 \\
\hline R1 & S.I. Km & 6,82 & 21,55 & 21,8 & 26,6 & 30,09 & 22,26 & 26,6 & 19,28 & 31,19 & 26,5 \\
\hline R1 & S.I. Km & 5,39 & 22,15 & 21,78 & 26,3 & 30,31 & 22,44 & 26,74 & 19,85 & 31,17 & 26,83 \\
\hline 7 & L.I. & 7,47 & 26,65 & 21,77 & 27,39 & 30,61 & 22,45 & 26,46 & 21,55 & 30,35 & 24,85 \\
\hline 7 & L.I. & 7,85 & 26,85 & 22,41 & 27,77 & 31,09 & 22,79 & 26,98 & 22,1 & 30,74 & 25,68 \\
\hline 7 & L.I. & 7,85 & 26,82 & 22,05 & 27,85 & 31,02 & 22,76 & 26,65 & 22,03 & 30,24 & 24,82 \\
\hline 6 & L.I. Km & 6,16 & 20,64 & 21,63 & 23,75 & 29,92 & 19,09 & 21,61 & 17,57 & 25,21 & 20,79 \\
\hline 6 & L.I. Km & 6,06 & 20,3 & 21,4 & 23,62 & 29,6 & 18,89 & 21,29 & 17,91 & 25,83 & 20,76 \\
\hline 6 & L.I. Km & 6,06 & 20,73 & 21,67 & 24,04 & 29,77 & 19,22 & 21,71 & 17,71 & 27,06 & 21,03 \\
\hline 25 & P. & 7,47 & 23,73 & 21,76 & 27,09 & 32,23 & 22,75 & 27,66 & 21,23 & 32,7 & 26,78 \\
\hline 25 & P. & 7,05 & 24,14 & 21,13 & 26,75 & 31,55 & 22,14 & 27,03 & 21,69 & 32,66 & 27,2 \\
\hline 25 & P. & 7,11 & 24,98 & 21,33 & 26,82 & 31,56 & 22,45 & 27,3 & 22,21 & 32,68 & 27,24 \\
\hline 10 & P. Km & 8,88 & 26,34 & 23,82 & 27,9 & 33,5 & 23,56 & 29,58 & 22,33 & 34,51 & 26,89 \\
\hline 10 & P. Km & 8,94 & 27,67 & 24,14 & 28 & 34,34 & 23,91 & 30,38 & 22,26 & 34,72 & 26,97 \\
\hline
\end{tabular}




\begin{tabular}{|c|c|c|c|c|c|c|c|c|c|c|c|}
\hline ID & Тур & $\mathrm{C}_{\mathrm{t}}-18 \mathrm{~S}$ & $\mathrm{C}_{\mathrm{t}}-\mathrm{Act} \Omega$ & $\mathrm{C}_{\mathrm{t}}-\mathrm{H} 1^{\circ}$ & $\mathrm{C}_{\mathrm{t}}-\mathrm{H} 1 \mathrm{x}$ & $\mathrm{C}_{\mathrm{t}}-\mathrm{H} 1.1$ & $\mathrm{C}_{\mathrm{t}}-\mathrm{H} 1.2$ & $\mathrm{C}_{\mathrm{t}}-\mathrm{H} 1.3$ & $\mathrm{C}_{\mathrm{t}}-\mathrm{H} 1$. & $\mathrm{C}_{\mathrm{t}}-\mathrm{H} 1.5$ & $\mathrm{C}_{\mathrm{t}}-\mathrm{H} 3$ \\
\hline 10 & P. Km & 9,86 & 27 & 25,52 & 30,13 & 34,99 & 24,78 & 31,56 & 22,5 & 36,65 & 26,8 \\
\hline 19 & P. Km & 6,61 & 22,34 & 19,72 & 25,59 & 28,53 & 19,77 & 27,2 & 18,78 & 28,77 & 25,16 \\
\hline 19 & P. Km & 7,22 & 23,46 & 20,22 & 25,8 & 29,35 & 20,29 & 27,9 & 19,12 & 28,7 & 25,66 \\
\hline 19 & P. Km & 6,93 & 23,24 & 19,87 & 24,97 & 28,83 & 20,09 & 28,29 & 19,07 & 28,73 & 25,38 \\
\hline $24 c$ & P. Km & 6,2 & 20,34 & 18,97 & 22,47 & 30,23 & 18,64 & 26,06 & 16,37 & 29,89 & 23,79 \\
\hline $24 c$ & P. Km & 6,19 & 20,41 & 19,2 & 22,66 & 29,73 & 18,81 & 26,16 & 16,48 & 29,58 & 23,72 \\
\hline $24 c$ & P. Km & 6,3 & 21 & 19,16 & 22,61 & 29,72 & 19,02 & 26,31 & 16,59 & 29,51 & 24,14 \\
\hline
\end{tabular}


Tabelle 27: RT-PCR für Tumorkollektiv (Lungenproben)

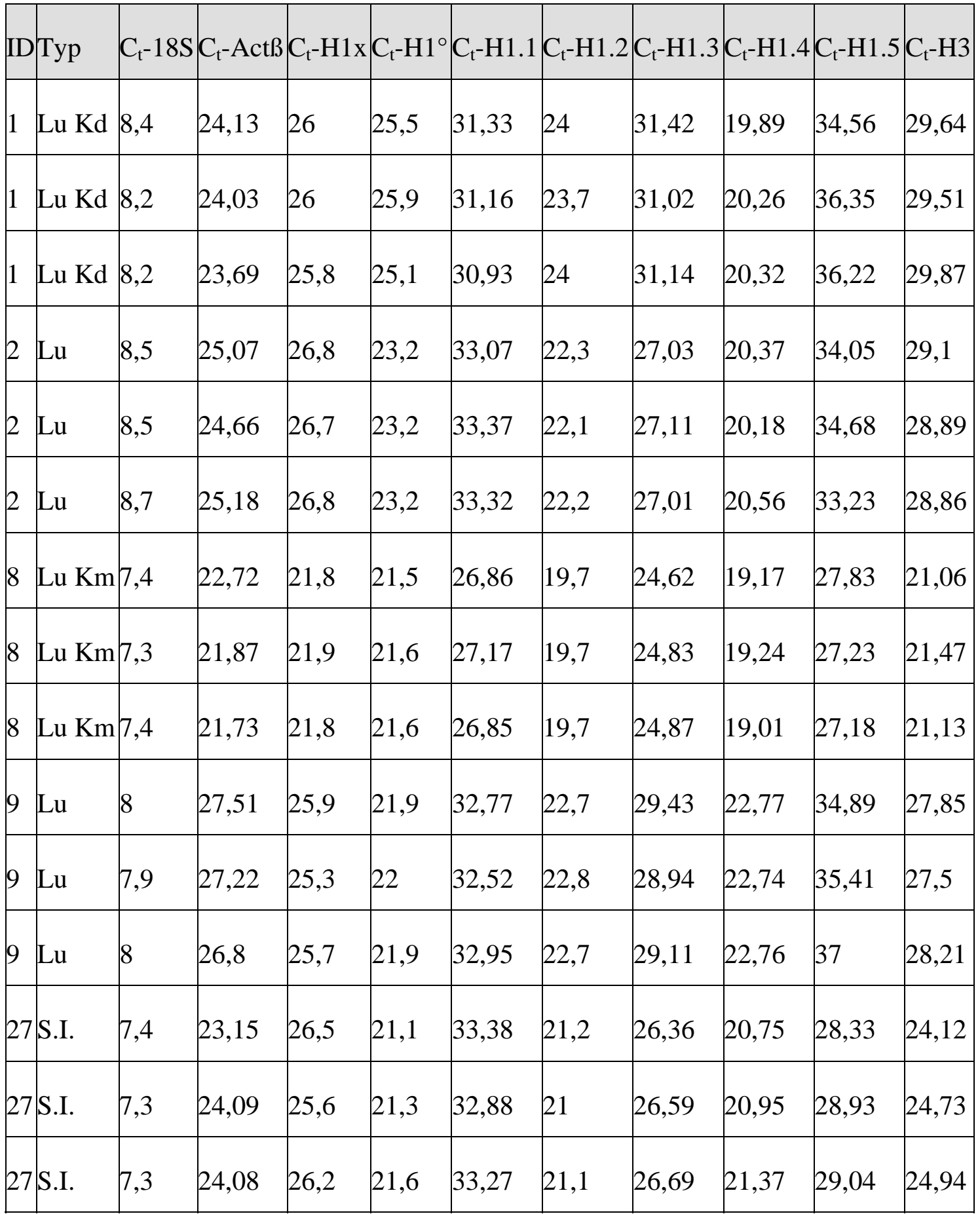

Anmerkg. SI: Dünndarm, LI: Dickdarm, Lu: Lunge, P: Pankreas; Kd: Karzinoid, Km: Karzinom 


\subsubsection{Originaldaten RT-PCR für Zellzyklus}

Tabelle 28: RT-PCR für Zellzyklus

\begin{tabular}{|c|c|c|c|c|c|c|c|c|c|c|c|}
\hline Тур & ZV & $\mathrm{C}_{\mathrm{t}}-18 \mathrm{~S}$ & $\mathrm{C}_{\mathrm{t}}-\mathrm{Act} \Omega$ & $\mathrm{C}_{\mathrm{t}}-\mathrm{H} 1$ & $\mathrm{x} \mathrm{C}_{\mathrm{t}}-\mathrm{H} 1$ & $\mathrm{C}_{\mathrm{t}}-\mathrm{H} 1$ & $\mathrm{C}_{\mathrm{t}}-\mathrm{H} 1.2$ & $\mathrm{C}_{\mathrm{t}}-\mathrm{H} 1.3$ & $\mathrm{C}_{\mathrm{t}}-\mathrm{H} 1.4$ & $\mathrm{C}_{\mathrm{t}}-\mathrm{H} 1.5$ & $5 \mathrm{C}_{\mathrm{t}}-\mathrm{H} 3$ \\
\hline $\mathrm{K}$ & 56 & 7,79 & 16,4 & 19,98 & 22,95 & 22,13 & 16,28 & 19,02 & 14,38 & 19,3 & 18,75 \\
\hline $\mathrm{K}$ & 56 & 7,84 & 16,37 & 19,99 & 22,9 & 22,11 & 16,2 & 18,94 & 14,31 & 19,48 & 18,61 \\
\hline $\mathrm{K}$ & 56 & 7,83 & 16,59 & 20,21 & 23,01 & 22,15 & 16,4 & 19,06 & 14,57 & 19,57 & 18,62 \\
\hline $\mathrm{Oh}$ & 56 & 7,83 & 16,83 & 23,28 & 24,8 & 24,29 & 18,4 & 23,29 & 16,87 & 21,51 & 19,64 \\
\hline Oh & 56 & 7,75 & 16,88 & 23,11 & 24,66 & 24,05 & 18,12 & 23,19 & 16,57 & 21,32 & 19,5 \\
\hline $\mathrm{Oh}$ & 56 & 7,87 & 17,14 & 23,28 & 24,87 & 24,31 & 18,31 & 23,37 & 16,72 & 21,58 & 19,68 \\
\hline $2 \mathrm{~h}$ & 56 & 7,7 & 16,01 & 20,53 & 23,07 & 21,58 & 15,87 & 19,73 & 13,99 & 18,1 & 17,49 \\
\hline $2 \mathrm{~h}$ & 56 & 7,84 & 16,3 & 20,92 & 23,49 & 21,89 & 16,19 & 19,95 & 14,25 & 18,66 & 17,63 \\
\hline $2 \mathrm{~h}$ & 56 & 7,83 & 16,16 & 20,69 & 23,12 & 21,67 & 15,95 & 20,18 & 13,98 & 18,1 & 17,55 \\
\hline $4 \mathrm{~h}$ & 56 & 7,66 & 15,24 & 19,08 & 22,71 & 21,39 & 14,7 & 18,5 & 13,57 & 18,16 & 16,71 \\
\hline $4 \mathrm{~h}$ & 56 & 7,69 & 15,65 & 19,57 & 23,03 & 21,57 & 14,84 & 18,59 & 13,56 & 18 & 16,8 \\
\hline $4 \mathrm{~h}$ & 56 & 7,8 & 16,5 & 19,51 & 22,97 & 21,21 & 14,97 & 18,77 & 13,68 & 18,03 & 17 \\
\hline $6 \mathrm{~h}$ & 56 & 7,42 & 14,91 & 18,3 & 22,45 & 20,92 & 13,93 & 17,39 & 12,61 & 16,27 & 16,07 \\
\hline $6 h$ & 56 & 7,64 & 15,48 & 19 & 22,87 & 20,96 & 14,53 & 17,89 & 12,72 & 16,94 & 16,64 \\
\hline $6 \mathrm{~h}$ & 56 & 7,75 & 15,9 & 19,4 & 23,14 & 21,12 & 14,79 & 18,25 & 12,9 & 17,17 & 16,72 \\
\hline $8 \mathrm{~h}$ & 56 & 8,21 & 16,75 & 20,04 & 22,35 & 22,02 & 16,01 & 19,57 & 14 & 18,69 & 17,95 \\
\hline $8 \mathrm{~h}$ & 56 & 8,15 & 16,87 & 20,01 & 22,41 & 21,58 & 15,97 & 19,66 & 13,98 & 18,65 & 17,87 \\
\hline
\end{tabular}




\begin{tabular}{|c|c|c|c|c|c|c|c|c|c|c|c|}
\hline Тур & $\mathrm{ZV}$ & $\mathrm{C}_{\mathrm{t}}-18 \mathrm{~S}$ & $\mathrm{C}_{\mathrm{t}}-\mathrm{Act} \Omega$ & $\mathrm{C}_{\mathrm{t}}-\mathrm{H} 1 \mathrm{x}$ & $\mathrm{C}_{\mathrm{t}}-\mathrm{H} 1^{\circ}$ & $\mathrm{C}_{\mathrm{t}}-\mathrm{H} 1.1$ & $\mathrm{C}_{\mathrm{t}}-\mathrm{H} 1.2$ & $\mathrm{C}_{\mathrm{t}}-\mathrm{H} 1.3$ & $\mathrm{C}_{\mathrm{t}}-\mathrm{H} 1.4$ & $\mathrm{C}_{\mathrm{t}}-\mathrm{H} 1.5$ & $\mathrm{C}_{\mathrm{t}}-\mathrm{H} 3$ \\
\hline $8 \mathrm{~h}$ & 56 & 8,18 & 17,14 & 20,23 & 22,47 & 20,93 & 15,89 & 19,52 & 13,95 & 18,75 & 17,9 \\
\hline $10 \mathrm{~h}$ & 56 & 7,87 & 15,67 & 20,1 & 22,9 & 22,27 & 16,12 & 20,16 & 14,34 & 19,39 & 18,18 \\
\hline $10 \mathrm{~h}$ & 56 & 8,08 & 16,05 & 20,18 & 22,99 & 22,28 & 16,18 & 20,35 & 14,59 & 19,77 & 18,45 \\
\hline $10 \mathrm{~h}$ & 56 & 7,93 & 16,15 & 20,27 & 22,92 & 22,13 & 16,12 & 20,15 & 14,57 & 19,82 & 18,29 \\
\hline K & 66 & 7,97 & 16,79 & 21,07 & 23,5 & 23,07 & 16,68 & 19,79 & 14,65 & 19,5 & 18,63 \\
\hline K & 66 & 7,98 & 16,9 & 21,18 & 23,51 & 23,31 & 16,67 & 19,71 & 14,56 & 19,49 & 18,65 \\
\hline K & 66 & 7,83 & 16,89 & 21,07 & & 23,08 & 17,44 & 19,66 & 14,59 & 19,52 & 18,55 \\
\hline $\mathrm{Oh}$ & 66 & 7,87 & 16,44 & 24,2 & 24,37 & 24,42 & 18,22 & 24,01 & 16,74 & 20,59 & 19,46 \\
\hline $\mathrm{Oh}$ & 66 & 7,89 & 16,6 & 24,5 & 24,32 & 24,64 & 18,23 & 24,16 & 15,97 & 20,64 & 19,67 \\
\hline $\mathrm{Oh}$ & 66 & 7,87 & 16,56 & 24,2 & 24,29 & 24,63 & 18,31 & 24,01 & 16,29 & 21,37 & 19,46 \\
\hline $2 \mathrm{~h}$ & 66 & 7,95 & 16,65 & 22,05 & 24,5 & 22,73 & 16,9 & 21,77 & 15,37 & 19,64 & 18,49 \\
\hline $2 \mathrm{~h}$ & 66 & 7,88 & 16,46 & 21,93 & 24,4 & 22,84 & 16,73 & 21,6 & 14,99 & 19,36 & 18,24 \\
\hline $2 \mathrm{~h}$ & 66 & 7,87 & 16,28 & 21,86 & 24,1 & 22,78 & 16,75 & 21,56 & 14,85 & 19,54 & 18,37 \\
\hline $4 h$ & 66 & 7,82 & 16,13 & 20,8 & 23,77 & 22 & 16,11 & 20,34 & 14,33 & 18,67 & 17,44 \\
\hline $4 h$ & 66 & 8,08 & 16,48 & 20,77 & 23,84 & 22,23 & 15,91 & 20,4 & 14,31 & 18,94 & 17,7 \\
\hline $4 h$ & 66 & 7,98 & 16,49 & 20,85 & 23,72 & 22,15 & 16,25 & 20,56 & 14,42 & 18,86 & 17,84 \\
\hline $6 h$ & 66 & 8,12 & 16,88 & 20,74 & 24,2 & 22,06 & 15,59 & 19,93 & 14,04 & 19,13 & 17,45 \\
\hline $6 h$ & 66 & 8,05 & 16,92 & 20,68 & 23,89 & 22,1 & 15,63 & 19,74 & 14,04 & 18,82 & 17,59 \\
\hline $6 h$ & 66 & 8,16 & 17,23 & 21,74 & 24,01 & 22,18 & 15,78 & 20,01 & 14,24 & 19,58 & 17,68 \\
\hline
\end{tabular}




\begin{tabular}{|c|c|c|c|c|c|c|c|c|c|c|c|}
\hline Тур & ZV & $\mathrm{C}_{\mathrm{t}}-18 \mathrm{~S}$ & $\mathrm{C}_{\mathrm{t}}-\mathrm{Act} \Omega$ & $\mathrm{C}_{\mathrm{t}}-\mathrm{H} 1 \mathrm{x}$ & $\mathrm{C}_{\mathrm{t}}-\mathrm{H} 1^{\circ}$ & $\mathrm{C}_{\mathrm{t}}-\mathrm{H} 1.1$ & $\mathrm{C}_{\mathrm{t}}-\mathrm{H} 1.2$ & $\mathrm{C}_{\mathrm{t}}-\mathrm{H} 1 . \mathrm{z}^{3}$ & $\mathrm{C}_{\mathrm{t}}-\mathrm{H} 1.4$ & $\mathrm{C}_{\mathrm{t}}-\mathrm{H} 1.5$ & $\mathrm{C}_{\mathrm{t}}-\mathrm{H} 3$ \\
\hline $8 \mathrm{~h}$ & 66 & 7,82 & 16,04 & 20,31 & 23,45 & 21,81 & 15,08 & 19,72 & 13,73 & 18,41 & 17,22 \\
\hline $8 \mathrm{~h}$ & 66 & 7,84 & 16,26 & 20,52 & 23,38 & 22,33 & 15,56 & 19,63 & 13,71 & 18,56 & 17,33 \\
\hline $8 \mathrm{~h}$ & 66 & 7,91 & 16,57 & 20,44 & 23,28 & 22,38 & 15,57 & 19,74 & 13,96 & 18,64 & 17,39 \\
\hline $10 \mathrm{~h}$ & 66 & 8,98 & 17,71 & 22,38 & 25,39 & 23,09 & 17,99 & 22,57 & 15,99 & 21,73 & 20,29 \\
\hline $10 \mathrm{~h}$ & 66 & 8,87 & 17,99 & 22,45 & 25,01 & 23,08 & 17,92 & 22,29 & 16,34 & 21,25 & 19,88 \\
\hline $10 \mathrm{~h}$ & 66 & 9,16 & 18,85 & 22,57 & 25,29 & 23,81 & 18,3 & 22,7 & 16,44 & 21,36 & 20,28 \\
\hline $\mathrm{K}$ & 66 & 7,96 & 16,92 & 21,47 & 22,8 & 22 & 16,33 & 19,72 & 14,91 & 19,58 & 18,2 \\
\hline K & 66 & 8 & 17,17 & 21,45 & 22,76 & 22,48 & 16,4 & 19,68 & 14,84 & 19,53 & 18,15 \\
\hline $\mathrm{K}$ & 66 & 7,94 & 17,21 & 21,25 & 22,73 & 22,83 & 16,33 & 19,65 & 15,05 & 19,54 & 18,36 \\
\hline Oh & 66 & 7,89 & 16,9 & 24,2 & 24,57 & 23,75 & 18,47 & 24,33 & 16,76 & 21,31 & 19,79 \\
\hline Oh & 66 & 7,76 & 16,84 & 23,96 & 24,15 & 24,11 & 18,06 & 23,87 & 16,5 & 20,96 & 19,42 \\
\hline $\mathrm{Oh}$ & 66 & 7,95 & 17,36 & 24,23 & 24,4 & 24,19 & 18,57 & 24,23 & 16,98 & 21,33 & 19,72 \\
\hline $2 \mathrm{~h}$ & 66 & 8,23 & 17,04 & 22,28 & 25,24 & 23,02 & 17,53 & 21,69 & 15,88 & 20,66 & 19,05 \\
\hline $2 \mathrm{~h}$ & 66 & 8,05 & 17,14 & 21,78 & 24,67 & 23,04 & 16,96 & 21,49 & 15,23 & 20,08 & 18,7 \\
\hline $2 \mathrm{~h}$ & 66 & 8,64 & 18,22 & 22,64 & 25,4 & 23,11 & 17,92 & 22,45 & 16,19 & 21 & 19,63 \\
\hline $4 \mathrm{~h}$ & 66 & 7,86 & 15,87 & 20,22 & 23,38 & 21,81 & N/A & 20,28 & 14,08 & 18,37 & 17,44 \\
\hline $4 h$ & 66 & 7,89 & 17,45 & 20,74 & 23,25 & 22,01 & N/A & 20,52 & 14,25 & 18,48 & 17,64 \\
\hline $4 \mathrm{~h}$ & 66 & 8,27 & 17,4 & 21,2 & 23,79 & 22,5 & N/A & 21,04 & 14,72 & 18,97 & 18,21 \\
\hline $6 \mathrm{~h}$ & 66 & 7,9 & 15,98 & 20,42 & 23,52 & 21,63 & 15,57 & 19,79 & 13,61 & 17,84 & 17,58 \\
\hline
\end{tabular}




\begin{tabular}{|c|c|c|c|c|c|c|c|c|c|c|c|}
\hline Тур & $\mathrm{ZV}$ & $\mathrm{C}_{\mathrm{t}}-18 \mathrm{~S}$ & $\mathrm{C}_{\mathrm{t}}-\mathrm{Act} ß$ & $\mathrm{C}_{\mathrm{t}}-\mathrm{H} 1 \mathrm{x}$ & $\mathrm{C}_{\mathrm{t}}-\mathrm{H} 1^{\circ}$ & $\mathrm{C}_{\mathrm{t}}-\mathrm{H} 1.1$ & $\mathrm{C}_{\mathrm{t}}-\mathrm{H} 1.2$ & $\mathrm{C}_{\mathrm{t}}-\mathrm{H} 1.3$ & $\mathrm{C}_{\mathrm{t}}-\mathrm{H} 1.4$ & $\mathrm{C}_{\mathrm{t}}-\mathrm{H} 1.5$ & $\mathrm{C}_{\mathrm{t}}-\mathrm{H} 3$ \\
\hline $6 \mathrm{~h}$ & 66 & 7,76 & 16,25 & 20,02 & 23,24 & 21,88 & 15,42 & 19,58 & 13,48 & 17,56 & 17,26 \\
\hline $6 \mathrm{~h}$ & 66 & 7,93 & 16,76 & 19,96 & 23,41 & 22,19 & 15,71 & 19,84 & 13,69 & 17,95 & 17,86 \\
\hline $8 \mathrm{~h}$ & 66 & 7,7 & 15,73 & 19,89 & 22,99 & 22,15 & 14,97 & 18,99 & 13,18 & 17,51 & 16,82 \\
\hline $8 \mathrm{~h}$ & 66 & 7,75 & 16,28 & 20,14 & 23,08 & 22,13 & 15,58 & 19,46 & 13,5 & 17,86 & 17,13 \\
\hline $8 \mathrm{~h}$ & 66 & 7,8 & 16,86 & 20,13 & 23,03 & 22,32 & 15,7 & 19,49 & 13,62 & 17,6 & 17,24 \\
\hline $10 \mathrm{~h}$ & 66 & 8,6 & 16,42 & 21,56 & 23,9 & 23,83 & 17,45 & 21,81 & 15,41 & 20,28 & 19,72 \\
\hline $10 \mathrm{~h}$ & 66 & 8,52 & 16,64 & 21,36 & 23,58 & 24,24 & 17,29 & 21,64 & 15,36 & 20,03 & 19,19 \\
\hline $10 \mathrm{~h}$ & 66 & 8,45 & 17,45 & 21,14 & 23,85 & 23,79 & 17,41 & 21,64 & 15,45 & 19,84 & 19,29 \\
\hline $\mathrm{NaBu}$ & & 7,32 & 17,33 & 18,66 & 22,28 & 23,46 & 17,58 & 20,71 & 16,22 & 21,44 & 21,37 \\
\hline $\mathrm{NaBu}$ & & 7,36 & 17,7 & 18,86 & 22,31 & 23,81 & 17,38 & 20,78 & 16,38 & 21,42 & 21,33 \\
\hline $\mathrm{NaBu}$ & & 7,36 & 17,8 & 18,69 & 22,38 & 23,65 & 17,71 & 20,76 & 16,47 & 21,63 & 21,25 \\
\hline $\mathrm{K}$ & 56 & 7,27 & 16,05 & 19,83 & 22,19 & 22,47 & 16,02 & 19,58 & 14,73 & 19,29 & 18,79 \\
\hline $\mathrm{K}$ & 56 & 7,24 & 15,98 & 19,72 & 22,16 & 22,34 & 15,97 & 19,63 & 14,68 & 19,08 & 18,66 \\
\hline $\mathrm{K}$ & 56 & 7,24 & 16,35 & 19,91 & 22,17 & 22,51 & 16,23 & 19,7 & 14,86 & 19,47 & 18,67 \\
\hline $\mathrm{K}$ & 66 & 7,24 & 16,25 & 20,31 & 21,95 & 22,66 & 16,09 & 19,6 & 14,36 & 18,57 & 18,32 \\
\hline $\mathrm{K}$ & 66 & 7,22 & 16,07 & 20,25 & 21,71 & 22,65 & 16,36 & 19,59 & 13,95 & 18,19 & 18,17 \\
\hline $\mathrm{K}$ & 66 & 7,26 & 16,61 & 20,18 & 21,57 & 22,83 & 16,25 & 19,74 & 14,17 & 18,31 & 18,22 \\
\hline
\end{tabular}




\subsubsection{ISH-Sequenzen}

Sonde 2 im Vektor pBluescript II KS+:

... TTGTAAAACGACGGCCAGTGAGCGCGCGTAATACGACTCACTATAGGGCGAATTGGAGCTCCACCGC GGTGGCGGCCGCCGTCTTCTTGGCCTTGCCGCCTTTGTCCTTCTTGGCGCCAGCGCCCTTCTTGTGCGAG CGCTGCTCCGGCTTCTGGCCCCTGGCGGGCTTCTTGTCCGCGCGCCGGGAGCCGGCCGCGCCCGGGGCTG CCTTCTTCGCTTTGTGCGCGGTGGGGGCCGGGGCGGTGGCGGCCGCTCTAGAACTAGTGGATCCCCCGGG CTGCAGGAATTCGATATC. . .

Not I-Schnittstellen

GGCCGC...GGTGGC: H1x-Teilsequenz aus Konstrukt IM28 in pOTB7 (Happel et al., 2005)

Sonde 3 im Vektor pBluescript II KS+:

... TTGTAAAACGACGGCCAGTGAGCGCGCGTAATACGACTCACTATAGGGCGAATTGGAGCTCCACCGC GGTGGCGGCCGCTCTAGAACTAGTGGATCCCCCGGGCTGCAGGAATTCtggtgget ctgaaaagagcet $t$ ttgggttttagaagtaggcgttcgcctatttcttcttgggcgccgccttcttaggcttgacaaccttggg cttagcggccttgggcttcacagccttagcagcacttttggcagctttcttgggcttcgcaaccttggcc ttctttgggctcttagccactttcttggttacagtCTCGAGGGGGGGCCGGTACC. . .

Xho I-, Eco RI-Schnittstelle

tggtgg... tacagt: H1x-Teilsequenz aus Konstrukt pWA 311 (Albig et al., 1998)

\subsubsection{GFP-Konstrukte Sequenzen}

\section{pJW 9:}

...GATCTCGAGCTCAAGCTT atgtccgtggagctcgaggaggccctgccagtgacgaccgccgagggaa tggccaagaaggtgaccaaggctggcggctcggcggcgttgtccccatctaagaagaggaagaatagcaa gaagaagaaccagccgggcaagtacagccagctggtggtggagaccatccgtaggctgggcgagcgcaac ggctcgtcgctggccaagatctacaccgaggccaagaaggttccgtggttcgaccagcagaatgggcgca cctacctcaagtactcgatcaaggcgctggtgcagaacgacacgcttctgcaggtgaagggcaccggcgc caacggttcct tcaagctcaaccgcaagaagctggagggcggcggggagcggcgcggagccccggcggcc gccaccgccccggcccccaccgcgcacaaagcgaagaaggcagccccgggcgcggccggctcccggcgcg cggacaagaagcccgccaggggccagaagccggagcagcgctcgcacaagaagggcgctggcgccaagaa ggacaaaggcggcaaggccaagaagacggcggccgccgggggcaagaaggtgaagaaggcggccaagccc 
agcgtccccaaagtgcccaagggccgcaagGATCCACCGGTCGCCACCATGGTGAGCAAGGGCGAGGAGC TGTTCACCGGGGTGGTGCCCATCCTGGTCGAGCTGGACGGCGACGTAAACGGCCACAAGTTCAGCGTGTC CGGCGAGGGCGAGGGCGATGCCACCTACGGCAAGCTGACCCTGAAGTTCATCTGCACCACCGGCAAGCTG CCCGTGCCCTGGCCCACCCTCGTGACCACCCTGACCTACGGCGTGCAGTGCTTCAGCCGCTACCCCGACC ACATGAAGCAGCACGACTTCTTCAAGTCCGCCATGCCCGAAGGCTACGTCCAGGAGCGCACCATCTTCTT CAAGGACGACGGCAACTACAAGACCCGCGCCGAGGTGAAGTTCGAGGGCGACACCCTGGTGAACCGCATC GAGCTGAAGGGCATCGACTTCAAGGAGGACGGCAACATCCTGGGGCACAAGCTGGAGTACAACTACAACA GCCACAACGTCTATATCATGGCCGACAAGCAGAAGAACGGCATCAAGGTGAACTTCAAGATCCGCCACAA CATCGAGGACGGCAGCGTGCAGCTCGCCGACCACTACCAGCAGAACACCCCCATCGGCGACGGCCCCGTG CTGCTGCCCGACAACCACTACCTGAGCACCCAGTCCGCCCTGAGCAAAGACCCCAACGAGAAGCGCGATC ACATGGTCCTGCTGGAGTTCGTGACCGCCGCCGGGATCACTCTCGGCATGGACGAGCTGTACAAGT . . .

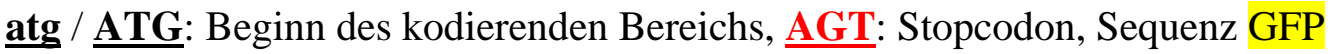

\section{pJW 34:}

TAGTTATTACTAGCGCTACCGGACTCAgatctcaagtggaggctgcaacggct tcaacaaaaactgtcct gtgccttctctgcacccccaatactggaatcagcagagatcgggccgccagcct tgcacaagcccccccg gggagggtggggcccgggaccctctccaggacatggtctcctttgctgtgttcccgccatcatt tccetg tgcacgggagagggggaggggtgcacccaggaactaagagcgaatcccttccccatcctctcacaggaat tcctctgggtgtcacagcctcaccccogcccaccctgtcccaccetggagcccccatt tggctttggggg gaccggcggcagctact tgtggat tacaaaatgaggccctgggaacatcagcggcaacagggtgggggga gcggcgaggcagtgtccctagagaggtcctgccgtagtcctccattccccgggttgtgcctaggctccca gaggcacaaccagaacccggggtgcagctggagagtgcctcccatccgccatcccctttggatggggegg aaaacccccgaggatgtcctagcgcagt tcacgt tgccccagccgaccacgtgagggcgcgccctgtgtt agtt tggacaaat taaagctcctct tgcgggcaggcctggagccccccgggccgggacaaggctcgggtg cccgtggcgttctctgggt tgccggccgccaagctcccggccgtggggcctcctctggggcccgcgctat tggcctccaaacgaggtgccccctcctctcgcgctcccgcagcctagggtgcacctctccgttcgcett tgctgagccct tccaggacgcaagtcgectctccactgcgccgggagctcaggccetgtccggggcgccc cgctgcgggcgcggcggcgctggagaggcgcggtccgagaagccagcggccggagaaggggctccaagaa gcacaagt tggcgctggccccggaccaggctgttgttgttctcaacgtggtccgccatgaagctataaaa agccgagagaagcgccctcccgccagagcgcagcgcgcacgcccagcgagt tccagaggcgccagtggaa gctgcggcggcggtgtctcgcgttcggcgggatttctcttcgctccggctcggcctaggtctacgtcccc agctccagccgccggctcggactcggtctctgaccccaactcggtcccetagtccggcccoggctccgg gcccccaaccetcgctccggcccggcccggcccccaccccagccetgccgcccggccccaggcccggcc gcggccgctcccgcctggagccgccgcgcgcccccagcccccetgcacccctcggcccetcgcettcct ct tccoggcgcggcccccogget tccgcgcgecgccogccaccaatcctct tgctaccatggctaccatg tccgtggagctcgaggaggccctgccagtgacgaccgccgagggaatggccaagaaggtgaccaaggetg gcggctcggcggcgttgtccccatctaagaagaggaagaatagcaagaagaagaaccagccgggcaagta cagccagctggtggtggagaccatccgtaggctgggcgagcgcaacggctcgtcgctggccaagatctac 
accgaggccaagaaggttccgtggttcgaccagcagaatgggcgcacctacctcaagtactcgatcaagg cgctggtgcagaacgacacgcttctgcaggtgaagggcaccggcgccaacggttccttcaagctcaaccg caagaagctggagggcggcggggagcggcgcggagccccggcggccgccaccgcccoggccccaccgcg cacaaagcgaagaaggcagccccgggcgcggccggctcccggcgcgcggacaagaagcccgccaggggcc agaagccggagcagcgctcgcacaagaagggcgctggcgccaagaaggacaaaggcggcaaggccaagaa gacggcggccgccgggggcaagaaggtgaagaaggcggccaagcccagcgtccccaaagtgcccaagggc cgcaagGATCCACCGGTCGCCACCATGGTGAGCAAGGGCGAGGAGCTGTTCACCGGGGTGGTGCCCATCC TGGTCGAGCTGGACGGCGACGTAAACGGCCACAAGTTCAGCGTGTCCGGCGAGGGCGAGGGCGATGCCAC CTACGGCAAGCTGACCCTGAAGTTCATCTGCACCACCGGCAAGCTGCCCGTGCCCTGGCCCACCCTCGTG ACCACCCTGACCTACGGCGTGCAGTGCTTCAGCCGCTACCCCGACCACATGAAGCAGCACGACTTCTTCA AGTCCGCCATGCCCGAAGGCTACGTCCAGGAGCGCACCATCTTCTTCAAGGACGACGGCAACTACAAGAC CCGCGCCGAGGTGAAGTTCGAGGGCGACACCCTGGTGAACCGCATCGAGCTGAAGGGCATCGACTTCAAG GAGGACGGCAACATCCTGGGGCACAAGCTGGAGTACAACTACAACAGCCACAACGTCTATATCATGGCCG ACAAGCAGAAGAACGGCATCAAGGTGAACTTCAAGATCCGCCACAACATCGAGGACGGCAGCGTGCAGCT CGCCGACCACTACCAGCAGAACACCCCCATCGGCGACGGCCCCGTGCTGCTGCCCGACAACCACTACCTG AGCACCCAGTCCGCCCTGAGCAAAGACCCCAACGAGAAGCGCGATCACATGGTCCTGCTGGAGTTCGTGA CCGCCGCCGGGATCACTCTCGGCATGGACGAGCTGTACAAGTAAAGCGGCCGCGACTCTAGATCATAATC AGCCATACCACATTTGTAGAGGTTTTACTTGCTTTAAAAAACCTCCCACACCTCCCCCTGAACCTGAAAC ATAAAATGAATGCAATTGTTGTTGTTAACTTGTTTATTG...

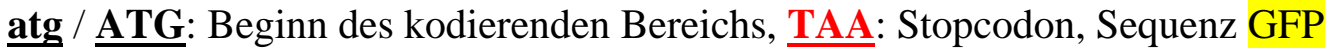

Bgl II-, Bam HI-, Nco I-Schnittstelle

\subsubsection{SiRNA X2 und T1 in pSilencer}

\section{pSilencer mit siX2}

... TTTTAAAAAACAGCACAAAAGGAAACTCACCCTAACTGTAAAGTAATTGTGTGTTTTGAGACTATAA ATATCCCTTGGAGAAAAGCCTTGTTTGGGCCagatctacaccgaggccaat tcaagagat tggcctcggt gtagatcttttt AATTCCTGCAGCCCGGGGGATCCACTAGTTCTAGAGCGGCCGCCACCGCGGTGGAGC TCCAGCTTTTGTTCCCTTTAGTGAGgGTTAATTGCGCGCTTGGCG . . .

ApaI-, EcoRI-Schnittstelle

T3-Primer-Bindungsstelle

agatct...: eingefügtes Oligonukleotid siX2 
pSilencer mit siT1

... TTTTAAAAAAACAGCACAAAAGGAAACTCACCCTAACTGTAAAGTAATTGTGTGTTTTGAGACTATAA ATATCCCTTGGAGAAAAGCCTTGTTTGGGCCtcctcttgctaccatgtccttttcaagagaggacatggt agcaagaggatttttt AATTCCTGCAGCCCGGGGGATCCACTAGTTCTAGAGCGGCCGCCACCGCGGTG GAGCTCCAGCTTTTGTTCCCTTTAGTGAGGGTTAATTGCGCGCTTGGCG . . .

ApaI-, EcoRI-Schnittstelle

T3-Primer-Bindungsstelle

tcctct...: eingefügtes Oligonukleotid siT1

\subsubsection{Multiples Sequenzalignment der H1-Subtyp-mRNA-Sequenzen}

Multalin version 5.4.1

(Corpet, 1988)

Symbol comparison table: dna

Gap weight: 5

Gap length weight: 0

Consensus levels: high $=90 \%$ low $=50 \%$

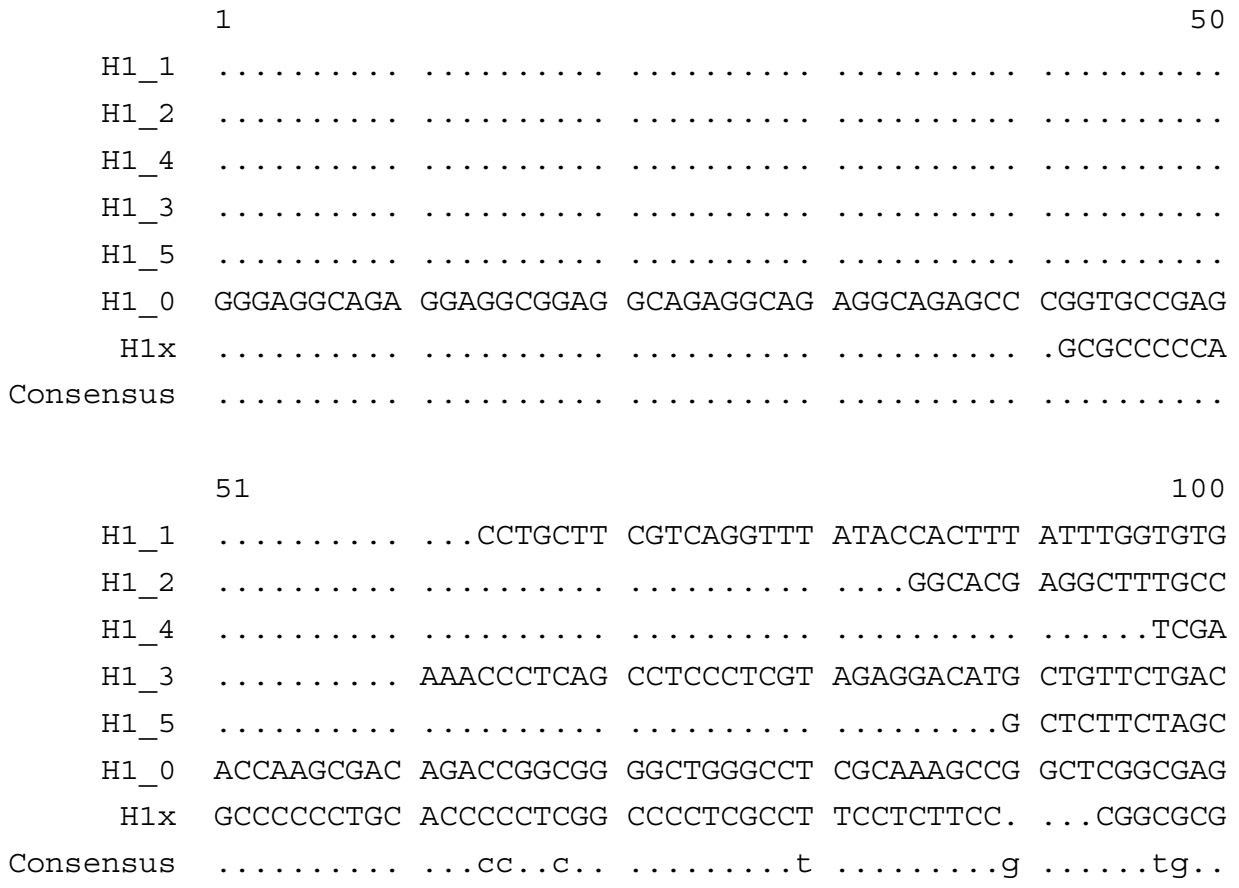




\begin{tabular}{|c|c|c|c|c|c|}
\hline $\mathrm{H} 1$ _1 & STGGTTAGT & CAC. & $\cdots \cdots$ & $\cdots$ & CATGTCTG \\
\hline $\mathrm{H} 1$ _2 & ACTTGTACCC & GAGTTTTTGA & ТТСТС.... & $\ldots \ldots A \mathrm{AA}$ & CATGTCCGAG \\
\hline $\mathrm{H} 1 \_4$ & АTTGCTCTCG & CTCACGCTTG & ССттс.... & $\ldots \ldots A A$ & CATGTCCGAG \\
\hline $\mathrm{H} 1{ }_{-} 3$ & AGTTTGAGAT & TACTTATTGT & CTTTTCTGGG & AAGACAAAAA & CATGTCGGAG \\
\hline $\mathrm{H} 1 \_5$ & AGTTTCTTGC & CAC $\ldots \ldots$ & $\ldots \ldots \ldots$ & $\ldots \ldots \ldots$ & CATGTCGGAA \\
\hline $\mathrm{H}{ }_{-} \mathrm{O}$ & СТCTCCCGAC & ACCCGAGCCG & GGGAGGAAAA & GCAGCGACTC & CTCGCTCGCA \\
\hline $\mathrm{H} 1 \mathrm{x}$ & GCCCCCCGGC & TTCCGCGCGC & CGCCCGCCAC & САAтC.... & . СТСTTGCT \\
\hline onsensus & $a . t t \ldots . c$ &. ac ...... & $\ldots \ldots \ldots$ & $\ldots \ldots \ldots$ & catgtc. Ga. \\
\hline & 51 & & & & 200 \\
\hline $\mathrm{H} 1$ _1 & ACAGTGCCTC & CCGCCCCCGC & CGCTTCTGCT & GCTCCTGAGA & AACCTTTAGC \\
\hline $\mathrm{H} 1 \_2$ & АСTGCTCCTG & CCGCTCCCGC & TGCCGCGCCT & CCTGCGGAGA & AGGCC \\
\hline $\mathrm{H} 1 \_4$ & ACTGCGCCTG & CCGCGCCCGC & TGCTCCGGCC & CCTGCCGAGA & AGAC \\
\hline $\mathrm{H} 1{ }^{3} 3$ & АСTGCTCCAC & TTGCTCCTAC & САTTCСTGCA & CCCGCAGAAA & $A A A C A$ \\
\hline $\mathrm{H} 1 \_5$ & ACCGCTCCTG & CCGAGACAGC & CACCCCAGCG & CCGGTGGAGA & AATCC \\
\hline $\mathrm{H} 1 \_0$ & TCCCCGGGAG & CCGCACTCCA & GACTGGCCCG & GTAGTCAGGG & GCTCA \\
\hline $\mathrm{H} 1 \mathrm{x}$ & ACCATGTCCG & TGGAGCTCGA & GGAGGCCCTG & CCAGTGACGA & CCGCCGAGGG \\
\hline onsensus & ac.gcgcctg & $\mathrm{ccGc} \cdot \mathrm{CCCgC}$ & .gct.c.gc. & cc.gc.gaga & a..C.CC.G. \\
\hline & 201 & & & & 250 \\
\hline $\mathrm{H} 1 \_1$ & TGGCAAGAAG & GCA. . & & & $\ldots$ \\
\hline $\mathrm{H} 1 \_2$ & AAAGAAGAAG & GCG $\ldots \ldots$ & $\ldots \ldots$ & $\ldots \ldots \ldots$ & $\ldots$ \\
\hline $\mathrm{H} 1 \_4$ & GAAGAAGAAG & GCC... & $\ldots \ldots$ & $\ldots \ldots \ldots$ & $\ldots$ \\
\hline $\mathrm{H} 1 \_3$ & GAAGAAAAAG & GCG. . & $\ldots \ldots$ & $\ldots \ldots$ & $\ldots$ \\
\hline $\mathrm{H} 1{ }^{5}$ & TAAGAAGAAG & GCA $\ldots \ldots$ & $\ldots \ldots \ldots$ & $\ldots \ldots \ldots$ & $\ldots$ \\
\hline $\mathrm{H} 1 \_0$ & AGATCCCGAG & GCAGGCTTTG & СТCAGCСТCC & GACGAGGGCT & GGCCCTTTGG \\
\hline $\mathrm{H} 1 \mathrm{x}$ & AATGGCCAAG & AAGG. & . & . & \\
\hline ensus & IaAG & gc. & . & . & . \\
\hline & 251 & & & & 300 \\
\hline $\mathrm{H} 1 \_1$ & & ${ }^{\circ}$ & $\ldots$ & $\ldots \ldots A \mathrm{AA}$ & GAAACCTGCT \\
\hline $\mathrm{H} 1$ _2 & & . & $\ldots \ldots$ & $\ldots \ldots \ldots \mathrm{GC}$ & CAAAAAGG. . \\
\hline $\mathrm{H} 1 \_4$ & & $\ldots \ldots$ & $\ldots \ldots$ & $\ldots \ldots \ldots$ CG & CAAGTCTG. \\
\hline $\mathrm{H} 1{ }_{-} 3$ & & $\ldots \ldots$ & . & $\ldots \ldots A A$ & GAAGGCAG. . \\
\hline $\mathrm{H} 1 \_5$ & & . & $\ldots \ldots$ & $\ldots \ldots A C$ & TAAGAAGGCT \\
\hline $\mathrm{H} 1$ _O & AAGGCGCCTT & CAACAGCCGG & ACCAGACAGG & CCACCATGAC & CGAGAATTCC \\
\hline $\mathrm{H} 1 \mathrm{x}$ & & $\cdots$ & $\ldots \ldots$ & $\ldots \ldots \mathrm{TGAC}$ & CAAGGCTGGC \\
\hline isus & & & $\ldots$ & $\ldots \ldots \ldots$ & caAg.ctg \\
\hline
\end{tabular}


301

H1_1 AAGGCTGCAG CAGCCTCCAA GAAAAAACCC GCTGGCCCTT CCGTG.....

H1_2 ....... TTG GGGGTACGCC TCGTAAGGCG TCTGGTCCCC CGGTG....

H1_4 ......... CAG GTGCGGCCAA GCGCAAAGCG TCTGGGCCCC CGGTG.... .

H1_3 ....GCGCAA CTGCTGGGAA ACGCAAAGCA TCCGGACCCC CAGTA.....

H1_5 GCCGGCGCCG GCGCTGCTAA GCGCAAAGCG ACGGGGCCCC CAGTC.... .

H1_0 ACGTCCGCCC CTGCGGCCAA GCCCAAGCGG GCCAAGGCCT CCAAGAAGTC

H1x GgCtCGgCGg CGTTGtCCCC AtCTAAgAAg AgGAAgAAtA GCAAgAAgAA

Consensus .....gC.g C.gc.gccaa gcgcAAagcg .c.gggcccC c.gtg.....

H1_1 . . . . . . . . . T CAGAGCTGAT CGTGCAGGCT GCTTCCTCCT

H1_2 ............ CAGAGCTCAT CACCAAGGCT GTGGCCGCCT

H1_4 ${ }_{1} \ldots \ldots \ldots \ldots \ldots \ldots$. $\ldots \ldots$ CCGAGCTCAT TACTAAAGCT GTTGCCGCCT

H1_3 ............ CTGAGCTTAT CACCAAGGCA GTGGCAGCTT

H1_5 ............ . . CAGAGCTGAT CACCAAGGCT GTGGCTGCTT

H1_0 CACAGACCAC CCCAAGTATT CAGACATGAT CGTGGCTGCC ATCCAGGCCG

H1x GAACCAGCCG GGCAAGTACA GCCAGCTGGT GGTGGAGACC ATCCGTAGGC $\ldots \ldots \ldots \ldots \ldots . \ldots \ldots$ cagAgcTgaT cac.aaggCt gt.gc.gcct

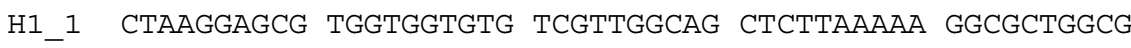

H1_2 CTAAAGAGCG TAGCGGAGTT TCTCTGGCTG CTCTGAAAAA AGCGTTGGCT

H1_4 CCAAGGAGCG CAGCGGCGTA TCTTTGgCCG CTCTCAAGAA AGCGCTGGCA

H1_3 CTAAGgAgCG CAGCGGCGTT TCTCTGGCCG CGCTTAAGAA AGCGCTTGCG

H1_5 CTAAGGAGCG CAATGGCCTT TCTTTGGCAG CCCTTAAGAA GGCCTTAGCG

H1_0 AgAAGAACCG CGCTGGCTCC TCGCGCCAGT CCATTCAGAA GTATATCAAG

H1x TGGGCGAGCG CAACGGCTCG TCGCTGGCCA AGATCTACAC CGAGGCCAAG ctaaggAgCG cagcGGcgt. TCtctggc.g c.cTtaAgAa .gcg.t.gcg

451

H1_1 GCCGCAGGCT ACGACGTGGA GAAGAACAA. . CAGCCGCA TTAAGCTGGG

H1 2 GCCGCCGGCT ATGATGTGGA GAAAAACAA. . CAGCCGTA TCAAACTTGG

H1_4 GCCGCTGGCT ATGACGTGGA GAAGAACAA. . CAgCCGCA tCAAGCTGGG

H1_3 GCTGCCGGCT ACGATGTAGA AAAAAACAA. . CAgCCGTA tCAAGCTTGG

H1_5 GCCGGTGGCT ACGACGTGGA GAAGAATAA. . CAgCCGCA TTAAGCTGGG

H1_0 AgCCACTACA AgGTGgGtGA GAACGCTGA. . CTCGCAGA tCAAGTTGTC

H1x AAGGTTCCGT GGTTCGACCA GCAGAATGGg CGCACCTACC TCAAGTACTC gccgc.ggct a.gacGtggA gaAgaacaa. ..Cagccgca TcAAgctggg 
501

550

H1_1 CAttAagAgC CtgGtaAgCA AgggaAcGtT GgtgCAgACA AAgggtACCG

H1_2 TCtCAAGAgC CTGGTGAgCA AgGgCACTCT GGTGCAAACG AAAGGCACCG

H1_4 TCTCAAGAGC CTGGTGAGCA AGGGCACCCT GGTGCAGACC AAGGGCACCG

H1_3 CCTCAAGAGC TTGGTGAGCA AAgGTACCCT GGTGCAGACC AAAGGTACCG

H1_5 CCTCAAGAGC TTGGTGAGCA AGGGCACCCT GGTGCAGACC AAGGGCACTG

H1_0 CATCAAGCGC CTGGTCACCA CCGGTGTCCT CAAGCAGACC AAAGGGGTGG

H1x GATCAAGGCG CTGGTGCAgA ACGACACGCT TCTGCAgGTG AAgGGCACCG

Consensus CCTCAAGagC CTGGTgagcA agGgcacCCT ggtGCAgacC AAgGGcaccG

551

600

H1 1 GAGCCTCGGG TTCCTTCAAG CTCAACAAGA AGGCGTCCTC CGTGGAAACC

H1_2 GTGCTTCTGG CTCCTTTAAA CTCAACAAGA AGGCAGCCTC CGGGGAAGCC

H1_4 GCGCGTCGGg TTCCTTCAAA CTCAACAAGA AGgCGGCCTC TGGGGAAGCC

H1_3 GTGCTTCTGG CTCCTTCAAA CTCAACAAGA AAGCGGCTTC CGGGGAAGGC

H1_5 GTGCTTCTGG CTCCTTTAAA CTCAACAAGA AGGCGGCCTC CGGGGAAGCC

H1_0 GGgCCTCGgG GTCCTTCCGg CTAGCCAAGA GCGACGAACC CAAGAAGTCA

H1x GCGCCAACGG TTCCTTCAAG CT.............AACCG CAAGAAGCTG

Consensus G.GC.tc.GG .TCCTTcaaa CTcaacaaga aggcggcctc cggGgAagcC

601

650

H1_1 AAGCCCGGCG CCTCAAAGGT GGCTACA... .......AAAA CTAAGGCAAC

H1_2 AAGCCCAAGg TTAAAAAGGC GGGCGGAACC AAACCTAAGA AGCCAGTTGG

H1_4 AAGCCTAAGG CTAAAAAGGC AGGCGCGGCC AAGGCCAAGA AGCCAGCAGG

H1_3 AAACCCAAGG CCAAAAAGGC TGGCGCAGCC AAGCCTAGGA AGCCTGCTGG

H1_5 AAGCCCAAAG CCAAGAAGGC AGGCGCCGCT AAAGCTAAGA AGCCCGCGGG

H1_0 GTGGCCTTCA AGAAGACCAA GAAGGAAATC AAGAAGGTA. .. GCCACGCC

H1x GAGGGCGGCG GGGAGCGGCG CGGAGCCCCG GCGGCCGCCA CCGCCCCGGC

Consensus aagcccaa.g C.aaaaaggc .ggcgca.cC aag.c.aaga agcc.gc.gg

651

700

H1 1 GGGTGCATCT AAAAAGCTCA AAAAGGCCAC GGGGG. . . . . . . CTAGCA

H1_2 GGCAGCC... AAGAAGCCCA AGAAGGCGGC TGGCGGCGCA ACTCCGAAGA

H1_4 AGCGGCG... AAGAAGCCCA AGAAGGCGAC GGGGGCGGCC ACCCCCAAGA

H1_3 GGCAGCC... AAGAAGCCCA AGAAGGTGGC TGGCGCCGCT ACCCCGAAGA

H1_5 GGCCACGCCT AAGAAGGCCA AGAAGGCTGC AGGGG. . . . . . . CGAAAA

H1_0 AAAGAAGGCA TCCAAGCCCA AGAAGGCTGC CTCCAAAGCC CCAACCAAGA

H1x CCCCACCGCG CACAAAGCGA AGAAGGCAGC CCCGGGCGCG GCCGGCTCCC

Consensus ggc.gc..c. aagAAgCCCA AgAAGGC.gC .gggg..gC. .c..c.aaga 
701

H1_1 AAAAGAGCGT CAAGACTCCG AAAAAGGCTA AAAAGCCTGC GGC......

H1_2 AgAGCGCTAA GAAAACACCG AAGAAAGCGA AGAAGCCGGC CGCGGCCACT

H1_4 AGAGCGCCAA GAAGACCCCA AAGAAGGCGA AGAAGCCGGC TGCAGCTGCT

H1_3 AAAGCATCAA AAAGACTCCT AAGAAGGTAA AGAAGCCAGC AACCGCTGCT

H1_5 AGGCAGTGAA GAAGACTCCG AAGAAGGCGA AGAAGCCCGC GGCGGC...T

H1_0 AACCCAAAGC CACCCCGGTC AAGAAGGCCA AGAAGAAGCT GGC..... T

H1x GGCGCGCGGA CAAGAAGCCC GCCAGGGGCC AGAAGCCGGA GCA...... G

Consensus agagcg..aa .Aagac.CC. aagAagGc.a AgAAGccggc ggc.gc...t

751

800

H1_1 . AACAAGGA AATCCTCCAA GAATCCAAAA AAACCCAAAA C........

H1 2 GTAACCAAGA AAgTGGCTAA GAgCCCAAAg AAgGCCAAGG T.......

H1_4 GGAGCCAAAA AAGCG... AA AAGCCCGAAA AAGGCGAAAG C........

H1_3 GGgACCAAGA AAgTGGCCAA GAgtgCGAAA AAgGTGAAAA C........

H1_5 GGCGTCAAAA AgGTGGCGAA GAGCCCTAAg AAgGCCAAGG CCG......

H1 0 GCCACGCCCA AGAAAGCCAA AAAACCCAAG ACTGTCAAAG CCAAGCCGGT

H1x CGCTCGCACA AGAAGGGCGC TGGCGCCAAG AAGGACAAAG GCGGCAAGGC

Consensus gg.accaa.A Aag.ggccaa gagccC.AAg AaggccAAag C........

801

850

H1_1 .... TGTA AAGCCCAAGA AAGTAGCTAA AAGCCCTGCT AAAGCTAAGG

H1_2 ..... TGCG AAGCCCAAGA AAGCTGCCAA AAGTGCTGCT AAGGCT....

H1_4 ......AGCC AAGCCAAAAA AGGCGCCCAA GAGCCCAGCG AAGGCCAAAG

H1_3 ......АCCT CAGCCAAAAA AAGCTGCCAA GAGTCCAGCT AAGGCCAAAG

H1_5 .... CTGCC AAACCGAAAA AGGCAACCAA GAGTCCTGCC AAGCCCAAGG

H1_0 CAAGGCATCC AAGCCCAAAA AGGCCAAACC AGTGAAACCC AAAGCAAAGT

H1x CAAGAAGACG GCGGCCGCCG GGGGCAAGAA GGTGAAGAAG GCGGCCAAGC

Consensus .....gc. aagcCcaaaa agGc..ccaa gag.cc.gc. aaggCcaagg

851

900

H1_1 CTGtAAAACC CAAGGCGGCC AAgGCTAGgG TGACGAA..........

H1 $2 \ldots \ldots \ldots \ldots \ldots . . \ldots . . \ldots$

H1_4 CAGTTAAACC CAAGGCGGCT AAACCAAAGA CCGCCAA...........

H1_3 CCCCTAAGCC CAAGGCGGCC AAGCCTAAGT CGGGGAA...........

H1 5 CAGTTAAGCC GAAGGCGGCA AAGCCCAAAG CCGCTAA............

H1_0 CCAGTGCCAA GAGGGCCGGC AAgAAGAAGT GACAATGAAG TCTTTTCTTG

H1x CCAGCGTCCC CAAAGTGCCC AAg......gG CCGCAAGTGA GCGTGTCGGC

Consensus C...taa.CC caaggcggcC AAgcc.aagg ccgc.aa........... 
H1_1

H1_2

H1_4

H1_3

H1_5

H1_o

$\mathrm{H} 1 \mathrm{x}$

Consensus

951

H1_1

H1_2

H1_4

H1_3

H1_5

H1_0

$\mathrm{H} 1 \mathrm{x}$

Consensus

1001

1050

H1_1

$\mathrm{H} 1$-2

H1_ 4

H1_3

H1_ 5

H1_0

$\mathrm{H} 1 \mathrm{x}$

Consensus

1051

1100

H1_1

H1_2

$\mathrm{H} 1$ - 4

H1_3

H1 5

H1_0

$\mathrm{H} 1 \mathrm{x}$

Consensus

CGGACACTCC CTCCTGTCTC CTATTTTCTG TAAATAATTT TCTCCTTTTT CGGTCAGAGC GGCCGGCGTG GACTTTTCGG TGTTTTTGTT TTTCT.

1000

TAAGAGACAG GATTTGGATT CTTCAGAAAT TACAgAATAA TTCATTTTTC

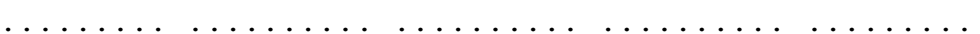

.

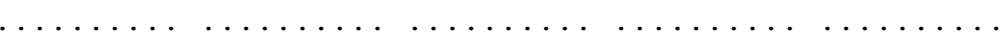

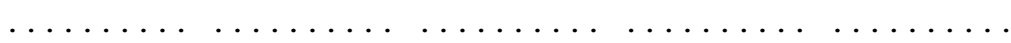

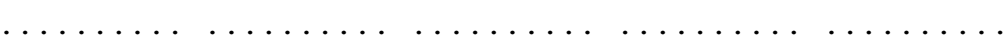

$\ldots \ldots \ldots \ldots \ldots \ldots \ldots \ldots \ldots \ldots \ldots \ldots \ldots \ldots \ldots \ldots \ldots \ldots \ldots \ldots$

CTTAACCAGT TGTGCAAGGA CAGCAACAAC CAATCTAATG ATGAGAATGT ACCCCAAGTG 
1101

H1_1

H1_2

H1_4

H1_3

H1_ 5

H1_0

ACTTATATTT TGTTTTGCTA TTAACCTACT TACGGGGTTA GGGATTTGCG

$\mathrm{H} 1 \mathrm{X}$

Consensus

ACGTAGATTT TGTACGGCTC

1151

1200

H1_1

H1_2

H1_ 4

H1_3

H1_5

H1_0

GGGGGGCTTG TGTGTTTTGT TGGCTTGTTT GCCATGAAGg TAGATGTGG

$\mathrm{H} 1 \mathrm{x}$

Consensus

1201

1250

H1_1

H1_2

H1_4

H1_3

H1_5

H1_0

TGGGGAgAAG ACACAAGGCA GTTTGTTCTG GCTAGATGAg AGGGAACCCA

$\mathrm{H} 1 \mathrm{x}$

Consensus

1251

1300

H1_1

H1_2

H1 4

$\mathrm{H} 13$

H1_5

H1_0

GGAATTGTGA GGTTAGCAGG AATATCTTTA GGGTGAGTGA GTTTTCCTTG

Consensus 
H1_1

H1_2

H1_4

H1_3

H1_5

H1_0

AGTTGGGCAC CCGTTGTGAg AGTTTCAGAA CCTTTGGCCA GCAGGAGAGA

$\mathrm{H} 1 \mathrm{x}$

Consensus

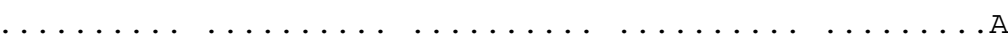

1351

1400

H1_1 ....GCCAAA GACTGCCAAA CCCAAGAAAG CGGCACCCAA GAAAAAGTA.

H1 2 ....GCCCAA GGTTGTCAAG CCTAAGAAGG CGGCGCCCAA GAAGAAATAG

H1_4 ...GCCCAA GGCAGCCAAG CCAAAGAAGG CGGCAGCCAA GAAAAAGTAG

H1_3 ....GCCGAA GGTTACAAAG GCAAAGAAGG CAGCTCCGAA GAAAAAGTG.

H1_5 ....GCCCAA AGCAGCAAAA CCTAAAGCTG CAAAGGCCAA GAAGGCG...

H1 0 GgtgGtAggg AgCAgCCAgC CGgCAAAgGA AgGAgGtgGA AAAAAACCGC

H1x CGCCGGCCGG GGCCGCGAGg CCTGGTCTGA GCCTCAGGGA GGGGCCCCGG

Consensus ....Gcccaa ggc.gccAag CC.aagaagg cggc..ccaA gaaaaagt..

1401

1450

H1_1

H1_2 GCGAACGCCT ACTTCTAAAA CCCAAAAGGC TCTTTTCAGA GCCACCACTG

H1_ $4 \ldots \ldots \ldots \ldots \ldots \ldots \ldots \ldots$. . . . . . . . . .

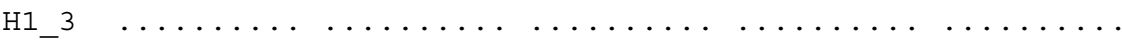

H1_5

H1_0

CACCGGGCTG ACTTCCACCT CCCAGTGGTG AGCAGTGGGG GCCCAAACCC

$\mathrm{H} 1 \mathrm{x}$ GTCCTCTCAG TCTTTCCCCT CCCCC..... AACGATGTAG CGTTTTTCGT

Consensus

1451

1500

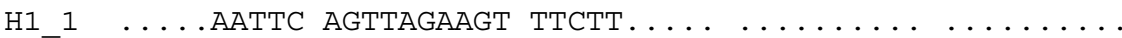

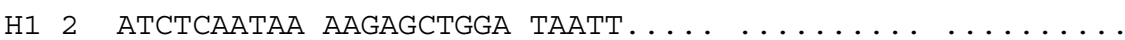

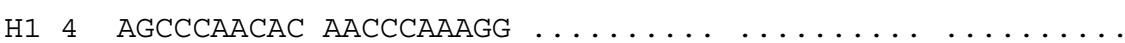

$\mathrm{H} 13 \ldots \ldots \ldots$ A ACTGGCGGG $\mathrm{ACGTT} \ldots \ldots \ldots \ldots \ldots \ldots$

H1 5 . GCTGCCAAA AAgAAGTAGG AAGCT.................

H1_0 AGTTTCCTTC TCATTTTTGT TAGTTTGCCC TTTCGGCCTC CCTATTTTCT

H1x TGTTTGCTTT AgGTTTTTGA AACAGCCCCG GCGACGCCTC TATTGGCTCT

.g.t..t. aa.t.t.g. .a.tt. . 
H1_1

H1_2

H1_4

H1_3

H1_5

H1_0

TAGGGAAGGg GAgTGGGGTC CAAGTGACAg CTGGATGGgA GAAGCCATAG

$\mathrm{H} 1 \mathrm{x}$ CGGCCTTGGC AACGGCCGTC GTCATGGTTA CTGGCCCCTA GGCGCCGATG

Consensus

1551

1600

H1_1

H1_2

H1_ 4

H1_3

H1_5

H1_0

TTTCTCCCAG TCAGCTAGGA TGTAGCCATT GGGGGATCTT TGTGGCTTCA

$\mathrm{H} 1 \mathrm{x}$

Consensus

1601

1650

H1_1

H1_2

H1_4

H1_ 3

H1_5

H1_0

GCAAATTCTC TTGTTAAACC GGAGTGAAAA CTTCAGGGGA AGGGTGGGGA

$\mathrm{H} 1 \mathrm{x}$

Consensus

1651

1700

H1_1

H1_2

H1 4

$\mathrm{H} 13$

H1_ 5

H1_0

GTCAGCCAAG TGCCTCAGTG TGCCCTGTTG AAACTTAGGT TTTTCCACGC

Consensus 
H1_1

H1_2

$\mathrm{H} 1$ _ 4

H1_3

H1_5

H1_o

TTCCTCCTGT ACAAGAgGTg TCTTTGCTTG GTTTGGTGGg GCTGCGGCCA

$\mathrm{H} 1 \mathrm{x}$ Consensus ..CCTGCCCA CCGGGCGGGG TCGCTGGTTG GCCGGGCCCA GGCGCGC...

H1_1

H1_2

H1_ 4

$\mathrm{H} 1{ }^{3} 3$

H1_5

H1_0

CTGCGGGAGG GGGAGGGGGA GTGGGCGGGC AGTGGATAGT AAGACTTACT

$\mathrm{H} 1 \mathrm{x}$ . . G GGGACGCGGA GGCCGCGCAT CCT. 
H1_1

H1_2

H1_4

H1_3

H1_5

H1_0

GCAGTCGATT TGGGATTTGC TAAGTAGTTT TACAGAGCTA GATCTGTGTG

$\mathrm{H} 1 \mathrm{x}$

Consensus

1951

2000

H1_1

H1_2

H1_4

H1_3

H1_5

H1_0

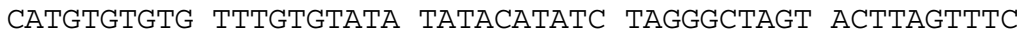

$\mathrm{H} 1 \mathrm{x}$

Consensus

2001

2050

H1_1

H1_2

H1_4

H1_ 3

H1_5

H1_0

ACACCCGGGA GCTGGGAGAA AAAACCTGTA CAGTTGTCTT TCTCTTATTT

$\mathrm{H} 1 \mathrm{x}$

CCACCC.

TCCT TGCCTTTGGG

Consensus

2051

2100

H1 1

CTAGT

H1_2

H1_ 4

H1 3

H1_5

H1_0

".

H1x TGCGCGACAA ACAATCGCTC CGGGCTCAGG GCTGCGCGGC TCTTCCCTTC 


\begin{tabular}{|c|c|c|c|c|c|}
\hline & 2101 & & & & 2150 \\
\hline H1_1 & AACCCAACGG & СТСТTTTAAG & AGCCAC & . & \\
\hline H1_2 & AAAAAAA. & $\ldots$ & & $\ldots$ & \\
\hline $\mathrm{H} 1 \_4$ & $\cdots$ & $\ldots \ldots \ldots$ & . & $\cdots \cdots$ & - \\
\hline $\mathrm{H} 1{ }^{2} 3$ & $\ldots \ldots \ldots$ & $\ldots \ldots \ldots$ & $\ldots \ldots \ldots$ & $\cdots \ldots \ldots$ & $\cdots$ \\
\hline H1_5 & GTGAAAACCG & $c \ldots \ldots$ & $\ldots \ldots \ldots$ & $\ldots \ldots \ldots$ & $\ldots$ \\
\hline H1_O & TTTTAAACAA & GTGTTACTTG & TGCCGGGAAA & АтTTTGCTGT & СТTTGTAATT \\
\hline $\mathrm{H} 1 \mathrm{x}$ & ATTCCATGGG & сстттттTтя & GGCACAATAA & AGCGT. . . . & . \\
\hline onsensus & .....аa... & . & . & $\ldots$ & $\ldots$ \\
\hline & 2151 & & & & 2200 \\
\hline H1_1 & & . & & & . \\
\hline $\mathrm{H} 1 \_2$ & $\ldots \ldots \ldots$ & $\ldots \ldots \ldots$ & $\ldots \ldots \ldots$ & $\ldots \ldots \ldots$ & $\ldots$ \\
\hline $\mathrm{H} 1 \_4$ & $\ldots \ldots \ldots$ & $\ldots \ldots \ldots$ & $\ldots \ldots \ldots$ & $\ldots \ldots \ldots$ & $\ldots \ldots \ldots$ \\
\hline $\mathrm{H} 1$ _3 & $\ldots \ldots$ & $\ldots \ldots \ldots$ & $\ldots \ldots \ldots$ & $\ldots \ldots \ldots$ & $\ldots \ldots \ldots$ \\
\hline $\mathrm{H} 1$ _5 & $\ldots \ldots \ldots$ & $\ldots \ldots \ldots$ & $\ldots \ldots \ldots$ & $\ldots \ldots \ldots$ & $\ldots \ldots \ldots$ \\
\hline $\mathrm{H} 1$ _O & TTAАAАСТTТ & АААATAААТT & GGAAAGGGAG & AAAAAAAAAA & $\mathrm{A} A \mathrm{~A} A \mathrm{~A} A \mathrm{~A} A \mathrm{~A} \mathrm{~A}$ \\
\hline $\mathrm{H} 1 \mathrm{x}$ & TTAAACСТTT & C... & & & \\
\hline isus & & & & & \\
\hline
\end{tabular}





\section{Literaturverzeichnis}

Alami, R., Y. Fan, S. Pack, T. M. Sonbuchner, A. Besse, Q. Lin, J. M. Greally, A. I. Skoultchi \& E. E. Bouhassira (2003). "Mammalian linker-histone subtypes differentially affect gene expression in vivo." Proc Natl Acad Sci U S A 100(10): 5920-5.

Albig, W., B. Drabent, J. Kunz, M. Kalff-Suske, K. H. Grzeschik \& D. Doenecke (1993). "All known human H1 histone genes except the H1(0) gene are clustered on chromosome 6." Genomics 16(3): 649-54.

Albig, W., E. Kardalinou, B. Drabent, A. Zimmer \& D. Doenecke (1991). "Isolation and characterization of two human H1 histone genes within clusters of core histone genes." Genomics 10(4): 940-8.

Albig, W., D. M. Runge, M. Kratzmeier \& D. Doenecke (1998). "Heterologous expression of human H1 histones in yeast." FEBS Lett 435(2-3): 245-50.

Allan, J., T. Mitchell, N. Harborne, L. Bohm \& C. Crane-Robinson (1986). "Roles of H1 domains in determining higher order chromatin structure and H1 location." $J$ Mol Biol 187(4): 591-601.

Alonso, A., B. Breuer, H. Bouterfa \& D. Doenecke (1988). "Early increase in histone H1(0) mRNA during differentiation of F9 cells to parietal endoderm." Embo $J$ 7(10): 3003-8.

Altschul, S. F., T. L. Madden, A. A. Schaffer, J. Zhang, Z. Zhang, W. Miller \& D. J. Lipman (1997). "Gapped BLAST and PSI-BLAST: a new generation of protein database search programs." Nucleic Acids Res 25(17): 3389-402.

Arents, G., R. W. Burlingame, B. C. Wang, W. E. Love \& E. N. Moudrianakis (1991). "The nucleosomal core histone octamer at 3.1 A resolution: a tripartite protein assembly and a left-handed superhelix." Proc Natl Acad Sci U S A 88(22): 10148-52. 
Arents, G. \& E. N. Moudrianakis (1995). "The histone fold: a ubiquitous architectural motif utilized in DNA compaction and protein dimerization." Proc Natl Acad Sci U S A 92(24): 11170-4.

Ausio, J. (2006). "Histone variants--the structure behind the function." Brief Funct Genomic Proteomic 5(3): 228-43.

Ausio, J., D. W. Abbott, X. Wang \& S. C. Moore (2001). "Histone variants and histone modifications: a structural perspective." Biochem Cell Biol 79(6): 693-708.

Bailleul, B., K. Brown, M. Ramsden, R. J. Akhurst, F. Fee \& A. Balmain (1989). "Chemical induction of oncogene mutations and growth factor activity in mouse skin carcinogenesis." Environ Health Perspect 81: 23-7.

Bajetta, E., L. Ferrari, A. Martinetti, L. Celio, G. Procopio, S. Artale, N. Zilembo, M. Di Bartolomeo, E. Seregni \& E. Bombardieri (1999). "Chromogranin A, neuron specific enolase, carcinoembryonic antigen, and hydroxyindole acetic acid evaluation in patients with neuroendocrine tumors." Cancer 86(5): 858-65.

Ballal, N. R. \& H. Busch (1973). "Two-dimensional gel electrophoresis of acid-soluble nucleolar proteins of Walker 256 carcinosarcoma, regenerating liver, and thioacetamide-treated liver." Cancer Res 33(11): 2737-43.

Barra, J. L., L. Rhounim, J. L. Rossignol \& G. Faugeron (2000). "Histone H1 is dispensable for methylation-associated gene silencing in Ascobolus immersus and essential for long life span." Mol Cell Biol 20(1): 61-9.

Bas, A., G. Forsberg, S. Hammarstrom \& M. L. Hammarstrom (2004). "Utility of the housekeeping genes 18S rRNA, beta-actin and glyceraldehyde-3-phosphatedehydrogenase for normalization in real-time quantitative reverse transcriptasepolymerase chain reaction analysis of gene expression in human $T$ lymphocytes." Scand J Immunol 59(6): 566-73.

Bereta, J. \& M. Bereta (1995). "Stimulation of glyceraldehyde-3-phosphate dehydrogenase mRNA levels by endogenous nitric oxide in cytokine-activated endothelium." Biochem Biophys Res Commun 217(1): 363-9. 
Birnboim, H. C. \& J. Doly (1979). "A rapid alkaline extraction procedure for screening recombinant plasmid DNA." Nucleic Acids Res 7(6): 1513-23.

Bouterfa, H. L., F. J. Piedrafita, D. Doenecke \& M. Pfahl (1995). "Regulation of H1(0) gene expression by nuclear receptors through an unusual response element: implications for regulation of cell proliferation." DNA Cell Biol 14(11): 909-19.

Bouterfa, H. L., S. M. Triebe \& D. R. Doenecke (1993). "Differential regulation of the human H1 zero-histone-gene transcription in human tumor-cell lines." Eur $J$ Biochem 217(1): 353-60.

Briggs, M. R., J. T. Kadonaga, S. P. Bell \& R. Tjian (1986). "Purification and biochemical characterization of the promoter-specific transcription factor, Sp1." Science 234(4772): 47-52.

Brown, D. T. (2003). "Histone H1 and the dynamic regulation of chromatin function." Biochem Cell Biol 81(3): 221-7.

Brown, D. T., B. T. Alexander \& D. B. Sittman (1996). "Differential effect of H1 variant overexpression on cell cycle progression and gene expression." Nucleic Acids Res 24(3): 486-93.

Brown, D. T., T. Izard \& T. Misteli (2006). "Mapping the interaction surface of linker histone H1(0) with the nucleosome of native chromatin in vivo." Nat Struct Mol Biol 13(3): 250-5.

Bustin, S. A. (2000). "Absolute quantification of mRNA using real-time reverse transcription polymerase chain reaction assays." J Mol Endocrinol 25(2): 16993.

Bustin, S. A. (2002). "Quantification of mRNA using real-time reverse transcription PCR (RT-PCR): trends and problems." J Mol Endocrinol 29(1): 23-39.

Carter, C. W., Jr. (1978). "Histone packing in the nucleosome core particle of chromatin." Proc Natl Acad Sci U S A 75(8): 3649-53. 
Cerf, C., G. Lippens, V. Ramakrishnan, S. Muyldermans, A. Segers, L. Wyns, S. J. Wodak \& K. Hallenga (1994). "Homo- and heteronuclear two-dimensional NMR studies of the globular domain of histone H1: full assignment, tertiary structure, and comparison with the globular domain of histone H5." Biochemistry 33(37): 11079-86.

Chabanas, A., E. Khoury, P. Goeltz, P. Froussard, R. Gjerset, B. Dod, H. Eisen \& J. J. Lawrence (1985). "Effects of butyric acid on cell cycle regulation and induction of histone H1(0) in mouse cells and tissue culture. Inducibility of H1 (0)in the late S-G2 phase of the cell cycle." J Mol Biol 183(2): 141-51.

Chomczynski, P. \& N. Sacchi (1987). "Single-step method of RNA isolation by acid guanidinium thiocyanate-phenol-chloroform extraction." Anal Biochem 162(1): 156-9.

Clark, K. L., E. D. Halay, E. Lai \& S. K. Burley (1993). "Co-crystal structure of the HNF-3/fork head DNA-recognition motif resembles histone H5." Nature 364(6436): 412-20.

Class, R., S. Lindman, C. Fassbender, H. P. Leinenbach, S. Rawer, J. G. Emrich, L. W. Brady \& M. Zeppezauer (1996). "Histone H1 suppresses tumor growth of leukemia cells in vitro, ex vivo and in an animal model suggesting extracellular functions of histones." Am J Clin Oncol 19(5): 522-31.

Cole, R. D. (1984). "A minireview of microheterogeneity in H1 histone and its possible significance." Anal Biochem 136(1): 24-30.

Coles, L. S. \& J. R. Wells (1985). "An H1 histone gene-specific 5' element and evolution of H1 and H5 genes." Nucleic Acids Res 13(2): 585-94.

Corpet, F. (1988). "Multiple sequence alignment with hierarchical clustering." Nucleic Acids Res 16(22): 10881-90.

Cox, K. H., D. V. DeLeon, L. M. Angerer \& R. C. Angerer (1984). "Detection of mRNAs in sea urchin embryos by in situ hybridization using asymmetric RNA probes." Dev Biol 101(2): 485-502. 
Cuisset, L., L. Tichonicky \& M. Delpech (1999). "Quantitative analysis of histone H1 degrees protein synthesis in HTC cells." Eur J Biochem 261(3): 593-9.

Dailey, L., S. B. Roberts \& N. Heintz (1988). "Purification of the human histone H4 gene-specific transcription factors H4TF-1 and H4TF-2." Genes Dev 2(12B): 1700-12.

Dalton, S. \& J. R. Wells (1988). "Maximal binding levels of an H1 histone genespecific factor in S-phase correlate with maximal $\mathrm{H} 1$ gene transcription." $\mathrm{Mol}$ Cell Biol 8(10): 4576-8.

Davey, C. A., D. F. Sargent, K. Luger, A. W. Maeder \& T. J. Richmond (2002). "Solvent mediated interactions in the structure of the nucleosome core particle at 1.9 a resolution." J Mol Biol 319(5): 1097-113.

Davie, J. R., G. P. Delcuve, B. E. Nickel, R. Moirier \& G. Bailey (1987). "Reduced levels of histones H1o and H1b, and unaltered content of methylated DNA in rainbow trout hepatocellular carcinoma chromatin." Cancer Res 47(20): 540710.

Davis, B. J. (1964). "Disc Electrophoresis. Ii. Method and Application to Human Serum Proteins." Ann N Y Acad Sci 121: 404-27.

Denhardt, D. T. (1966). "A membrane-filter technique for the detection of complementary DNA." Biochem Biophys Res Commun 23(5): 641-6.

D'Incalci, M., P. Allavena, R. S. Wu \& W. M. Bonner (1986). "H1 variant synthesis in proliferating and quiescent human cells." Eur J Biochem 154(2): 273-9.

Doenecke, D., W. Albig, C. Bode, B. Drabent, K. Franke, K. Gavenis \& O. Witt (1997). "Histones: genetic diversity and tissue-specific gene expression." Histochem Cell Biol 107(1): 1-10.

Doenecke, D., W. Albig, H. Bouterfa \& B. Drabent (1994). "Organization and expression of H1 histone and H1 replacement histone genes." J Cell Biochem 54(4): 423-31. 
Downs, J. A., E. Kosmidou, A. Morgan \& S. P. Jackson (2003). "Suppression of homologous recombination by the Saccharomyces cerevisiae linker histone." Mol Cell 11(6): 1685-92.

Drabent, B., K. Franke, C. Bode, U. Kosciessa, H. Bouterfa, H. Hameister \& D. Doenecke (1995). "Isolation of two murine H1 histone genes and chromosomal mapping of the H1 gene complement." Mamm Genome 6(8): 505-11.

Drabent, B., P. Saftig, C. Bode \& D. Doenecke (2000). "Spermatogenesis proceeds normally in mice without linker histone H1t." Histochem Cell Biol 113(6): 43342.

Duncliffe, K. N., M. E. Rondahl \& J. R. Wells (1995). "A H1 histone gene-specific ACbox-related element influences transcription from a major chicken $\mathrm{H} 1$ promoter." Gene 163(2): 227-32.

Egan, S. E., J. A. Wright \& A. H. Greenberg (1991). "Molecular determinants of metastatic transformation." Environ Health Perspect 93: 91-5.

Eickbush, T. H. \& E. N. Moudrianakis (1978). "The histone core complex: an octamer assembled by two sets of protein-protein interactions." Biochemistry 17(23): 4955-64.

Eilers, A., H. Bouterfa, S. Triebe \& D. Doenecke (1994). "Role of a distal promoter element in the S-phase control of the human H1.2 histone gene transcription." Eur J Biochem 223(2): 567-74.

Evans, R. M. (1988). "The steroid and thyroid hormone receptor superfamily." Science 240(4854): 889-95.

Fan, Y., T. Nikitina, E. M. Morin-Kensicki, J. Zhao, T. R. Magnuson, C. L. Woodcock \& A. I. Skoultchi (2003). "H1 linker histones are essential for mouse development and affect nucleosome spacing in vivo." Mol Cell Biol 23(13): 4559-72. 
Fan, Y., A. Sirotkin, R. G. Russell, J. Ayala \& A. I. Skoultchi (2001). "Individual somatic H1 subtypes are dispensable for mouse development even in mice lacking the H1(0) replacement subtype." Mol Cell Biol 21(23): 7933-43.

Fletcher, C., N. Heintz \& R. G. Roeder (1987). "Purification and characterization of OTF-1, a transcription factor regulating cell cycle expression of a human histone H2b gene." Cell 51(5): 773-81.

Frank, D., D. Doenecke \& W. Albig (2003). "Differential expression of human replacement and cell cycle dependent H3 histone genes." Gene 312: 135-43.

Franke, K., B. Drabent \& D. Doenecke (1998). "Testicular expression of the mouse histone H1.1 gene." Histochem Cell Biol 109(4): 383-90.

Freeman, W. M., S. J. Walker \& K. E. Vrana (1999). "Quantitative RT-PCR: pitfalls and potential." Biotechniques 26(1): 112-22, 124-5.

Funayama, R., M. Saito, H. Tanobe \& F. Ishikawa (2006). "Loss of linker histone H1 in cellular senescence." J Cell Biol 175(6): 869-80.

Gabrilovich, D. I., P. Cheng, Y. Fan, B. Yu, E. Nikitina, A. Sirotkin, M. Shurin, T. Oyama, Y. Adachi, S. Nadaf, D. P. Carbone \& A. I. Skoultchi (2002). "H1(0) histone and differentiation of dendritic cells. A molecular target for tumorderived factors." J Leukoc Biol 72(2): 285-96.

Gallinari, P., F. La Bella \& N. Heintz (1989). "Characterization and purification of H1TF2, a novel CCAAT-binding protein that interacts with a histone H1 subtype-specific consensus element." Mol Cell Biol 9(4): 1566-75.

Garcia, B. A., S. A. Busby, C. M. Barber, J. Shabanowitz, C. D. Allis \& D. F. Hunt (2004). "Characterization of phosphorylation sites on histone H1 isoforms by tandem mass spectrometry." J Proteome Res 3(6): 1219-27.

Giancotti, V., A. Bandiera, L. Ciani, D. Santoro, C. Crane-Robinson, G. H. Goodwin, M. Boiocchi, R. Dolcetti \& B. Casetta (1993). "High-mobility-group (HMG) 
proteins and histone $\mathrm{H} 1$ subtypes expression in normal and tumor tissues of mouse." Eur J Biochem 213(2): 825-32.

Goodlad, G. A. \& C. M. Clark (1995). "H1 histone sub-type distribution and DNA topoisomerase activity in skeletal muscle of tumour-bearing rats." Cancer Lett 98(1): 111-4.

Graham, F. L., J. Smiley, W. C. Russell \& R. Nairn (1977). "Characteristics of a human cell line transformed by DNA from human adenovirus type 5." J Gen Virol 36(1): 59-74.

Grimes, S. R., S. A. Wolfe \& D. A. Koppel (1992). "Tissue-specific binding of testis nuclear proteins to a sequence element within the promoter of the testis-specific histone H1t gene." Arch Biochem Biophys 296(2): 402-9.

Grunwald, D., S. Khochbin \& J. J. Lawrence (1991). "Cell cycle-related accumulation of H1(0) mRNA: induction in murine erythroleukemia cells." Exp Cell Res 194(2): 174-9.

Haller, F., B. Kulle, S. Schwager, B. Gunawan, A. von Heydebreck, H. Sultmann \& L. Fuzesi (2004). "Equivalence test in quantitative reverse transcription polymerase chain reaction: confirmation of reference genes suitable for normalization." Anal Biochem 335(1): 1-9.

Hanahan, D. \& R. A. Weinberg (2000). "The hallmarks of cancer." Cell 100(1): 57-70.

Happel, N., E. Schulze \& D. Doenecke (2005). "Characterisation of human histone H1x." Biol Chem 386(6): 541-51.

Harp, J. M., B. L. Hanson, D. E. Timm \& G. J. Bunick (2000). "Asymmetries in the nucleosome core particle at 2.5 A resolution." Acta Crystallogr D Biol Crystallogr 56(Pt 12): 1513-34.

Harvey, A. C. \& J. A. Downs (2004). "What functions do linker histones provide?" Mol Microbiol 53(3): 771-5. 
Hashimoto, H., M. Tsuneyoshi \& M. Enjoji (1985). "Malignant smooth muscle tumors of the retroperitoneum and mesentery: a clinicopathologic analysis of 44 cases." J Surg Oncol 28(3): 177-86.

Heid, C. A., J. Stevens, K. J. Livak \& P. M. Williams (1996). "Real time quantitative PCR." Genome Res 6(10): 986-94.

Heintz, N. (1991). "The regulation of histone gene expression during the cell cycle." Biochim Biophys Acta 1088(3): 327-39.

Heintz, N., H. L. Sive \& R. G. Roeder (1983). "Regulation of human histone gene expression: kinetics of accumulation and changes in the rate of synthesis and in the half-lives of individual histone mRNAs during the HeLa cell cycle." Mol Cell Biol 3(4): 539-50.

Henriquez, J. P., J. C. Casar, L. Fuentealba, D. J. Carey \& E. Brandan (2002). "Extracellular matrix histone H1 binds to perlecan, is present in regenerating skeletal muscle and stimulates myoblast proliferation." J Cell Sci 115(Pt 10): 2041-51.

Higuchi, R., C. Fockler, G. Dollinger \& R. Watson (1993). "Kinetic PCR analysis: realtime monitoring of DNA amplification reactions." Biotechnology (N Y) 11(9): 1026-30.

Huelin, C., M. Gonzalez, S. Pedrinaci, B. de la Higuera, M. A. Piris, J. San Miguel, F. Ruiz-Cabello \& F. Garrido (1988). "Distribution of the CD45R antigen in the maturation of lymphoid and myeloid series: the CD45R negative phenotype is a constant finding in T CD4 positive lymphoproliferative disorders." $\mathrm{Br} \quad \mathrm{J}$ Haematol 69(2): 173-9.

Hurt, M. M., N. B. Pandey \& W. F. Marzluff (1989). "A region in the coding sequence is required for high-level expression of murine histone H3 gene." Proc Natl Acad Sci U S A 86(12): 4450-4. 
Ikegami, S., T. Taguchi, M. Ohashi, M. Oguro, H. Nagano \& Y. Mano (1978). "Aphidicolin prevents mitotic cell division by interfering with the activity of DNA polymerase-alpha." Nature 275(5679): 458-60.

Isenberg, I. (1979). "Histones." Annu Rev Biochem 48: 159-91.

Kasinsky, H. E., J. D. Lewis, J. B. Dacks \& J. Ausio (2001). "Origin of H1 linker histones." Faseb J 15(1): 34-42.

Kedes, L. H., A. C. Chang, D. Houseman \& S. N. Cohen (1975). "Isolation of histone genes from unfractionated sea urchin DNA by subculture cloning in E. coli." Nature 255(5509): 533-8.

Keppel, F., B. Allet \& H. Eisen (1977). "Appearance of a chromatin protein during the erythroid differentiation of Friend virus-transformed cells." Proc Natl Acad Sci U S A 74(2): 653-6.

Khochbin, S. (2001). "Histone H1 diversity: bridging regulatory signals to linker histone function." Gene 271(1): 1-12.

Khochbin, S., C. Gorka \& J. J. Lawrence (1991). "Multiple control level governing H10 mRNA and protein accumulation." FEBS Lett 283(1): 65-7.

Khochbin, S. \& J. J. Lawrence (1994). "Molecular basis of the activation of basal histone H1(0) gene expression." Nucleic Acids Res 22(15): 2887-93.

Khochbin, S. \& A. P. Wolffe (1993). "Developmental regulation and butyrate-inducible transcription of the Xenopus histone H1(0) promoter." Gene 128(2): 173-80.

Khochbin, S. \& A. P. Wolffe (1994). "Developmentally regulated expression of linkerhistone variants in vertebrates." Eur J Biochem 225(2): 501-10.

Kinkade, J. M., Jr. \& R. D. Cole (1966). "The resolution of four lysine-rich histones derived from calf thymus." J Biol Chem 241(24): 5790-7. 
Kloppel, G., A. Perren \& P. U. Heitz (2004). "The gastroenteropancreatic neuroendocrine cell system and its tumors: the WHO classification." Ann NY Acad Sci 1014: 13-27.

Koeffler, H. P., F. McCormick \& C. Denny (1991). "Molecular mechanisms of cancer." West J Med 155(5): 505-14.

Konishi, A., S. Shimizu, J. Hirota, T. Takao, Y. Fan, Y. Matsuoka, L. Zhang, Y. Yoneda, Y. Fujii, A. I. Skoultchi \& Y. Tsujimoto (2003). "Involvement of histone H1.2 in apoptosis induced by DNA double-strand breaks." Cell 114(6): 673-88.

Kornberg, R. D. \& Y. Lorch (1999). "Twenty-five years of the nucleosome, fundamental particle of the eukaryote chromosome." Cell 98(3): 285-94.

Kostova, N. N., L. N. Srebreva, A. D. Milev, O. G. Bogdanova, I. Rundquist, H. H. Lindner \& D. V. Markov (2005). "Immunohistochemical demonstration of histone H1(0) in human breast carcinoma." Histochem Cell Biol: 1-9.

Kress, H., R. Tonjes \& D. Doenecke (1986). "Butyrate induced accumulation of a 2.3 kb polyadenylated H1(0) histone mRNA in HeLa cells." Nucleic Acids Res 14(18): 7189-97.

Krieg, P. A. \& D. A. Melton (1987). "In vitro RNA synthesis with SP6 RNA polymerase." Methods Enzymol 155: 397-415.

Kundahl, E., R. Richman \& R. A. Flickinger (1981). "The effect of added H1 histone and polylysine on DNA synthesis and cell division of cultured mammalian cells." J Cell Physiol 108(3): 291-8.

La Bella, F., P. Gallinari, J. McKinney \& N. Heintz (1989). "Histone H1 subtypespecific consensus elements mediate cell cycle-regulated transcription in vitro." Genes Dev 3(12A): 1982-90.

Laemmli, U. K. (1970). "Cleavage of structural proteins during the assembly of the head of bacteriophage T4." Nature (London, United Kingdom) 227(5259): 680-685. 
Lamberts, S. W., L. J. Hofland \& F. R. Nobels (2001). "Neuroendocrine tumor markers." Front Neuroendocrinol 22(4): 309-39.

Lane, D. P. \& L. V. Crawford (1979). "T antigen is bound to a host protein in SV40transformed cells." Nature 278(5701): 261-3.

Lea, M. A. (1987). "Relationship of H1(0) histone to differentiation and cancer." Cancer Biochem Biophys 9(3): 199-209.

Leder, A. \& P. Leder (1975). "Butyric acid, a potent inducer of erythroid differentiation in cultured erythroleukemic cells." Cell 5(3): 319-22.

Lee, H., R. Habas \& C. Abate-Shen (2004). "MSX1 cooperates with histone H1b for inhibition of transcription and myogenesis." Science 304(5677): 1675-8.

Lehman, T. A., R. Reddel, A. M. Peiifer, E. Spillare, M. E. Kaighn, A. Weston, B. I. Gerwin \& C. C. Harris (1991). "Oncogenes and tumor-suppressor genes." Environ Health Perspect 93: 133-4.

Lennox, R. W. \& L. H. Cohen (1983). "The histone H1 complements of dividing and nondividing cells of the mouse." J Biol Chem 258(1): 262-8.

Lennox, R. W., R. G. Oshima \& L. H. Cohen (1982). "The H1 histones and their interphase phosphorylated states in differentiated and undifferentiated cell lines derived from murine teratocarcinomas." J Biol Chem 257(9): 5183-9.

Lindblom, A. \& A. Liljegren (2000). "Regular review: tumour markers in malignancies." Bmj 320(7232): 424-7.

Linzer, D. I. \& A. J. Levine (1979). "Characterization of a 54K dalton cellular SV40 tumor antigen present in SV40-transformed cells and uninfected embryonal carcinoma cells." Cell 17(1): 43-52.

Livak, K. J. \& T. D. Schmittgen (2001). "Analysis of relative gene expression data using real-time quantitative PCR and the 2(-Delta Delta C(T)) Method." Methods 25(4): 402-8. 
Luger, K., A. W. Mader, R. K. Richmond, D. F. Sargent \& T. J. Richmond (1997). "Crystal structure of the nucleosome core particle at 2.8 A resolution." Nature 389(6648): 251-60.

Mannironi, C., V. Rossi, A. Biondi, P. Ubezio, G. Giudici, G. Masera \& M. D'Incalci (1988). "Comparison of histone variant synthesis in human lymphocytic leukemia cells and in normal lymphocytes." Cancer Res 48(13): 3670-5.

Martianov, I., S. Brancorsini, R. Catena, A. Gansmuller, N. Kotaja, M. Parvinen, P. Sassone-Corsi \& I. Davidson (2005). "Polar nuclear localization of H1T2, a histone $\mathrm{H} 1$ variant, required for spermatid elongation and DNA condensation during spermiogenesis." Proc Natl Acad Sci U S A 102(8): 2808-13.

Martinelli, R. \& N. Heintz (1994). "H1TF2A, the large subunit of a heterodimeric, glutamine-rich CCAAT-binding transcription factor involved in histone $\mathrm{H} 1$ cell cycle regulation." Mol Cell Biol 14(12): 8322-32.

Mason, D. Y. \& K. C. Gatter (1987). "The role of immunocytochemistry in diagnostic pathology." J Clin Pathol 40(9): 1042-54.

Meergans, T., W. Albig \& D. Doenecke (1997). "Varied expression patterns of human H1 histone genes in different cell lines." DNA Cell Biol 16(9): 1041-9.

Meergans, T., W. Albig \& D. Doenecke (1998). "Conserved sequence elements in human main type-H1 histone gene promoters: their role in $\mathrm{H} 1$ gene expression." Eur J Biochem 256(2): 436-46.

Moreno, C. S., L. Matyunina, E. B. Dickerson, N. Schubert, N. J. Bowen, S. Logani, B. B. Benigno \& J. F. McDonald (2007). "Evidence that p53-Mediated Cell-CycleArrest Inhibits Chemotherapeutic Treatment of Ovarian Carcinomas." PLoS ONE 2: e441.

Neville, A. M., A. M. Mackay, J. Westwood, C. Turberville \& D. J. Laurence (1975). "Human tumour-associated and tumour-specific antigens: some concepts in relation to clinical oncology." J Clin Pathol Suppl (Assoc Clin Pathol) 6: 10212. 
Okabe-Kado, J., Y. Honma, M. Hayashi \& M. Hozumi (1981). "Effects of histone fractions on induction of differentiation of cultured mouse myeloid leukemia cells." Cancer Res 41(5): 1997-2002.

Ornstein, L. (1964). "Disc Electrophoresis. I. Background and Theory." Ann N Y Acad Sci 121: 321-49.

Osborn, M. (1983). "Intermediate filaments as histologic markers: an overview." $J$ Invest Dermatol 81(1 Suppl): 104s-9s.

Osborn, M. \& K. Weber (1983). "Tumor diagnosis by intermediate filament typing: a novel tool for surgical pathology." Lab Invest 48(4): 372-94.

Osley, M. A. (1991). "The regulation of histone synthesis in the cell cycle." Annu Rev Biochem 60: 827-61.

Parseghian, M. H. \& B. A. Hamkalo (2001). "A compendium of the histone H1 family of somatic subtypes: an elusive cast of characters and their characteristics." Biochem Cell Biol 79(3): 289-304.

Parseghian, M. H., D. A. Harris, D. R. Rishwain \& B. A. Hamkalo (1994). "Characterization of a set of antibodies specific for three human histone H1 subtypes." Chromosoma 103(3): 198-208.

Parseghian, M. H., A. H. Henschen, K. G. Krieglstein \& B. A. Hamkalo (1994). "A proposal for a coherent mammalian histone $\mathrm{H} 1$ nomenclature correlated with amino acid sequences." Protein Sci 3(4): 575-87.

Perrino, F. W. \& L. A. Loeb (1990). "Animal cell DNA polymerases in DNA repair." Mutat Res 236(2-3): 289-300.

Peterson, C. L. \& M. A. Laniel (2004). "Histones and histone modifications." Curr Biol 14(14): R546-51.

Pina, B., P. Martinez \& P. Suau (1987). "Changes in H1 complement in differentiating rat-brain cortical neurons." Eur J Biochem 164(1): 71-6. 
Plumb, M., J. Stein \& G. Stein (1983). "Coordinate regulation of multiple histone mRNAs during the cell cycle in HeLa cells." Nucleic Acids Res 11(8): 2391-410.

Pohlmeyer, K., J. Broer, G. Mayer, E. Gumz, F. Wiederhold, A. Caliebe, R. Wick, H. Siede, W. Muhlhard, B. Behnke \& J. Beuth (2000). "The recombinant human histones H1 zero and H1.2 cause different toxicity profiles on the human leukemia cell line K562." Anticancer Res 20(4): 2499-503.

Ponte, I., R. Vila \& P. Suau (2003). "Sequence complexity of histone H1 subtypes." Mol Biol Evol 20(3): 371-80.

Port, M., H. U. Schmelz, T. Stassen, K. Mueller, M. Stockinger, R. Obermair \& M. Abend (2007). "Correcting false gene expression measurements from degraded RNA using RTQ-PCR." Diagn Mol Pathol 16(1): 38-49.

Pruss, D., B. Bartholomew, J. Persinger, J. Hayes, G. Arents, E. N. Moudrianakis \& A. P. Wolffe (1996). "An asymmetric model for the nucleosome: a binding site for linker histones inside the DNA gyres." Science 274(5287): 614-7.

Pulvertaft, J. V. (1964). "Cytology of Burkitt's Tumour (African Lymphoma)." Lancet 39: $238-40$.

Rabini, S., K. Franke, P. Saftig, C. Bode, D. Doenecke \& B. Drabent (2000). "Spermatogenesis in mice is not affected by histone H1.1 deficiency." Exp Cell Res 255(1): 114-24.

Rasheed, B. K., E. C. Whisenant, R. D. Ghai, V. E. Papaioannou \& Y. M. Bhatnagar (1989). "Biochemical and immunocytochemical analysis of a histone H1 variant from the mouse testis." J Cell Sci 94 ( Pt 1): 61-71.

Ririe, K. M., R. P. Rasmussen \& C. T. Wittwer (1997). "Product differentiation by analysis of DNA melting curves during the polymerase chain reaction." Anal Biochem 245(2): 154-60. 
Robinson, P. J., L. Fairall, V. A. Huynh \& D. Rhodes (2006). "EM measurements define the dimensions of the "30-nm" chromatin fiber: evidence for a compact, interdigitated structure." Proc Natl Acad Sci U S A 103(17): 6506-11.

Roge, R., J. Thorsen, C. Torring, A. Ozbay, B. K. Moller \& J. Carstens (2007). "Commonly used reference genes are actively regulated in in vitro stimulated lymphocytes." Scand J Immunol 65(2): 202-9.

Romeis, B. (1989) "Mikroskopische Technik", 17.Auflage, S. 490. (Herausgeber P. Böck, Urban \& Schwarzenberg Verlag, München, ISBN 3-541-1127-1).

Rousseau, S., M. Asselin, J. Renaud \& A. Ruiz-Carrillo (1993). "Transcription of the histone H5 gene is regulated by three differentiation-specific enhancers." Mol Cell Biol 13(8): 4904-17.

Saiki, R. K., S. Scharf, F. Faloona, K. B. Mullis, G. T. Horn, H. A. Erlich \& N. Arnheim (1985). "Enzymatic amplification of beta-globin genomic sequences and restriction site analysis for diagnosis of sickle cell anemia." Science 230(4732): 1350-4.

Salinovich, O. \& R. C. Montelaro (1986). "Reversible staining and peptide mapping of proteins transferred to nitrocellulose after separation by sodium dodecylsulfatepolyacrylamide gel electrophoresis." Anal Biochem 156(2): 341-7.

Sanger, F., S. Nicklen \& A. R. Coulson (1977). "DNA sequencing with chainterminating inhibitors." Proc Natl Acad Sci U S A 74(12): 5463-7.

Schalch, T., S. Duda, D. F. Sargent \& T. J. Richmond (2005). "X-ray structure of a tetranucleosome and its implications for the chromatin fibre." Nature 436(7047): 138-41.

Scharf, S. J., G. T. Horn \& H. A. Erlich (1986). "Direct cloning and sequence analysis of enzymatically amplified genomic sequences." Science 233(4768): 1076-8. 
Schneeberger, C., P. Speiser, F. Kury \& R. Zeillinger (1995). "Quantitative detection of reverse transcriptase-PCR products by means of a novel and sensitive DNA stain." PCR Methods Appl 4(4): 234-8.

Seyedin, S. M., R. D. Cole \& W. S. Kistler (1981). "H1 histones from mammalian testes. The widespread occurrence of H1t." Exp Cell Res 136(2): 399-405.

Simpson, R. T. (1978). "Structure of the chromatosome, a chromatin particle containing 160 base pairs of DNA and all the histones." Biochemistry 17(25): 5524-31.

Sirotkin, A. M., W. Edelmann, G. Cheng, A. Klein-Szanto, R. Kucherlapati \& A. I. Skoultchi (1995). "Mice develop normally without the H1(0) linker histone." Proc Natl Acad Sci U S A 92(14): 6434-8.

Smith, B. J., M. R. Harris, C. M. Sigournay, E. L. Mayes \& M. Bustin (1984). "A survey of H1o-and H5-like protein structure and distribution in higher and lower eukaryotes." Eur J Biochem 138(2): 309-17.

Stellwagen, R. H. \& R. D. Cole (1969). "Chromosomal proteins." Annu Rev Biochem 38: 951-90.

Stoldt, S., D. Wenzel, E. Schulze, D. Doenecke \& N. Happel (2007). "G1 phasedependent nucleolar accumulation of human histone H1x." Biol Cell.

Sulimova, G. E., A.S. Kutsenko, E.R. Rakhmanaliev, I.G. Udina, A.A. Kompaniytsev, A.I. Protopopov, E.V. Moisjak, E.A. Klimov, O.V. Muravenko, A.V. Zelenin, E.A. Braga, V.I. Kashuba, E. R. Zabarovsky \& L. L. Kisselev (2002). "Human chromosome 3: integration of 60 NotI

clones into a physical and gene map." Cytogenet Genome Res 98: 177 -183.

Tan, K. B., T. W. Borun, R. Charpentier, V. J. Cristofalo \& C. M. Croce (1982). "Normal and neoplastic human cells have different histone H1 compositions." $J$ Biol Chem 257(10): 5337-8. 
Tanaka, M., J. D. Hennebold, J. Macfarlane \& E. Y. Adashi (2001). "A mammalian oocyte-specific linker histone gene H1oo: homology with the genes for the oocyte-specific cleavage stage histone (cs-H1) of sea urchin and the B4/H1M histone of the frog." Development 128(5): 655-64.

Tanaka, M., M. Kihara, J. D. Hennebold, J. J. Eppig, M. M. Viveiros, B. R. Emery, D. T. Carrell, N. J. Kirkman, B. Meczekalski, J. Zhou, C. A. Bondy, M. Becker, R. M. Schultz, T. Misteli, R. De La Fuente, G. J. King \& E. Y. Adashi (2005). "H1FOO is coupled to the initiation of oocytic growth." Biol Reprod 72(1): 13542.

Thellin, O., W. Zorzi, B. Lakaye, B. De Borman, B. Coumans, G. Hennen, T. Grisar, A. Igout \& E. Heinen (1999). "Housekeeping genes as internal standards: use and limits." J Biotechnol 75(2-3): 291-5.

Thoma, F., T. Koller \& A. Klug (1979). "Involvement of histone H1 in the organization of the nucleosome and of the salt-dependent superstructures of chromatin." $J$ Cell Biol 83(2 Pt 1): 403-27.

Thomas, J. O. (1999). "Histone H1: location and role." Curr Opin Cell Biol 11(3): 3127.

Tonjes, R. R., D. Paul \& D. Doenecke (1997). "Transgenic mice transcribing the human H1 zero histone gene exhibit a normal phenotype." Eur J Biochem 245(1): 97102.

Touroutoglou, N., A. Arcenas \& J. A. Ajani (1995), "Neuroendocrine Tumors of the Gastrointestinal Tract", Online publication, http://www.cancernetwork.com/ textbook/morev18.htm

Towbin, H., T. Staehelin \& J. Gordon (1979). "Electrophoretic transfer of proteins from polyacrylamide gels to nitrocellulose sheets: procedure and some applications." Proc Natl Acad Sci U S A 76(9): 4350-4. 
Trainor, C. D., S. J. Stamler \& J. D. Engel (1987). "Erythroid-specific transcription of the chicken histone H5 gene is directed by a 3' enhancer." Nature 328(6133): 827-30.

van Wijnen, A. J., R. F. Massung, J. L. Stein \& G. S. Stein (1988). "Human H1 histone gene promoter CCAAT box binding protein HiNF-B is a mosaic factor." Biochemistry 27(17): 6534-41.

van Wijnen, A. J., K. L. Wright, R. F. Massung, M. Gerretsen, J. L. Stein \& G. S. Stein (1988). "Two target sites for protein binding in the promoter region of a cell cycle regulated human H1 histone gene." Nucleic Acids Res 16(2): 571-92.

WHO (2003), World Health Organization, Online publication, http://www.who.int/ mediacentre/news/releases/2003/pr27/en/

Wiedenmann, B. \& U. F. Pape (2004). "From basic to clinical research in gastroenteropancreatic neuroendocrine tumor disease -- the clinician-scientist perspective." Neuroendocrinology 80 Suppl 1: 94-8.

Wilander, E. (1989). "Diagnostic pathology of gastrointestinal and pancreatic neuroendocrine tumours." Acta Oncol 28(3): 363-9.

Wisniewski, J. R., A. Zougman, S. Krueger \& M. Mann (2006). "Mass spectrometric mapping of linker histone $\mathrm{H} 1$ variants reveals multiple acetylations, methylations and phosphorylation as well as differences between cell culture and tissue." Mol Cell Proteomics.

Yamamoto, T. \& M. Horikoshi (1996). "Cloning of the cDNA encoding a novel subtype of histone H1." Gene 173(2): 281-5.

Yan, W., L. Ma, K. H. Burns \& M. M. Matzuk (2003). "HILS1 is a spermatid-specific linker histone H1-like protein implicated in chromatin remodeling during mammalian spermiogenesis." Proc Natl Acad Sci U S A 100(18): 10546-51. 
Zhang, J. \& C. D. Byrne (1999). "Differential priming of RNA templates during cDNA synthesis markedly affects both accuracy and reproducibility of quantitative competitive reverse-transcriptase PCR." Biochem J 337 ( Pt 2): 231-41.

Zhou, Y. B., S. E. Gerchman, V. Ramakrishnan, A. Travers \& S. Muyldermans (1998). "Position and orientation of the globular domain of linker histone H5 on the nucleosome." Nature 395(6700): 402-5.

Zlatanova, J. \& D. Doenecke (1994). "Histone H1 zero: a major player in cell differentiation?" Faseb J 8(15): 1260-8.

Zlatanova, J. S. (1980). "Synthesis of histone H1(0) is not inhibited in hydroxyureatreated Friend cells." FEBS Lett 112(2): 199-202. 


\section{Lebenslauf}

\section{Persönliche Daten}

Name:

\section{Julia Warneboldt}

Geburtstag:

09.05.1979

Geburtsort:

Münster

Staatsangehörigkeit:

deutsch

\section{Schulausbildung}

$1985-1989$

Grundschule Braunschweig

$1989-1991$

Orientierungsstufe Braunschweig

$1991-1998$

Gymnasium Gaußschule Braunschweig

Jun. 1998

Abitur

\section{Studiengang und Promotion}

Okt. 1998 - Sep. 2003

Sep. 2000

Jan. 2003 - Sep. 2003

Jan. 2004 - Jul. 2007

Jul. 2007
Philipps-Universität Marburg,

Fach: Humanbiologie

Diplomvorprüfung

Diplomarbeit im Fach Biochemie am Institut für physiologische Chemie der Philipps-Universität Marburg bei Prof. Dr. M. Löffler, Thema „Expression und Charakterisierung von Dihydroorotat-Dehydrogenase aus Ustilago maydis und Arabidopsis thaliana“

Dissertation am Institut für Biochemie und Physiologie der Georg-August-Universität zu Göttingen, Abteilung Molekulare Zellbiologie bei Prof. Dr. D. Doenecke, Thema: „Expressionsanalyse des humanen Histonsubtyps $\mathrm{H} 1 \mathrm{x}$ “

Doktorprüfung 